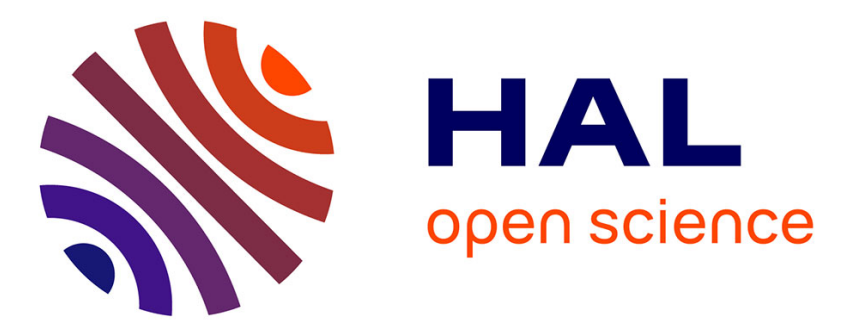

\title{
Process modeling of innovative design using systems engineering
}

Qiang Zhang

\section{To cite this version:}

Qiang Zhang. Process modeling of innovative design using systems engineering. Modeling and Simulation. Université de Strasbourg, 2014. English. NNT : 2014STRAD007 . tel-01198939

\section{HAL Id: tel-01198939 \\ https://theses.hal.science/tel-01198939}

Submitted on 14 Sep 2015

HAL is a multi-disciplinary open access archive for the deposit and dissemination of scientific research documents, whether they are published or not. The documents may come from teaching and research institutions in France or abroad, or from public or private research centers.
L'archive ouverte pluridisciplinaire HAL, est destinée au dépôt et à la diffusion de documents scientifiques de niveau recherche, publiés ou non, émanant des établissements d'enseignement et de recherche français ou étrangers, des laboratoires publics ou privés. 
$\mathrm{N}^{\circ}$ d'ordre :

École Doctorale Mathématiques, Sciences de l'Information et de l'Ingénieur

UdS - INSA - ENGEES

\title{
THÈSE
}

présentée pour obtenir le grade de

Docteur de l'Université de Strasbourg

Discipline : Génie Industriel

par

\section{Qiang ZHANG}

\section{Process Modeling of Innovative Design using Systems Engineering}

(Modélisation de processus de conception innovante en utilisant

l'Ingénierie Système )

Soutenue prévue le 28 février 2014

\begin{abstract}
Membres du jury
Directeur de thèse:

M. Emmanuel CAILLAUD Professeur

Université de Strasbourg

Co-directrice de thèse : Mme. Claude BARON

Professeur

INSA Toulouse

Rapporteur externe :

M. Marc ZOLGHADRI

Professeur

SUPMECA

Rapporteur externe :

M. Vincent CHAPURLAT

Professeur

Ecole des Mines d' Alès

Co-encadrant de thèse: Mme. Ioana DENIAUD

Maître de Conférences Université de Strasbourg
\end{abstract}





\section{Remerciements}

Je souhaite remercier M. Emmanuel Caillaud de m'avoir accepté et encouragé à faire cette thèse sous sa direction. Ses conseils, sa vision du sujet, et la confiance qu'il m'a accordée ont largement contribué à la réalisation de cette thèse.

Je remercie également Mme. Claude Baron pour m'avoir encadré durant ces trois et demi années. Malgré la distance géographique, les conseils que elle m'a prodigués ainsi que

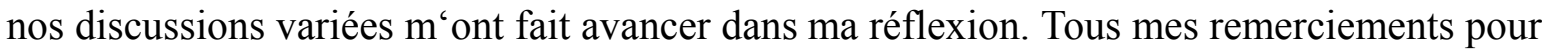
son aide pendant la rédaction des articles et de mon mémoire de thèse.

Je remercie ensuite Mme. Ioana Deniaud d'avoir co-encadré ma thèse. Je le remercie son encadrement au quotidien dans l'exploration et les discussions tout au long de mes travaux. Merci à vous pour cette expérience particulièrement enrichissante.

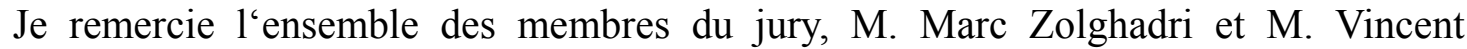
Chapurlat d'avoir accepté d'être rapporteurs. Leurs intérêts, leurs conseils pertinents ainsi que leurs remarques constructives à mes travaux ontcontribué à l'amélioration de la qualité de cette thèse.

Je remercie la structure d'accueil de cette thèse, LGECO, de m'avoir offert des conditions pour réaliser mes travaux. Je remercie mes collègues de LGECO pour les différentes discussions et cette ambiance de travail.

Je remercie ensuite mes amis français et chinois pour leur affection et soutien. En particulier, Danielle Lainé, Wilma.

Je remercie également Qun Cao, pour son soutien, ses encouragements et son aide au quotidien.

Enfin, je tiens à adresser un grand MERCI à mes parents et mes grands-parents pour m'avoir toujours soutenu et encouragé pendant ces années. 


\section{CONTENTS}

1 INTRODUCTION 1

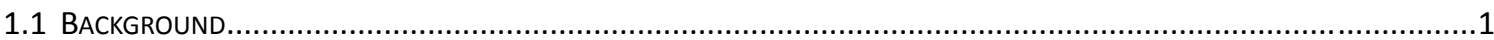

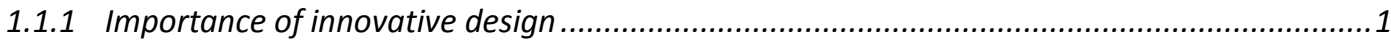

1.1.2 Context of innovative design: product development and innovation ....................................

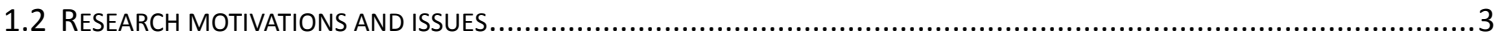

1.2.1 Research motivations .................................................................................................

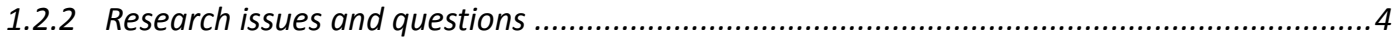

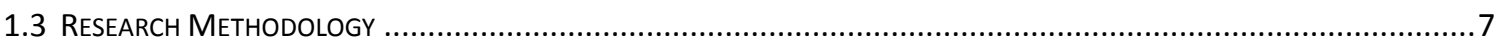

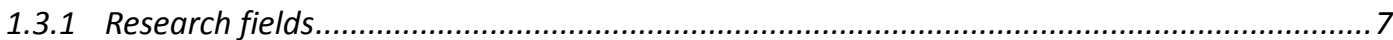

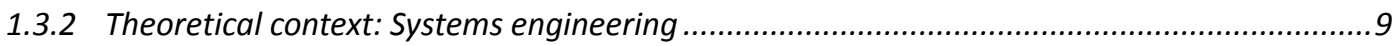

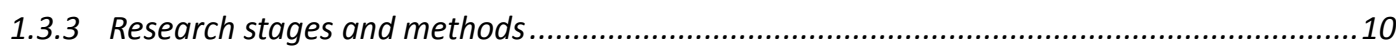

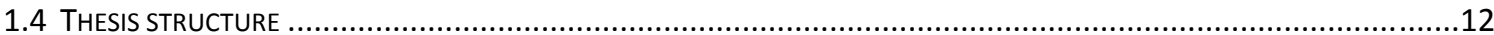

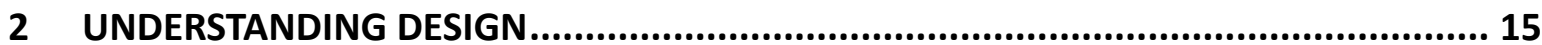

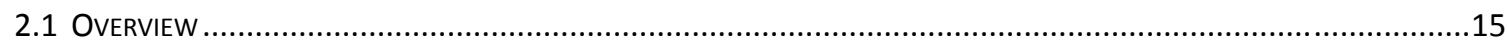

2.2 WHAT IS DESIGN?

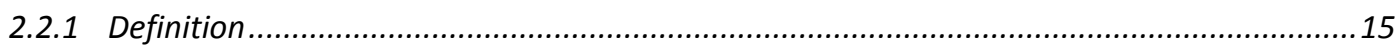

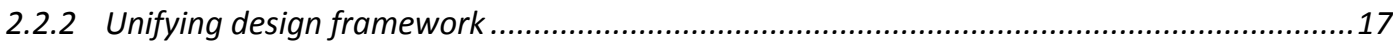

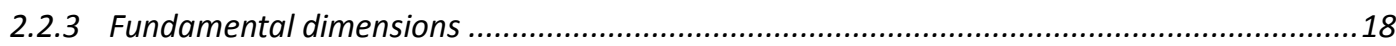

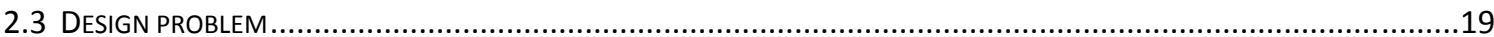

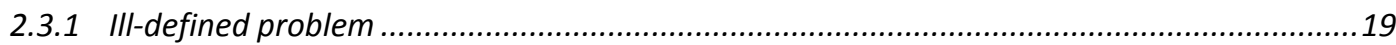

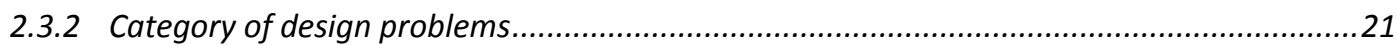

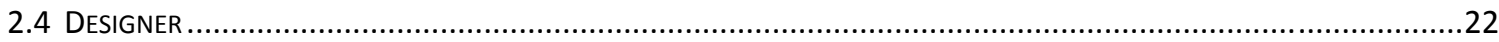

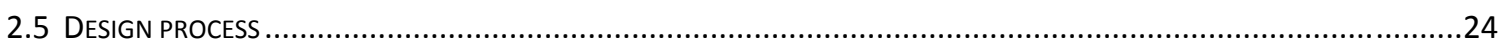

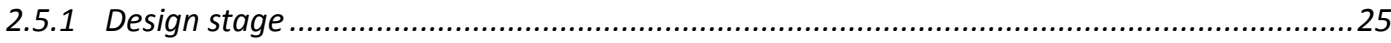

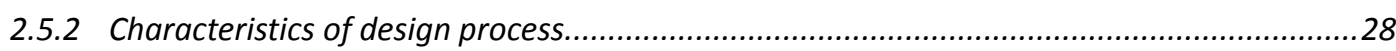

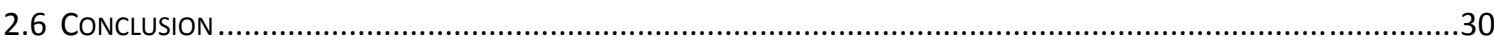

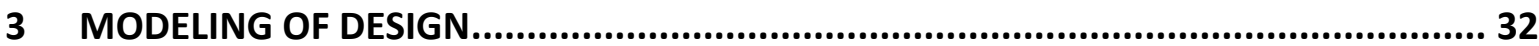

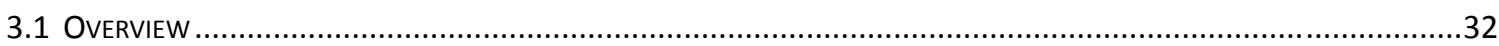

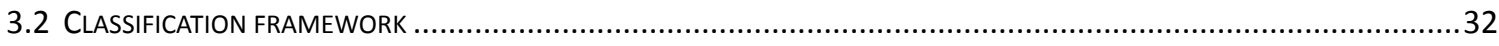

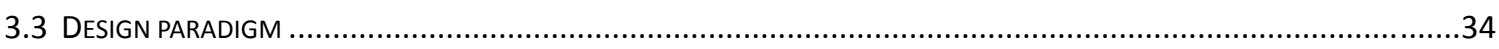

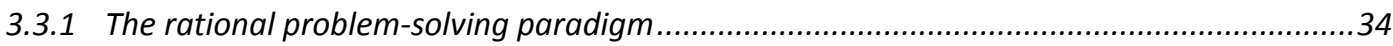

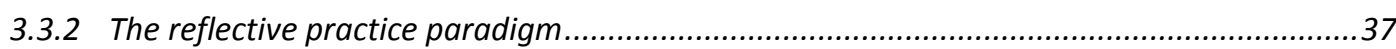

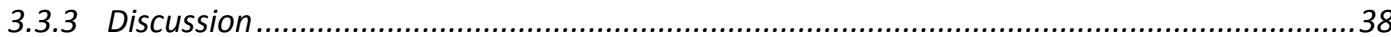

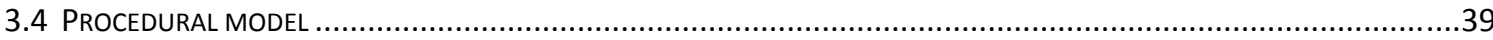

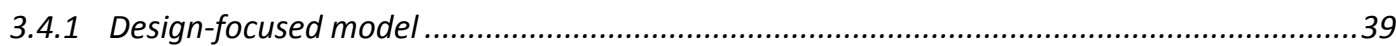

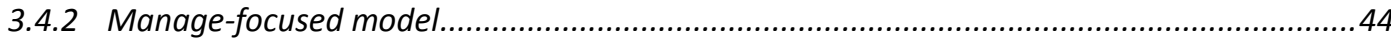




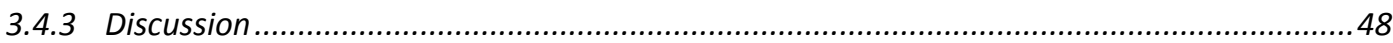

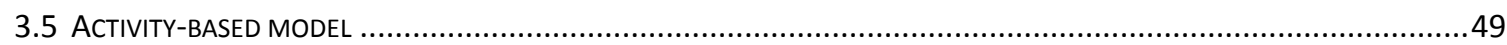

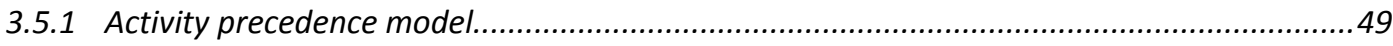

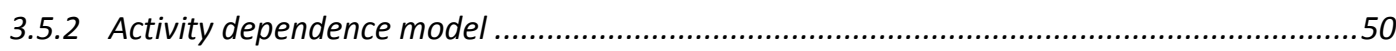

3.5.3 Dynamic activity model ............................................................................................ 51

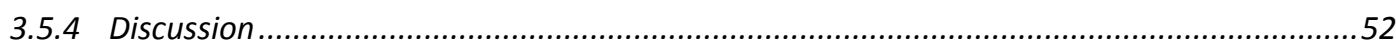

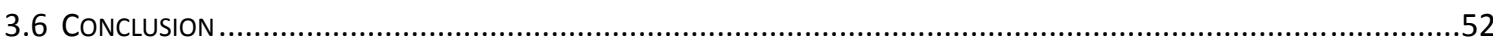

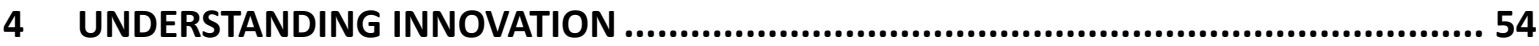

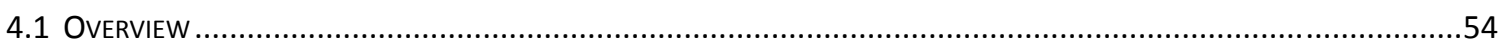

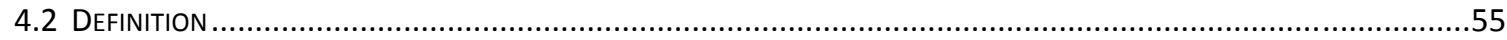

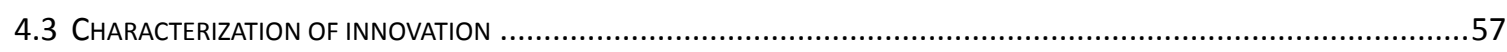

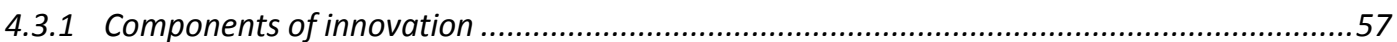

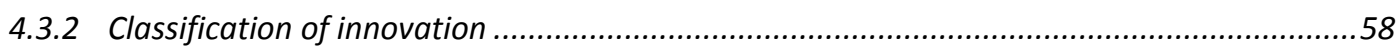

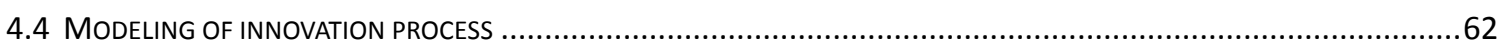

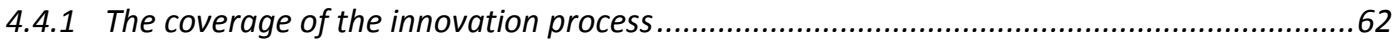

4.4.2 The evolution of innovation process models ....................................................................65

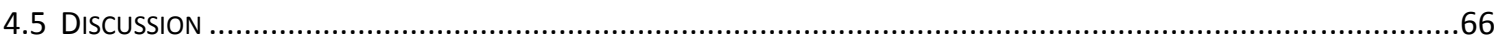

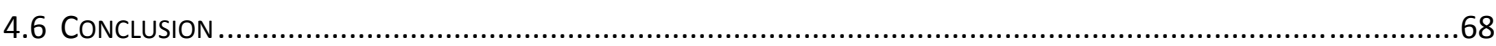

5 ANALYSIS AND REPRESENTATION OF INNOVATIVE DESIGN ................................. 70

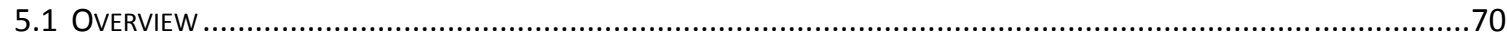

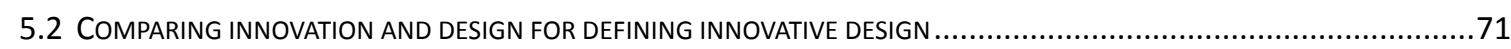

5.2.1 The theoretical comparison between design and innovation...........................................71

5.2.2 The relationship between design and innovation.......................................................... 74

5.2 .3 Definition of innovative design ................................................................................... 76

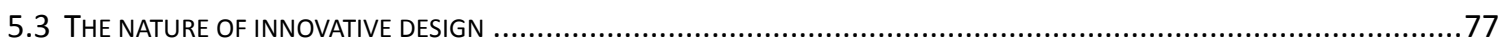

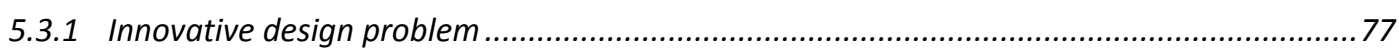

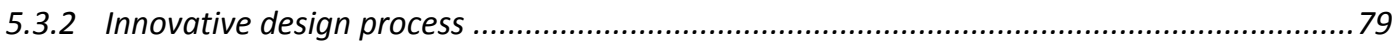

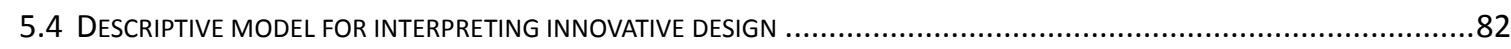

5.4.1 Constructing the basic framework of innovative design ................................................84

5.4.2 Modifying the basic framework by considering the innovation process ..............................87

5.4.3 Modifying the basic framework by introducing the designer and the environment space ...90

5.4.4 Integrated descriptive model of innovative design .........................................................94

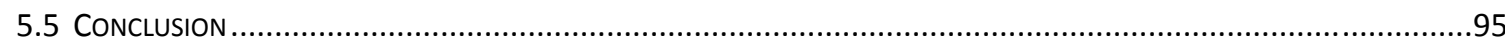

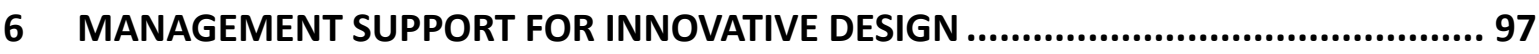

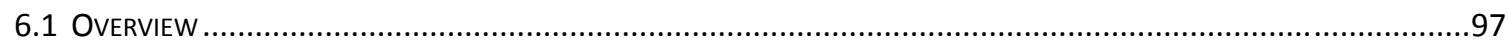

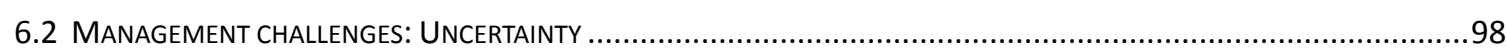

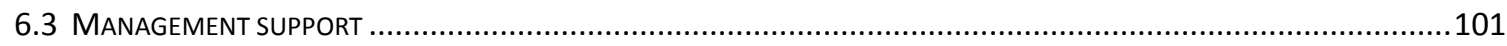

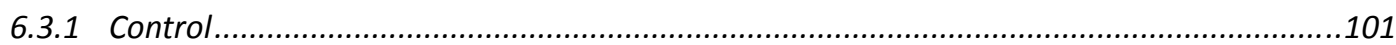

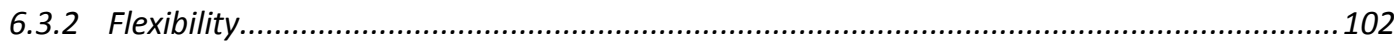




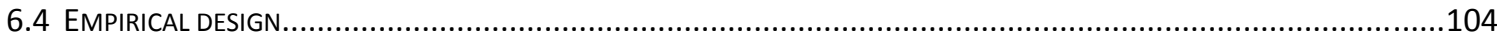

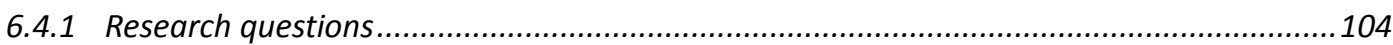

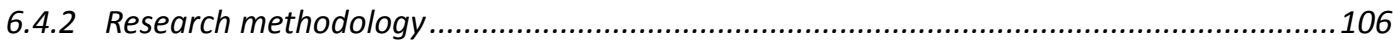

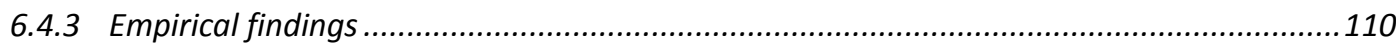

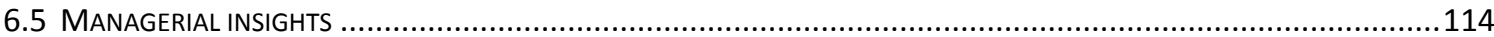

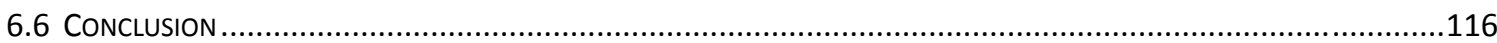

7 PROCESS MODELING OF INNOVATIVE DESIGN FOR MANAGEMENT SUPPORT ........118

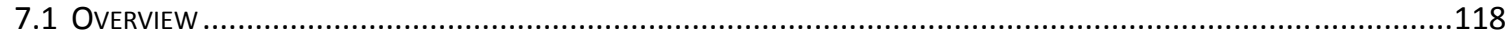

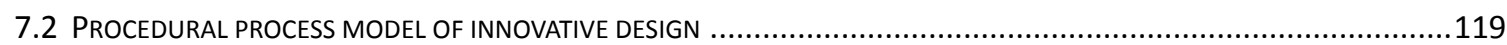

7.2.1 Theoretical basis: Combing the rational problem-solving paradigm and the reflective practice paradigm.

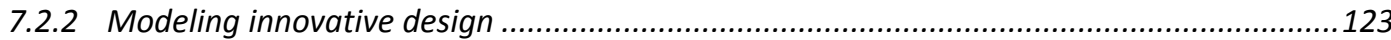

7.3 ACTIVITY-BASED ADAPTIVE PROCESS MODEL OF INNOVATIVE DESIGN ................................................................129

7.3.1 Theoretical basis: Framing innovative design as complex adaptive systems .....................130

7.3.2 Adaptive model framework and model elements ......................................................132

7.3.3 Expert evaluation to adapt the model........................................................................... 137

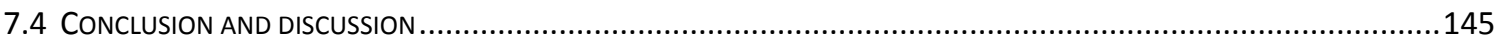

8 VERIFICATION AND REFLECTION ..............................................................147

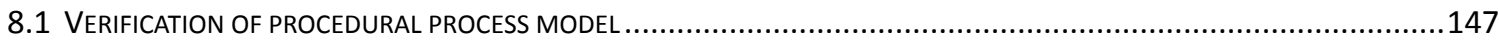

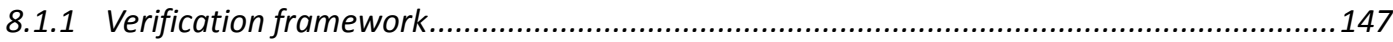

8.1.2 Case description and data synthesis...................................................................... 148

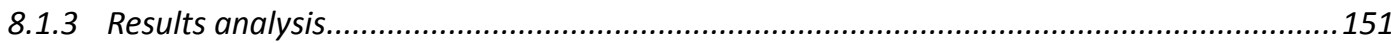

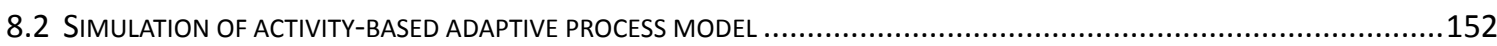

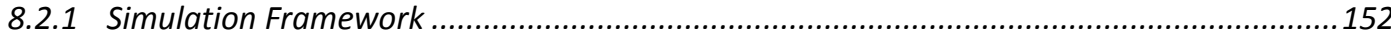

8.2.2 Case description and model inputs............................................................................. 153

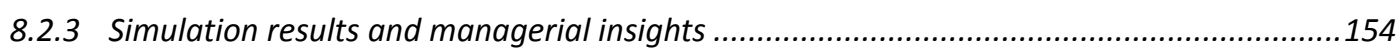

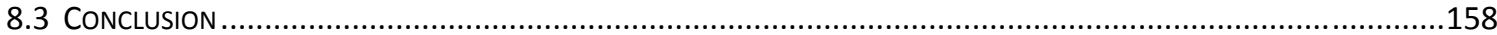

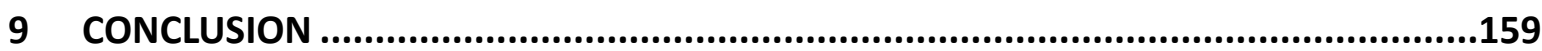

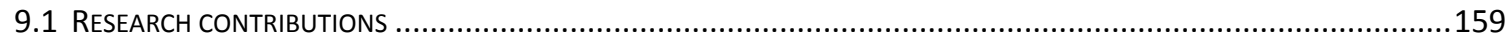

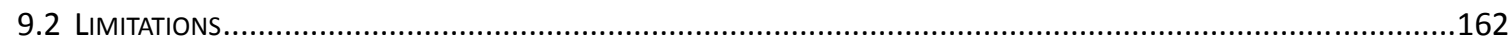

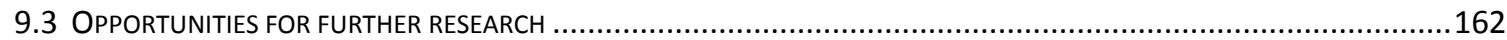

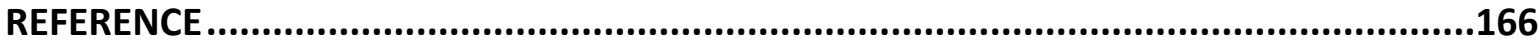

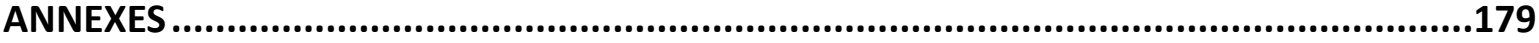

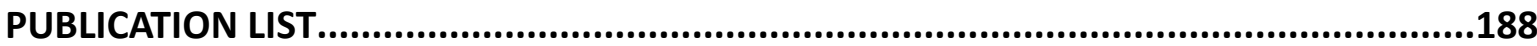





\section{LIST OF FIGURES}

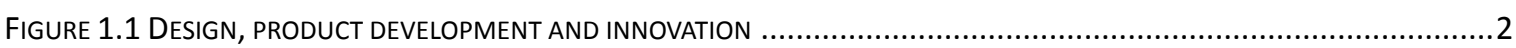

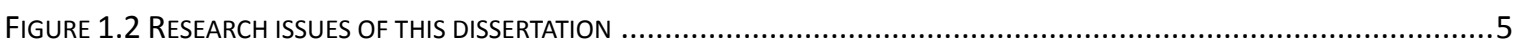

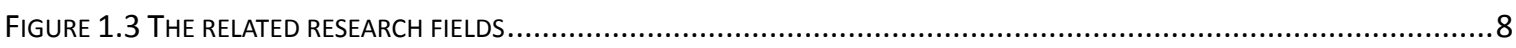

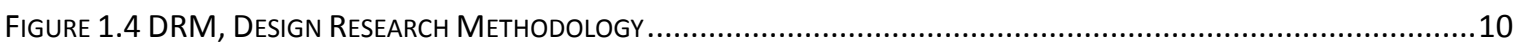

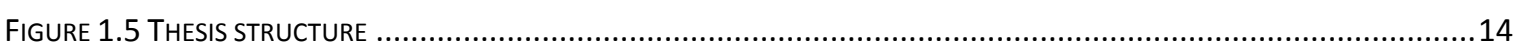

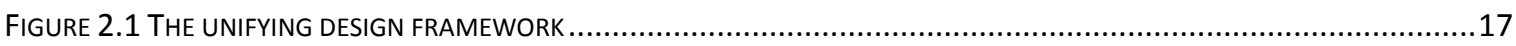

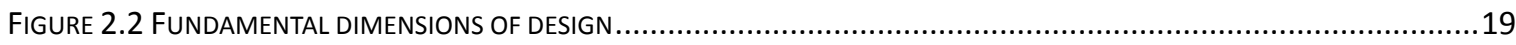

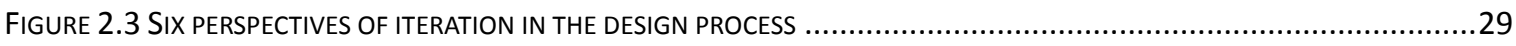

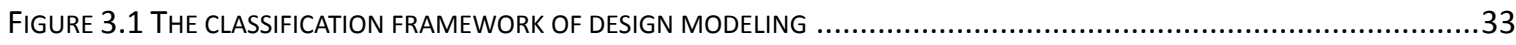

FIGURE 3.2 THE VIEWS OF RATIONAL PROBLEM-SOLVING PARADIGM ON THREE DIMENSIONS OF DESIGN.............................35

FIGURE 3.3 THE VIEWS OF REFLECTIVE PRACTICE PARADIGM ON THREE DIMENSIONS OF DESIGN ...................................37

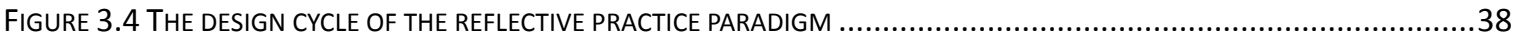

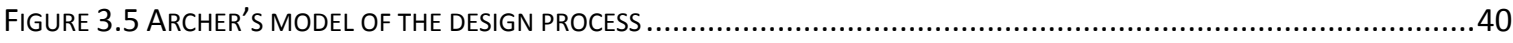

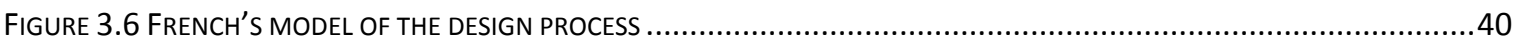

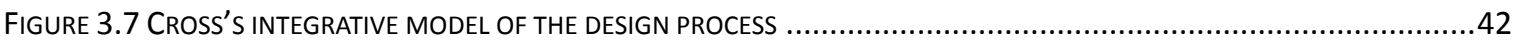

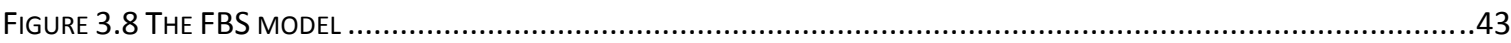

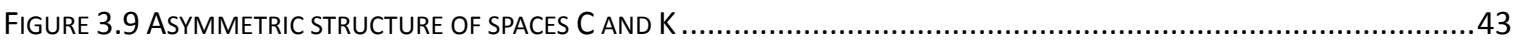

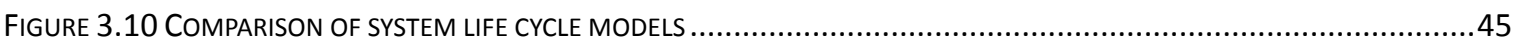

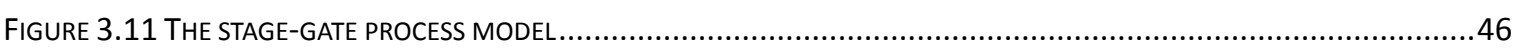

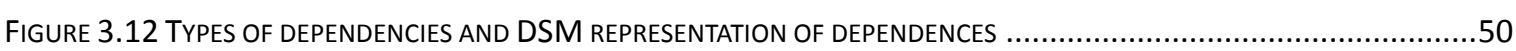

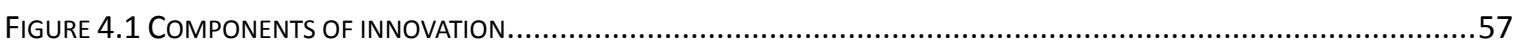

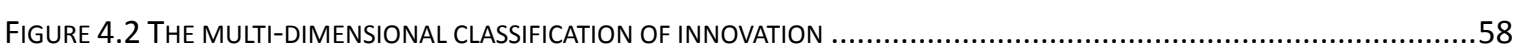

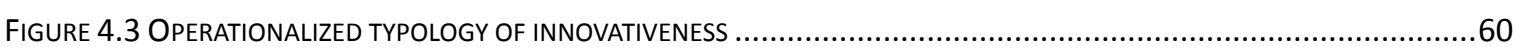

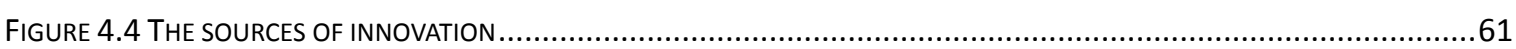

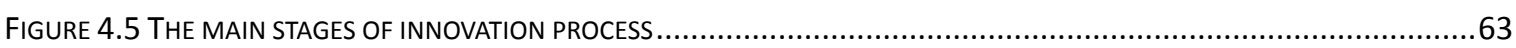

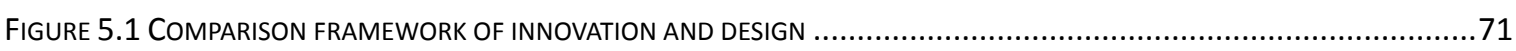

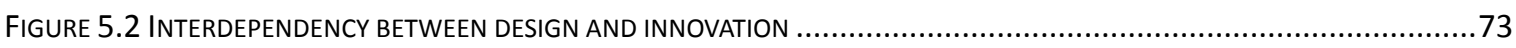

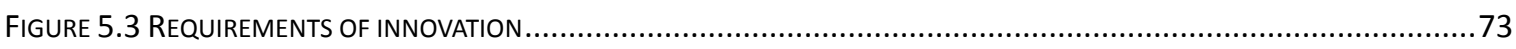

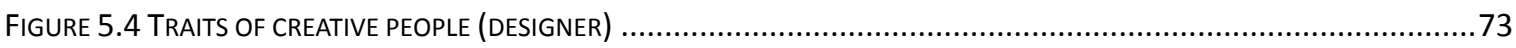

FIGURE 5.5 FOUR TYPES OF THE RELATIONSHIP BETWEEN DESIGN AND INNOVATION ................................................75

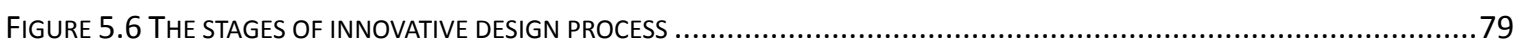


FIGURE 5.7 TRIGGERS OF EXPANDING PRODUCT IDENTITY .80

FIGURE 5.8 RESEARCH FRAMEWORK OF THE DESCRIPTIVE MODEL OF INNOVATIVE DESIGN ..........................................83

FIGURE 5.9 ORIGINAL BASIC FRAMEWORK OF INNOVATIVE DESIGN BASED ON THE FBS MODEL....................................86

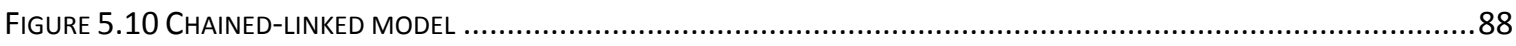

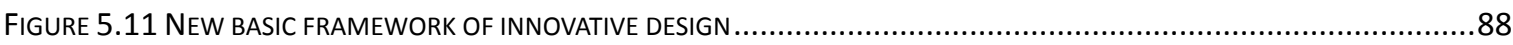

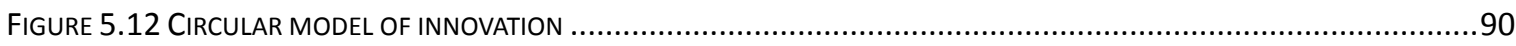

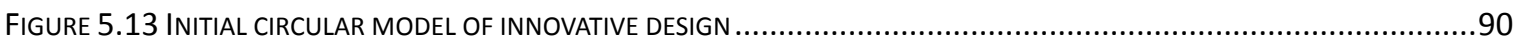

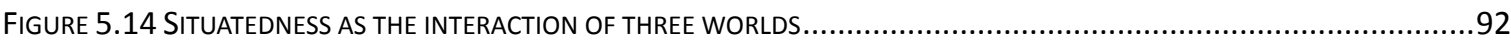

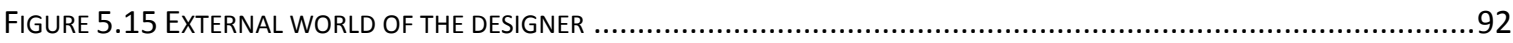

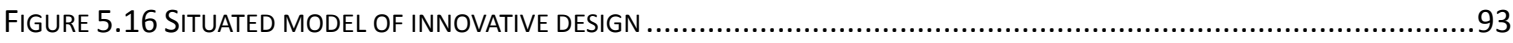

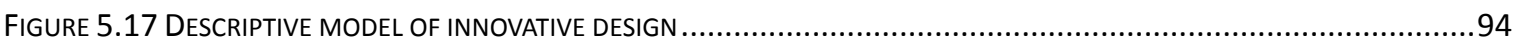

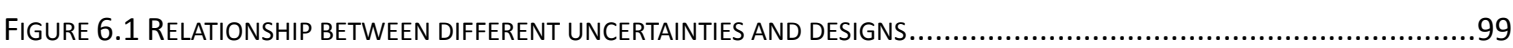

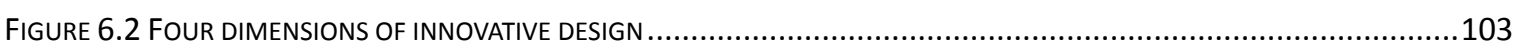

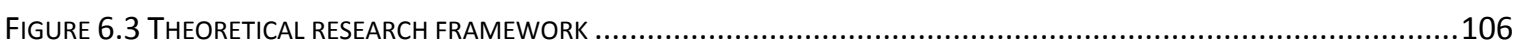

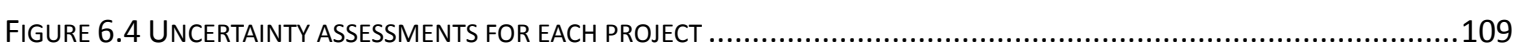

FIGURE 7.1 THE BASIC PROCESS FRAMEWORK OF INNOVATIVE DESIGN IN THE PROJECT-LEVEL .......................................124

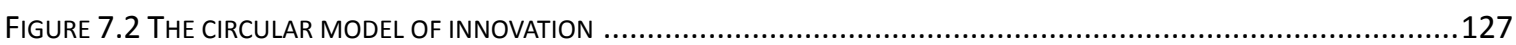

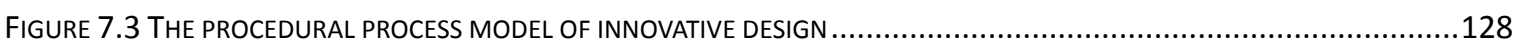

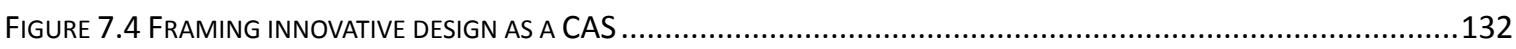

FIGURE 7.5 THE MODEL FRAMEWORK OF ACTIVITY-NETWORK ADAPTIVE PROCESS MODEL ..........................................133

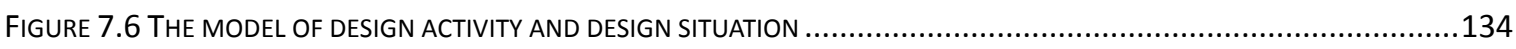

FIGURE 7.7 THE PROFILE OF THE PROBABILITY OF ACHIEVING DESIGN TARGETS .....................................................137

FIGURE 7.8 ALTERNATIVE PROFILES OF THE PROBABILITY OF ACHIEVING DESIGN TARGETS...........................................137

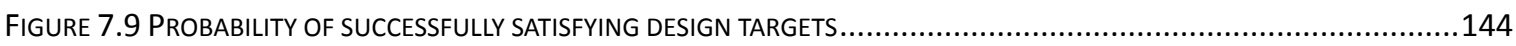

FIGURE 8.1 THE VERIFICATION FRAMEWORK OF THE PROCEDURAL PROCESS MODEL ............................................147

FIGURE 8.2 THE WHOLE AUtOMOBILE DEVELOPMENT AND DESIGN PROCESS .....................................................150

FIGURE 8.3 THE SIMULATION FRAMEWORK OF THE ACTIVITY-BASED ADAPTIVE MODEL............................................153

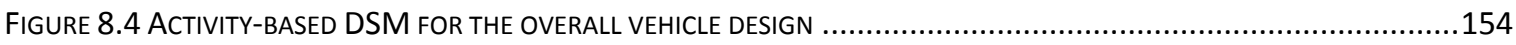

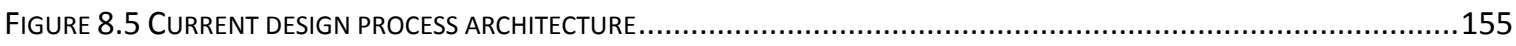

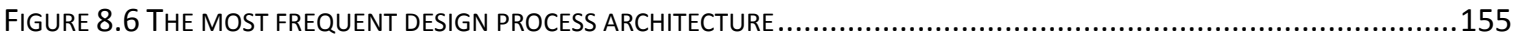

FIGURE 8.7 INFORMATION VALUE PROFILE INCREASING THE PROBABILITY OF SATISFYING EACH DESIGN TARGET IN THIS SIMULATION 


\section{LIST OF TABLES}

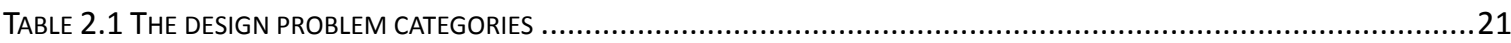

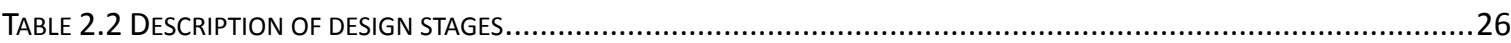

TABLE 2.3 A COMPARISON OF DESIGN STAGES OF DESIGN PROCESS MODELS......................................................27

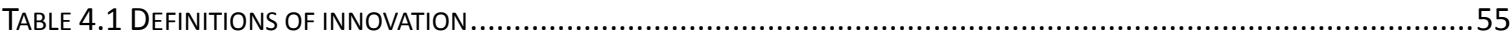

TABLE 4.2 WORD FREQUENCY COUNT BASED ON DISCIPLINES AND ATTRIBUTES......................................................59

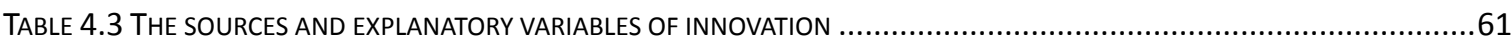

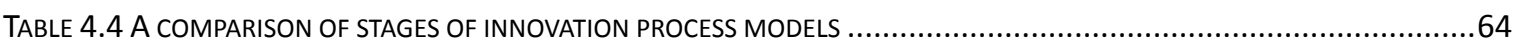

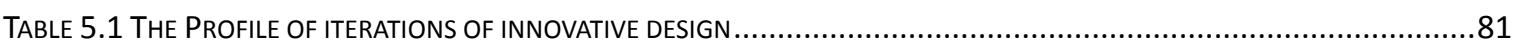

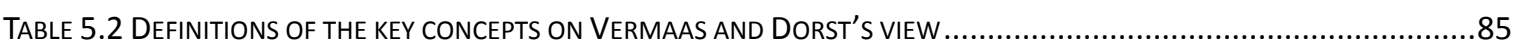

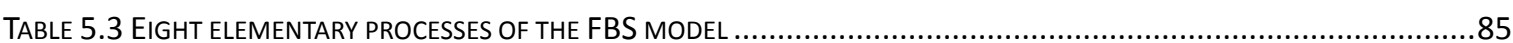

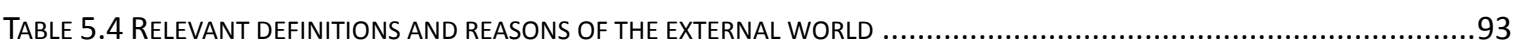

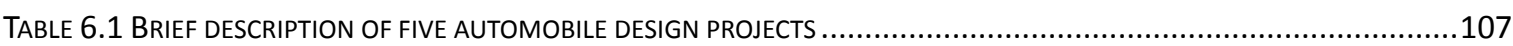

TABLE 6.2 ProJeCt PRACTICES OF CASE STUDIES IN TERMS OF CONTROL AND FLEXIBILITY...........................................109

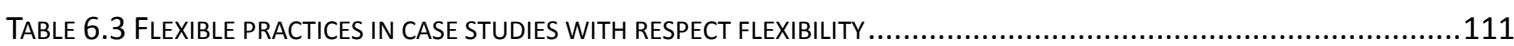

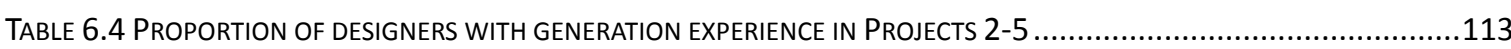

TABLE 7.1 APPROPRIATENESS OF USING PARADIGMS FOR RESEARCH GOALS, OBJECTS AND SUBJECTS IN THIS DISSERTATION......120

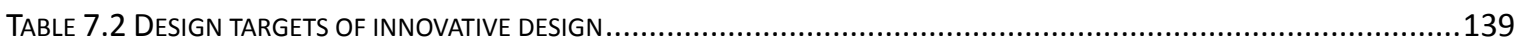

TABLE 7.3 THE CORRESPONDING RELATIONSHIP BETWEEN DESIGN STAGES AND DESIGN TARGETS..................................141

TABLE 8.1 THE BRIEF DESCRIPTION OF TWO AUTOMOBILE INNOVATIVE DESIGN PROJECTS .........................................149

TABLE 8.2 THE MARKETPLACE AND ECONOMIC INDICATORS OF THE TWO PROJECTS ..................................................149

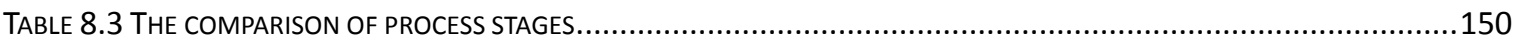

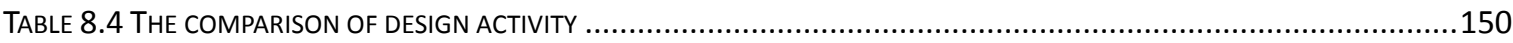





\section{INTRODUCTION}

\subsection{Background}

\subsubsection{Importance of innovative design}

Companies wish to differentiate offering by design in a relevant, meaningful and valued way. This strategy implies two questions: Where does a core idea around a differentiated, meaningful and valued offering come from? What is its relationship with design?

The first question refers to innovation strategy. Harsh competition has led to increased emphasis on innovation. Managers consider innovation as the main source of differentiation and competitive advantage. Innovation applies ideas and new knowledge to the production of goods and services to improve product quality and process performance. Innovation thus has become to a crucial dimension of business strategy.

The second question mostly concerns design strategy. Currently, design is increasingly recognized by managers as a strategy tool to be responsible for the sustainable competitiveness. Design turns news ideas into practical and attractive propositions for users or customers. With this, companies can develop products and services that truly matter customer's life and thereby improve the business influence. Design not only plays a key role in developing brands (Brunner et al., 2008), but also is "one of the primary idea generators for the creation of viable business platforms" (Best, 2008).

With the background of innovation, design can be understood as being the essence of innovation, since design itself always introduces something new. Therefore, it is suggested to build design-driven innovation (Brunner et al., 2008). In other words, innovative design is consider as the means of innovation strategy toward business success.

\subsubsection{Context of innovative design: product development and innovation}

Through the change of business strategy as discussed above, it actually reflects the change of the relationship between design, product development and innovation. Historically, the three terms are distinguished from the process steps included (Marxt and Hacklin, 2005). As seen in Figure 1.1(a), design emerges as a discrete functional sub activity, to be integrated at specific stages of the product development process (Perks et al., 2005). Design activities are classed into four stages: task clarification, conceptual design, 
embodiment design and detail design (Pahl and Beitz, 1996). Product development includes the generation of product ideas and production. Product innovation mainly focuses on the entire process from preliminary investigation to market introduction. Within the view, design is treated as a downstream step in which designers develops an already idea or concept to attract consumers, rather than play an earlier role in the work of innovation (Tim, 2008).

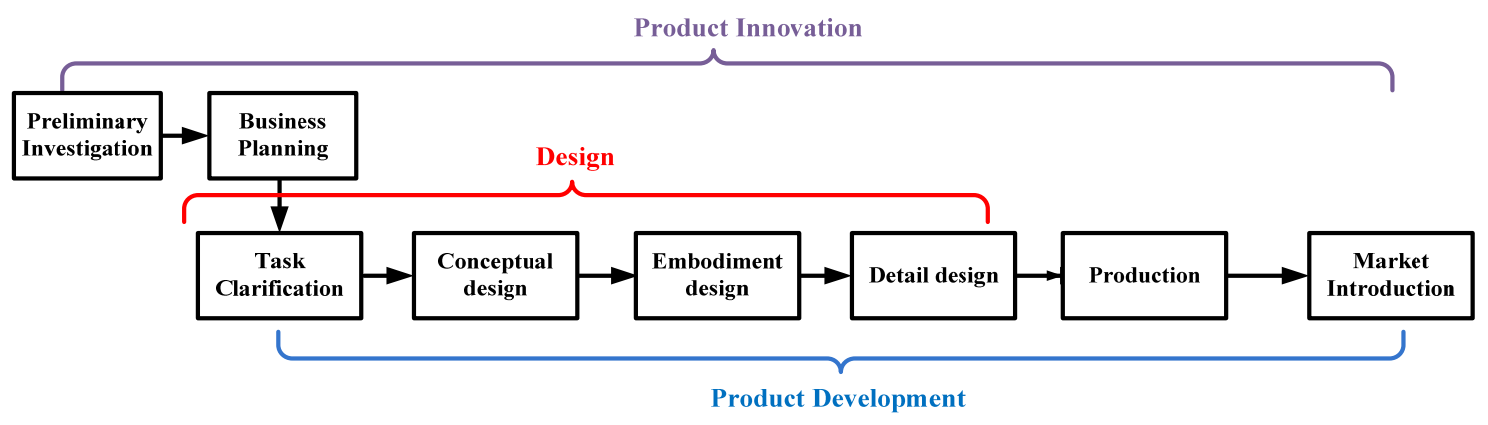

(a) the relationships between product innovation, design and product development

Product Innovation

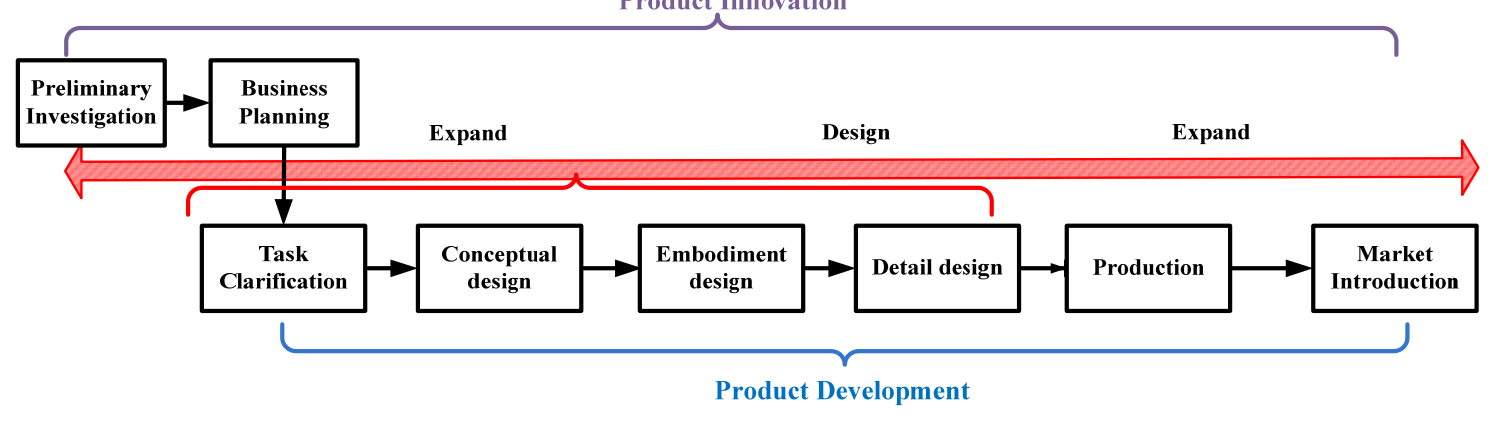

(b) the enlargement of the role of design

Figure 1.1 Design, product development and innovation

Currently, in response to the design-driven innovation, it is suggested that design should be the process leader of product development process (Von Stamm 2008; Perks et al., 2005), as shown in Figure 1.1 (b). It results in the evolution of the relationship between design, product development and innovation. Design in the situation is seen as the main force of innovation. The boundaries of design activities are increasingly extended to product development with considering the whole product life cycle (Herbert, 2011). At the stage of idea generation, designers interact directly with the market in order to get initial product idea or concept. Designers also provide supports or even take participate in the production and market introduction stage. It is obvious that these roles beyond those tasks demanded by traditional design activity. As Marxt and Hacklin said, design, product development and innovation maybe are the same in the end (Marxt and Hacklin, 2005). 


\subsection{Research motivations and issues}

\subsubsection{Research motivations}

As discussed in Section1.1, design is the essential part of the process of product innovation, and has an important role in generating long-term firm success. However, as one of the most distinguished and purposed activities, design does not have any unified for it. In design research, several researchers, from different experiences and observations, have expressed their views on design, such as the problem-solving process (Simon, 1999), the reflective practices (Schön, Donald A., 1995), the decision-making process (Von Stamm, 2008), the evolution process between concept and knowledge (Hatchuel and Weil, 2003) etc.

Although there is no agreement on the answers to design, certain aspects generally can be noted which have a strong bearing on design. According to Simon (1999), design aims at changing existing situations into preferred ones. Firstly it establishes requirements based on human needs, and then transforms them into performance specifications and functions, which are then mapped and converted into a design solution (using creativity, scientific principles and technical knowledge) that can be economically manufactured and produced. Design process thus can be considered as a series of actions and staged gateways that guide and control research and development, which typically include both the technical process (design activities) and non-technical process (organizational activities).

What made some companies, such as BMW, Apple and IDEO, have 'better' design performance than others? Good innovative design does not emerge by accident, but rather as the result of a managed design process (Bruce and Bessant, 2002). Therefore, the main question "how to design and manage these activities that heavily influence design efficiency and performance?" is of great interest to both individuals and organizations.

Different from routine design in which design prototypes with variables and structures do not change, innovative design requires some degree of innovation. It is commonly viewed that innovation requires loose setting, free environment and a lack of strict boundaries. Innovative design thus inclines to focus on how process factors such as flexibility, informality, and feedback influence innovation.

Despite the importance of innovation, the uncertainty caused by innovation present a great challenge to the design team. For an innovative design with market uncertainty and technology uncertainty, the resulting capabilities of the design and the exact means to achieve the expected goal are uncertain. And even greater challenge comes from the changing or emergent information during this process. In such environments, the design 
team knows these events are possible, but do not know whether they will happen. That is, these cases are applicable in case of "variable" and "foreseen uncertainty" (Pich et al. 2002). Moreover, in the case of innovative design, it causes radical expansion or change of product identity, and tries to break away from existing rules and to generate new rules (Le Masson et al., 2010). During this process, it applies the creative ideas or creatively applies the existing ideas to create a product, process or service for a customer and market (Zhang et al. 2011). It is impossible to recognize all relevant influence factors and their functional relationships, even the unexpected emerging events during operation. Innovative design thus may involve unforeseen uncertainty and chaos, even a blend of types.

Without the ability to control these uncertainties, it will lead to different risks of design failure. Thus, a certain amount of process control is also required to secure the effective use of resources and the achievement of design project goals. Meanwhile, it also requires a high level of autonomy and an open environment to encourage innovation. Therefore, as for innovative design, the main question above becomes "Can companies carry out control and provide structures for activities of innovative design while at the same time encouraging more innovation?" That is, companies must weigh the benefits and cost of the integration between control and innovation to ensure that reduce more risks that they create.

A well-managed innovative design process can have the ability to encourage innovation by rapidly adopting new technological and market information, and to embrace environmental turbulence by structuralizing the process. In contrast, a poorly-managed process can severely harm the design result. This thesis is motivated by the commercial importance discussed in Section 1.1 and the operational contradiction. Therefore, this thesis will argue that:

The well-managed innovative design process may be modeled by the systematic method. The models can balance innovation and control, each respectively influencing process creativity and process reliability.

The motivation is necessarily abstract to encompass the content of this thesis. It is analyzed and decomposed further in the following sections.

\subsubsection{Research issues and questions}

According to the research motivation in the preceding section, the primary goal of this dissertation is a series of useful process models to help designers and managers effectively managing innovative design for balancing innovation and control in a way that constructs 
design process and makes daily decisions. To build these process models, in accordance with the logical research sequence of innovative design, companies should firstly understand and analyze, then describe and finally support innovative design by process modeling, as illustrated in Figure 1.2. In this dissertation, the research motivation is decomposed into three main research issues: definition and analysis, process description and management support, which are summarized as following:

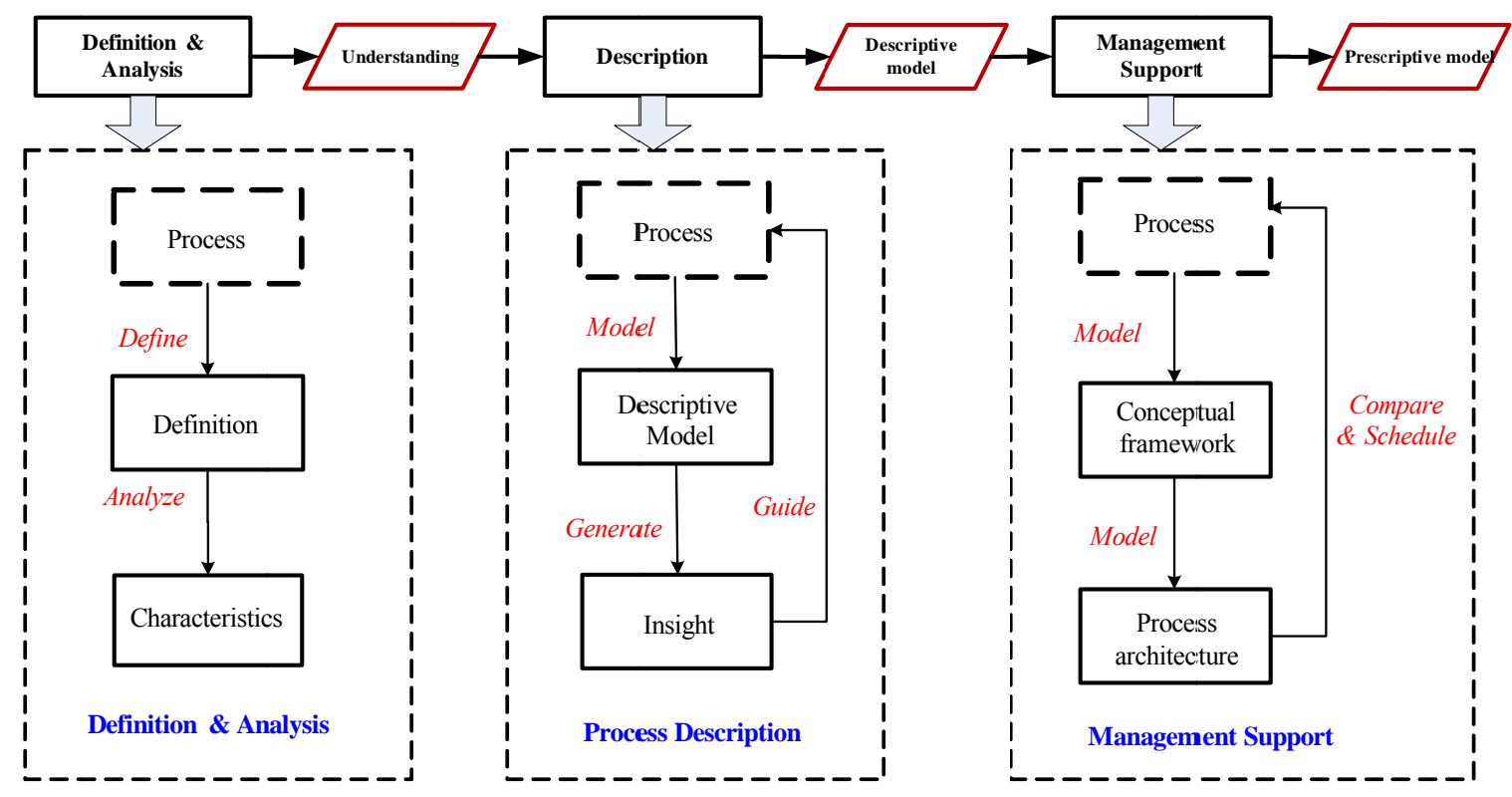

Figure 1.2 Research issues of this dissertation

\subsubsection{Definition and analysis}

Process improvement requires process understanding (Whitney, 1990). Having a comprehensive understanding of innovative design is important for both individuals and organizations. Before discussing how to support and improve innovative design, it firstly should clarify the scope and the content of innovative design to construct the discussion basis. The benefits of offering a formal definition can define the scope and the content, directing research efforts. So the first question of this thesis is:

- Question 1: What is innovative design?

In the literature, there exist several definitions of innovative design. However, as core elements of innovative design, design and innovation, as well as their relationship in theoretical and practical aspects, have greatly changed in the past two decades. Whether do these changes require a reconsideration of the definition of innovative design? Hence,

- Question 1-1: How do we define innovative design to incorporate these changes?

- Question 1-2: Within the new definitions and understanding of innovative design, what characteristics does innovative design have? 


\subsubsection{Process description}

Companies should understand well the innovative design process in order to identify and evaluate improvement opportunities. It involves identifying key processes which could improve the design performance, and evaluating the impact of environmental factors upon design results. A descriptive process model can support this analysis, by which it could build a detailed, common understanding of the process and thereby facilitate the modeler to identify improvement opportunities. This dissertation will develop a descriptive process model incorporating these analysis requirements. Therefore, within this issue, the main research question is:

- Question 2: How should we describe the process of innovative design?

As for the start point to answer this question, documenting what, how and when design activities should be done, by a visual form, could assist designers and managers understand the innovative design process and achieve the focused collaboration. Then, to help designers better find successful factors of innovative design, and to aid companies to understand which processes may generate creative output, we need to identify which process or design activity can improve the design performance, and which process factors could influence the process performance. Therefore, the main question above can be divided into three sub-questions:

- Question 2-1: What are fundamental processes of innovative design to facilitate in understanding the patterns involved in the process?

- Question 2-2: When and where could innovation emerge, proceed and grow during this process?

- Question 2-3: What are the factors affecting the success of innovative design?

\subsubsection{Management support}

As discussed in Section 1.2.1, companies try to construct an appropriate design process to balance control and innovation. Thus, in this dissertation, management support is concerned with how to balance control and innovation during the innovative design process. In terms of control, traditional models of design process prescribe a design process as a recommended sequence of activities in a systematic way, emphasizing hierarchical structures and the division of work and responsibilities. These representations can offer a genetic base to construct the entire process of innovative design. However, these design models raise the question as to what extent they foster or hamper innovation. In terms of innovation, some authors identify some flexible practices to increase innovation. This dissertation will show how process models to support the balance between control and 
innovation. Thus, the main research question of the research issue "management support" is:

- Question 3: How do we model the innovative design process in a systematic method to stand by management support?

Many companies prescribe standard, high-level processes that aim to ensure good practices such as proper evaluation and review activities. Such prescriptions highlight the particular perceptive and understanding of this process. Although these documentations have limited utility and cannot be applied into other cases, they are useful in promoting the development of the shared understanding. Hence, as a start point of management support, this dissertation will develop a procedural process model that prescribes the innovative design stages and their process structure to balance control and innovation. So the first two sub-questions of Question 3 are:

- Question 3-1: What design stages should be performed in the procedural level?

- Question 3-2: What structure do we employ in the procedural level to balance control and innovation of innovative design?

Based on the procedural process model, in order to make the schedule and realistic commitment, given a series of goals or objectives, design managers must determine an appropriate way to balance innovation and control, namely appropriate process architecture. Different process architectures mean that companies adopt different paths to reach the expected goal. Hence, this dissertation will propose an adaptive activity-based process model to capture process behaviors of innovative design. It aims to provide a simulation support in which alternative process architectures to balance control and innovation may be explored. This model can be used as the basis of the approach of design process optimization. Therefore, the adaptive activity-based process model focuses on the following sub-question.

- Question 3-3: How do we model and generate alternative process architectures to balance innovation and control?

\subsection{Research Methodology}

\subsubsection{Research fields}

In order to achieve research objectives and answer research questions in the preceding section, five major research fields are explored in our study, consisting of design, innovation, product development and system theory and systems engineering, as shown in Figure 1.3. In this dissertation, these research fields provide theoretical methods for the 
process modeling of innovative design.

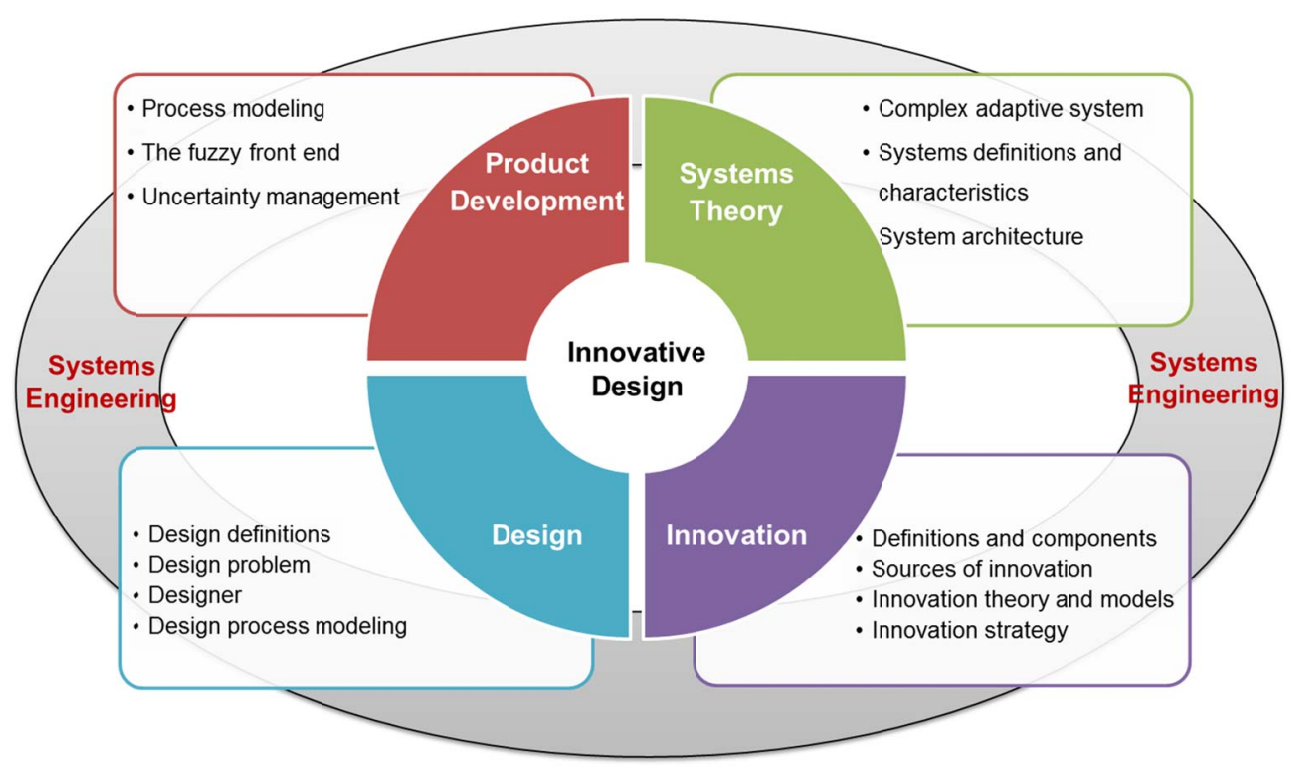

Figure 1.3 The related research fields

Innovative design, as a kind of design, could benefit from related theories and methods of design, such as design definitions and classification, design paradigms, design process modeling as well as creativity in design. Although the design research is not considered as the mature field yet, the related research contributes to understand innovative design in general, and provides related methods and models to the process modeling of innovative design. Moreover, through the review in the field of design, we could analyze the change of the role of design in innovation and product development. These observations can lay a theoretical basis of the definition and analysis of innovative design.

Innovation, as the ultimate goal and the drive force of the whole innovative design process, plays a very important role in defining and modeling innovative design. The content and scope of innovation determine the definition and characteristics of innovative design. In addition, innovation itself is not a new phenomenon, its position, content and scope have greatly changed in the past two decades. These changes necessarily result in the reconsideration of innovative design. Moreover, the process theory of innovation could generate useful insights for describing and explaining a board class of processes, sequences, and performance conditions to innovative design.

Since innovative design is the key process of product development (PD), models and methods of PD, particularly new product development, can be also adopted by innovative design. Firstly, the fuzzy front end of PD can contribute to the study of how to capture the innovative opportunities during the innovative design process. Secondly, uncertainty management of PD is also useful to how to deal with uncertainties that innovative design 
faces; thirdly, planning and schedule techniques of PD provide basic frameworks and models to construct the process architecture of innovative design.

Additionally, systems theory has the potential to provide a trans-disciplinary framework for a simultaneously critical and normative exploration of the relationships between our perceptions and the reality. Instead of focusing on the components, systems approach views the world in terms of irreducibly integrated systems. The attention is drawn to the interacting and integrated systems. Therefore, the methods and concepts of systems theory can offer us the system thinking perspectives and systematic methodology to comprehensively analyze and model innovative design.

\subsubsection{Theoretical context: Systems engineering}

As illustrated in Figure 1.3, systems engineering, as the basis of process modeling for innovative design, plays the role of theoretical context to connect the four domains above.

Systems engineering, as an effective way to manage complexity and change, has been recognized as a preferred mechanism to establish the agreement for the creation of products or services. The fundamental purposes of systems engineering are to guarantee that the system matches real needs through proper specification of demands, to predict the properties and behavior of the system, and to guarantee them through the design of an appropriate architecture(Meinadier, 1998).

Additionally, it is also a cooperative and interdisciplinary process for solving problems that aims to ensure a proper compromise between system strategy and constraints (AFIS, 2010). Compliance with the processes and recommendations in the systems engineering standard, designers can develop feasible and cost-effective systems by defining a complete and consistent set of requirements. Besides, systems can satisfy not only the nominal requirements with respect to cost, time and risk constraints, but also each stakeholder.

Finally, Systems engineering has much wider concerns than addressing the product system, and also encompasses social interaction and organizational systems. Any successful product and design are not isolated from its environments. Innovative design needs multi-discipline human's involvement to generate more creative ideas. And it requires addressing all needs of stakeholder, including project and organization.

Therefore, in order to achieve the research goal "developing well-managed innovative design process to balance innovation and control by process modeling", systems engineering provides operational and management standards, methods and models for innovative design. 


\subsubsection{Research stages and methods}

Design research methodology (DRM) is proposed by Blessing and Chakrabarti (Blessing and Chakrabarti, 2009) to help design research to become more effective and efficient. The DRM consists of four stages: Research Clarification, Descriptive Study I, Prescriptive Study and Descriptive Study II, as shown in Figure 1.4.

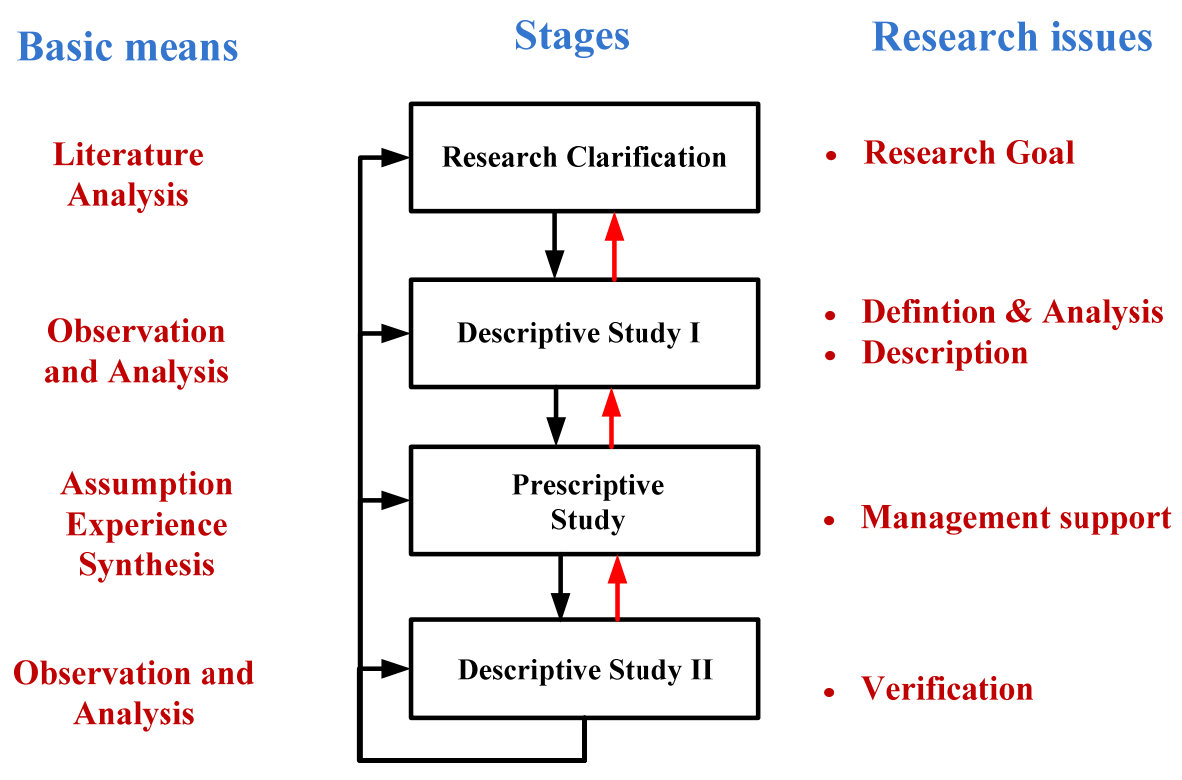

Figure 1.4 DRM, Design Research Methodology

In this dissertation, we follow the research stages to precede our study. According to the research stages, the section discusses research methods and ideas that are applied in each stage of the research.

\section{- Research clarification: Literature review}

In this stage, the research goals are developed and the related theory basis is synthesized by literatures reviews.

In Section 1.2, research issues and questions have been established. In the following study, we firstly attempt to build up a deeper understanding of design in terms of design problem, designer and design process, and then review existing design models. Thirdly, we do so review the literature in the field of innovation, for factors that influence the success of innovative design. Comparing the diverse range of models and modeling approaches with the desired situation of innovative design, we can find advantages and disadvantages of the existing models that support our assumptions, and thereby formulate realistic and worthwhile research goals. 


\section{- Descriptive Study I: Definition and analysis + Process description}

Having a clear research goals, the descriptive study I stage aims to develop a detailed understanding of innovative design. That is, this stage should focus on the two research issues: "definition and analysis" that respond to Questions 1-1 and 1-2 in Section 1.2.2 ; and "process description" that answer Questions 2-1, 2-2 and 2-3 in Section 1.2.2.

With regard to the first research issue, the relationship between design and innovation is firstly discussed by the theoretical comparison. Their relationship determines how to define innovative design and its desired situation. Then, within the new definition of innovative design, a series of problems about the nature of innovative design is discussed. Such as, what is the innovative design problem? Are there special characteristics that are different from other design? Similarly, what stages should this innovative design process include? What characteristics?

The second crucial research issue of this stage is to describe the innovative design process. The purpose is to make the description detailed enough to determine which elements and process can improve the process performance as efficiently and effectively as possible. Therefore, we construct the descriptive model of innovative design for interpreting these elements and processes in this research stage.

\section{- Prescriptive Study: Management support}

The main focus of the prescriptive study is to develop prescriptive models which distill the theories into pragmatic approaches or descriptions of best practice. In short, this stage should realize the third and most important research issue "management support" to balance control and innovation.

This research content is divided into three parts. The first part is to study project practices that respectively support innovation and control by literature reviews. However, only by literature reviews, it cannot provide enough insights to consider how to balance innovation and control in practices. Hence, we observe and analyze how these project practices to be applied into a series of innovative design project of an automobile company, and compare these projects to highlight managerial insights about how to balance innovation and control.

Based on these managerial insights, the second part is to develop the prescriptive procedural process model to answer Questions 3-1 and 3-2 in Section 1.2.2. In the project-level, we construct the basic process framework of innovative design based on the Vee model, which builds up a formal process for innovative design; in the operation-level, we develop a circular model that tries to map flexible practices introduced into process 
elements of innovative design.

However, the procedural process model is too general to guide the detail operation of designers and managers. Therefore, we move down into the activity-level to construct the process architecture of innovative design in the third part. This part attempts to answer Questions 3-3 in Section 1.2.2. Since the assumptions of traditional activity-based techniques and models do not adequately reflect the realities of innovative design (e.g. design activities and their interactions and variable are known a priori; the expected goal can be achieved by these known design activities), we adopt basic ideas of the complex adaptive systems to dynamically develop the activity-based adaptive process model.

\section{- Descriptive Study II: Verification}

This descriptive study II discusses how empirical studies can be used to verify the application and impact of the procedural process model and the activity-based model that have been proposed in the prescriptive study.

Since the procedural process model is a general conceptual framework, its verification is to identify whether the procedural model can be used for management support to balance innovation and control, and to evaluate the assumptions behind the model process. To achieve these goals, we apply this procedural model into a series of innovative design project with different performance in an automobile company. By comparing design processes of these projects with the procedural model, we can evaluate that whether the procedural model has the expected effect on management support.

With regard to the adaptive activity-based model, its verification is to identify whether this model can successfully construct the process architecture of innovative design. Hence, we use a discrete-event simulation to construct the process architecture of an innovative design project based on the adaptive process model. By comparing the simulation result with the current design process used by the automobile company, it not only can verify the activity-based adaptive model, but also highlight several related managerial insights.

\subsection{Thesis structure}

This dissertation proceeds in nine chapters, as shown in Figure 1.5. Based on the analysis of design research methodology in the previous section, the research parts are analyzed as follows: the research clarification stage includes Chapters 1-4; Chapter 5 focuses on the descriptive study I; Chapters 6 and 7 correspond to the prescriptive study; Chapter 8 solves the verification problems of the descriptive study II. More details:

In Chapter 1, the research motivation, and research issues and questions are defined, 
and the research methodology is discussed.

Chapter 2 concerns on the understanding of design in terms of design problem, designer and design process. It indicates that design is a complex human activities, and involves a collection of many different logically connected knowledge and disciplines. And there is no definition that can be widely accepted.

Chapter 3 reviews published models of design and product development based on the level of model abstraction (the design paradigm, the procedural model and the activity-based model). It is argued that design paradigms provide us with the theoretical foundation of process modeling, and there is no single procedural model and activity-based model that can provide an adequate description and prescription of innovative design.

Chapter 4 focuses on the synthesis of innovation. We compare definitions of innovation to identify the commonplaces. Based on these commonplaces, we construct the multi-dimensional classification to characterize innovation and identify key components of innovation. And then we review innovation process models. Finally, we synthesize three aspects of changes for innovation.

In Chapter 5, drawing on the literature review about design and innovation, as well as the theoretical comparison between the both, the definition of innovative design is proposed. Then, the nature of innovative design is analyzed. Finally, the descriptive model of innovative design is developed step by step.

Chapter 6 provides the practical basis of process modeling of innovation design. After analyzing management challenges that the innovative design project faces, we identify project practices that support flexibility and control. Then an empirical study is performed to investigate how to deal with these practices. This study demonstrates that innovation and flexibility can coexist, and provides managerial insights about how to deal with the balance.

Chapter 7 introduces the procedural process model and the activity-based adaptive model of innovative design. The former model is developed in two levels: in the project-level, the basic process framework of innovative design based on the Vee model is developed; in the operation-level, a circular model that maps flexible practices into process elements of innovative design is constructed. The latter model considers innovative design as the complex adaptive system to dynamically construct the process architecture.

Chapter 8 verifies the procedural process model and the activity-based adaptive model by a series of case studies.

In Chapter 9, research contributions and limitations are reviewed, and opportunities for further work are highlighted. 


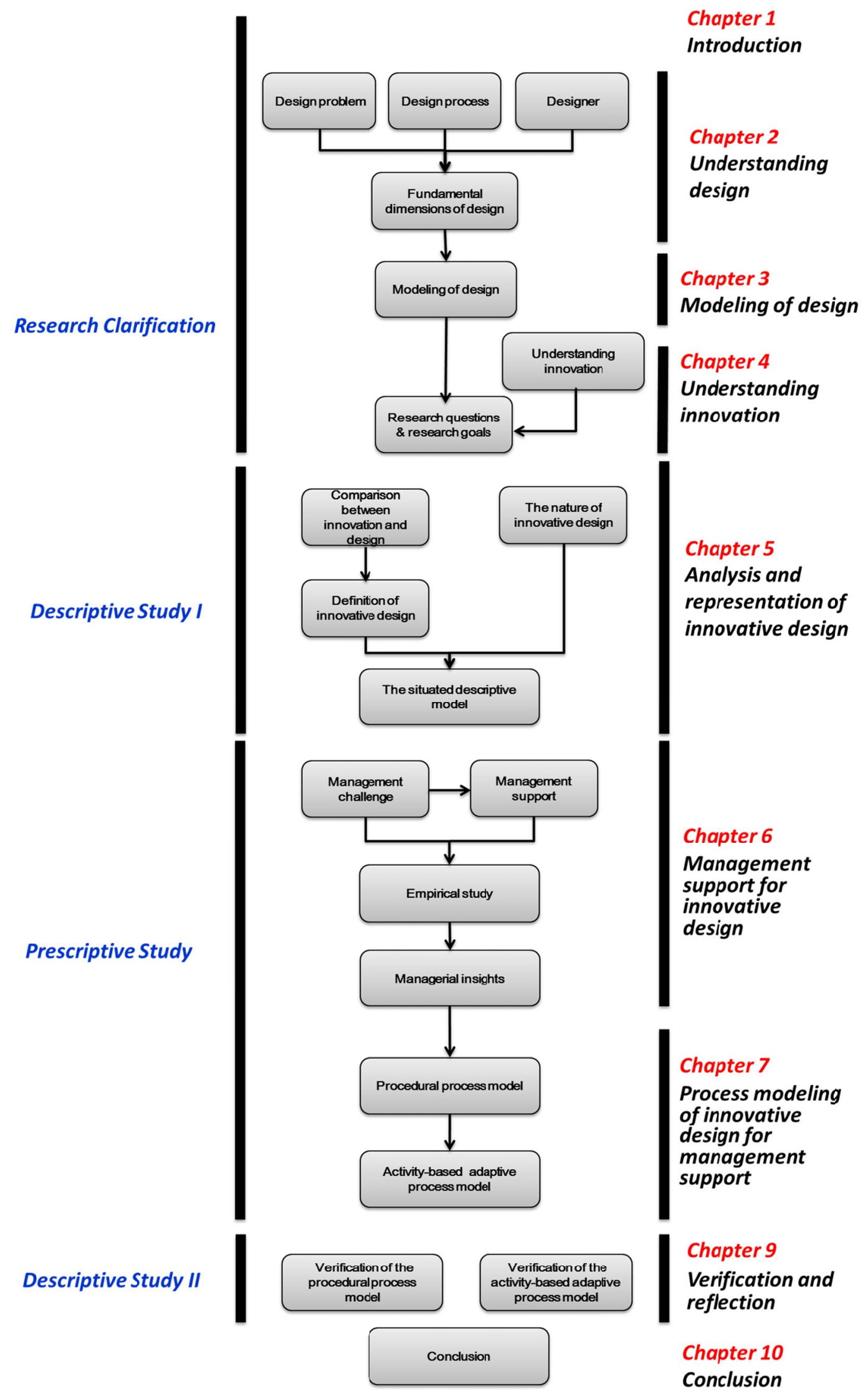

Figure 1.5 Thesis structure 


\section{UNDERSTANDING DESIGN}

\subsection{Overview}

People always have designed things. One of the basic characteristics of human being is that they make a range of tools and other artifacts to achieve their purpose (Cross, 2008). Here are some of human activities are characterized as design: architectural design, software design, service design, product design, information system design, engineering design, fashion design, game design etc. Therefore, the nature point to begin any discussion of the term "design" is to state what design is.

Design as one of the most distinguished and purposed activities, while the extensive research undertaken since the 1950s, does not have any unified structure or organization for it. Although there is no single model or explanation that can furnish a perfect definition of design, these researches provide us with the powerful base to understand and explain design. In this chapter, we attempt to review the related research works in the field of design, in which we firstly adopt a unifying design framework and identify fundamental dimensions of design, and then understand and analyze design.

Discuss proceeds as follows. Firstly, the unifying design framework and the fundamental dimensions of design are developed by reviewing definitions of design in Section 2.2. Then, the fundamental dimension of design-the design problem, the designer and the design process- are respectively discussed in Sections 2.3, 2.4 and 2.5.

\subsection{What is design?}

\subsubsection{Definition}

In a traditional understanding, design is often associated with a person who is involved in both the design and the production of an object. Resulting from the division of work and the need for specialization, the concept began to change. Consequently, two strands of design evolved, respectively "design as art" and "design as engineering" (Von Stamm, 2008). In many fields, the term design still connotes art, such as the fashion design of clothing, interior design of house (Maier and Fadel, 2009). In this dissertation, we intend only to emphasize design as engineering, which includes products, machines, structures, and the like. An artist's practicing activities when creating a work of art cannot be considered as our subject. 
In current design research, several researchers, from different experiences and observations, have expressed their views on design. Clearly, although design has been performed for many centuries, does not have any unified definition for it. Some of these viewpoints are expressed below:

- Design is reflective conversation with the materials of a design situation (Schön, Donald A., 1995).

- Design can be defined as a goal-oriented, constrained, decision-making, exploration and learning activity that operates within a situation that depends on the designer's perception of the situation and results in the description of a future engineering system (Gero and Kannengiesser, 2004).

- Design can be modeled as the interplay between two interdependent spaces with different structure and logics: the space of concepts (C) and the space of knowledge (K) (Hatchuel and Weil, 2003).

- Design is the conscious decision-making process by which information (an idea) is transformed into an outcome, be it tangible (product) or intangible (service) (Von Stamm, 2008).

- Design is conceiving and giving form to artifacts that solve problems (Ulrich, 2011).

These definitions of design reflect various viewpoints of these proponents. Some view it as a rational problem-solving process, others as a reflective process or a decision-making process, and still others as an evolving process between knowledge and concept. The rational problem solving approach in design is the combination of practice-based phase models of the design process, a model of the designer as an information processor from the field of cognitive psychology, and some thinking on the nature of the design problem (Dorst, 1997). The reflective process argues that the design process cannot be simply grasped by any design approach, but that the work of designers much resembles the work of an artist who applies different kinds of methods and knowledge in a flexible manner. In design process, designers observe and interpret what they are 'seeing', and then decide on new actions. The decision theory considers design as a decision-making process (Hazelrigg, 1996). Accordingly, if one wants to understand design, one ought to study how best to make decisions, which is the province of several fields of mathematics, particularly the application of utility theory.

Although there is no agreement on the answers to the definition of design, certain aspects generally can be noted which have a strong bearing on design. These include: purpose, constraints, reflection, information process, exploration, function, transformation, 
situation, and knowledge. Taking account of these key words and trying to integrate and unify the definition, design can be described as:

Design is a process of establishing requirements based on needs and dissatisfaction with the current state of artifact, transforming them into performance specification and functions, which are then mapped and converted into design solutions (using creativity, scientific principles and technical knowledge) that can be economically manufactured and produced.

\subsubsection{Unifying design framework}

As we discussed above, design refers to different things in different definitions. From engineering design to software design to product design, design objects in these domains vary, and the techniques and methods used by these domains are highly specialized. Therefore, to analyze these perspectives and models, a unifying design framework across these domains is necessary. According to this integrated definition above, design is a problem-solving process through which the needs are transformed into design solutions. Ulrich proposes a unifying design framework to describe this process (Ulrich, 2011), as shown in Figure 2.1. In this framework design is one part of the problem-solving process beginning with the gap of user experiences, leading a plan for an artifact, and finally resulting in the production of this artifact. The problem-solving process includes the design and the production of the artifact. Hence, in this dissertation, we adopt Ulrich's design framework as the unifying design framework to discuss.

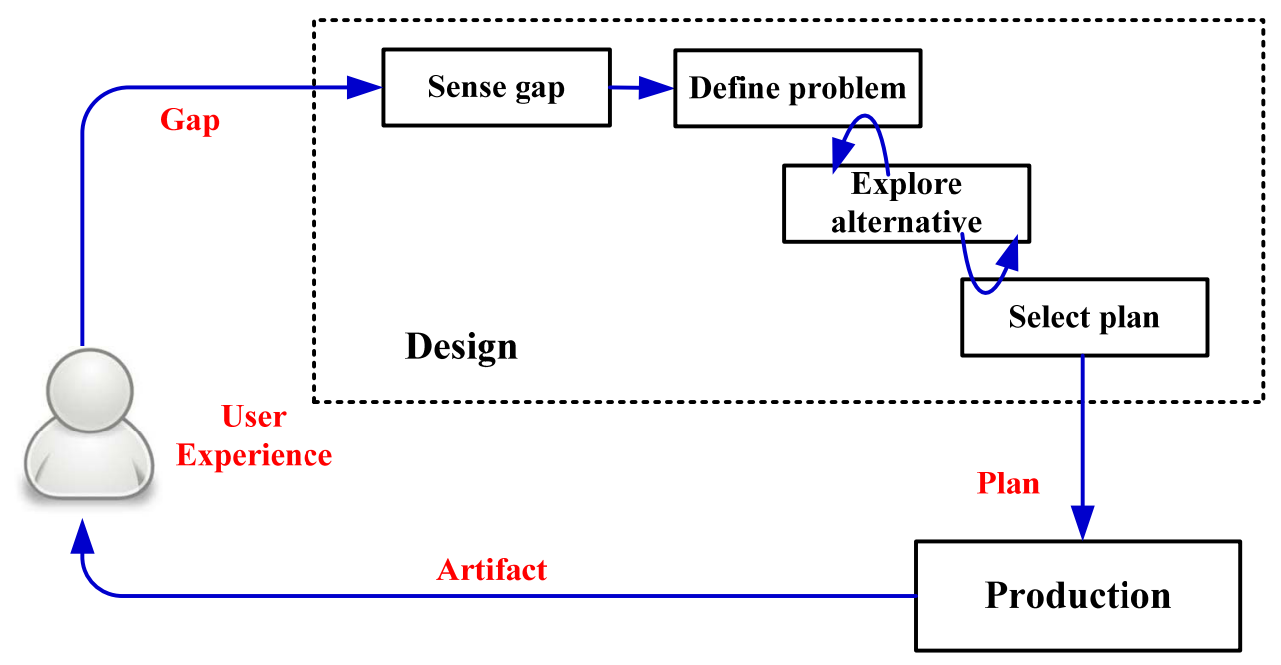

Figure 2.1 The unifying design framework (Ulrich, 2011)

As illustrated in Figure 2.1, design transforms a gap into a plan. In this process, it can be decomposed into four steps: sense gap, define problem, explore alternative and select 
plan. Design begins with the recognition of the gap between the user experience and the current state of artifact. The gap is the motivation of design. Problem definition is to explain this gap by designers. Within a professional design process, problem definition can be expressed in the form of requirement list, design specification or customer needs. Given the problem, designers explore possible alternatives. Because it usually exists several available problem solutions, designers need to perform some sort of evaluation and select from these alternatives. The plan can be represented with drawing, compute model or design documents. Finally, production transforms the plan to an artifact.

\subsubsection{Fundamental dimensions}

Based on the unifying design framework above, the quality of design outcomes (i.e. plan) is influenced by at least three characteristics of the design process: (1) does the designer sense the gap between the user experience and the current state of artifact? Then does the designer define the problem consistent with the gap? In other words, does the designer understand the design problem? (2) Is the scope of exploration represented in a way that includes possible good design solutions? (3) Does the design find an appropriate and satisfied design solution within the solution space that has been defined? In Ulrich's words, "Did the designer understand this problem, and frame it in a way that exploration could potentially lead to a good solution, find such a solution within the solution space, and deliver an artifact consistent with the plan?" (Ulrich, 2011)

According to the analysis above, to characterize design, three dimensions of design should be described as follows (Dorst, 1997; Ullman, 1992), as illustrated in Figure 2.2:

- Design problem being solved, as evidenced by what the initial and final design state are.

- Designer, that is, who is performing the design (their characteristics and the constraints on them).

- Design process itself, focusing on how to transform from the gap between the user experience and the current state of artifact to the design plan.

Two of these three dimensions are often ignored by classical design theories. Classical design theories and methodologies emphasize effectiveness and efficiency of the design process. However, recent empirical studies have proved that the definition of design problem and the designer are also the determinant elements (Cross, 2004; Dorst, 1997; Ullman, 1992; Valkenburg and Dorst, 1998). So we also should emphasize the "design problem" and "designer" dimensions. The following sections (Sections 2.3, 2.4 and 2.5) present the three dimensions to understand well design in detail. 


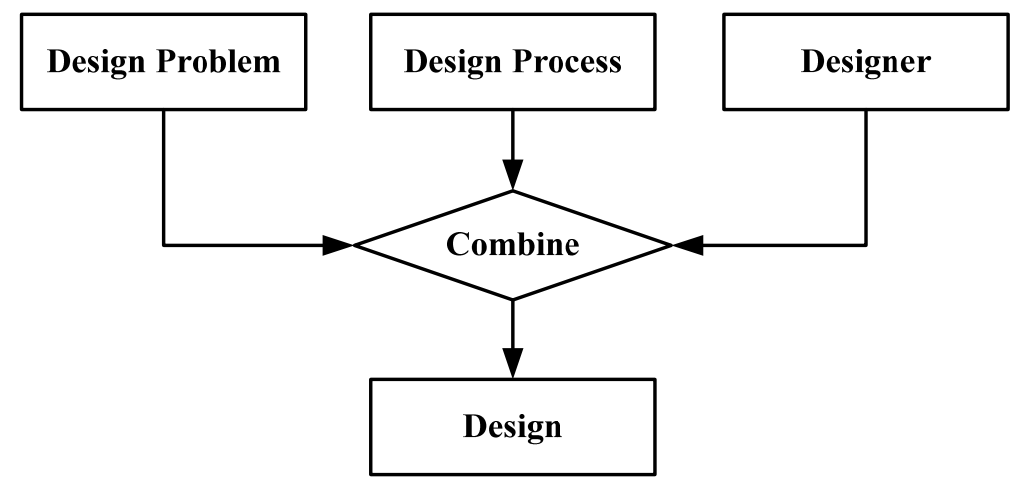

Figure 2.2 Fundamental dimensions of design

\subsection{Design problem}

Design problems range from relatively small component design to the design of large scale system such as automobile and space shuttles. These design problems originate as some form of problem statement provided to the designer by the user (the client, the company management and other stakeholders) (Cross, 2008), and vary in their form and contents. For example, it can be expressed in the form of a design brief, a customer needs list and other documents.

\subsubsection{Ill-defined problem}

Design problems are widely considered as an ill-defined problem (Cross, 2001), in contrast to well-defined or well-structured problem. The well-defined problems have clear goals, and known ways of generating the expected results. In order to characterize design problem in a uniform, we identify the generic characteristics of the ill-defined problem: ambiguity, complexity of problem structure and situated problem.

\section{(1) Ambiguity}

Ambiguity refers to the lack of clarity or consistency in the formulation of design problems (Yan and Stephen, 1998).This phenomenon is reflected in several aspects: Firstly, when the problem is initially set, the goals are usually not clear, and many constraints and criteria are unknown. And the design context is often messy and complex, and poorly understood. Thus, there is no definitive formulation of the design problem (Cross, 2001). In addition, the design problem is not inherently consistent. There exist several conflicts and inconsistency that need to be solved during the design process. Thirdly, the lack of definitive solution also causes the ambiguity of design problems.

When facing ambiguity, the ways of formulating design problems are dependent on the ways of solving it. It is usually possible to perform some steps to improve the initial 
definition of the problem by gathering information from the clients and research. In Dorst and Cross's words, design problem and design solution evolve together (Dorst and Cross, 2001). The way the solution is conceived influences the way the problem is conceived.

(2) Complexity of problem structure

Most design problems involve multiple functional requirements that require multi-disciplinary knowledge. The dependence relationships of requirements and the interactions of various disciplinary knowledge result in the complexity of problem structure. If the object of a design problem is a complex product that involves multiple functions, components, relationships between these components, it exacerbates the complexity.

The kind of complexity would result in two effects for design (Yan and Stephen, 1998): Firstly, it is difficult to accurately and comprehensively understand and solve the design problem for designers. For instance, while making decisions on the ways in which components are integrated together to form a coherent whole, it requires knowledge of these component's core concepts, the way in which these components are integrated and linked each other (Hobday, 1998). As a result, designers may not explore enough all possible alternative solutions.

Secondly, even if possible alternative solutions are generated, the quantity of these solutions could greatly raise the coordination problem for designers, especially for an original alternative. Additionally, the larger the number of components, the more difficult the decision choices would be (technology, the technology chosen).

(3) Situated problem

Because design problem cannot be clarified at the beginning of the design process, it needs a much deeper restructuration and interpretation by designers in a multistep problem-solving process (Dorst, 2006). It means that the design process and the very structure of ill-structured problem are determined by actions that designers take. In Schön's words, designers' perceptions on the world outside have very important influences on the world under construction (Schön, 1995). Designer observes and interprets what they are 'seeing', and then decide on new actions, instead of simply performing the recommended actions. Furthermore, because design encourages designers to be aware of what they are doing from the perceived design situation and remembered design activities (Reymen et al., 2006), it results in the learning activities and the generation of new knowledge. These activities illustrate that the design problem is seen through the eyes of designers in the current design situation, that is to say, the situated problem-solving. 


\subsubsection{Category of design problems}

A design is strongly influenced by lifestyle, training and experience of designers, and creativity and effort a designer puts into a design varies, depending on the type of design problem (Evbuomwan et al., 1996). In the design research, to categorize different design problems has been proven to be useful for both analysis and construction of design tools, methods and techniques. We discuss the variety of design problem in this section.

In the field of engineering design, the classification of design problem is generally related to the design output's distance from the current design's diagram (Howard et al., 2008). Several researchers propose different classifications for design problems (see Table 2.1). The columns are organized to exhibit the closely related design problems. These types are ordered by increasing the level of originality from left to right. Heading that originates from Evbuomwan et al.'s classification (e.g. routine design, redesign and non-routine design) were chosen to describe the level of originality of each design problem.

Table 2.1 The design problem categories

\begin{tabular}{l|c|c|c}
\hline \multirow{2}{*}{ Level of originality } & \multicolumn{2}{|c}{ Low } & High \\
\cline { 2 - 4 } & Routine design & Redesign & Non-routine design \\
\hline (Gero, 1990) & Routine design & $\begin{array}{c}\text { Innovative design, } \\
\text { Creative design }\end{array}$ \\
\hline (Pahl and Beitz, 1996) & $\begin{array}{c}\text { Selection, } \\
\text { Configuration }\end{array}$ & Redesign & Original design \\
\hline$($ Ullman, 2003) & $\begin{array}{c}\text { Routine Desig } \\
\text { (Belkadi, 2006) }\end{array}$ & & $\begin{array}{c}\text { Innovative Design, } \\
\text { Creative Design }\end{array}$ \\
\hline
\end{tabular}

In Table 2.1, it is observed that several authors (e.g. Ullman and Belkadi) distinguish three design types according to the initial state of the design problem. In this case, designers begin with their works with the assumption that the design output is either creative, innovative or routine, and then do their efforts based on this assumption. Gero's classification depends on the state space of potential designs and the value range of design variables. Pahl and Beitz emphasize the novelty of the solution principle and technology to distinguish different types of design problems.

Although these authors use different or similar terms to describe these types, there seems to be a general acceptance of the classification of design problem into routine design, redesign and non-routine design. By synthesizing definitions of these classifications above, three types of design problems can be defined as follows.

(1) Routine design. It represents that the goal and the knowledge of design variables, 
design strcuture are known in advance. There exists a design plan with sub-problem decomposition, alternatives and prototypical solutions. Moreover, the autonomy and the creativity are limited. It emphasize that how to choose the best solution from these existing solutions in order to satisfy the new problem in the same context.

(2) Redesign. It consists of two subtypes: variant design and adaptive design. The two types involve the modification of an existing design to satisfy new requirements or improve its performance.

(3) Non-routine design can be termed as original design, and includes innovative design and creative design.

- Innovative design. It still refers to the known product. In this case, the goal and the relative knowledge of the product are known. However, because of new design variables or features, the design plan and the concrete design activities are not determined in advance.

- Creative design. It creates new variables and features by inventing completely new solution principles. There is no similarity to those of the existing design problem and design plan a priori for the problem under consideration. Therefore, knowledge and the design plan are not known. Designers have a larger autonomy to perform their activities and utilize creativity. Modeling, simulation, prototype and experiment are utilized for developing new knowledge.

In reality, it is often not possible to define precisely the boundaries between the three types of design. For example, a complexity product is composed by different sub-systems. One of sub-systems maybe corresponds to innovative design, while another is routine design. Therefore, this should be considered to be only a broad classification.

\subsection{Designer}

We know that designers perceive and interpret design problem differently, depending on individual and group prerequisites and characteristics of the current situation (Dorst and Cross, 2001). Therefore, how do designers think when trying to solve a design problem? This question of design thinking is of great importance for both research and practice in design and related fields.

In the literature, there are several perspectives of research that have focused on different aspects of design thinking. Three perspectives are identified: the normative perspective, the empirical perspective and the design-as-an-art-perspective (Stempfle and Badke-Schaub, 2002). In order to understand better behaviors and decisions of designers, it 
is firstly necessary to distinguish main points and disadvantages of these perspectives, and then discuss the way to solve design problems.

The normative perspective is dominated by systematic design methodologists, such as Pahl and Beitz (1996), Cross (2001). These researchers have proposed a systematic method to support design activity in engineering and product design in order to obtain the optimum result. These works are based on the rational analysis of design tasks and their requirements. This leads to an assumption that design theories and methods are independent of the detailed properties of designers are meant to support. Within this perspective, the designer is an objective reality.

However, the empirical perspective argues that designers rarely follow the methodology described by design methodologists. They criticize that the design methodologies originate from the empirical studies in design. Moreover, these design methodologies accounts of design neglect many of the specific factors and constraints designers need to cope with their dairy work, such as the economic constraints, time pressure and teamwork (Stempfle and Badke-Schaub, 2002).

The last perspective, the design-as-an-art-perspective, argues that designers not only do not strictly perform design activities according to the design methodology, but also apply different kinds of methods in a flexible manner in a process of appreciation, action and re-appreciation, and constantly reflection on the current design tasks and design situation (Schön, Donald A., 1995; Valkenburg and Dorst, 1998). Within this view, the designer is an active person.

Although the three perspectives have contributed to our understanding of design thinking, every perspective has its specific shortcomings. The normative perspective neglects to focus on what the designers actually do, while the empirical perspective is not always theory-based. Although the design-as-an-art-perspective provides a novel way of considering the designer, the related methods are not still clear.

Hence, the successive question to be explored is how designers to solve ill-defined design problems. In an experimental research study, Lawson (1994) compares the way in which designers and scientist solved the same problem. He found that designers solve the problem by synthesis (i.e. the solution-focused approach), whereas scientists solve the problem by analysis. Some other researchers suggest that designers tend to use conjectures about solution concepts as means of developing their perceptions of the problem (Darke, 1984; Schön, Donald A., 1995). That is so-called "the co-evolution process between design problem and design solution" explained by Dorst and Cross ( 2001).

However, the appropriate use of the "solution-focused" approach to design is 
something that seems to develop with experience (Cross, 2001; Stempfle and Badke-Schaub, 2002). Thus, experienced designers and novice designers adopt different thinking style and strategies to solve design problems. Experienced designers are able to draw on their knowledge of the previous projects, and they can learn the value of rapid problem exploration through the solution conjecture. In comparison, novice designers can often spend much more time to understand the problem before generating solutions. Another difference between experienced designers and novice designers lies in the strategy of problem exploration. Novice designers prefer to the "depth-first" strategy to a problem, whereas experienced designers pursue the "breadth-first" and the top-down strategy (Cross, 2001).

\subsection{Design process}

The understanding of design process is very important both to the management of the design project and to aid the improvement of product. Generally, design process is the specific series of events, actions or methods by which a procedure or set of procedures are followed, in order to achieve an intended (Best, 2006). In this process, it consists of a series of activities and methods which are performed together to meet the requirements or the goals of a problem.

Similar to the definition of design, there also are different views about design process, such as the problem-solving process, the reflective process and the decision process. Based on the paradigm of rational problem-solving, the design process can be considered as a problem-solving process (Simon, 1999). While based on the paradigm of reflective practice, design process is a process of situated reflection (Schön, Donald A., 1995).

However, as Cross said, these simplifying design paradigms in the past have failed to capture the full complexity of design (Cross et al., 1992). The general consensus is that there is no best practice design process. The design process varies from product to product and industry to industry. Even though companies are confronted by similar challenges and constraints, they often deal with them differently (Clarkson and Eckert, 2005). However, there are some commonalities across these processes used, and that these typically consist of four or five distinct stages (Best, 2006; Design Council, 2007). These commonalities are modified and adapted to reflect the problem or user needs (Clarkson and Eckert, 2005). In this section, we thus firstly identify typical design stages that include the core design activities by synthesizing existing process models. Then we discuss the related characteristics of design process. 


\subsubsection{Design stage}

Literature on design process is vast, but mostly inconclusive. The main debate concerns the activity of defining, developing a process for design. Some authors have performed the comparison of design methodologies and design process models, and then identify the set of design stages. Howard et al.(2008) analyze 23 process models of mechanical design, and identify six main design stages: establishing a need, analysis of task, conceptual design, embodiment design, detailed design, and implementation. By summarizing the work of Howard et al. and considering much more recent process models, $\mathrm{Xu}$ (2010) synthesizes 42 models and identifies similar set of common design stages. Clarkon and Eckert have generated a comprehensive review of current design practices and methodologies (Clarkson and Eckert, 2005). Other authors, Kim and Meiren (2010), Ogot (2004) discuss design stages in the field of service engineering and mechanical engineering. The research group of Prof. Blessing (Eisenbart et al., 2011; Gericke and Blessing, 2012) extends the focus of the comparisons of design models from mainly mechanical engineering and architecture to other design disciplines such as service design, software design and mechatronics, and tries to develop a consensus model of discipline-specific models.

The synthesized result is based on the existing comparisons of process models mentioned above (see Table 2.3). The analysis focuses on the coverage of design process. That is to say, what stages should be addressed in design process. The column heading is based on the comparison of Howard et al.(2008) and is extended to the whole product life cycle by adding the usage and disposal stage (more detail, see Table 2.2). Some findings of the analysis of the life-cycle coverage of these process models are listed in the following:

(1) Most process models cover the core stages of design process, i.e. establishing a need, analysis of task, conceptual design, embodiment design, and detailed design (Gericke and Blessing, 2012). However, these stages often overlap. For example, it is not easy to formulate a function without already using a conceptual model.

(2) More recent process models emphasize the stage of establishing a need. Different models use different terms to describe the stage, such as discover (Design Council, 2007), the Fuzzy Front End (FFE) (Koen et al., 2001). They argue that it is critical to define the nature of the problem that is being addressed through design (Rhea, 2003). Moreover, this stage is one of the most critical, and the one which makes best use of the designer's knowledge and skills.

(3) Following the four major stages is the production stage, which is also included by some process models, explaining what happens when the final design documents 
are completed. They emphasize that designers provide support or even take participate in the stage of production and market introduction.

(4) The last two stages "usage" and "disposal" are covered by few process models in our comparison. The result is related to our selected models that are mainly from the discipline of mechanical engineering. Gericke and Blessing found the process models of building design, software design, service design and systems engineering cover the two stages (Gericke and Blessing, 2012). In addition, some process models of eco-design also involve these stages, particularly in the disposal stage (Tischner et al., 2000; O'Brien, 2002).

Table 2.2 Description of design stages

\begin{tabular}{l|l}
\hline \multicolumn{1}{c|}{ Design stage } & \multicolumn{1}{c}{ Description } \\
\hline Establishing needs & $\begin{array}{l}\text { Initiation by the design process by technology improvement, or the } \\
\text { identification of a need or a problem }\end{array}$ \\
\hline Task clarification & $\begin{array}{l}\text { To clarify the given task in more detail; to collect information about the } \\
\text { requirements that have to be fulfilled by the product and the constraints }\end{array}$ \\
\hline Conceptual design & To determine the principle solution that solves the design problem. \\
\hline Embodiment design & $\begin{array}{l}\text { The working principle is elaborated in the form of preliminary layouts, } \\
\text { which are the evaluated to generate a definitive layout. }\end{array}$ \\
\hline Detailed design & \begin{tabular}{l} 
Integration of sub-solutions, refinement and finalization of the solution. \\
\hline Production
\end{tabular} \\
\hline Use & Integration, manufacturing, installation, test, approval, launch of the product \\
\hline Disposal & Operation, monitoring, maintenance of the product \\
\hline
\end{tabular}


Table 2.3 A comparison of design stages of design process models

\begin{tabular}{|c|c|c|c|c|c|c|c|c|}
\hline Model & Establishing a need & Task analysis & Concept design & Embodiment design & Detail design & Production & Usage & Disposal \\
\hline (Booz et al., 1967) & & $\begin{array}{c}\text { New product strategy } \\
\text { development }\end{array}$ & $\begin{array}{c}\text { Idea generation, } \\
\text { Screening \& Evaluation }\end{array}$ & \multicolumn{2}{|c|}{ Business analysis, Development, Testing } & $\begin{array}{c}\text { Commercializatio } \\
\mathrm{n}\end{array}$ & & \\
\hline (Archer, 1968) & & Programing, Data collection & Analysis, Synthesis & Development & Communication & & & \\
\hline (Hubka, 1980) & & Elaboration of assigned problem & Conceptual design & Layout design & Detailed design & & & \\
\hline (Pugh, 1990) & Market & Specification & Conception design & Detail design & Manufacture & Sell & & \\
\hline $\begin{array}{l}\text { (Cooper and Press, } \\
\text { 1995) }\end{array}$ & & $\begin{array}{l}\text { Define, understand and think } \\
\text { about problem }\end{array}$ & \multicolumn{2}{|c|}{ Develop idea } & Detail design and test & & & \\
\hline $\begin{array}{l}\text { (Ulrich and Eppinger, } \\
\text { 1995) }\end{array}$ & & Strategic planning & Concept development & System-level design & $\begin{array}{c}\text { Detail design, testing } \\
\& \text { refinement }\end{array}$ & $\begin{array}{l}\text { Production } \\
\text { ramp-up }\end{array}$ & & \\
\hline (Baxter, 1995) & $\begin{array}{c}\text { Assess innovative } \\
\text { opportunity }\end{array}$ & Possible product & Possible concepts & Possible embodiments & Possible details & New product & & \\
\hline (Pahl and Beitz, 1996) & & Planning and clarifying task & Conceptual design & Embodiment design & Detail design & & & \\
\hline (French, 1998) & Need & Analysis of problem & Conceptual design & Embodiment design & Detailing & & & \\
\hline (Dym and Little, 1999) & & Problem definition & Conceptual design & Preliminary design & Detailed design & Communication & & \\
\hline (Cross, 2001) & $\begin{array}{l}\text { Identifying } \\
\text { opportunities }\end{array}$ & \begin{tabular}{|c|}
$\begin{array}{c}\text { Clarifying objectives, establishing } \\
\text { functions, setting requirement, } \\
\text { determining characteristics }\end{array}$ \\
\end{tabular} & \multicolumn{2}{|c|}{ Generating alterative, evaluation alternative, } & Improving details & & & \\
\hline VDI 2221 & & Planning & Conceptual design & Embodiment design & Detail design & & & \\
\hline (Ullman, 2003) & Project planning & Specification definition & \multicolumn{3}{|c|}{ Conceptual design } & $\begin{array}{c}\text { Product } \\
\text { development }\end{array}$ & $\begin{array}{l}\text { Product } \\
\text { support }\end{array}$ & \\
\hline $\begin{array}{l}\text { Industrial Innovation } \\
\text { Process } 2006 \\
\end{array}$ & Mission statement & Market research & Ideas phase & Concept phase & Feasibility phase & Pre-production & & \\
\hline (Design Council, 2007) & Discover & Define & \multicolumn{3}{|c|}{ Develop } & Deliver & & \\
\hline (ISO/IEC 15288, 2002) & & \multicolumn{2}{|l|}{ Concept } & \multicolumn{2}{|c|}{ Development } & Production & $\begin{array}{c}\text { Utilization } \\
\text { Support }\end{array}$ & Retirement \\
\hline (IEEE 1220, 2005) & & \multicolumn{2}{|c|}{ System definition } & \multicolumn{2}{|c|}{ Preliminary design/Detailed design/FAIT } & $\begin{array}{c}5 \text { Produc } \\
\text { tion }\end{array}$ & Support & \\
\hline (EIA 632, 2001) & $\begin{array}{l}\text { Acquisition and } \\
\text { Supply }\end{array}$ & \multicolumn{4}{|c|}{ System design } & Product realize & & \\
\hline
\end{tabular}




\subsubsection{Characteristics of design process}

Any design process usually exhibits several phenomena, such as non-linear, non-optimal, exploratory, creativity, and learning.

(1) The notion "non-linear" means that design follows cycles of mutual adjustment between designer and customer. (2) For the notion "non-optimal", designers are looking for good, acceptable and satisfactory solution rather than for the only best solution from all the possible ones (Simon, 1995). (3) Practical design problems can rarely be solved effectively without exploration. The initial step of design is a "problem" or "idea" to describe an object which is not completely defined. There are too many discrete alternatives to consider, and the mathematical complexity would be overwhelming even if the problems could be formalized (Ulrich, 2011). Therefore the "exploratory process" is to formulate these incomplete, even ambiguous problems and ideas, that is, the expansion of concept (Hatchuel \& Weil, 2003). (4) "Creativity" is the non-separate and buill-in part of design, which cannot be just "additional" attribute. (5) In addition, the design process involves "learning" about emerging features and knowledge as design proceeds (Gero, 1990).

These phenomena above represent different facets of the overall design process. Most viewpoints are, however, complementary to each other, and influence the process architecture of design. Here, process architecture involves the structure of activities, their relationships, and the principles and guidelines governing their design and evolution (Browning 2009;Browning and Eppinger 2002). In this dissertation, in order to characterize the design process in a uniform, we identify two main characteristics of the process architecture of design: iteration and uncertainty.

\subsubsection{Iteration}

Design iteration is the fundamental characteristic of the design process (Browning and Eppinger, 2002; Unger, 2003; Safoutin, 2003; Wynn et al., 2007). Eppigner et al. (1997) define it as "the repetition of tasks to improve an evolving development process". It is generally accepted that understanding design iteration is therefore fundamental to accelerating and improving product development practices.

Because a design activity likely involves different amounts of work and represents different states, iteration can be recognized as different nature. For example, some focus on specific manifestations of iterative activity such as rework (Cooper, 1993) or redesign (Terwiesch and Loch, 1999) in response to the change of external information (e.g. requirement changes). Some researchers advocate that the iterative exploration is the basic characteristic of creative problem-solving. Different designers provide new perspectives 
and ideas in their feedback, improving the product definition through design cycles. Moreover, iteration can vary in the breadth of iteration, the number of inter-phase loops and the degree of planning (Unger, 2003).

Researchers have proposed various classifications to distinguish different perspectives of iteration, such as planned and unplanned iteration (Unger, 2003); repetition, incremental, progressive and feedback (Safoutin, 2003). Based on the previous efforts, Wynn et al. (2007) propose a comprehensive framework that comprises six non-orthogonal perspectives of iteration in the design process (see Figure 2.3).

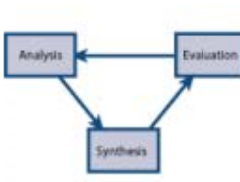

1. Exploration

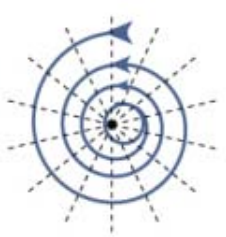

2. Convergence

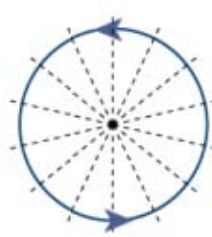

3. Refinement
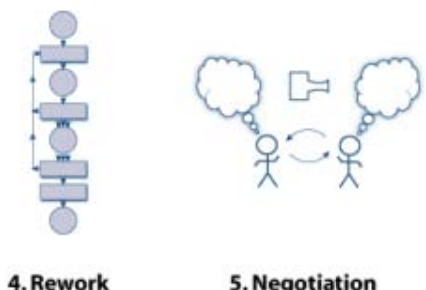

5. Negotiation

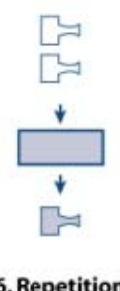

6. Repetition

Figure 2.3 Six perspectives of iteration in the design process (Wynn et al., 2007)

- Exploration. The design process involves a repeated process of solution space divergence followed by convergence to explore the problem and solution spaces.

- Convergence. Some Engineering problems can be considered as the selection of parameters to meet well-defined performance objectives. When the parameters and the objectives do not match well and the solution is not directly identified, it needs iteration to converge upon a "satisficing" design.

- Refinement. When satisfying the main requirements, it maybe undergo further refinement to achieve the secondary characteristics.

- Negotiation. The solving of some design problems needs contributions from personnel who comes from other departments and have different knowledge background. In this case, iteration allows trade-offs between competing goals to be negotiated.

- Repetition. Similar tasks are often performed at different point in the design cycle to apply a similar operation to different information.

- Rework. Design activities may require rework in response to problems that emerge as analysis is conducted, or following external influence.

\subsubsection{Uncertainty}

Uncertainty is an inevitable issue for most projects, but even the experienced managers 
have difficulty to deal with it (De Meyer et al. 2002). Different projects are characterized by different types of uncertainty. Some authors classify uncertainty by its sources (market uncertainty, technology uncertainty), causes (epistemic uncertainty, random uncertainty) and impacts (MacCormack and Verganti 2003; Chapman 1990).

In this dissertation, uncertainty is associated with making design decisions. When one design choice is selected, one of the problems that designers face is to estimate the consequences (Yan and Stephen, 1998). If designers have adequate information about the relationship and nature of activities, the estimation of the consequences has low uncertainty. Conversely, this design choice has high uncertainty. Hence, uncertainty has to do with information. With this, there are four types of uncertainty identified in the design process: variation, foreseen uncertainty, unforeseen uncertainty and chaos (De Meyer et al.,2002).

- Variation is derived from the small influences and yields a range of value on a particular activity. In this case, mangers and designers can identify the relationship and nature of activities, thus build up a well-defined design process.

- Foreseen uncertainty is identifiable and understood influences that design teams cannot be sure will occur. The foreseen uncertainty can be reduced via the development of several alternative plans.

- Unforeseen uncertainty can't be identified at the start of the design process. So it is difficult to develop an alternative plan to handle the unforeseen case.

- In the situation of chaos, there is no causal relationship between the project's original objects and the final result. The latter two are dealt with the learning and adjustment.

Although each uncertainty type is distinct, a single design process typically encounters some combination of all four. So how to deal with the combination of these uncertainties is a great challenge for managers and designers.

\subsection{Conclusion}

The aim of this chapter is to comprehensively understand and analyze design. In order to achieve this purpose, we firstly introduce the unifying design framework and fundamental dimensions (i.e. design problem, designer and design process) by reviewing definitions of design. Then, we respectively discuss design problem, designer and design process in detail. In summary:

Design problem is widely considered as the ill-define problem. We mainly discuss characteristics of the ill-define problems in term of the ambiguity and the complexity of 
problem structure and the situated problem, and then synthesize the category of design problems. As for the second dimension "designer", we review three perspectives of design thinking (i.e. the normative perspective, the empirical perspective and the design-as-an-art-perspective design thinking), and identify their advantages and disadvantages. It is argued that the perception and the interpretation of designers for design problems and design solutions depend on individual and group prerequisites and the characteristics of the current situation. With regard to the third dimension "design process", typical design stages are identified by reviewing design process models, and we find that more and more process models emphasize the front end of the design process. Finally, in order to characterize design process in a uniform, we analyze the characteristics of the process architecture of design: iteration and uncertainty.

Through the review of fundamental dimensions of design, we can see that design is the complex human activities, and involves a collection of many different logically connected knowledge and disciplines. We did not reach a state in which there is a coherent tradition of scientific research and practices that is matured enough to embody the theory and the application. But this review provides us with the basement to understand innovative design. For example, what is innovative design? Are there differences between design and innovative design within the three fundamental dimensions? Does innovative design have same characteristics?

After building the comprehensive understanding of design, the next step is to review design models and methods that attempt to describe and explain some aspect of design practices. Thus, the next chapter focuses on the modeling of design. 


\section{MODELING OF DESIGN}

\subsection{Overview}

Many researchers have proposed models and methods to describe and explain some aspects of design practices. Although these researchers have produced rich knowledge about specific aspects of design since the 1950s, no single model can be generally accepted to describe and explain design. The majority of these process models have a relatively narrow focus, ranging from the design paradigm to the activity-based level in terms of the level of abstraction, or from the generation of design concepts to the management of the design project in terms of focus.

The aim of this chapter is to review existing design models from different views. A classification framework of design modeling is introduced in Section 3.2. The rational problem-solving paradigm and the reflective practices paradigm are analyzed in Section 3.3. Then, the procedural models and the activity-based models are discussed in Sections 3.4 and 3.5. Section 3.6 concludes this chapter.

\subsection{Classification framework}

As discussed in the previous chapter, design is an ill-defined problem. It is difficult to describe well every aspect of design. Thus it is a great challenge to describe the relationships between different design models. Some authors have proposed many classification frameworks to frame the discussion of the literature in terms of discipline, the historical development of form.

In the field of design, the classification framework focuses on descriptive methodological and philosophical frameworks of the engineering design process. Finger and Dixon (1989a; 1989b) categorize these models into three classes from an engineering design standpoint: descriptive model, prescriptive model and computer-based model. Later, Evbuomwan et al. (1996) also adopt the same framework to synthesize design models. Smith and Morrow (1999) concentrate on engineering models of product development process and emphasize on quantitative, graphical and formal models, categorizing the papers by modeling framework and objectives such as sequencing and scheduling models, decomposition models, stochastic lead time models, design reviews timing models, and parallelism models. Krishnan and Ulrich (2001) organize their papers around the decision of product development. As the complement of previous works, Browning and Ramasesh 
(2007) use the purpose-based framework to review the activity network-based process models.

In general views, Blessing (1996) distinguishes stage-based models, activity-based model and combined models. She further divides the models into the solution-oriented and the problem-oriented. Following the work of Blessing, Wynn and Clarkson (2005) perform a comprehensive literature review by characterizing process models as abstract, procedural or analytical models, and further as design-focused or project-focused.

Based on the framework of Blessing and Wynn and Clarkson, our classification framework of design modeling is proposed (see Figure 3.1). These models are classified into three main types based on the degree of abstraction: design paradigm, procedural model and activity-based model. Furth more, each type is decomposed into a series of sub-types. More details are discussed as follows.

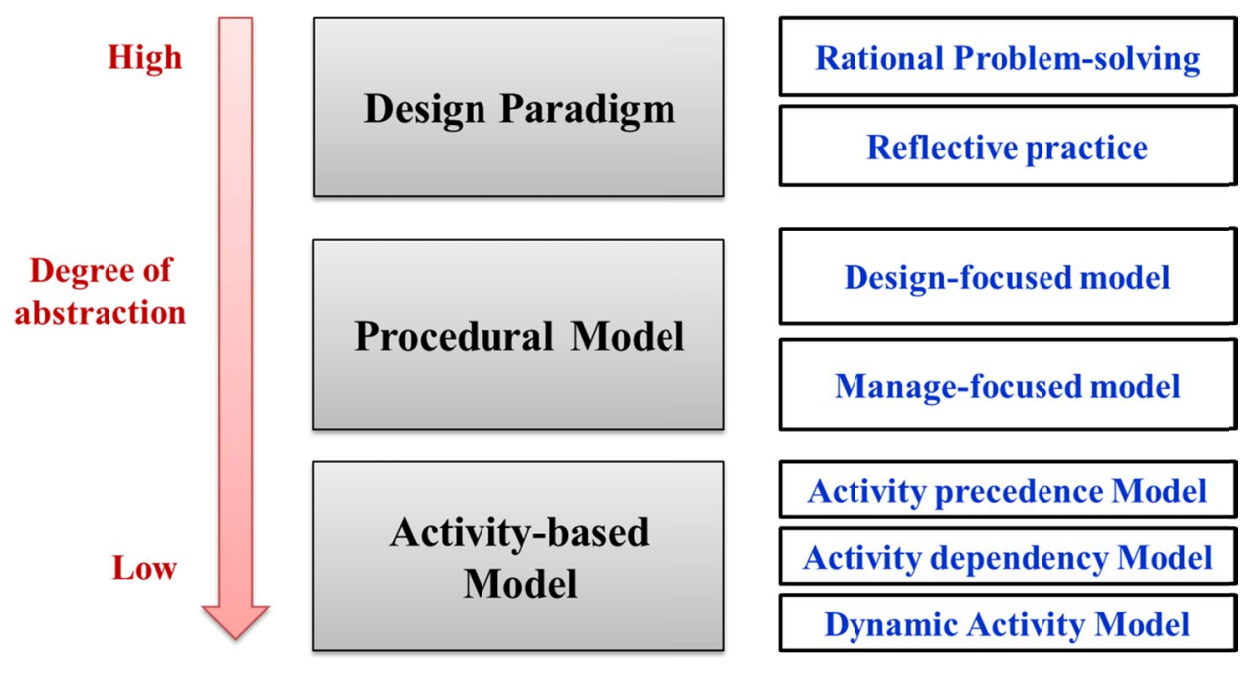

Figure 3.1 The classification framework of design modeling

Design paradigm. Each researcher proposes the design model in own special way, which based on unique assumptions and goals. These assumptions and goals are formed by design paradigms that define the domain and the subject of research. Meanwhile, design paradigm implies the methodologist's perception of the scope, characteristics and ways of working of design methodology itself (Dorst, 1997, p. 11). Therefore, in order to understand well the nature of the existing design models, we should firstly analyze design paradigm. In this dissertation, we mainly discuss two design paradigms: the rational problem-solving paradigm and the reflective practice paradigm.

Procedural model. Procedural models are more concrete in nature than design paradigm. Unlike the stage-based model that divides the process into a series of temporal stages, the procedural model emphasizes a specific aspect of design. Thus, the term 
"procedural model" has a much wider scope than the term "stage-based model". The latter one is one part of the former. According to different focuses, we divide procedural models into the design-focused model and the manage-focused model.

Activity-based model. A design activity is a subdivision of the design process related to the individual's problem solving process. It is a much finer division than a stage. Thus, activity-based models aim to provide the low-level support, involving the modeling and the analysis of a specific situation which can be operationalized. According to the representation of activity connectivity, we further discuss the task precedence model, the activity dependence model and the dynamic activity model.

\subsection{Design paradigm}

There are two paradigms for design methodology that represents two fundamental views of looking at design, the rational problem-solving paradigm and the reflective practice paradigm (Dorst and Dijkhuis, 1995). The rational problem-solving paradigm introduced by Simon has considerable influence on design theories and methodologies ever since. Most works in design theory and methodology still follow the assumption. In the 1980s, researchers adopted a "situated cognition" perspective to propose an absolutely different alternative. As a representative exponent of the views, Schön describes design as the reflection-in-action, adopting the constructionist theory (Schön, Donald A., 1995) .

\subsubsection{The rational problem-solving paradigm}

The introduction of the rational problem-solving paradigm to design, at the start of 1970s by Simon, helps systemize design models and problems, and builds the connection with other problem-solving domains. Meanwhile, this paradigm provides the fundament in design cognitive and design ergonomics (Simon, 1969). Although there are some works are criticized by some researchers, the conceptual frameworks of the rational problem-solving still loom over the design field.

The rational problem solving paradigm addresses more knowledge about all three dimensions of design (design problem, designer and design process). It is the combination of practice-based stage models of the design process, a model of the designer as an information processor from the field of cognitive psychology, and some thinking on the ill-structured of the design problem (Dorst, 1997). More importantly, it considers the way the three dimensions merge in the design theory (the problem-solving theory). Therefore, Simon's design theory can be characterized by describing how to view the design process, designers and design problem (see Figure 3.2). We will respectively discuss the three dimensions in the following sections. 


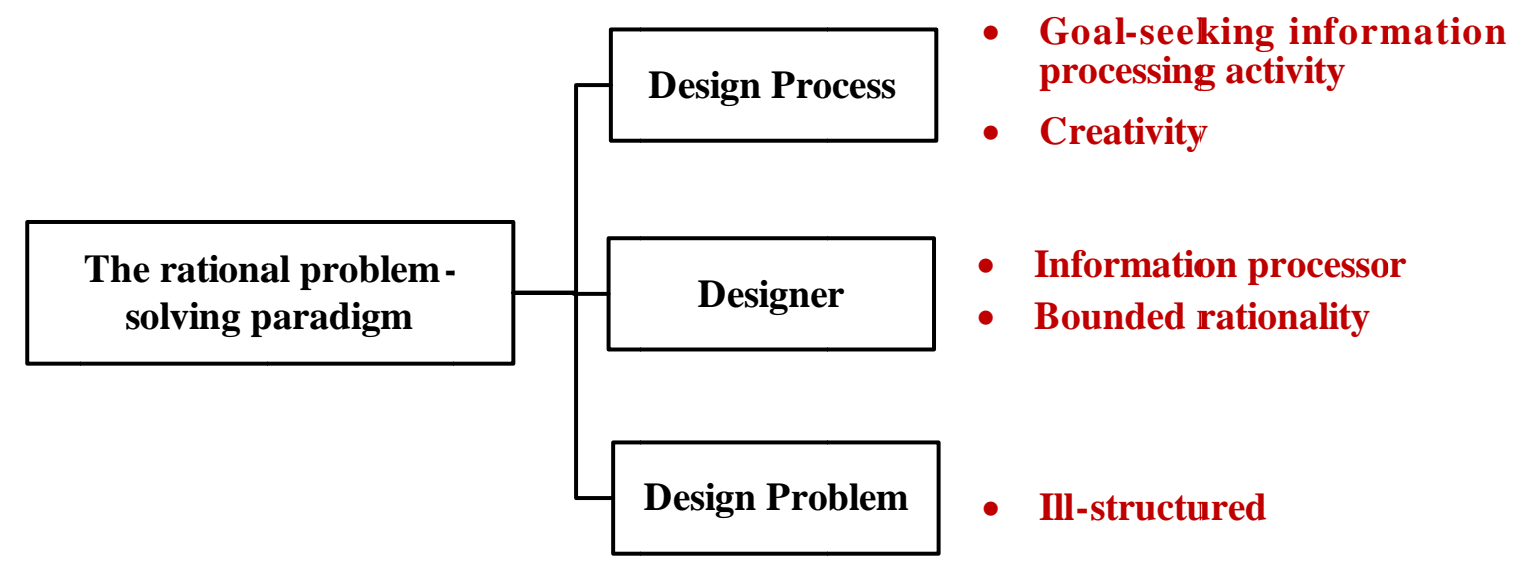

Figure 3.2 The views of rational problem-solving paradigm on three dimensions of design

\subsubsection{Design process: goal-seeking information processing activity}

Simon and his collaborators analyze the problem solving as the information process and the design as the problem-solving process, and thus design as an information processing activity. The entire theoretical application process can be referred to the two theoretical steps: (1) the problem-solving process is considered as a goal-seeking information processing activity (Newell and Simon, 1972); (2) this approach is applied to design (Simon, 1969).

Thus, the design problem can be understood as a search problem in the design space that contains many possible arrangements of problem materials, only one or a few of which satisfy problem criterion (Greeno and Simon, 1998). Thus the design process can be viewed as a search process, in which search steps are taken towards a goal state. In this process, "to search the set of possibilities" and "to narrow the set of possibilities" is adopted to solve problems. Meanwhile, the constraints on the goal are used to guide the cutting of possibilities.

Additionally, in Simon's terms, creativity and discovery in the design process are describable within the bounded rationality perspective. But he does not deny that creativity may play a role in the design process. The two terms "intuition" and "imagination" are used to explain creativity in design. "Intuition is a genuine enough phenomenon which can be explained rather simply: most intuitive leaps are acts of recognition" (Simon, 1999). Therefore, the process is not only search, but also relies on individual recognition. "Imagination" provides "a plan to the problem-solver, at least in the sense of a list of the elements he is dealing with, and a list of which of these are related."(Simon et al., 1979). The imagination is the only entry to list a plan, yet it doesn't change the nature of problem-solving. 


\subsubsection{Design problem: ill-structured problem}

In the classic paper "The structure of ill-structured problem" (Simon,1973) nicely explain the characteristics of design problem, and gives some important conclusions as follows:

(1) In his paper, he tries to set out to find the relation between "ill-structured problem" and "well-structured problem". If the problem-solving effort involves learning, or the redefinition of the problem, the problem cannot be considered well-structured (Dorst, 2006). In Simon's views, there is no real boundary between well-structured problem and ill-structured problems. For example, "even if we regard chess playing as a well-structured problem in the small, by most criteria it must be regarded as an ill-structured problem in the large" (Simon, 1973).

(2) An ill-structured global problem is the set of well-structured problems, and the construction of well-structured problem from the ill-structured problem is the way to solve the ill-structured problem.

(3) "The general problem-solving mechanisms that have shown themselves to be efficacious for handing large, albeit apparently well-structured domains should be extendable to ill-structured domains without any need for introducing qualitatively new components." Therefore, the ill-structured design problem means that it is impossible to enumerate all possible solutions.

\subsubsection{Designer: information processor and bounded rationality}

Because the design process is seen as the goal-seeking information processing activity operating in an objective reality, Simon does not take the human perception into account. This leads to an assumption that design theories and methods are independent on detailed properties of designers. Thus, within this paradigm, a designer is an information processor as an objective reality.

Another important point for designers in this paradigm is the "bounded rationality". The "bounded rationality" as a part of Simon's bigger project tries to explain human behavior through "simple and constrained, yet informed and decision rules". The "bounded rationality" is the notion that the rationality of individuals is limited by the information they have, the cognitive limitations of their minds, and the finite amount of time they have to make decisions. The notion is refutations of all the classic hypothesis of optimal choice, and complements the rationality as optimization. For Simon, discovery and creative in science, art and design can be described with the bounded rationality. When applying it into the design process, "Seldom will it be feasible to examine all possible designs to decide which one is, in some sense, optimal" (Simon, 1999, p. 119), because the problem-solving 
is limited by the information processing capacity of the acting subject.

\subsubsection{The reflective practice paradigm}

The rational problem-solving paradigm may have been the dominant methodological paradigm in the field of design in the 1970s and early 1980. But there exist some different views. They argue that some important aspects of design practices are not captured only by the rational problem-solving paradigms, considering design as a subjective and human activity.

The reflective practices paradigm proposed by Schön (1983) as a representative exponent of different views provides a novel way of considering the design. Since this paradigm's vagueness and inconsistency for design practices, it has not been widely used. But it provides an alternative approach to design at a very fundamental level (Dorst, 1997), and points out these shortages of the rational problem solving paradigm. In this section, we analyze the reflective practice paradigms in three dimensions of design, as shown in Figure 3.3. More details will be discussed in the following sections.

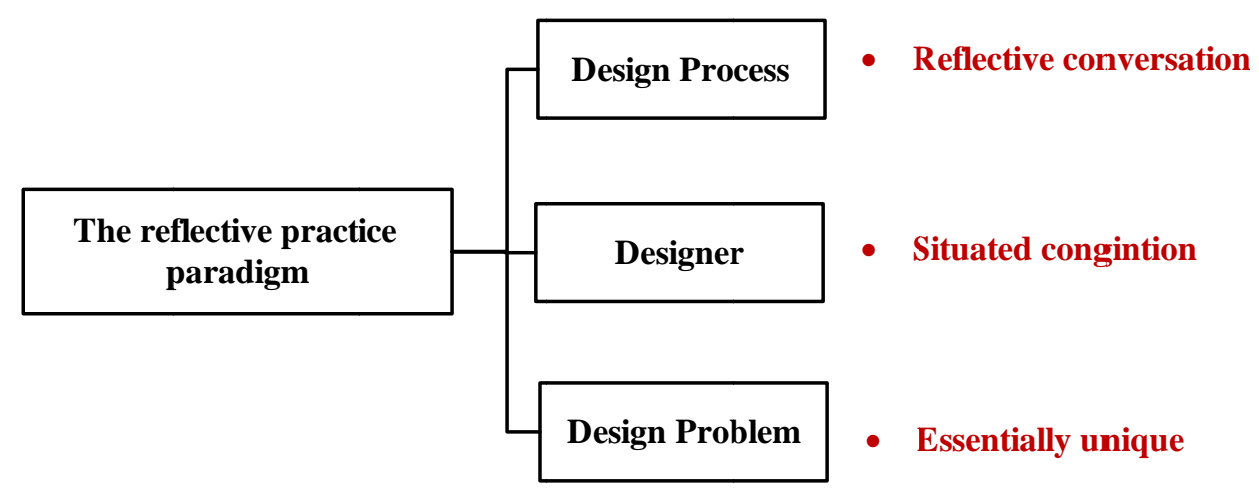

Figure 3.3 The views of reflective practice paradigm on three dimensions of design

\subsubsection{Design process: reflective conversation}

Schön (1992) considers the design process as "a reflective conversation with the materials of a design situation". In this paradigm, it does not give a complete design process, but presents a design mechanism, within which design activities are described in much more detail.

Within this reflective conversation, designers work by choosing and naming the related factors, framing a problem in a certain way, then taking an experimental move based on naming and framing of the design task, as well as evaluating those moves in terms of the coherence and the accordance of these moves and the problem-solving value (Schön, 1992; Schön, Donald A., 1995).Thus, the reflective conversation is a process of naming, framing, making moves and evaluating them (Dorst, 1997). See also Figure 3.4. 


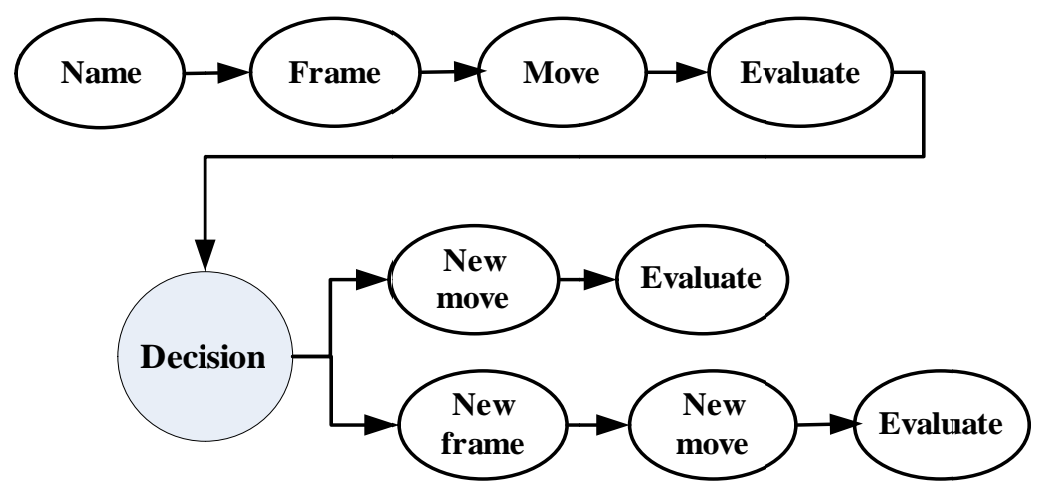

Figure 3.4 The design cycle of the reflective practice paradigm (Dorst, 1997)

\subsubsection{Designer: situated cognition}

The reflective paradigm is based on the constructionist view of human perception and thought process, in which the human's perceptions on world outside have very important influences on the world under construction. Thus, within this view, the designer is an active person. Through the execution of "experiments" and reflection in the current situation/context, designers actively construct a view of the design problem and the design situation based on their experience. However, within the rational problem-solving paradigm, designers are considered as an information processor, and simply perform the recommended actions.

\subsubsection{Design problem: unique problem}

Schön argues that the design problem is essentially unique. Different from the rational problem-solving paradigm that emphasizes that the "problem-solving" is generally considered as handling problems which are "given', the reflective paradigm pays more attention to the "problem setting". In practice, problems do not present themselves to designers as given. The formulation of the design problem is determined by the knowledge of designers in the current situation. And there is no prior to determine that which design solution or analysis approach is the best.

\subsubsection{Discussion}

According to the analysis above, the rational problem-solving paradigm and the reflective practice paradigm differ fundamentally in the way they treat the three fundamental dimensions (designer, design problem and design process) of design. In Dorst's Ph.D thesis, he undertakes a comparison of the two paradigms: The rational problem-solving paradigm not only takes "designer" as a parameter, but also "design problem" that described as an ill-structured problem. More attentions are paid on "design process". The design process is modeled in great detail, and related methods are proposed 
(e.g. optimization method). However, the reflective practice paradigm does not consider three dimensions as an independent parameter, rather as a uniform to describe the design process.

These differences between the two paradigms indicate that it is difficult to merge the two paradigms into one. But it does not mean the two ones conflict each other. In fact, two paradigms focus on different aspect of design, and are complementary (Dorst, 1997; Visser, 2002). They are appropriate to describe the activities in different design stages. Dorst concludes that the selection of the design paradigm depends on three factors: the research goals, the objects of study, and, most importantly, the kind of design activity (Dorst, 1997, pp. 166-167). Seen from this conclusion, the premise of modeling design process should be a comprehensive analysis of the design process, and then we select the appropriate paradigm to develop the process model according to the results of analysis of the three factors.

\subsection{Procedural model}

\subsubsection{Design-focused model}

Design-focused model supports the design of better products by the application of models and methods in the design process. The history of design is one of constant evolution. The exploration of design models and methods began to be taken seriously in the work of Bauhaus in the early $20^{\text {th }}$ century. The new design approach proposed by Bauhaus radically changes the attitude to design, specifically industrial design. After that, many academics and practitioners propose different models to describe behaviors and characteristics of design, or prescribe process models or methods to guide design activities. The next section will review some well-known models of design from a historical perspective.

\subsubsection{Traditional stage-based model}

Many researchers and practitioners have in the past tried to find common stages for the design process. These design process Models are often drawn in this flow-diagram form, with the development of the design proceeding from one stage to next, but with feedback loops (Cross, 2001). Here, the stages of a design process are related to an abstract problem solving process (Albers and Braun, 2012). These methods accompanying each model are intended for use by engineers and designers to support the execution of individual design steps.

Archer (1968) plays a key role in the design method moves and proposes a model of 
the design process (see Figure 3.5). Within the design process, Archer identifies six types of stage that feature many feedback loops: programming, data collection, analysis, synthesis, development and communication. This design process includes the interaction of the world outside of the design process, such as the needs of clients, the training and experience of designers. The output is the communication of the solution. Moreover, Archer defines design as employing a combination of the intuitive and the cognitive, and therefore attempts to formalize a creative process. As shown in Figure 3.5, this process is divided into three broad processes: analytical, creative and executive.

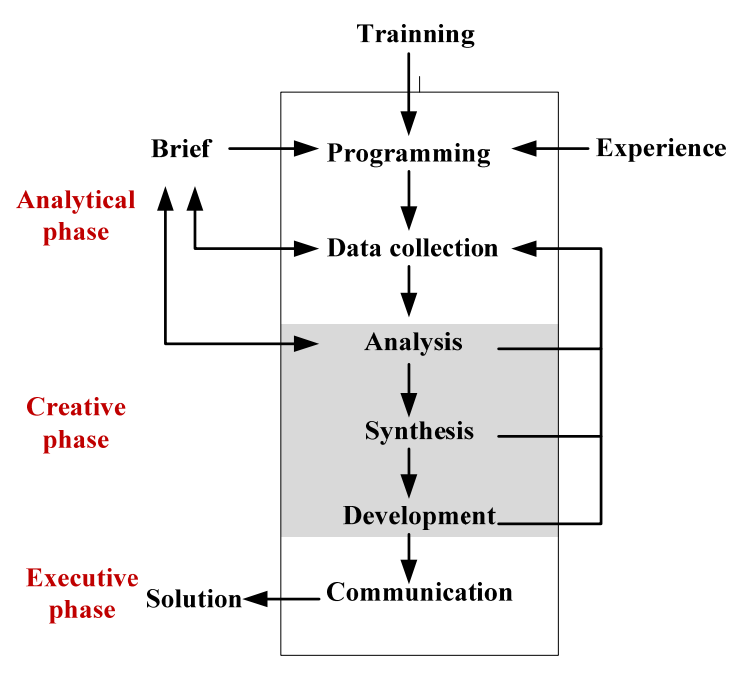

Figure 3.5 Archer's model of the design process

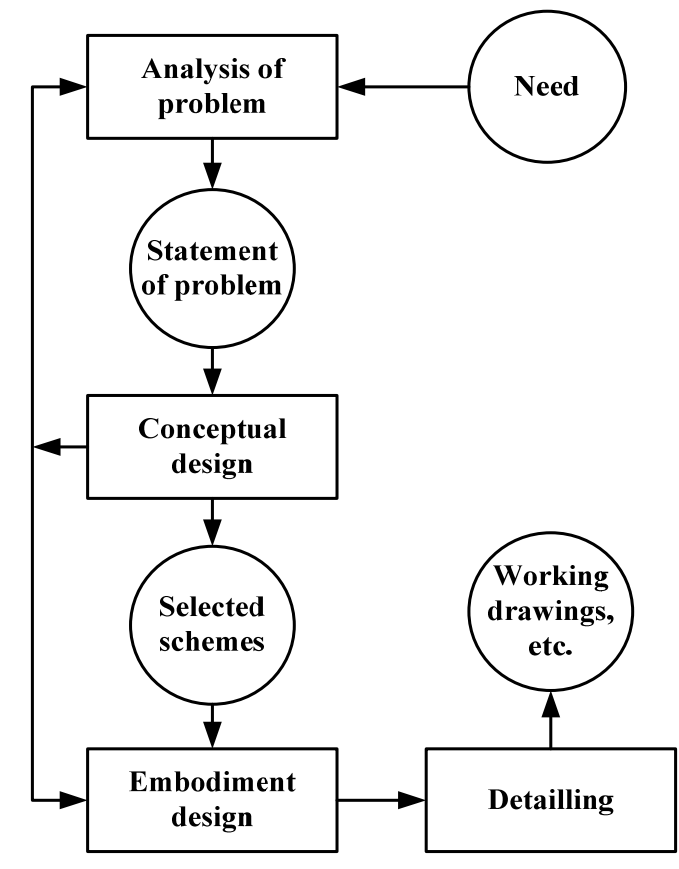

Figure 3.6 French's model of the design process

Another typical example of the more common stage-based models is proposed by French (1998). This model, shown in Figure 3.6, is based on design practices in industry, which consists of four stages: analysis of problem, conceptual design, embodiment design and detailing. These stages and activities involved are typical of the traditional engineering design process.

Some much more complex models have been proposed. Perhaps the most well-known of stage-based models was proposed by Pahl and Beitz (1996) for engineering design. This model emphasizes the fine detail of the numerous tasks and activities which they consider to be most useful strategic guidelines for design. Although adopting different terms, other examples of traditional stage-based models in the literature have converged upon the similar form with the above models. Other examples can be found in the work of Baxter (1995), Ullman (2003) and Dym and Little (1999). 
Over the last decades, companies have actively sought to adopt a methodology that acknowledges other competing factors within business. In practice, even the simplest design process is highly complex socio-technical process (Wynn and Clarkson, 2005). It requires that the design model should take wider design and business activities into account, such as the market and the human resource management.

Based on these considerations above, Pugh (1990) focuses on a concept called total design in which it incorporates everything from the early identification of the market and user needs to the selling of a product that meets that need, and proposes a 'design core' model which consists of activities that are imperative for any design activity. Similarly, this point is highlighted by Ulrich and Eppinge (1995), who describe a complex product design (passenger aircraft) that organized by tens of thousands of persons, and develop related structured process model.

\subsubsection{Design model of today}

It would appear, due to the frequent reference and use, that the traditional representations are effective for education and management. The kind of representation follows a general systematic procedure of firstly analyzing and understanding the design problem as much as possible, then dividing the problem into a series of sub-problems, and find the appropriate solutions for these sub-problems, finally combining all sub-solutions into a whole solution. However, the procedure is criticized because it is based on the problem-oriented rather solution-oriented (Cross, 2001). In practice, designers prefer to consider design problems and solutions simultaneously. Moreover, the level of complexity that occurs within the design process is accentuated by factors such technology, sustainability, social responsibility (Design Council, 2007). It means that there may never be an ideal methodology process, and requires the design process to meet the changing environment.

An example of these is Cross's models as shown in Figure 3.7 (Cross, 2001). This model attempts to capture the nature of the design process, in which problems and solutions are developed together, or co-evolve (Dorst and Cross, 2001). Although it exists a logical relationship from the problem to the solution, this model represents the symmetrical, communication between problem and solution, sub-problem and sub-sollution.

Another well-known model is the Function-Behavior-Structure (FBS) model of designing proposed by Gero (1990). The FBS model is considered as a theoretical base for understanding design, and as a conceptual basis for computerized tools intended for support designer. According the FBS model, design consists of eight elementary steps, which are defined in terms of the key concepts of function, behavior and structure (see Figure 3.8). 
Five of them transform the desired functions of the artifact into design descriptions in sequence. The first step is called formulation step and transforms the functions into its expected behaviors that is expected to perform these functions. Then the expected behaviors are transformed into the structures of the artifact (intended to enable the artifact to exhibit the expected behaviors) by the synthesis step. Thirdly, the actual behaviors of the structure are derived from the structures in the analysis step. After further steps of evaluating the structure for its actual behavior against the expected behavior, if the evaluation is satisfactory, the structure is finally transformed into a design description from which an artifact may be produced. If the evaluation is not satisfactory, the design process returns to the earlier steps in the sequence of five, and this defines three elementary loop-back steps. Five of them transform the desired functions of the artifact into the design descriptions in sequence. And the designer carries out these steps on the basis of knowledge stored in and retrieved by design prototypes.

In the latter paper, Gero and Kannengiesser (2004) extend the FBS model and reconstruct the eight elementary processes by introducing the concept 'situatedness', in which a recursive interrelationship between different environments and a model of constructive memory provides the foundation of reconstruction. Although the FBS model has developed gradually, there are some critiques for the definitions of the key concepts. Vermaas and Dorst $(2005$; 2007) identify two problems with the FBS model: the absence of a stable definition of function, and the model's double aim of describing actual design and prescribing improved design.

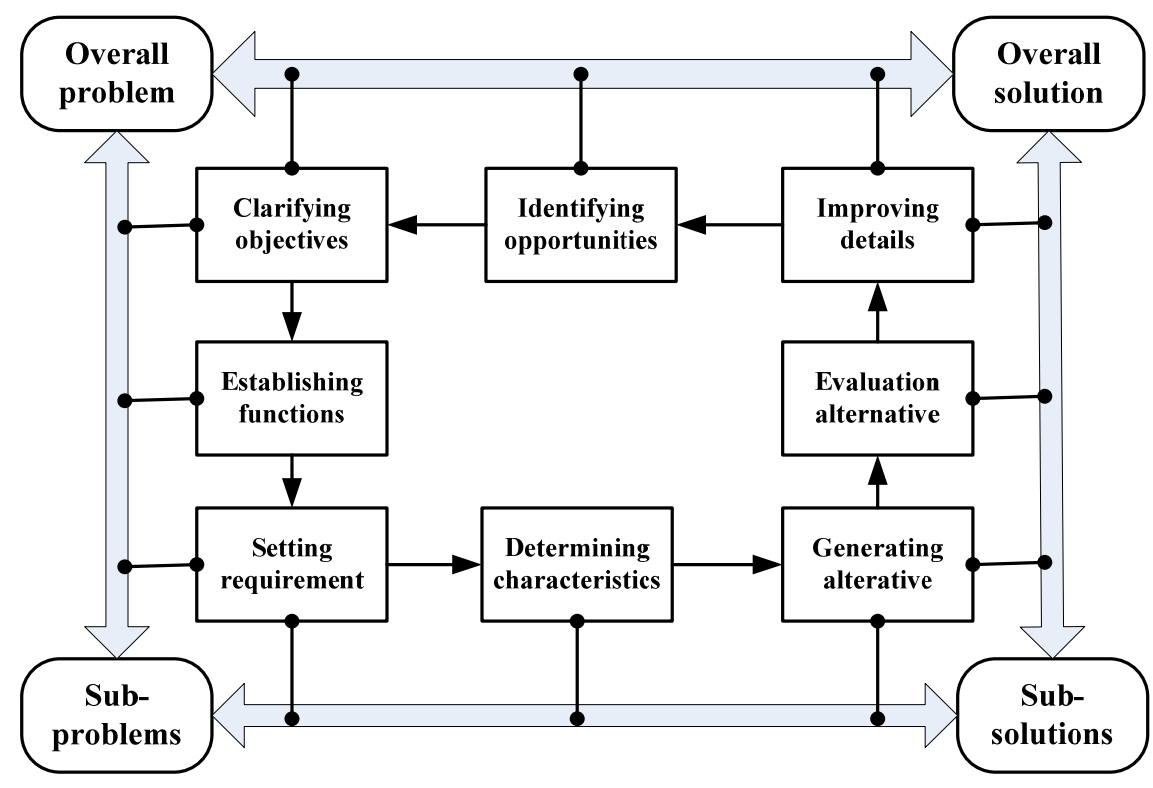

Figure 3.7 Cross's integrative model of the design process 


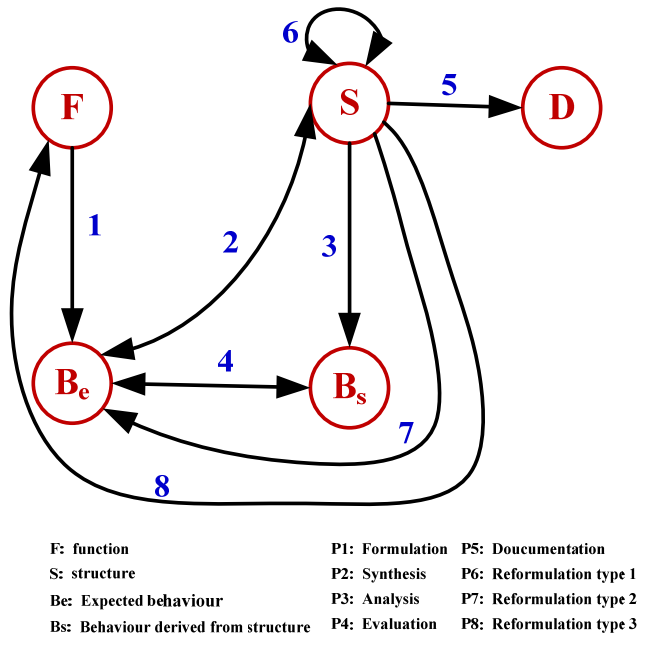

Figure 3.8 The FBS model

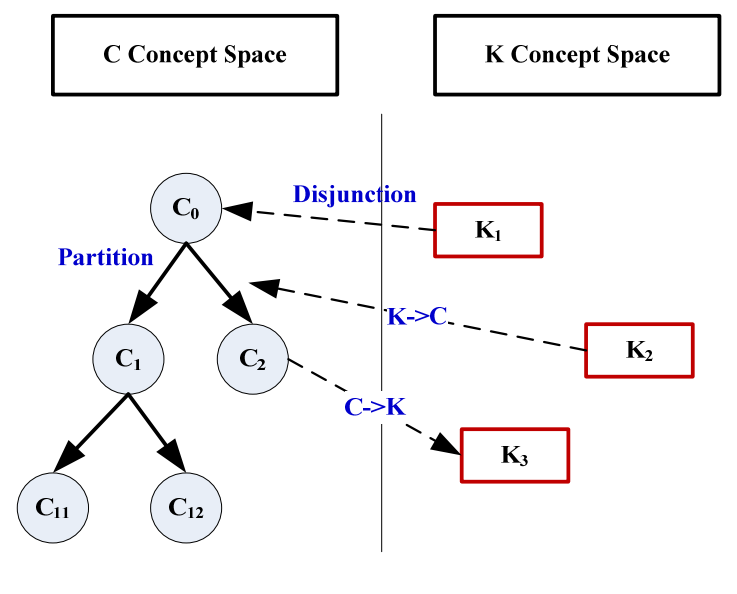

Figure 3.9 Asymmetric structure of spaces C and $\mathrm{K}$

The C-K theory (C: concept; K: knowledge) is proposed by Hatchuel and Weil (2003) to provide a rigorous, unified formal framework for design. Within this model (see Figure 3.9), design can be modeled as the interplay between two interdependent spaces with different structure and logics: the space of concepts $(\mathrm{C})$ and the space of knowledge $(\mathrm{K})$ (Hatchuel and Weil, 2009). Space K contains all established true propositions. Space C contains "concepts" which are undecidable proposition in K about partially unknown object $\mathrm{x}$. Design proceeds step by step to partition of C-sets until a partitioned "C-set" becomes a "K-set". The double expansion of the $\mathrm{C}$ and $\mathrm{K}$ spaces is realized by four types of operators: $\mathrm{C} \rightarrow \mathrm{C}, \mathrm{C} \rightarrow \mathrm{K}, \mathrm{K} \rightarrow \mathrm{C}, \mathrm{K} \rightarrow \mathrm{K}$.

The C-K theory allows the operationalization of the concept of "expandable rationality", which is claimed to be better adapted to the bounded rationality (Hatchuel, 2001). Moreover, it claims that the $\mathrm{C}-\mathrm{K}$ theory is a generalization of all usual design theories, especially of those whose underlying paradigm is the rational problem-solving paradigm. Recently, the $\mathrm{C}-\mathrm{K}$ theory has been discussed and extended by some researchers. Kazakçı and Tsoukias (2005) introduce the environment (E) into the C-K theory to build personal design assistant-creative and adaptive design tools. Ben Mahmoud-Jouini et al. (2006) use the C-K theory with classic creativity techniques to build an innovation strategy in a car supplier company. In our opinion, despite many practical applications, this theory needs to further discuss how to operationalize. 


\subsubsection{Manage-focused model}

Manage-focused models advocate approaches to support or improve the design project management as opposed to the design-focused model. These models concern the development of a new business activity around product design, and attempt to understand the interaction between new product and new business (Roozenburg and Eekels, 1995).

In the field of systems engineering, various standard organizations, government agencies and engineering communities have proposed their particular models to construct the system life cycle. The system life cycle models have evolved significantly over the past two decades. When constructing the system life cycle model, there are many organizational factors that can impact which life cycle processes are appropriate for a specific system. In addition, technical factors will also influence the types of life cycle models appropriate for a given system. Thus it is not a single life cycle model that can provide specific guidance for all project situations.

Forsberg et al. (2005) compare different life cycle models from the standard organization to commercial and government organization, as shown in Figure 2. Although these models are different in details, all life cycle models consist of a series of stages regulated by a set of decision gates which confirm that the system is mature enough to leave one stage and enter another. In addition, these models emphasize three phrases: (1) the conceptual phrase, which is to evaluate new business opportunities and to develop initial system requirements and a feasible design solution; (2) the development phrase, which is to design a system-of-interest so as to be implemented, integrated, verified and validated; and (3) the post-develoment phrase, which includes the production, deployment, operation, and support of the system (Deniaud et al., 2011).

With regard to the form of models, various life cycle models, such as the waterfall, spiral, and Vee development models, are useful in defining the start, stop, and activities appropriate to life cycle stages. Here, in order to facilitate the discussion, we adopt the process structuration in terms of organizational dimension to classify these manage-focused models. As far as the organizational dimension concerned, the process structuration consists of (1) the degree of formal segmentation of the temporal progression in stages; and (2) the degree of rigidity of the operation sequence of design activities.

Therefore, based on the definition of process structuration, there are linear, recursive and chaotic system view for the process structure (McCarthy et al., 2006). These system views provide different insights and descriptive theories about the process structure and behavior of design projects. We will respectively review the three system views in the following sections. 


General Life cycle (ISO 15288:2008 )
\begin{tabular}{|l|c|c|c|c|c|}
\hline $\begin{array}{c}\text { Exploratory } \\
\text { Stage }\end{array}$ & Concept Stage & Development Stage & $\begin{array}{c}\text { Production } \\
\text { Stage }\end{array}$ & Utilization Stage & Retirement \\
& & Stagpert Stage & \multicolumn{1}{c|}{} \\
\hline
\end{tabular}

Typical High-Tech Commercial Systems Integrator

\begin{tabular}{|c|c|c|c|c|c|c|c|c|}
\hline \multicolumn{4}{|c|}{ Study Period } & \multicolumn{3}{|c|}{ Implementation Period } & \multicolumn{3}{|c|}{ Operation Period } \\
\hline $\begin{array}{c}\text { Requirement } \\
\text { Defincept } \\
\text { Definition } \\
\text { Phase }\end{array}$ & $\begin{array}{c}\text { System } \\
\text { Specification } \\
\text { Phase }\end{array}$ & $\begin{array}{c}\text { Acq } \\
\text { Prep } \\
\text { Phase }\end{array}$ & $\begin{array}{c}\text { ource } \\
\text { select } \\
\text { Phase }\end{array}$ & Development Phase & $\begin{array}{c}\text { Verification } \\
\text { Phase }\end{array}$ & $\begin{array}{c}\text { Deployment } \\
\text { Phase }\end{array}$ & $\begin{array}{c}\text { Operation and } \\
\text { maintemance } \\
\text { Phase }\end{array}$ & $\begin{array}{c}\text { Deactivation } \\
\text { Phase }\end{array}$ \\
\hline
\end{tabular}

Typical High-Tech Commercial Manufacturer

\begin{tabular}{|c|c|c|c|c|c|c|c|}
\hline \multicolumn{3}{|c|}{ Study Period } & \multicolumn{3}{c|}{ Implementation Period } & \multicolumn{3}{c|}{ Operation Period } \\
\hline $\begin{array}{c}\text { Produtc } \\
\text { Requirement } \\
\text { Phase }\end{array}$ & $\begin{array}{c}\text { Product } \\
\text { Definition } \\
\text { Phase }\end{array}$ & $\begin{array}{c}\text { Product Development } \\
\text { Phase }\end{array}$ & $\begin{array}{c}\text { Engr } \\
\text { Model } \\
\text { Phase }\end{array}$ & $\begin{array}{c}\text { Interner Test Phase } \\
\text { Phenternal Text } \\
\text { Phase }\end{array}$ & $\begin{array}{c}\text { Full-scale } \\
\text { Production } \\
\text { Phase }\end{array}$ & $\begin{array}{c}\text { Manufacturing } \\
\text { Sales, and } \\
\text { Support Phase }\end{array}$ & $\begin{array}{c}\text { Deactivation } \\
\text { Phase }\end{array}$ \\
\hline
\end{tabular}

US Departement of Defens 5000.2

\begin{tabular}{|c|c|c|c|c|c|}
\hline $\begin{array}{c}\text { User } \\
\text { Needs }\end{array}$ & \multicolumn{2}{|c|}{ Pre-System Acquisition } & \multicolumn{2}{c|}{ Pre-System Acquisition } & Sustainment \\
\hline $\begin{array}{c}\text { Tech } \\
\text { opport }\end{array}$ & $\begin{array}{c}\text { Material Solution } \\
\text { Phase }\end{array}$ & $\begin{array}{c}\text { Technology } \\
\text { Development }\end{array}$ & $\begin{array}{c}\text { Engineering and } \\
\text { Manufacturing Development }\end{array}$ & $\begin{array}{c}\text { Production and } \\
\text { Deployment }\end{array}$ & Operation and support \\
\hline
\end{tabular}

US Departement of Energy

\begin{tabular}{|c|c|c|c|c|c|c|c|}
\hline \multicolumn{3}{|c|}{ Project Planning Period } & \multicolumn{3}{|c|}{ Project Execution } & \multicolumn{2}{|c|}{ Mission } \\
\hline Pre-Project & $\begin{array}{l}\text { Preconceptual } \\
\text { Planning }\end{array}$ & $\begin{array}{l}\text { Conceptual } \\
\text { Design }\end{array}$ & $\begin{array}{c}\text { Preliminary } \\
\text { Design }\end{array}$ & Final Design & Construction & Acceptance & Operation \\
\hline$\nabla$ & $\nabla$ & & $\nabla$ & & $\nabla$ & $\nabla$ & $\nabla^{\text {Турі }}$ \\
\hline $\begin{array}{l}\text { New initiativ } \\
\text { Approval }\end{array}$ & $\begin{array}{c}\text { Concept } \\
\text { Approval }\end{array}$ & & $\begin{array}{r}\text { Developme } \\
\text { Approval }\end{array}$ & & $\begin{array}{l}\text { Production } \\
\text { Approval }\end{array}$ & $\begin{array}{c}\text { Operation } \\
\text { Approval }\end{array}$ & $\begin{array}{l}\text { ctivation } \\
\text { proval }\end{array}$ \\
\hline
\end{tabular}

Figure 3.10 Comparison of system life cycle models (Forsberg et al., 2005)

\subsubsection{Linear model}

Linear models stem from the traditional and logical project management methods that seek to deliver the appropriate product on time and within cost (McCarthy et al., 2006). By focusing on the process structure, the linear models attempt to explain how process behaviors affect the quality, cost, reliability, product variety and managerial complexity.

The waterfall model is a sequential process in which progress is seen as flowing steadily downwards through the stages of the system life cycle.

Probably the best-known linear model is the staged-gate processes are proposed by Cooper (1990). This model was popular for decades because of their controlled design structures. These processes follow a series of steps, and are characterized by rigid reviews, and tend to freeze the design concept early. Figure 3.11 is the general process of the stage-gate model that shows the regimented and stages nature of the product development. This model includes concept development, product design, testing and validation, and product launch and ramp-up. The gates between stages, through which each point must pass to continue, are used for rationalizing decisions and planning. The inputs into the model are new ideas and market idea, and the output is a new product. Once a stage is completed, it is often difficult to go back.

The linear model performs well when the products have stable definitions, have high 
standards and use well-established technologies. However, when the products have high technological uncertainty and market uncertainty, the limitations of the staged process are illustrated in three aspects: Firstly, if early concept definitions or design specifications are poor, the stages process maybe make companies face market risk (Unger and Eppinger 2011); Secondly, it is sometimes difficult to deal with parallel tasks with stages; lastly, this model can be inefficient in that projects must wait at a gate until all necessary activities have been completed (Cooper, 1998).

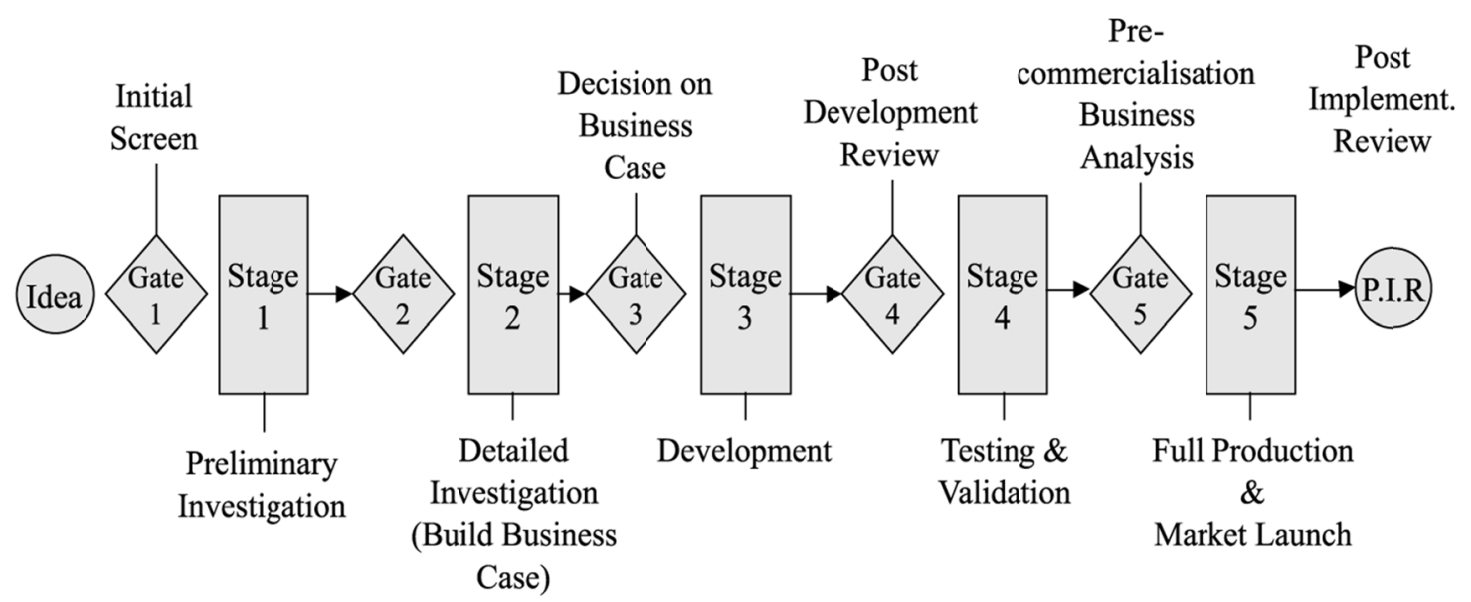

Figure 3.11 The stage-gate process model

\subsubsection{Recursive model}

Although these linear models provide us with the causal relationships between process control and design performance, they tend to ignore the features and behaviors of design (Zhang et al., 2012a). Consequently, researchers have developed recursive models to understand and describe better these process features and behaviors. The recursive model considers that the connections and sequences between different stages are not rigid, and describes this process as a series of small and large recursive cycle with feedback and feed-forward loops.

Ajamian and Koen (2002) propose a technology stage-gate model (TechSG) that attempts to manage technology development efforts with high uncertainties and risks. Like the traditional stage-based model, the TechSG process consists of a series of gates or reviews. However, the details of the development plan are known only to the next stage. Another example is that, in the mid-1990s, Ward et al. (1995) investigate the product development at Toyota to understand its ability to standardize and capitalize on developments. In Toyota, product development studies sets of alternatives simultaneously, and argues that seemingly superfluous alternatives would be reused. In this way, Toyota develops a set-based concurrent engineering model which involves exploring a number of 
solutions for a relatively long time.

In the field of software design, the best known recursive model is the spiral model proposed by (Boehm, 1988). The spiral model includes a series of planned iteration that consists of feedbacks and spans several phases of development. In this model, the project repeats the conceptual design, system level design, detailed design, and integration and testing. The characteristic "repeat" requires managers to evaluate risk early in the project to avoid major costs. In sum, the spiral model can reduce expensive rework and emphasizes the risk, thus reducing the development cost and time. But the process complexity caused by iteration results in the management complexity.

Other process models expand the menu of choices for many companies, such as design-to-budget, prototype-iteration process (MacCormack et al., 2001), V-model (Forsberg and Mooz, 1991). Although the main part of the design-to-budget process is still staged process, this model combines the detailed design and testing stages to induce developers to iterate through several designs until the budget limit is researched. The prototype-iteration process model tries to gain fast iteration by the early prototypes. This model could be very advantageous when the initial specifications are vague.

The Vee-model is used to visualize the system engineering focus, particularly during the conceptual stage and the development stage. In the Vee model, time and system maturity proceed from left to right, in which a top-down approach(specification and design) followed by a bottom-up one(integration and validation) (Bonjour and Micaelli, 2010). This model represents the design logic behind a complex system, including the mechanism of problem decompose and the mechanism of adjustment. These mechanisms enable refining of the definition of needs while evaluating the pertinence of proposed solutions.

\subsubsection{Chaotic models}

As for the chaotic framework, it focuses on the radical innovative design process with non-linear behaviors. Such these processes are difficult to predict, since a small change of process variables maybe result in absolutely different process route and output.

In the literature, there are not too many efforts to this kind of model. Chen and Van de Ven (1996) examine the effects of feedback loops in product development through a chaos-system algorithm. This result indicates that the process of innovation begins with a chaotic state and ends with the stable state. Koput (1997) studies innovative activities of innovation by a chaotic framework, and investigates how process feedback loops influence these innovative activities. 


\subsubsection{Discussion}

According to the analysis above, procedural models provide the high-level models, emphasizing some aspect of design. Design-focused models mainly focus on the solving the technical problem of design problem, while the manage-focused models emphasize the support for design management. Meanwhile, there are some perspectives for the design-focused and manage-focused models as follows:

(1) There is still no single model agreed to describe design. Most design-focused models have similar concepts and models developed in 1960s or 1970s, which means that these models are the result of the evolution process. The trend of the evolution process illustrates that recent models can satisfy the specific situation but have many similarities. For example, recent process models take project-related or company-related factors into account, but the basic process still can be traced back the similar roots. Additionally, although there are some efforts to explore the nature of design (e.g. C-K theory), but it is not enough.

(2) Most design-focused models still adopt the "isolated views" to consider design. Wynn and Clarkson (2005) and Gericke and Blessing (2012) argue that design is not an isolated system, rather is embedded in an ecosystem with multiple interdependencies and interactions. However, most current design-focused models do not refer to other disciplines or other business factors.

(3) The three views (linear, recursive and chaotic views) of manage-based models are not rival but complement each other. The three views provide a complementary hierarchy or ladder of abstraction for interpreting different types of design projects. Each of these models has distinct advantages and disadvantages, suggesting that companies should select the appropriate process model according to their own specific characteristics.

(4) The trend of combing the design-focused model with the manage-focused model is emerging. In the literature of manage-focused model, some researchers in the field of management propose some models that incorporate the design-focused model and the manage-focused model. These models attempt to propose related strategy to deal with the general problems that the design process may encounter (e.g. the uncertainty, the complexity). The trend means that we maybe use the related management method or models to develop a comprehensive model of design. 


\subsection{Activity-based model}

Procedural models offer insights into and references to development projects and design projects. However, they are too general to provide operational insights and advices for design managers and designers. Therefore, we move down much more concert level, the activity-based level, to further review design models. Comparing with procedural models, activity-based models could provide the guide to the daily decisions which are made by design managers and designers (Wynn, 2007).

In the literature, Browning and Ramasesh (2007) perform a comprehensive literature review of activity network-based process models in terms of the model purpose, and divides these models into project visualization, project planning, project control, and project development. Based on the work of Browning and Ramasech, Wynn (2007) pays more attention on the model's representation of activity connectivity, and proposes another classification: task precedence model; task dependency model; dynamic task model.

In our opinion, the sequence of activities is governed by the information required and generated by design activities. The relationships of all activities can be represented as an activity-based network, through which it could generate several possible process architectures for design. The sequence of activities has an important influence on the efficiency and effectiveness of the design process. Thus, we adopt the second classification (task precedence model; task dependency model; dynamic task model) as the review framework in the forthcoming sections.

\subsubsection{Activity precedence model}

Activity precedence models represent the relationship between activities in terms of information precedence (Wynn, 2007). This kind of relationship indicates that the sink activity cannot be performed until the source activity has been completed.

Traditional activity-network techniques and models, such as the critical path method (CPM) (Kelley,Jr and Walker, 1959) and Program evaluation and review technique (PERT) (Malcolm et al., 1959), enable to construct a process model with 1) a set of activities 2) precedence relationships 3 ) the estimation activity duration. As the extension of CPM/PERT, many researchers developed many models to consider more characteristics of the design process. With tools such as the graphical Evaluation and review technique (GERT) (Neumann and Steinhardt, 1979) and its successor Q-GERT (Taylor and Moore 1980, Pritsker and Sigal 1983), the notion of identifying one critical path was replaced by a measure of task criticality, and they enable simulation-based analysis of activity networks with feedback loops. 


\subsubsection{Activity dependence model}

Because of the increasing complexity of process elements and deliverable elements, traditional activity-network techniques and models are not enough for representing a large number of feedback and iteration or for comparing alternative process architectures. The activity dependence model captures the information dependencies between activities. Different from the rigid sequence of the activity precedence model, the relationship between activities within activity dependence models indicates only the sink activity requires the information from the source activity.

One of them, a matrix-based method called the Design Structure Matrix (DSM) is developed and extended by Steward (1981) and Eppinger et al. (1994). Different from traditional activity-network techniques, the DSM method focuses on representing information flows rather than workflow. This DSM method is an information exchange model that allows the representation of complex task relations in order to determine a sensible sequence for tasks being modeled. These relations are mapped in a matrix. The matrix is used to map a set of items toward itself $(\mathrm{N} \times \mathrm{N})$ or map a set of items toward another set of items $(\mathrm{N} \times \mathrm{P})$. Figure 3.12 shows three types of dependencies, and how these three are represented traditionally in a graph and how they are presented in a DSM matrix. In the DSM matrix, the dependencies and relations are plotted in rows and columns.

Some researchers have used the DSM framework to explore alternative process architectures. Specifically, the DSM is a tool for representing and analyzing a complex network of activities. Browning (2001) provides a taxonomy of these approaches and identifies four types of DSM applications (i.e. task-based, parameter-based, team-based and component-based).

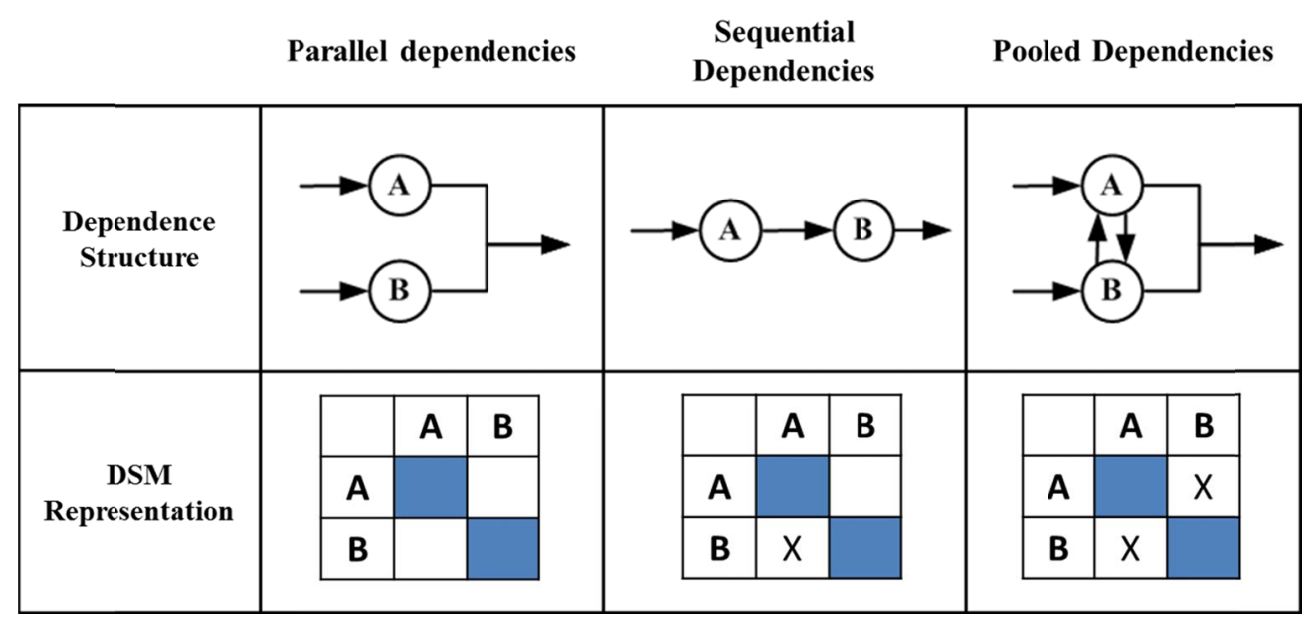

Figure 3.12 Types of dependencies and DSM representation of dependences 
Domain-mapping matrices (DMM) are an extension of the DSM which allows modeling of dependencies between dual domains in product development. Danilovic (2004) studies on the product architecture vs. organization, and in 2005, he discusses the DMM and the DSM to enable the systematic identification of interdependencies and relations in a multi-project environment (Danilovic and Sandkull, 2005). In a recent paper, Danilovic and Browning (2007) studies the application of DMMs to explore connectivity between the process domains of tasks, components and teams.

\subsubsection{Dynamic activity model}

Most activity-based techniques and models above to construct the process architecture have two assumptions: first, design activities (including interactions and variables) are known a priori (Browning and Ramasesh, 2007); second, the expected goal can be achieved by these known design activities. However, this is rarely the reality in the design project. In response to the realities of the process (i.e. goal uncertainty, ambiguity and instability in projects), natural and dynamic process models to construct process architectures are proposed in the literature.

The approach "signposting" characterizes design as a series of tasks concerned with the identification, estimation and iterative refinement of key deign and performance parameters (Clarkson and Hamilton 2000; O'Donovan et al. 2004; Wynn et al. 2006). The selection of design activities are based on the confidence of performance parameters, that is, the levels of quality, maturity or value of design parameters.

The Manufacturing Integration and Design Automation System (MIDAS) (Chung et al. 2002) describes the design process with the local task to represent high-level goals, and the atomic task which represent the individual computer tools. Moreover, the MIDAS defines a process space of all possible activities and their arrangement.

The Adaptive Product Development Process Model (APDP) generates process space (sets of process architecture) based on the available activity modes (alternative design activities), where the availability of certain activity modes depends on the current state of design. Unlike the models above, the state of design account for not only the time and cost but also performance and risk. The APDP model assumes that the process architecture is determined dynamically by the state of the design. The selection of design activities is based on performance parameters, such as technical performance, the levels of quality, maturity or value of design parameters and so on. 


\subsubsection{Discussion}

In sum, the activity-based models propose much more detailed methods for process modeling of innovative design. However, the activity precedence models and the activity dependence models adopt the static view to construct the process architecture of design process. In response to the realities of the innovative design process (i.e. goal uncertainty, ambiguity and instability in projects), these dynamic process models are much practically because they do not require an overview of the process architecture. Therefore, in this dissertation, we mainly focus on dynamic process models.

(1) In general, the dynamic process models provide us with basic elements and frameworks to construct the process architecture of innovative design. It proposes that a complex adaptive system (CAS) framework is able to interpret the innovative design reality, to maintain a fit among designer behaviors, innovation and the design state.

(2) However, the dynamic process models generally focus on the entire product life cycle (i.e. concept, development, production, utilization, support and retirement). Central targets for the entire process are technical performance, product unit-cost and time-to-market (Tatikonda and Rosenthal, 2000). But the design process is one stage of the product life cycle, where the nature of design activities and the people involved are different from other stages (Zhang et al., 2012a). Thus, to reflect well the reality of innovative design, it needs a much more comprehensive set of targets.

\subsection{Conclusion}

The Chapter highlights that these existing models cover a variety of issues and disciplines, but does not provide an exhaustive list of implementations, and only reflects the focus of this dissertation. In summary:

Firstly, we develop a classification framework of design modeling to organize the review of this area. This classification consists of design paradigm, procedural models and activity-based models ordered by the level of abstraction.

Then we analyze two design paradigms (the rational problem-solving paradigm and the reflective practice paradigm) that provide theoretical foundations and assumptions of design modeling. We argue that two design paradigms differ fundamentally in the way of treating design, but are complementary by focusing on different aspect of design. Hence, it should combine the methods underlying the two paradigms in order to build a 
comprehensive process model.

Thirdly, we turn attention to the procedural models. Here, the design-focused models and the manage-focused models are reviewed. As for the former one, we discuss the evolution process of design models with the historical views. Comparing traditional design models with these ones of today, it can be observed that the development progression of design theory is an evolutionary process. Moreover, none is agreed to represent all aspects of the design process so far, and most models still adopt the "isolated" view. The review of the manage-focused models focuses on how to improve the effectiveness and efficacy of design or development process. In this aspect, we respectively synthesize manage-focused models in terms of the linear, recursive and chaotic system views, and argue that the three types complement each other. In addition, we also found that recent models are trying to combine the design-focused model with manage-focused model to gain the full-scale description.

Lastly, we move down the activity-level to review the modeling approaches available on the process structure. Here, three types of activity-based model (task precedence model. task dependency model, and dynamic task model) are synthesized. The first two types are based upon the relatively narrow and static view to construct the process architecture, while the dynamic task model could describe and explain better the realities of innovative design.

Through reviewing three different levels of models, this Chapter sets the context for process modeling of innovative design. The review of design paradigms provides us with the theoretical foundation of the modeling of innovative design. The procedural models offer useful insights to help to understand and model innovative design. The activity-based models propose much more detailed methods to construct the process architecture of innovative design. 


\section{UNDERSTANDING INNOVATION}

\subsection{Overview}

Innovation is not a new phenomenon. Human being seems to have tendency to consider new and better ways of doing things and to apply it into the practice (Plessis, 2007). Since Joseph Schumpeter's two famous books, The theory of Economy Development and Capitalism, Socialism, and Democracy at the beginning of the twentieth century, innovation represents the main driving force of economic development (Schumpeter 1934, 1942). During the last decade, as the market becomes more dynamic, companies need to innovate in response to the change of customer demands. Innovation has been considered as the major factor of strengthening competitiveness of companies and gain the new opportunity of the new market (OECD, 1997; Tomala \& Sénéchal, 2004). "Innovate or die" becomes a slogan in modern companies.

Innovation, as the driven force and the ultimate goal of innovative design, also plays a very important role in defining and modeling innovative design. Firstly, the content and the scope of innovation determine the definition and the characteristics of innovative design. As stated before, innovation itself is not a new question, but its place, scope and content have changed and it is now a characteristic of competition (Le Masson et al., 2010). These changes necessarily cause the reconsideration of innovative design. Hence, this chapter tries to identify these changes by reviewing key elements of innovation. Secondly, when managers and designers initiate and direct the development of an innovation over time, they need a process theory that explains how and why innovations develop. Although such a process theory may never reach the precision to tell managers and designers exactly what to do and how an innovation will turn out (Van de Ven et al., 2000), it may produce some useful fundamental insights for describing and explaining a board class of processes, sequences, and performance conditions to innovative design. So the second step is to review the related innovation models to identify the process theory of innovation.

Discussion proceeds in five sections. In Section 4.2, we compare definitions of innovation in order to identify key elements and components of innovation design. Section 4.3 constructs the multi-dimensional classification to characterize innovation, and identify key components of innovation. Section 4.4 reviews innovation process models. Section 4.5 synthesizes three aspects of change of innovation based on the brief of summary of innovation. 


\subsection{Definition}

Innovation involves a variety of types depending on the company's types, resources, capabilities, strategies and requirements. The form of innovation varies in team, department and professional discipline. Therefore, innovation is of interest to practitioners and researchers across a range of business and management disciplines and is the considerable topic in a variety of domains, such as economic, organization, knowledge, design, and engineering. Several researchers have proposed their definitions from different standpoints, as shown in Table 4.1.

Table 4.1 Definitions of innovation

\begin{tabular}{|c|c|}
\hline Authors & Definition \\
\hline (Schumpeter, 1934) & $\begin{array}{l}\text { Innovation includes the setting up of a new production function. } \\
\text { This covers the case of a new commodity and those of a new form } \\
\text { of organization, of the opening up of new markets and so on. }\end{array}$ \\
\hline (Kline \& Rosenberg, 1986) & $\begin{array}{l}\text { Innovation is the creation and marketing of the new, these gentles, } \\
\text { singly and in combination, make the outcome of innovation a highly } \\
\text { uncertain process. }\end{array}$ \\
\hline$(\mathrm{OECD}, 1991)$ & $\begin{array}{l}\text { Innovation is an iterative process initiated by the perception of a } \\
\text { new market and/or new service opportunity for a technology-based } \\
\text { invention which leads to development, production and market tasks } \\
\text { striving for the commercial success of the invention. }\end{array}$ \\
\hline (Freeman and Soete, 1997) & $\begin{array}{l}\text { An innovation is accomplished only with the first commercial } \\
\text { transaction involving the new product, process system or device. }\end{array}$ \\
\hline (Amabile et al., 1996) & $\begin{array}{l}\text { Innovation is the successful implementation of creative ideas within } \\
\text { an organization. }\end{array}$ \\
\hline (Luecke \& Katz, 2003) & $\begin{array}{l}\text { Innovation is understood as the successful introduction of a better } \\
\text { thing or method, which is the embodiment, combination, or } \\
\text { synthesis of knowledge in original, relevant, valued new products, } \\
\text { processes, or services. }\end{array}$ \\
\hline (Galanakis, 2006) & $\begin{array}{l}\text { the creation of new products, processes, knowledge or services by } \\
\text { using new or existing scientific or technological knowledge, which } \\
\text { provide a degree of novelty either to the developer, the industrial } \\
\text { sector, the nation or the world and succeed in the marketplace. }\end{array}$ \\
\hline (Plessis, 2007) & $\begin{array}{l}\text { Innovation as the creation of new knowledge and ideas to facilitate } \\
\text { new business outcomes, aimed at improving internal business } \\
\text { process and structures and to create market driven product and } \\
\text { services. Innovation encompasses both radical and incremental } \\
\text { innovation. }\end{array}$ \\
\hline (Wong et al., 2009) & $\begin{array}{l}\text { Innovation is defined as the effective application of new processes } \\
\text { and product to the organization }\end{array}$ \\
\hline (Baregheh et al., 2009) & $\begin{array}{l}\text { Innovation is the multi-stage process whereby organizations } \\
\text { transform ideas into improved products, service or processes, in } \\
\text { order to advance, compete and differentiate themselves successfully } \\
\text { in their marketplace. }\end{array}$ \\
\hline $\begin{array}{l}\text { (Beswick \& Gallagher, } \\
2010)\end{array}$ & $\begin{array}{l}\text { The successful exploitation of an idea that adds value to the } \\
\text { customer and commercial return for the creator }\end{array}$ \\
\hline
\end{tabular}


Here, we do not try to define a unified definition of innovation, rather find the key elements of innovation from these definitions to characterize innovation. In summary:

(1) Most definitions highlight the importance of creativity. In Table 4.1, we can observe that the term "new" is the most frequent word within the definitions. As the essential part of innovation (Amabile et al. 1996), creativity refers to how to generate more and better ideas, and includes the first introduction of a new innovation and the reintroduction of an improved innovation (Ali et al., 1995).

(2) They emphasize the creation of technological invention combined with the market introduction of the invention to end-user through the development, production, and market tasks (Abernathy and Clark, 1985). Hence, innovation is "the first attempt to carry it out into practice" (Fagerberg, 2006), and includes not only basic and applied research but also development, manufacturing, marketing, distribution, servicing and later product adoption and upgrading.

(3) Although each definition emphasizes the term "new", there is no agreement on what deserves the "innovation". In the literature, "innovativeness" is often considered as being the degree of newness of innovation. Highly innovative product means that it has a higher newness, and reversely the low innovative product seems being familiar to customers. But it immediately raises questions: From whose perspective the newness is considered? What is new?

(4) Many definitions identify different types of innovation, such as product, process or service (Baregheh et al., 2009). Because different type of innovation means the different characteristics, an appropriate process and management strategy are needed to manage each type of innovation.

(5) In Table 4.1, most definitions neglect the sources of innovation, and only OCED's definition explains that innovation has two sources (marketing and technology) from which discontinuities originate. Because innovation occurs as the departure of a creative idea, the understanding of "what are the sources of innovation?" is the basic problem.

According to the analysis above, although these definitions originate from different disciplines, there are commonplaces to define innovation (e.g. creativity and the entire process of innovation). Meanwhile, we can also identify key dimensions to comprehensively characterize innovation (e.g. innovativeness, type of innovation and source of innovation). Accordingly, we will characterize innovation according to these key dimensions identified in the following sections. 


\subsection{Characterization of innovation}

Through the analysis and the comparison of definitions in the previous section, we have identified commonplaces and key dimensions of innovation. In this section, we try to utilize these elements to characterize innovation in terms of components and the classification of innovation.

\subsubsection{Components of innovation}

Based on these commonplaces observed above (the first two points in Section 4.2), although it is very difficult to propose a multidisciplinary definition of innovation, we could conclude that innovation consists of two components (Von Stamm, 2008): creativity and implementation.

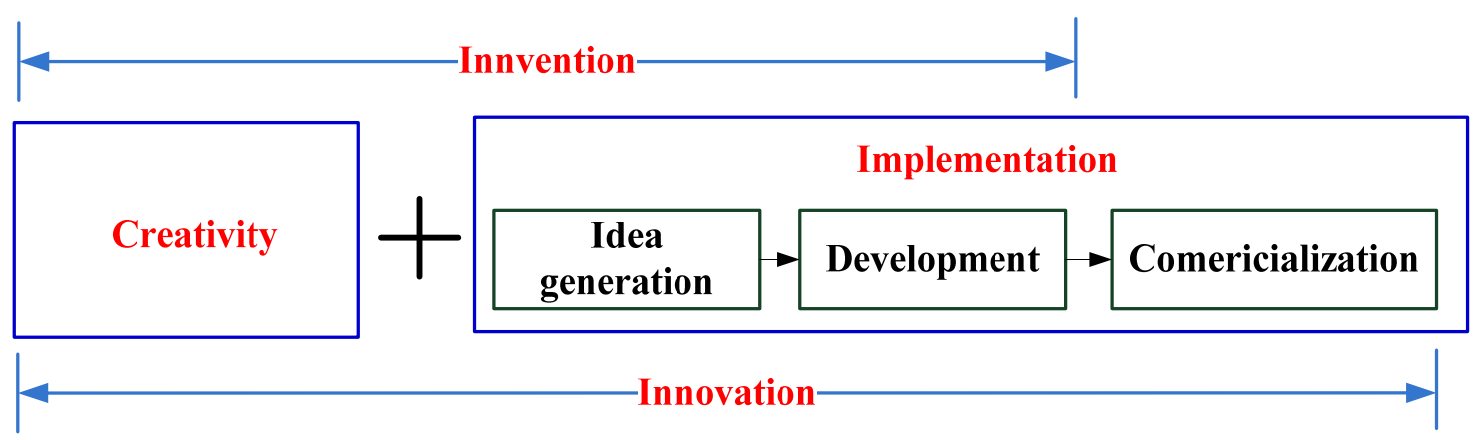

Figure 4.1 Components of innovation

Creativity, as the driven ability of generating creative ideas, is performed in the course of innovation. It is an inherently individual act and the development of an idea and the implementation where the team is needed.

As stated before, innovation is a process from creative ideas, development and production to commercialization. Thus we adopt the term "implementation" to describe the entire process. Implementation concerns how to translate creative ideas into practice, and includes three stages: idea generation, development and commercialization.

Often invention and innovation are used interchangeably. However, an important distinction is made between them, as shown in Figure 4.1 . Invention is the first occurrence of an idea for a new product or process, while innovation is the first attempt to carry it out into practice (Fagerberg, 2006). Long lags between invention and innovation may have to do with the fact that, in many cases, some or all of the conditions for commercialization may be lacking. There may not be a sufficient need (yet!) or it may be impossible to produce and/or market because some vital inputs or complementary factors are not available. 


\subsubsection{Classification of innovation}

In the literature, most researchers identify the classification of innovation only based on a single dimension of innovation, such as the product form, the level of novelty and the source of innovation (Cooper, 1998; Heany, 1983; OECD, 1997; Tidd, 1997). However, since innovation is now increasingly considered as a multidimensional concept (Navarro et al., 2004), it is difficult to utilize a single, even uniform dimension to characterize innovation. Hence, a much more holistic classification of innovation is needed to be performed. Xu (2010) constructs a multi-dimensional classification in terms of the novelty, the form (i.e. the type of innovation) and the success. But we argue that the success cannot be considered as the key dimensions.

In Section 4.2, we have identified the level of innovativeness, the type of innovation and the source of innovation as the key dimensions to characterize innovation. Hence, we firstly construct a multi-dimensional classification of innovation based on the three dimensions (see Figure 4.2). In axis of the level of innovativeness, we divide innovation into the incremental innovation, really new innovation and radical innovation (Garcia and Calantone, 2003); In axis of the type of innovation, it consists of service, process and product; for the source of innovation, we main emphasize the market pull and the technical push. In the following sections, we will further respectively analyze three dimensions.

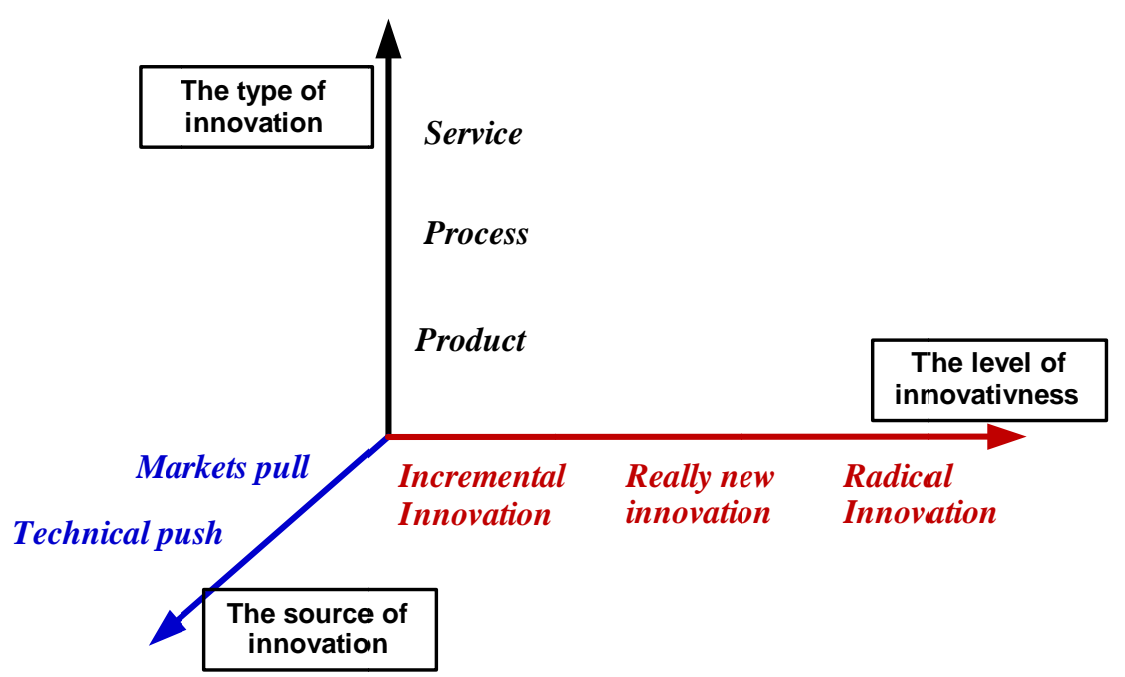

Figure 4.2 The multi-dimensional classification of innovation

\subsubsection{Type of innovation}

Baregheh et al. (2009) count the appearance frequency of different types of innovation by comparing definitions of innovation from different disciplines. Table 4.2 shows the synthesized result. Obviously, scholars from different disciplines have a consensus type of innovation. Almost every discipline includes product, service and process. The product 
innovation and service innovation are things that an organization offers, while the process innovation is the way in which these things are created and delivered.

Table 4.2 Word frequency count based on disciplines and attributes

\begin{tabular}{l|l}
\hline \multicolumn{1}{c|}{ Disciplines } & \multicolumn{1}{c}{ Type } \\
\hline Management & Product, Process, Service, Program \\
\hline Economy & Product, Process, Service, Technical \\
\hline Innovation / Entrepreneurship & Product, Service, Technical \\
\hline Technology/Science/Engineering & Product, Process, Service, Technical \\
\hline Knowledge & Product, Process, Service, Technical \\
\hline Marketing & Product, Process, Service \\
\hline Organization & Product, Process, Service \\
\hline
\end{tabular}

\subsubsection{Innovativeness}

Heany (1983) provides a check list for the degree of product innovation, based on six categories including style change, product line extension, product improvement, new product, start-up business and major innovation. Olson et al.(2006) suggest four levels of innovation: new-to-the-world product (products that are new to both, the company developing them and the marketplace using them), line extension (products that new to the marketplace but not to the company), me-too-product (those that are new to the company but not to the marketplace), and product modification (existing products that have been simply modified); Tidd (1997) make some observations regarding the degree of innovation. The three levels of innovation he identified are (i) incremental, (ii) radical and (iii) transformation.

Garcia and Calantone (2003) argue that this abundance of typologies has resulted in that the same name is used for describing different types of innovation and the same innovation is classified into different typologies. Then they propose an operationalized typology in terms of macro versus micro and marketing versus technological perspective in order to measure the degree of innovativeness (see Figure 4.3). The macro-level concerns the new characteristics of product innovation to the market, industry and world, while the micro-level focuses on the innovativeness of products in a point of view of the firms. Since innovation has two forces (marketing and technology) from which discontinuities originate, the marketing and technological perspectives mainly consider the newness to the market and technology. Based on this typology, Garcia and Calantone identify three types of innovation as following. 


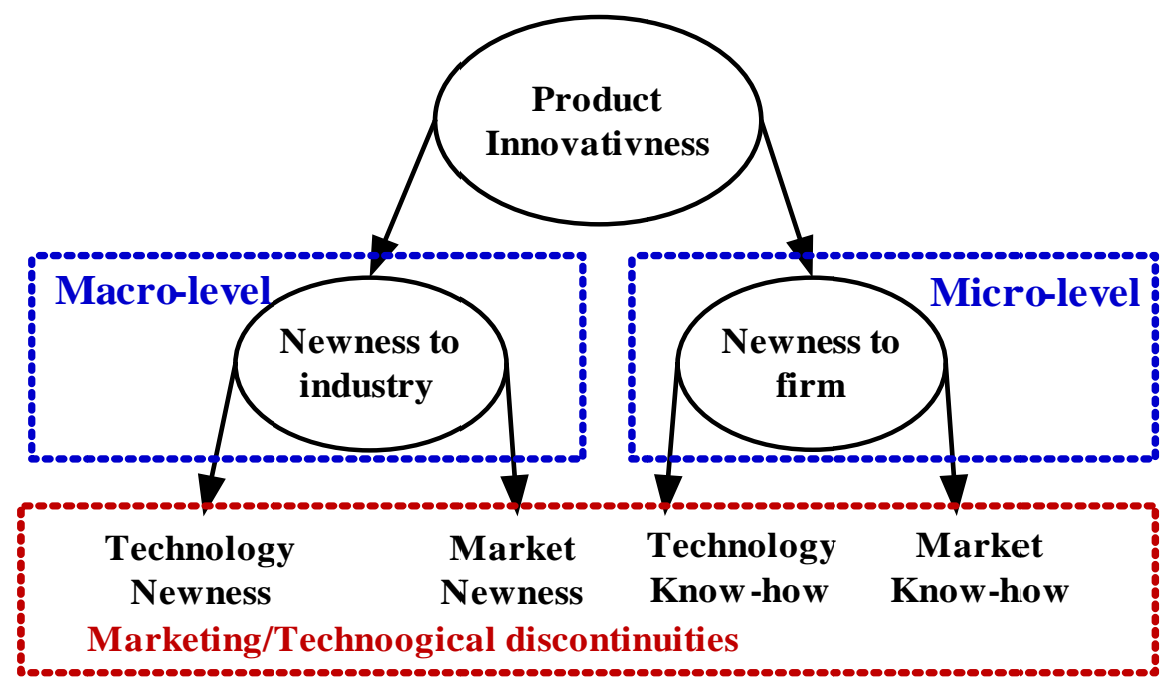

Figure 4.3 Operationalized typology of innovativeness (Garcia and Calantone, 2003)

- Radical innovation. The introduction of radical innovation results in the discontinuities of the macro and micro level. Moreover, the marketing and technological discontinuities occur in both levels.

- Really new innovation. On the macro level a really new product results in a marketing discontinuity or a technological discontinuity but does not include both. On the micro level any combination of marketing and/or technological discontinuities can occur in a firm.

- Incremental innovation. It can be defined as products that provide new features, benefits, or improvement to the existing technology in the existing market.

\subsubsection{Source of innovation}

Cooper (1999) considers the technological advance, intensified customer needs, shorter product life cycles and increased world competition as driving forces of innovation. In fact, the category equates with another category (i.e. technical push and market pull), as shown in Figure 4.4. The technical push leads to the scientific and technological advances which push a new product into the market, while the market pull places more emphasis on market needs.

To deeply study the topic, we raises a second question, namely "where do the sources come from?" OECD (1997) classifies the "sources of information for innovation" into five broad categories, including internal factors, external/commercial factors, education/research establishments, generally available information and other external factors. Padmore et al. (1998) identify the in-house, peers, suppliers, customers and public sector as the sources of innovation based on the classification of where the knowledge comes from. 
Then the next question is about "what are explanatory variables for the sources of innovation?" Becheikh et al. (2005) explain these variables by a systematic review of the literature on innovation from 1993-2003. We summaries and compare these categories and variables in Table 4.3.

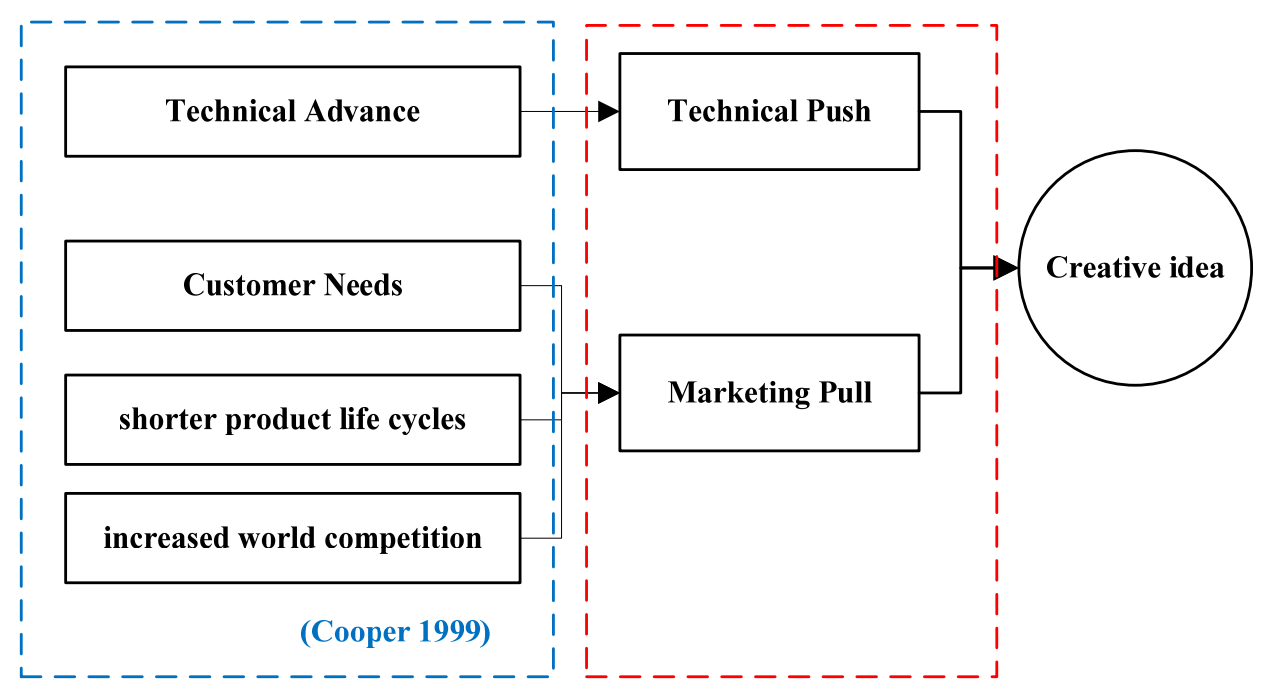

Figure 4.4 The sources of innovation

Table 4.3 The sources and explanatory variables of innovation

\begin{tabular}{|c|c|c|}
\hline \multicolumn{2}{|c|}{ Sources of innovation } & Explanatory variables \\
\hline$(\mathrm{OECD}, 1997)$ & (Padmore et al., 1998) & (Becheikh et al., 2005) \\
\hline Internal factors & In-house & $\begin{array}{l}\text { - Firms' general characteristics } \\
\text { - Firms' global strategies } \\
\text { - Firms' structure } \\
\text { - Control activities } \\
\text { - Firms' culture } \\
\text { - Management team } \\
\text { - Functional assets and strategies }\end{array}$ \\
\hline \multirow{3}{*}{$\begin{array}{l}\text { External/commercial } \\
\text { factors }\end{array}$} & Peers & \multirow{3}{*}{ - Firm's industry related variables } \\
\hline & Suppliers & \\
\hline & Customers & \\
\hline $\begin{array}{l}\text { Education /research } \\
\text { establishments }\end{array}$ & \multirow{2}{*}{ Public sector } & \multirow{2}{*}{$\begin{array}{l}\text { - Knowledge/technology acquisition } \\
\text { - Government and public policies }\end{array}$} \\
\hline $\begin{array}{l}\text { Generally available } \\
\text { information }\end{array}$ & & \\
\hline Other external & & $\begin{array}{l}\text { - Surrounding culture } \\
\text { - Firm's regional variables }\end{array}$ \\
\hline
\end{tabular}




\subsection{Modeling of innovation process}

As stated before, companies consider innovation as being the main source of differentiation and competitive advantage. If managers want to develop innovation, it needs a managerial view of why and how innovation emerges, proceeds and grows. It raises a series of questions. For example, what stages does the innovation process include? What is the scope of the activities of these stages and how do project managers organize these activities? How do these activities interact with other unities outside? In other words, it needs a process theory that shapes the ways in which we try to manage innovation (Tidd and Bessant, 2011).

In the literature, there are plenty of attempts to set up the conceptual model of the innovation process to build the process theory. Here, we compare the existing process models, not an exhaustive list of implementations, to synthesize the state of the art of innovation. Table 4.4 is the synthesized comparison result of these process models. It focuses on the stages of the innovation process. The column heading is based on the stages of the whole product life cycle, including idea generation and assessment, business planning, development, production, commercialization, usage and disposal.

The analysis of Table 4.4 is performed in two dimensions. The first dimension focuses on the coverage of the innovation process by reading Table 4.4 from the right to the left, while the second point is to discover the evolution development of innovation process models by analyzing these models from top to down. More details are discussed in the following sections.

\subsubsection{The coverage of the innovation process}

(1) Common stages of innovation

The columns of Table 4.4 show the coverage of different innovation process models. Although these models adopt different terms to name these stages of the innovation process, there are five common stages, as shown in Figure 4.5 (i.e. idea generation and assessment, business planning, development, production, commercialization). Notably, because this comparison does not include influence factors, such as market, researchers, knowledge, these stages distinguished are depicted in a sequential manner. But there exist lots of iterations and feed loops, even overlaps between these stages. 


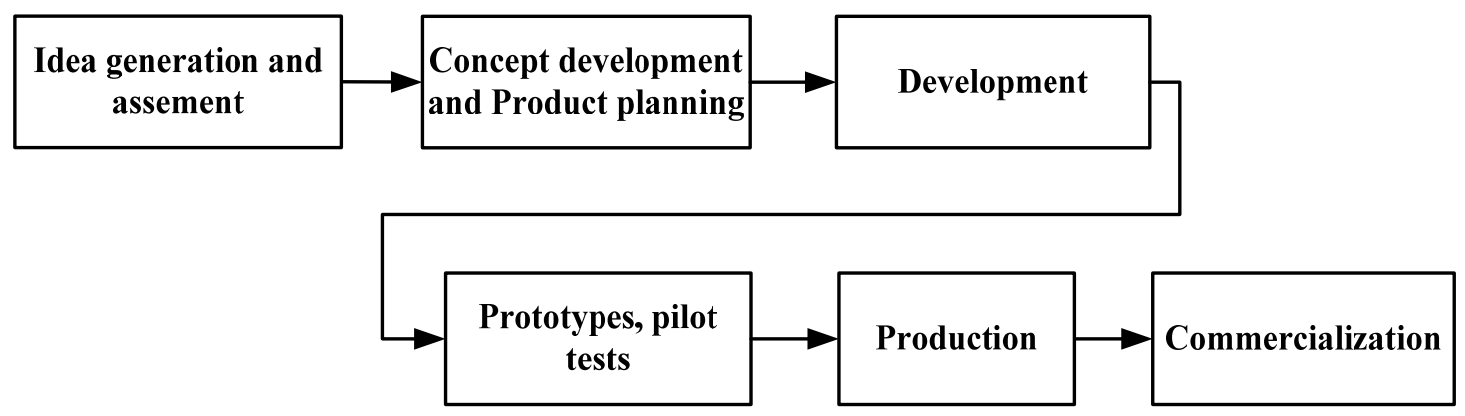

Figure 4.5 The main stages of innovation process

(2) The fuzzy front end

Most models emphasize the importance of the early stages of innovation (idea generation and assessment), that is, the "fuzzy front end" stage. It is in the front end where the company formulates the concept of a product to be developed and decides whether or not to invest resources in the further development of the concept.

Additionally, other researchers also prove the importance of the fuzzy front end by a series of empirical studies. Cooper and Kleinschmidt (1993) argue that "the greatest differences between winners and losers were found in the quality of execution of pre-development activities". Koen et al. (2001) also consider the fuzzy front end as being the key-contributing factor for large numbers of really new products introduced each year.

(3) Latter stages of innovation

In Table 4.4, few models pay attention to the latter stages of innovation (i.e. the stages after the implementation or commercialization). However, within the latter stages, the lessons learned, experiences and best practices will be accumulated into knowledge bases, or transformed into new impulses to generate more innovation $(\mathrm{Xu}, 2010)$.

As we know, knowledge or experience is the core component of innovation (Chapman and Magnusson, 2006; $\mathrm{Xu}$ et al., 2010). It is impossible to access to a modern innovative design without the accumulated knowledge. Therefore, in order to achieve the continuous innovation, the mechanism of knowledge management can be seamless integrated into the innovation process. In this perspective, the innovation process should be extended to the stage of usage and disposal. 
Table 4.4 A comparison of stages of innovation process models

\begin{tabular}{|c|c|c|c|c|c|c|c|c|}
\hline Source & \multicolumn{2}{|c|}{ Idea Generation and Assessment } & Business Planning & Development & Production & Commercialization & Usage & Disposal \\
\hline (Maidique, 1980) & \multicolumn{2}{|l|}{ Recognition } & Invention & Development & Implementation & Diffusion & & \\
\hline (Kline and Rosenberg, 1986) & \multicolumn{2}{|c|}{ Potential market } & Invention & Design/redesign/test & Produce & Distribute and market & & \\
\hline (Cooper, 1990) & \multicolumn{2}{|c|}{ Preliminary investigation } & Business planning & Development & Manufacturing & Market introduction & & \\
\hline (Rothwell, 1994) & \multicolumn{2}{|l|}{ Basic science } & \multicolumn{2}{|c|}{ Design and engineering } & manufacturing & Marketing/sales & & \\
\hline (Rothwell, 1994) & \multicolumn{2}{|l|}{ Market need } & \multicolumn{2}{|c|}{ development } & manufacturing & sales & & \\
\hline (Rothwell, 1994) & \multicolumn{2}{|l|}{ Idea generation } & \multicolumn{2}{|c|}{$\begin{array}{l}\text { Research, design and development/ } \\
\text { Prototype production }\end{array}$} & Manufacturing & Marketing/sales & & \\
\hline (Amabile et al., 1996) & \multicolumn{2}{|c|}{ Individual/group creativity } & \multicolumn{3}{|c|}{ Implementation of creativity } & Diffusion & & \\
\hline (Padmore et al., 1998) & \multicolumn{3}{|c|}{ Concept } & Design/ Prototype & Production & Distribution/sell & \multicolumn{2}{|c|}{$\begin{array}{l}\text { Reinvent/obsolete } \\
\text { /stable/update }\end{array}$} \\
\hline (Trott, 2008) & Theoretical conception & \multicolumn{2}{|c|}{ Technical invention } & \multicolumn{3}{|c|}{ Commercial exploitation } & & \\
\hline (Bernstein and Singh, 2006) & Idea generation & \multicolumn{2}{|c|}{ Innovation support } & development & Implementation & & & \\
\hline (Galanakis, 2006) & \multicolumn{3}{|c|}{ Idea generation } & Development & Manufacturing & Product success & & \\
\hline (Verworn et al., 2008) & \multicolumn{3}{|c|}{ Front end phase } & $\begin{array}{l}\text { Development/ } \\
\text { Prototype }\end{array}$ & Production & \begin{tabular}{|c|} 
Market \\
introduction/penetrati \\
on
\end{tabular} & & \\
\hline
\end{tabular}




\subsubsection{The evolution of innovation process models}

Looking at the rows of Table 4.4 from the upper to the down, it becomes obvious that the process architecture of innovation is changing over time. We can see that the innovation process model evolves from the linear model, coupling model, interactive model, to systems integration and networking model (Rothwell, 1994).

(1) The linear model

In multi-stage process linear model, the technology push and the market pull is the departure point; these motivations then lead to developments, developments to productions and productions to market. Most studies of innovation have now realized that the linear model does not represent the reality of innovation in several ways (Kline and Rosenberg, 1986; Padmore et al., 1998). Firstly, it does not reflect what scientist, inventors and innovators do. It suggests that everything begins with research, where the science is completed and packaged before becoming available for an invention. However, most innovation is finished with available knowledge in the firm. Secondly, there is no feedback path within the development process. The feedback from users and the marketing play a considerable role in the performance measure and the generation of creative ideas. In addition to this, the linear model does not illustrate well learning activities. Innovation is inherently uncertain, therefore involves learning processes (Pavitt, 2006).

(2) The coupling model

The linear model is regarded as being the simple picture of complex, interactive innovation. Therefore, more satisfying models are needed in order to better understand innovation. Around the 1970s some authors state explicitly that the successful innovation process is based on "a portfolio of wide-ranging and systematic studies covering many sectors and countries" (Cooper, 1980; Utterback et al., 1975), and propose a series of coupling models.

The coupling model can be considered as being a logically sequence that is composed of a series of functionally distinct but interacting stages. In view of the coupling model, the whole innovation process is a complex net where intra-organizational and extra-organizational link together with the different in-house functions. Probably, the well-known coupling model is "the chained-linked model" proposed by Kline and Rosenberg (1986). They argue that a key element in determining the success of innovation is the extent to which companies manage to maintain effective links between phases of the innovative process (OECD, 1997).

However, the coupling model has still some shortages: firstly, it does not explain what 
drives the engine of innovation and why some companies are better at doing so than others (Marinova and Philimore, 2003); secondly, it does not answer explicitly that how companies learn and obtain knowledge in development process; thirdly, In-house factor and national innovation environment have very considerable impacts on innovation performance. The model just stands top-level and omits relative details.

(3) The interactive model

With increasing remarkable competitive performance of Japanese companies in the 1980s, the innovation process model emphasizes the integration and the parallel development to shorten the product life cycle, that is the so-called "interactive model" (Rothwell, 1994). This model involves the activities of the various companies' department, even the external actor in a parallel rather than sequentially manner, and integrates different functions within the firm, including upstream with key supplier and downstream with demanding and active customers. Nowadays, many leading western companies are striving to master the essential feature of the interactive model.

(4) The systems integration and networking model

At the same time, companies have been facing new challenges, including technical advances, intensive customer needs, increasing diversification of the market and increasing world competition (Cooper, 1998). These challenges require that companies emphasize systems integration and extensive networking, flexible and customized response, continuous innovation, and to perform innovation within a given resource constraints.

To address these issues, some researchers propose the systems integration and networking model (Rothwell, 1994), the evolution model and the innovative milieu model (Marinova and Philimore, 2003). The systems integration and networking model includes internal organizational features, strong inter-firm vertical linkages, external horizontal linkages and more radically, the use of a sophisticated electronic toolkit; The evolution model considers that the innovation process is the evolution process between different elements. The innovative milieu model means the innovation cluster, which states that "innovation stems from a creative combination of genetic know-how and specific competencies" and "territorial organization is essential component".

\subsection{Discussion}

The brief summary of innovation shows the emergence of a lot of notions: product/or innovation, process innovation, radical innovation vs. really new innovation vs. incremental innovation, technology pull vs. market push, linear model, coupling model, interactive model and systems integration and networking model. The emergence of all notions reflects 
that there have been changes in the field of innovation, as illustrated in the following aspects.

(1) Innovation itself is not a new phenomenon, but its scope and content have changed.

For several companies, innovation focuses on a product or service with the constant industrial improvement or the updating technology. In general, these companies aim the well-identified market and constantly improve the known product's performance and functions. In this case, the product or the service has a series of stable "identities" (Le Masson et al., 2010). However, today innovation concerns more than the stable "identities". The rapid renewal and the tendency to one-off innovation on the new product make a big difficulty to clarify these identities for designer and customer. Take the mobile phone as an example: the mobile phone manufacturers try to increase the quality and storage capacity to cater to the customer's requirement. However, when Apple Inc. released the smartphone "iPhone" by introducing a series of absolutely original identities in 2007, such as multi-touch screen, it made a significant change to the mobile phone's identities. Moreover, the new identities of mobile phone are continuously proposed every year. Therefore, the start point of innovation is no longer the stable product identity.

As for the source of innovation, most researchers still focus on technology push and marketing pull. More recently, several researchers have emphasized the importance of industrial design for innovation (Best, 2006; Dell'Era and Verganti, 2009; Utterback, 2006; Verganti, 2008). This help identify a new type of innovation, "design-driven innovation" (Verganti, 2008), which radically changes the emotional and symbolic content of a product. Are the traditional views of innovation still effective for the "design-driven innovation"?

(2) Emphasizing the repeated, sustainable innovation, rather one-off innovation.

Some companies target one-off, radical innovative product or service in order to gain the strong competitive advantage. These products or services break away from the types of products existing in the industry and provides enough profits. However, the hope of acquiring a leading competitive advantage on the basis of blockbuster products or service has shown its limitation in the past (Le Masson et al., 2010). In practices, companies target innovative products with a continuous profit-earning capacity in order to finance all the problem failures. It requires that companies should find a way to manage and organize design in order to lead to a continuous innovation to compensate the cost caused by failed projects.

In Table 4.4, some researchers try to look for collective action to manage innovation to get the so called "innovation capability". In this perspective, innovation is no longer a 
phenomenon, rather the object of the action (Le Masson et al., 2010). Until the collective actions become standardized for product innovation, the entire process can improve the productivity of product innovation to achieve sustainable innovation (Garcia and Calantone, 2003).

(3) Increasing importance of design for innovation

An increased focus on product design is evident to varying degrees in industry (Luchs and Swan, 2011).Within industry, some argued that product design plays a key role in developing brands (Brunner et al., 2008). Others argued that, "design is one of the primary idea generators for the creation of viable business platforms" (Best, 2008). In short, product design is increasing recognized by managers as a strategic tool to be responsible the success of companies.

\subsection{Conclusion}

The main aim of this chapter is to identify the changes of innovation and the process theory of innovation, to support the definition and the understanding of innovative design. This two aims are achieved by four aspects of work. To summarize:

We begin with the review of definitions of innovation. Although it is obvious that these definitions originate from different disciplines, this leads to that fact that are some commonplaces between the various definitions of innovation.

Based on these commonplaces, we identify three key dimensions (e.g.: innovativeness, types of innovation and sources of innovation) to characterize innovation. Then, we further discuss these three dimensions, and divide each dimension into a series of sub-classes (the type of innovation: product, service and process; the innovativeness: radical innovation, really new innovation and incremental innovation; the source of innovation: the technological push and the market pull). Meanwhile, according to the comparison result, we also find common components of innovation: creativity and implementation.

And then we analyze and compare the existing innovation process models. This analysis is performed in two aspects. The first aspect focuses on the coverage of the innovation process, and discusses the role of each stage. The second one analyzes the evolution process of innovation process models from linear model, coupling model, interactive model, to systems integration and networking model, and then synthesizes characteristics of each model.

Finally, we synthesize three aspects of change in the innovation field. As we know that innovation is the driving force of innovative design, innovative design needs to be 
reconsidered be incorporating these changes. Additionally, the review of innovation process models helps to explore the application of the process theory of innovation into innovative design. 


\section{ANALYSIS AND REPRESENTATION OF INNOVATIVE DESIGN}

\subsection{Overview}

This chapter is located in the stage of the descriptive study $\mathrm{I}$ in Figure 1.4, and attempts to address the two main research issues introduced in Section 1.2.2, i.e. "definition and analysis" and "process description" of innovative design. The discussion of the two issues attempt to build a comprehensive understanding of innovative design, and provides the basis for the management support of innovative design. The research questions for exploring the two research issues were stated in Section 1.2.2.

- Question 1: What is innovative design?

- Question 2: How can we describe the process of innovative design?

With regard to the first question, although there are several definitions of innovative design in the literature, these definitions are still confined in the field of engineering design. According to the analysis in the previous chapters (Chapters 2-4), we found that the scope and content of innovation and design and their relationship have changed. Whether do these changes require a reconsideration of innovative design? If yes, it needs a new definition to reflect these changes. Within the new definition, what characteristics have the innovative design?

As for Question 2, three sub-questions arose from the understanding of innovation and design in Chapters 3 and 4: (1) what are the fundamental processes of innovative design to facilitate understanding the patterns involved in the process? (2) When and where could innovation emerge, proceed and grow during this process? (3) What are the factors affecting the success of innovative design?

Discussion of these questions is addressed in the following sections. First, in Section 5.2, a theoretical comparison between design and innovation and their relationship are discussed. Based on the comparison result, we propose the new definition of innovative design. Second, the nature of innovative design is analyzed in terms of innovative design problem and process in Section 5.3. Finally, a descriptive model of innovative design is constructed step by step to address the second research question in Section 5.4. 


\subsection{Comparing innovation and design for defining innovative design}

Design and innovation, as the core elements of innovative design, plays a determined role on defining and understanding innovative design. The previous chapters (Chapters 2 and 4) discuss fundamental dimensions of design and innovation and each dimension's characteristics. Although these reviews provide the basis to understand innovative design, the isolated issues are not enough to define innovative design. What is the relationship between design and innovation in innovative design? Is innovation the context of design, or the ultimate goal? The perspective of the relationship between design and innovation has great impact on research trend and technology of innovative design. Therefore, it needs to further consider the relationship between both, and then define innovative design.

In order to identify possible relationships between design and innovation, it firstly needs to distinguish the similarities and differences of both. Through the theoretical comparison between design and innovation, we will explore the possible relationships, and select the most appropriate one as the theoretical context of innovative design. Finally, the definition of innovative design is proposed based on these findings.

\subsubsection{The theoretical comparison between design and innovation}

As mentioned in Chapter 2, there are three fundamental dimensions (design problem, designer and design process) to characterize design. Here, we also adopt similar dimensions of innovation (innovative problem, innovative process and innovator) to compare design, as shown in Figure 5.1.

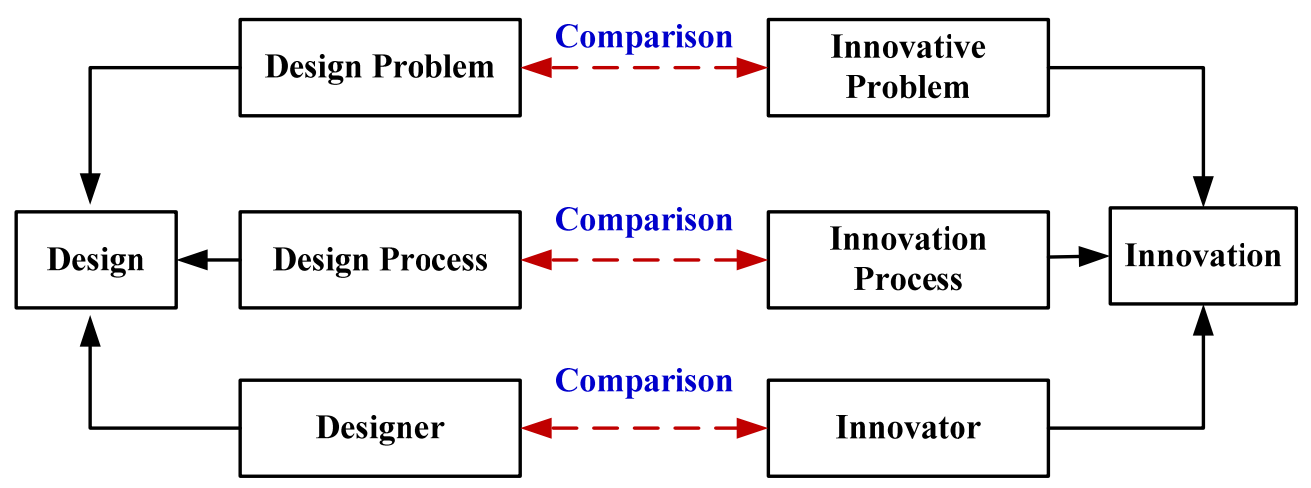

Figure 5.1 Comparison framework of innovation and design

(1) Design problem vs. innovative problem

In terms of the problem characteristic, design and innovation have similar features, such as the ill-defined problem and high uncertainty. These characteristics result in the evolution of the design problem and the design solution, and innovation also requires 
apparently an evolutionary process of innovative problems to make them gradually more concrete.

However, with regard to the motivation of the problem, some distinctions exist. As stated before, design problems originate from the gap between the user experience and the current state of the artifact. The formulation of design problems is to explain this gap by designers. But innovation can originate from other motivations, such as technology push and market pull. With the technology push, an innovator begins with a new or existing solution and then searches for possible application of that solution.

Even if the design problem and the innovative problem have the same motivation, the two types of problems are still not equivalent. According to the category of design problem in Section 2.2.3, the design problem can be divided into routine design, redesign and non-routine design. In the case of routine and redesign, the goal and the knowledge about design variables, features as well as the structure are known in advance. It means there is not much space for innovation. The non-routine design emphasizes the breakdown of the known design framework. In another aspect, innovation creates value by either improving what already exists (generally associated with the incremental innovation) or developing products, processes, or services that did not previously exist (generally associated with the radical innovation or the really new innovation). Therefore, only the non-routine design can generate a potential innovation into the downstream.

(2) Design process vs. Innovation process

According the analysis of the stages of design and innovation in Chapters 2 and 4, the design process is the transformation of information into a tangible outcome, while the innovation process is typically broader in scope than design, including technical design, manufacturing, management, and commercial activities involved in the marketing of a new (or improved) process or piece of equipment. In other words, design is an integral part of the development and the implementation of innovation (von Stamm, 2004).

It is noteworthy that the interdependency between design and innovation varies with the category of design problem, as shown in Figure 5.2. The non-routine design involves the creation of new variables and features by inventing completely new working principles. It partly overlaps with the fuzzy end stage of innovation (i.e. idea generation and assessment, and concept development). As far as the redesign and the routine design, they are treated as a downstream step in which designers develop already an idea or concept to attract consumers. Thus, their interdependencies with innovation are smaller than the non-routine design. 


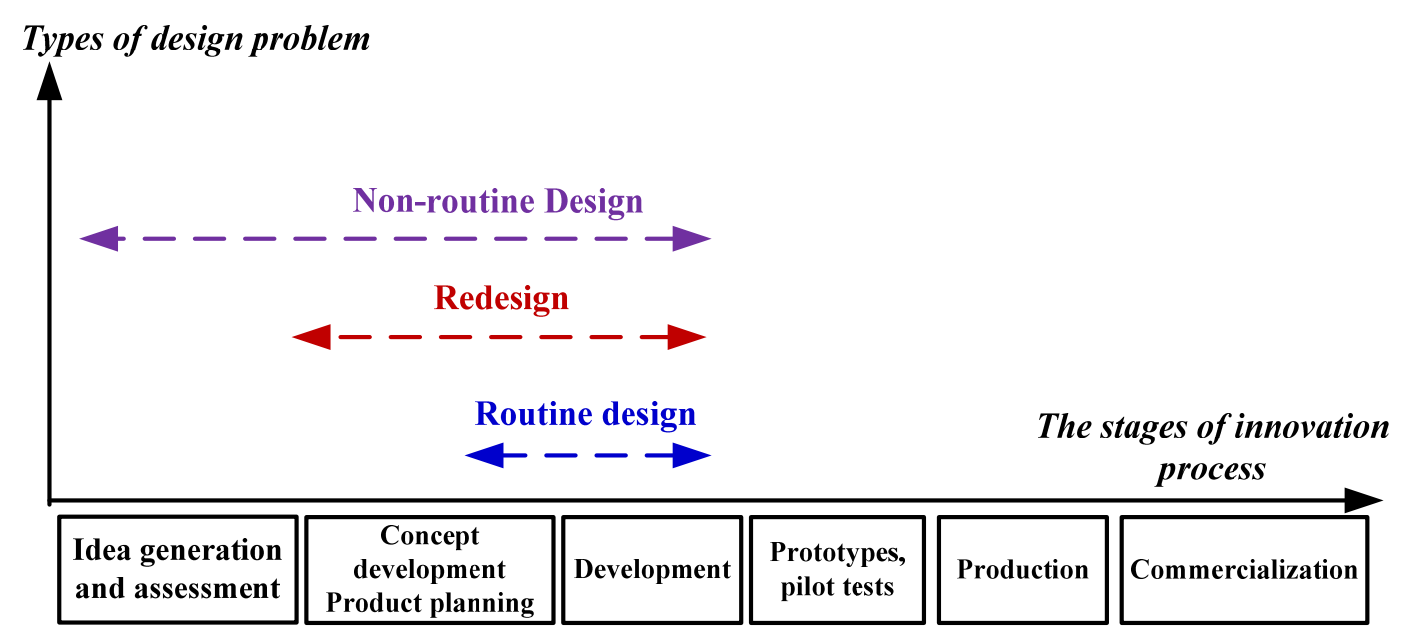

Figure $\mathbf{5 . 2}$ Interdependency between design and innovation

(3) Designer vs. Innovator

Both design and innovation require the designer and the innovator being the ability to look at things differently (Thompson and Lordan, 1999), that is to say, creativity. Figure 5.3 and Figure 5.4 list the required traits and requirements for the innovator and the designer (von Stamm, 2004).

- To challenge the status quo

- To have an understanding of and insight into consumer needs

- To develop imaginative and novel solutions

- The willingness to take risks

- Accepting high levels of ambiguity and uncertainty

- Thinking out of the box

- A passion to drive the idea through to con-clusions

- The ability to inspire passion in others

The requirments of innovation

Figure 5.3 Requirements of innovation

- Sensitive

- Flexible

- Specific interests

- Not motivated by money

- Fluent

- Divergent thinker

- Sense of destiny

- Imaginative
- Curious

- Adaptable

- Intuitive

- Open-ended

- Tolerant of ambiguity

- Original

- Independent

- Observant
- Ingenious

- Severely critical

- Perceive world differently

- Energetic

- Nonconforming

- Sees possibilities

- Sense of humor

- Confident
- Question-asker

- Self-actualizing

- Risk taker

- Can synthesize

- Self-disciplined

- Persistent

- Able to "fanaticize"

- Self-knowledgeable

The traits of creative people (designer)

Figure 5.4 Traits of creative people (designer) 
We can see that there is considerable overlap between the designers' skills and what is required of an innovator. But this great overlap does not mean that the designer is equal with the innovator. For example, as we have distinguished the different way of dealing with problems between designers and scientists that in Section 2.4, designers solve the problem by synthesis, while scientists prefer to utilize the analysis. People with adaptive skills are more likely to be dominant in an innovative company, while designers who have the innovative skills and mind are one part of the innovators (von Stamm, 2004). Thus, designers can make a valuable contribution to an innovation process, and they can be valuable members of the innovative team.

\subsubsection{The relationship between design and innovation}

Through the theoretical comparison above, we can see that design and innovation are quite similar endeavors, but there are several distinctions. How to treat these similarities and distinctions determines the relationship between design and innovation. We identify four types of the relationship, as illustrated in Figure 5.5.

(1) Type 1: In the light of goals, both design and innovation try to improve human conditions. In this sense, design and innovation are sort of synonymous.

(2) Type 2: The second type considers design and innovation to be complementary in terms of process scope. As analyzed in Section 4.3.2, the types of innovation consist of product innovation, service innovation and process innovation. The design process is often considered as the core phase or activity for the first two types. Moreover, when the design process is standardized for product innovation and service innovation, design can improve the productivity of product innovation (Garcia and Calantone, 2003). So design and innovation share an area of intersection, and at the same time they enlarge areas each other.

(3) Type 3: The most common perspective in the academy is illustrated in the type 3, in which researchers take innovation as the context of design, concerning design how to proceed in the innovative situation. Namely, it discusses the impact of innovation in the design process.

(4) Type 4: Within this type, design as the means of innovation (Le Masson et al., 2010). In this perspective, it is no longer a question of how the relevant theory of design be applied into the situation of innovation, but of the relevant theories of design can help understand and practice innovation. Design should be the process leader of the whole innovation process. 


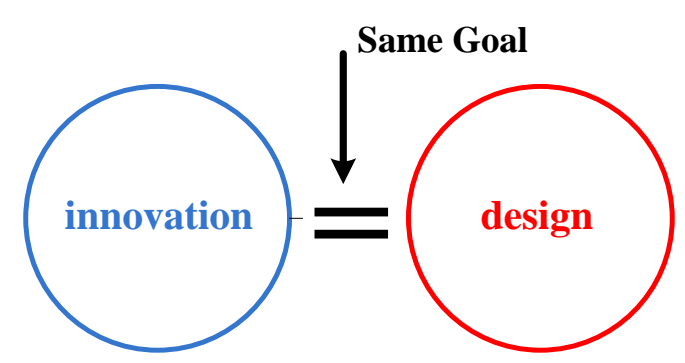

Type 1: Synonymous

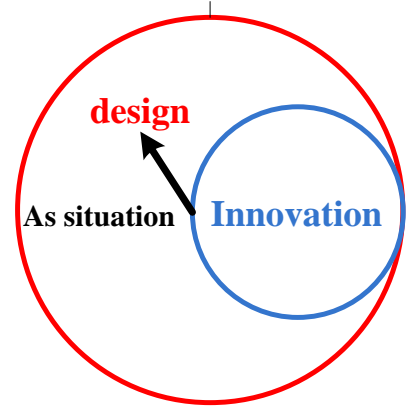

Type 3: Innovation as situation of design

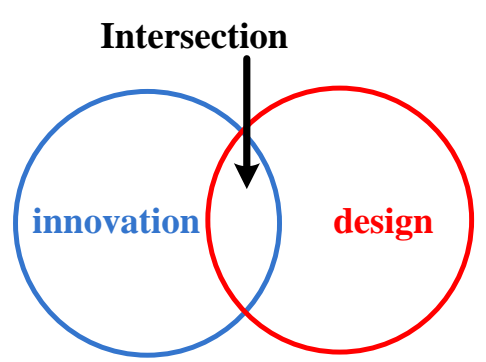

Type 2: Complementary

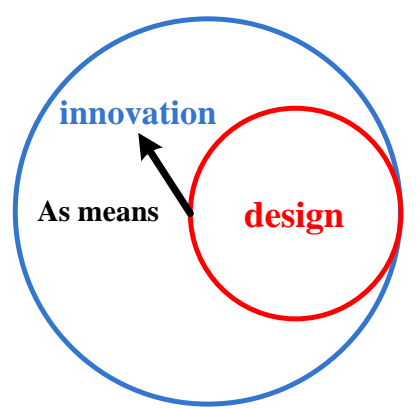

Type 4: Design as means of innovation

Figure 5.5 Four types of the relationship between design and innovation

The first three types described above, the product identities are stable and the underlying technologies are known in advance. Designers have precise and sufficient knowledge for the expected characteristics which will be used in order to design and produce it. Furthermore, targeted customers of design correspond to a well-known market.

However, we have realized that Innovation itself is not new, but its scope and content have changed (Damanpour and Daniel Wischnevsky, 2006; Le Masson et al., 2010). For numerous companies, innovation in a product or service is achieved by constant industrial improvements or updated technology. In general, these companies tap a well-defined market and keep improving the known product performance and functions. By way of example, take the cellphone market. Before 2001 designers were intent on improving battery life, the quality of sound and the screen, but they did not go beyond the basic cell structure. In other words at that time the cellphone featured a series of stable "identities". However, today's innovation reaches beyond these stable identities. However with consumers rapidly purchasing a new phone and with the introduction of one-off innovations, these identities cannot easily be seen by designers and customers alike (Le Masson et al., 2010). In this case, cellphone designers not only try to enhance basic functions, they also devise new hybrids, like laptops and phones. Also, how can radio, music and messages, even digital cameras be added to these devices? As a result product performance, the alternative architecture and functions are not defined in advance and these elements remain open issues. In other words, the starting point of innovation is no longer a stable product identity. 
To address these changes, it requires that companies find the way to organize and manage activities in order to achieve the repeated, sustainable innovation. In this perspective, innovation is not a phenomenon but an object of activities. A legitimate question that originates from the point of view is which activities should be involved? Within the type 4, design is seen as the mean of innovation. It means that designers should perform design activities to achieve the repeated and sustainable innovation. Based on the review of design and innovation in the previous chapters, there are several reasons to explain why design can be considered the mean to generate sustainable innovation.

(1) Innovation often involves a large amount of design activities and frequently focuses on characteristic and design-oriented features.

(2) Innovation requires a complex learning process in a context of uncertainty, using a variety of types of knowledge. In addition to this, innovation is the process of making an initial idea more practical and concrete to create value by a lot of participants from different disciplines. These features are common for the design process.

(3) Design originates from the gap between the user experience and the current state of the product. This gap does not require the predefinition of the product identities. In other words, it can explain the dynamic identities of the product at the starting point of design.

(4) Design itself consists of a large set of activities. Although design involves creativity that leads to iteration and feed-loops, it still has a repeated activity framework to generate sustainable innovation. Hence, when the design process has been standardized, the way of managing and organizing design activities could be taken as being the means of innovation.

The evidences above show that design activities could encourage creative behavior, and be taken as the main means to achieve the repeated, sustainable innovation. Consequently, in our opinion, the type 4-design as the means of innovation-is considered to be the starting point of the definition and the model of innovative design.

\subsubsection{Definition of innovative design}

In the literature, several researchers in design engineering have proposed definitions of innovative design (Evbuomwan et al., 1996; Gero, 1990). These authors assess the distance between the design framework and its output and it then serves as definition basis (Howard et al., 2008). In other words, these definitions are based on an ex post assessment of product innovativeness. This raises a number of issues: Who will assess this "distance"? The 
customer or a professional? What is "the good innovative design"? This underlines the fact that the existing definitions cannot fully account for the process characteristics of innovative design. Therefore, new definitions are needed to account for innovative design.

To address changes in the field of innovation and design, consider design as a means of developing innovation. Thus, how the design process is arranged and managed will impact innovation. Hence, in this sense, the definition of innovative design should convey the view of "ex post assessment" to the "process", focusing on a comprehensive process theory which can promote repeated and sustainable innovation.

Therefore, based on the "process" view, innovative design can be defined as "a kind of process from the exploration of innovative opportunities to the description of the product to be manufactured. During this process, innovative design endeavors to change the identity of products and breaks away from the existing design framework."

Within the new definition, there are several characteristics that are needed to be pointed out.

(1) The definition adopts the "process" view: innovative design is still considered being a design process, but the boundaries of design activities have been extended to the exploration of innovative opportunities.

(2) This definition is not based on static product identifies that determine the competencies and the products to be designed in advance.

(3) Innovative design concerns not the introduction of new design variables or features into the product to be designed, rather the reconstruction of the entire design framework. In terms of level of innovativeness, it is close to the so-called "creative design" identified in Section 2.3.

\subsection{The nature of innovative design}

This new definition in Section 5.2.3 emphasizes the dynamic product identity, the extension of the scope of design and the value created. The legal question that follows the definition of innovative design is "what is the nature of innovative design?" In accordance with the unifying design framework and fundamental dimensions in Chapter 2, we still analyze the nature of innovative design in terms of design problem and design process in this section.

\subsubsection{Innovative design problem}

As stated in Section 2.3, design problems vary in their form and contents, and are 
widely considered as an ill-defined problem. We identify the ambiguity, the complexity of problem structure and the situated problem in order to characterize "the ill-defined problem". Innovative design not only incorporates these characteristics, but also emerge new characteristics that further exacerbate the "ill-defined" problem. Here, we mainly discuss the emergent characteristics of innovative design.

\subsubsection{Expansive design problem}

With regard to routine design with stable product identities, it typically involves product improvement using existing technologies and design language, and targets toward existing market. Technology source and market need can be anticipated, studied and communicated within companies. In this case, innovative opportunities can be identified in organization (Reid and De Brentani, 2004).

However, as defined in Section 5.2.3, innovative design tries to change the product identities and to break the existing design framework. In Hatchuel's view, the dynamic product identities and the breakdown of the design framework are the results of "the unexpected expansion of the initial concept" (Hatchuel, 2001). When dealing with expansive or non-countable concepts, we could "expand the concept by adding unusual and innovative properties" (Hatchuel, 2001). To some extent, innovative design is an expansive process of initial concepts. Innovative design problem is expansive, but not stable.

\subsubsection{Non-definitive design problem}

Dorst and Cross observe that innovative design seems to be a matter of developing and refining the formulation of design problems and design solutions, with constant iteration of analysis, synthesis and evaluation processes between problem space and solution space (Dorst and Cross, 2001). This description of innovative design, as being the co-evolution of design problem and design solution, leads to presuppose that the "design problem" is unknown at every special point in design process.

Actually, this observation is in accordance with the expansive design problem. Within innovative design, designers always expand design concepts by adding unusual and innovative properties. So, it is difficult to identify and define design problems in an appropriate way. Moreover, designers perceive and interpret the design problem, depending on individual as well as group prerequisites and characteristics of the current situation (Dorst and Cross, 2001). Hence, what innovative properties should be added and how to add depend on designers. It results in the difficulty to clarify a definitive design problem. 


\subsubsection{Innovative design process}

According to the definition of innovative design proposed in Section 5.2.3, innovative design is a process, which proceeds from the exploration of innovative opportunities to the description of a product that is to be made. With this, innovative design is still considered as being a design process, but the boundaries of design activities have been extended to the whole product life cycle, emphasizing the exploration of innovative opportunities. In this perspective, we will analyze the stages of the innovative design process and iterations between these stages in this section.

\subsubsection{Stages of the innovative design process}

Based on the analysis above, the difference of innovative design from the common stages of design process lies in the exploration of innovative opportunities. How to expand product identity becomes the starting point of innovative design. After this stage, it still follows the common stages of design process identified in Section 2.5.

Hence, innovative design is an innovative opportunity-driven process, and includes exploration stage, task clarification, conceptual design, embodiment design and detail design, as shown in Figure 5.6.

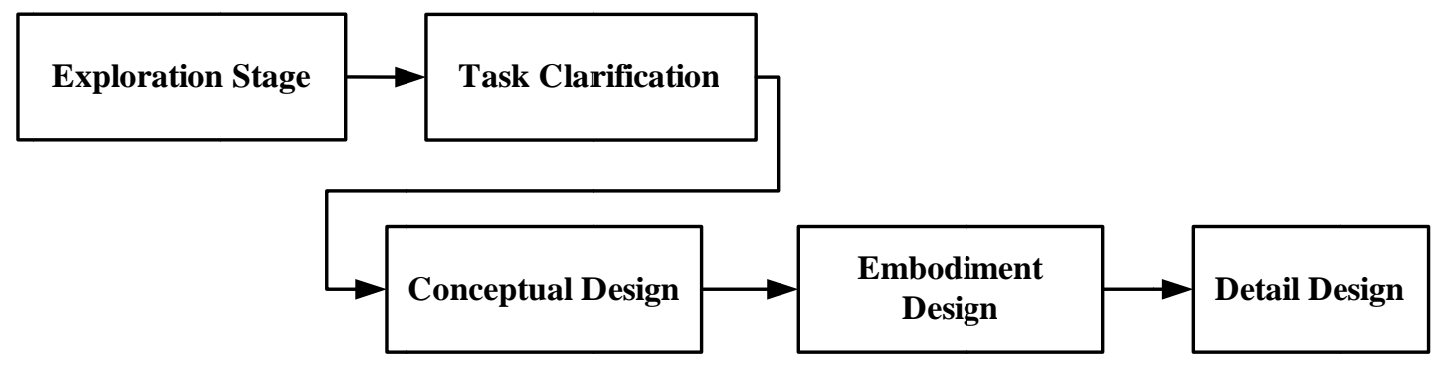

Figure 5.6 The stages of innovative design process

As discussed before, innovative design is an expansive design problem, and how to expand product identities becomes the starting point of innovative design. Hence, in this stage, designers and managers firstly should know how to expand product identities. In other words, which information can be initiated to trigger innovative opportunities within this process?

Traditionally, there are two main innovation impulses for the innovative opportunity: market demand and technology source (Burkart and Sayles, 2004; Rothwell, 1994). The market demand start by analyzing the customer needs, and subsequently looks for technologies and design languages to satisfy them. It requires a permanent search in market, especially in all areas of customer dissatisfaction. The technology source describes scientific and technological advances that push a new idea into a design process. It does not 
matter if a certain requirement already exists or not.

More recently, some authors have emphasized on the importance of industrial design for innovation. This concerns a new type of innovation, namely the 'design-driven' innovation, which begins with the comprehension of subtle and unspoken dynamics in sociocultural models and radical changes in the emotional and symbolic content of a product (Dell'Era and Verganti, 2009; Verganti, 2008, 2011). The design-driven innovation results in radical new design meaning and language (Verganti, 2011).

In brief, the market demand, the technology source and the design-driven constituted the triggers for expanding product identity. Thus, innovative design begins with the exploration of product identity (see Figure 5.7).

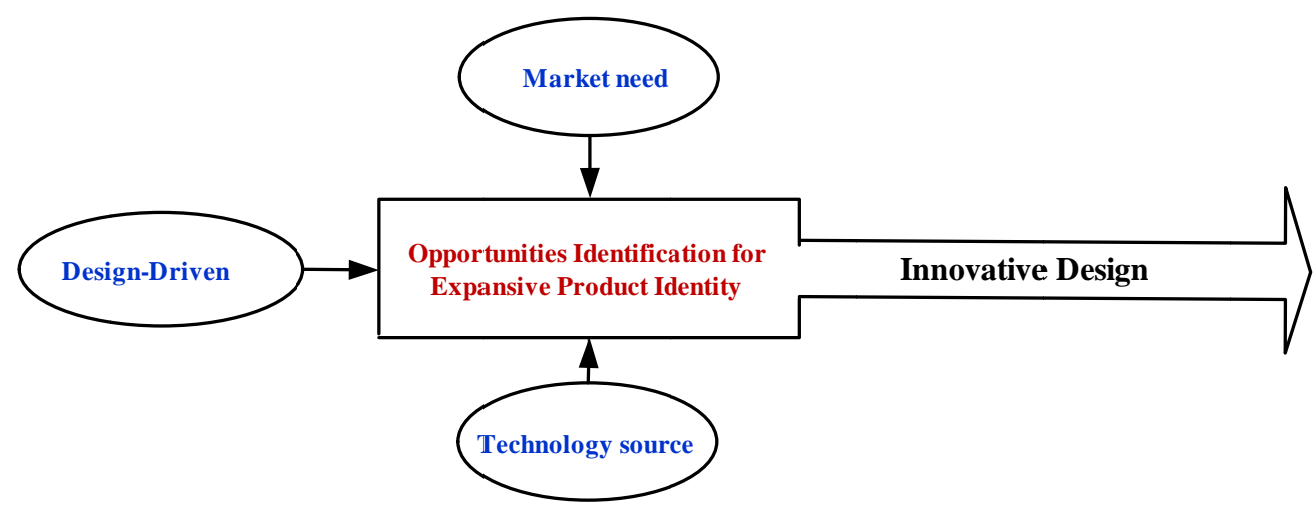

Figure 5.7 Triggers of expanding product identity

The next stage is the task clarification. The main missions of this task clarification are to collect information about the initial confrontation of the design problem, and to define it explicitly. These activities result in a "goal space" of the design process" in the form of a list of requirements.

When these are understood and validated, they are placed under project control, and thus, system concepts and system specifications are developed through conceptual design, embodiment design and detail design. In these stages, these innovative solutions are created by narrowing down the set of possibilities. Technical and economic constraints are used to guide the reducing these possibilities. Because the number of possibilities is large, there are also evaluations and decisions which are used to guide the process and select a satisfactory solution.

\subsubsection{Iteration}

Obviously, these stages distinguished above are not performed in a sequential manner as depicted, within which there exist lots of iterations and feedbacks. Iteration is the fundamental characteristic of innovative design process just as in routine design. 
Different stages have different focuses and objects. In Chapter 2, we have analyzed six types (i.e. exploration, convergence, refinement, negotiation, repetition and rework) of iterations proposed by Wynn et al. (2007). In this section, we adopt this classification to analyze iteration of every stage of the innovative design process. Table 5.1 shows the synthetic result of iterations. More details are described as follows.

Table 5.1 The Profile of iterations of innovative design

\begin{tabular}{c|c|c|c|c|c}
\hline $\begin{array}{c}\text { Iteration } \\
\text { Type }\end{array}$ & $\begin{array}{c}\text { Exploration } \\
\text { Stage }\end{array}$ & $\begin{array}{c}\text { Task } \\
\text { Clarification }\end{array}$ & $\begin{array}{c}\text { Concept } \\
\text { Design }\end{array}$ & $\begin{array}{c}\text { Embodiment } \\
\text { Design }\end{array}$ & $\begin{array}{c}\text { Detail } \\
\text { Design }\end{array}$ \\
\hline Exploration & $\bullet$ & $\bullet$ & $\bullet$ & & \\
\hline Convergence & & & & $\bullet$ & \\
\hline Refinement & & & & $\bullet$ & $\bullet$ \\
\hline Rework & & $\bullet$ & $\bullet$ & $\bullet$ & $\bullet$ \\
\hline Negotiation & $\bullet$ & & & $\bullet$ & $\bullet$ \\
\hline Repetition & & $\bullet$ & & & $\bullet$ \\
\hline
\end{tabular}

(1) Exploration plays a key role in the exploration stage, task clarification and concept design, as these stages involve a repeated process to explore alternative product identities, function and solution. Meanwhile, since some explorative works cannot be solved by individuals in the first three stages, it needs the integration of new ideas from different persons who are trained in different disciplines. Thus the negotiation process can also result in an iterative process.

(2) Following the first three stages, the whole design is divided into several work streams to respectively design components in the stage of embodiment design. During this process, it needs to converge upon a 'satisfying 'design by progressively selecting parameters to meet well-defined performance objectives, and may undergo further refinement to enhance other objectives. Additionally, because emergent new information and conflicts of design parameters, it leads to rework and negotiation. Thus, convergence, refinement, rework and negotiation dominate the stage of embodiment design.

(3) In the stage of detailed design, most design activities may adopt similar operations. The repetition thus often occurs in this stage. Moreover, the change of design and integration from outside also can result in the occurrence of rework and negotiation. 


\subsection{Descriptive model for interpreting innovative design}

In the previous sections, the definition and the analysis of innovative design shows that innovative design involves many variables whose characteristics and interactions are not well understood. Although this analysis can explain well the characteristics of innovative design, it is not sufficient to describe and interpret innovative design for designers or managers.

A design process can be considered as a complex set of integrated efforts. An inappropriate design process not only decreases operational efficiency of design but also increases possibility of failure. In recognition of the value of process models represent, understand, engineer, manage, and improve design process, having a comprehensive understanding of the process of innovative design through a process model is very useful to both individuals and organizations. Therefore, Question 2-"How can we describe the process of innovative design?" -is defined as the main research question in this section.

As analyzed in Chapter 3, traditional, linear models portray the design process as a recommended sequence of activities. It would appear, due to frequent reference and use, that the traditional, linear representations are effective for education and management. Two assumptions of these models should be mentioned (Roozenburg and Cross, 1991). First, design should advance from the general and abstract problems to the concrete and particular ones. Secondly, complex problems can be decomposed into a series of sub-problems, for which the sub-solutions are to be easily found.

However, it is evident that these traditional models do not correspond with the realities of innovative design that have been analyzed.

(1) Innovative design is a non-definitive design problem. In the sense of the problem structure, innovative design is more to an evolving process between the design problem and the corresponding design solution (Dorst and Cross, 2001). So it is difficult to clarify design problems at the beginning of design.

(2) These linear models cannot make a clear distinction between routine design and innovative design. The traditional models divide the whole process into sequential four stages: task clarification, conceptual design, embodiment design and detail design. However, the boundaries of design activities have been extended to the exploration of innovative opportunities. There is no descriptive model to clearly reflect the creative activities.

(3) These linear representations do not adequately represent either the designer or the environment. These failings result in part from the assumption that the designer is 
just a passive executor, instead of an active one. But design is a process during which the designer performs actions in order to change the environment. So designers observe and interpret what they are 'seeing', and then decide on new actions, instead of simply performing the recommended actions.

In order to address these limitations, we introduce a descriptive model of innovative design, based on the research framework in Figure 5.8.

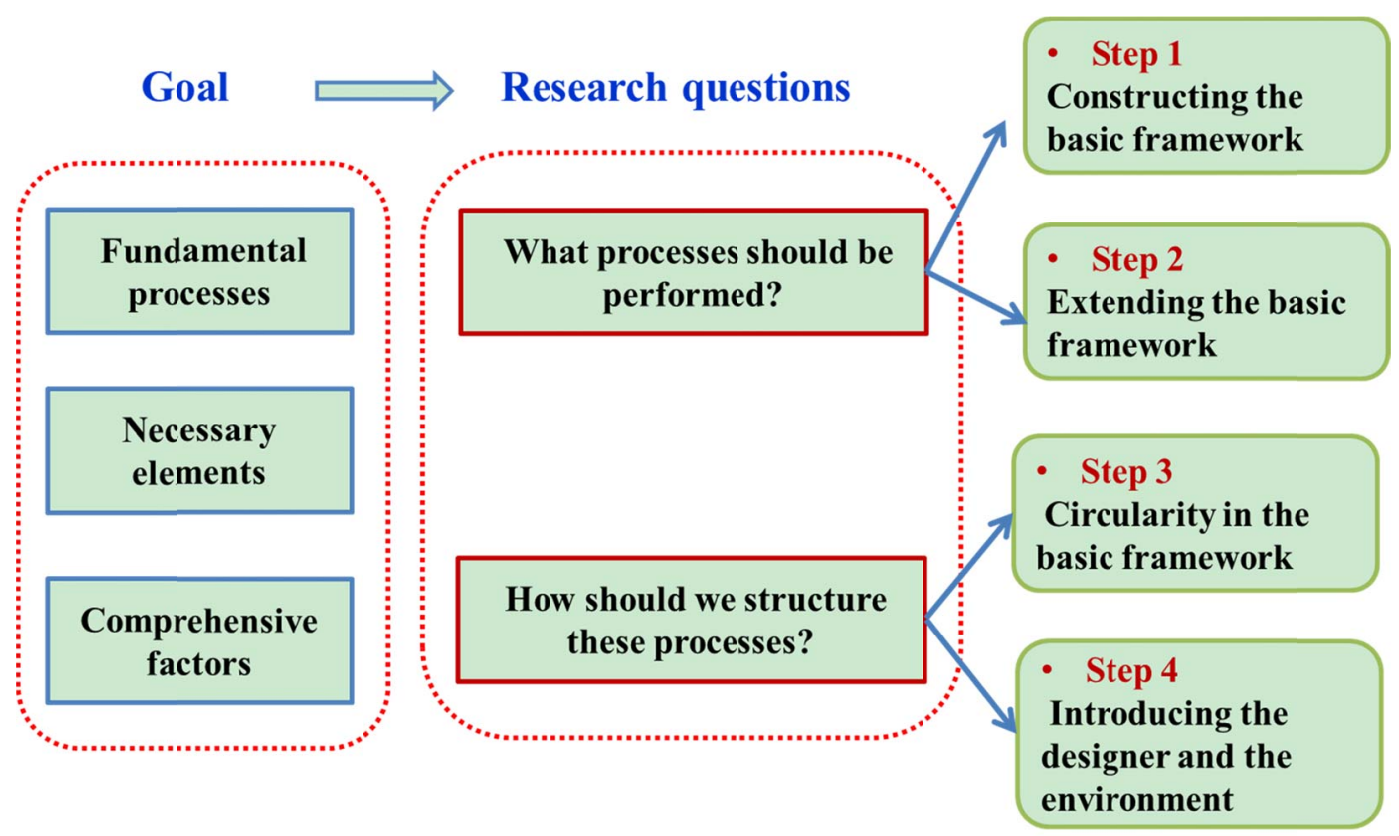

Figure 5.8 Research framework of the descriptive model of innovative design

The model will reflect the actual process and pattern of innovative design, will locate innovation opportunities in the design process and support a systematic perspective whose focus is on the external and internal factors affecting the success of innovative design. Based on the above propositions, in designing the model, we have had three goals in mind.

- The model should represent the fundamental processes of innovative design to be useful in understanding the patterns involved in the process.

- The model should involve all necessary elements in the innovative design process, so that we can know when and where the innovations could emerge, proceed and grow.

- The model should be comprehensive enough that it will be useful to the designers when discussing different factors affecting the success of innovative design.

According to the three goals, the main question of a descriptive model becomes "How should we describe the process of innovative design." This question can be divided into two sub-questions: "What processes should be performed", and "How should we structure these 
processes."

As for the first sub-question, we construct the basic framework of innovative design based on the FBS (Function-Behavior-Structure) model (Section 5.4.1). However, the basic framework is not able to take into consideration the entire innovative design process. Referring to the chained-linked model of innovation, the basic framework is extended by considering the innovation process (Section 5.4.2.1). Because the structure of innovative design is not linear, and inspired by the model of the CPS (Creative Problem Process), we solve the second sub-question by placing the basic framework into a circular form (Section 5.4.2.2). Further, we introduce the designer and the environment space into the model (Section 5.4.3). Section 5.4.4 integrates the two aspects, and finally proposes the descriptive model of innovative design. More details are discussed in the following sections.

\subsubsection{Constructing the basic framework of innovative design}

Gero (1990) proposes his FBS model of design as a theoretical base for understanding design, and as a conceptual basis for computerized tools intended for supporting the designer. According to the FBS model, design consists of eight elementary steps, which are defined in terms of the key concepts of function, behavior and structure. Five of them transform the desired functions of the artifact into the design descriptions in sequence. And the designer carries out these steps on the basis of knowledge stored in and retrieved by design prototypes.

Vermaas and Dorst (2007) identify two problems with the FBS model: the absence of a stable definition of function, and the model's double aims of describing the actual design and prescribing improved design. Because the second problem involves explaining how descriptive and prescriptive modeling could be distinguished and connected, it goes beyond the scope of this paper. So we focus on a solution to treat the first problem. Vermaas and Dorst's solution involves a redefinition of the three basic concepts (Table 5.2), and a reformulation of the eight elementary processes (Table 5.3). These proposals and analyses are considered as useful ones for understanding and developing the FBS model (Galle, 2009), particularly in (1) ensuring the stable conceptual framework over time, and (2) a clear separation between the internal concept (purpose) and the non-internal concept (function, behavior and structure).

The new FBS model modified by Vermaas and Dorst has been chosen as constructing the basic framework of innovative design, because: 
Table 5.2 Definitions of the key concepts on Vermaas and Dorst's view

\begin{tabular}{|c|c|}
\hline Purpose $(\mathrm{P})$ & The design intention \\
\hline Function(F) & $\begin{array}{l}\text { Those physical dispositions of an artefact that contribute to the purpose for which } \\
\text { the artefact is designed }\end{array}$ \\
\hline Behaviour(B) & The physical disposition of the artefact \\
\hline Structure(S) & $\begin{array}{l}\text { The materials of the artefact, the dimensions and geometry of these materials, and } \\
\text { their topological relations }\end{array}$ \\
\hline
\end{tabular}

Table 5.3 Eight elementary processes of the FBS model

\begin{tabular}{|c|c|c|c|}
\hline \multicolumn{3}{|c|}{ The eight elementary process } & \multirow{2}{*}{\begin{tabular}{|c|}
$\begin{array}{c}\text { Activities in } \\
\text { the creative } \\
\text { process }\end{array}$ \\
\\
Generation
\end{tabular}} \\
\hline Process 1: Formulation & $\mathrm{P} \rightarrow \mathrm{F}$ & $\begin{array}{l}\text { Transformation of the client's purposes into functions } \\
\text { (physical dispositions) expected to contribute to these } \\
\text { purposes }\end{array}$ & \\
\hline Process2: Synthesis & $\mathrm{F} \rightarrow \mathrm{S}$ & $\begin{array}{l}\text { Transformation of these functions (these physical } \\
\text { dispositions) into a structure of the artefact that is to } \\
\text { exhibit the functions }\end{array}$ & Generation \\
\hline Process3: Analysis & $\mathrm{S} \rightarrow \mathrm{B}$ & $\begin{array}{l}\text { Derivation of the actual behaviour (all the physical } \\
\text { dispositions) of the artefact from the description of the } \\
\text { structure }\end{array}$ & Evaluation \\
\hline Process4: Evaluation & $\mathrm{B} \leftrightarrow \mathrm{F}$ & Comparison of the actual behaviour and the functions & Evaluation \\
\hline Process5: Documentation & $\mathrm{S} \rightarrow \mathrm{D}$ & Production of the design description & $\mathrm{N} / \mathrm{A}$ \\
\hline Process6: Reformulation type1 & $\mathrm{S} \rightarrow \mathrm{S}^{\prime}$ & Choice of a new structure & Generation \\
\hline Process7: Reformulation type 2 & $\mathrm{~S} \rightarrow \mathrm{F}^{\prime}$ & Choice of new expected behaviour & Generation \\
\hline Process8: Reformulation type 3 & $\mathrm{~S} \rightarrow \mathrm{P}^{\prime}$ & Choice of new functions & Generation \\
\hline
\end{tabular}

(1) The new FBS model can be very useful in integrating the design process and the creative process (Howard et al., 2008). The creative process is an integral part of the innovative design. Three creative process elements (analysis, generation and evaluation) can be mapped onto a view of the design process (Table 5.3). Table 5.3 shows that Processes 1, 2, 6, 7, 8 correspond with the generation stage of the creative process, which results in the generation of new function, new behavior or new structure. The representation linking the creative process and design process provides us with a way, by which it is possible to judge whether the design stage properly corresponds to an innovative process. It will enable us to focus on the creative activities that the designer is actually performing.

(2) The new FBS model accords with the system view of innovative design, and it appears to be very appropriate to describe the main characteristics of innovative design. A foundational concept of the FBS model is the concept of "design state". A design state is defined as a representation of all possible states which also can be seen as a representation of all possible solutions at a certain moment in time. 
Because the design states are transferred with time, the state-transition reflects directly the evolving process between design problem and design solution in innovative design. Moreover, the transitions of these design states include a series of design activities.

(3) The degree of innovation depends on the distance from the existing design output with the variables and the goals of design, the new FBS model clearly represents these parameters. According to the definitions in Table 5.2, the 'variables' of design can be assigned to the 'behaviour', the 'structure' and the 'function', while the 'goal' of design corresponds to the 'purpose'. The greater the difference between these parameters, the higher the innovation degree.

Therefore, the new FBS model can provide us with a framework to describe the process of innovative design. Based on the definitions and the processes of Table 5.2 and Table 5.3, the basic framework for innovative design is constructed, as showed in Figure 5.9 .
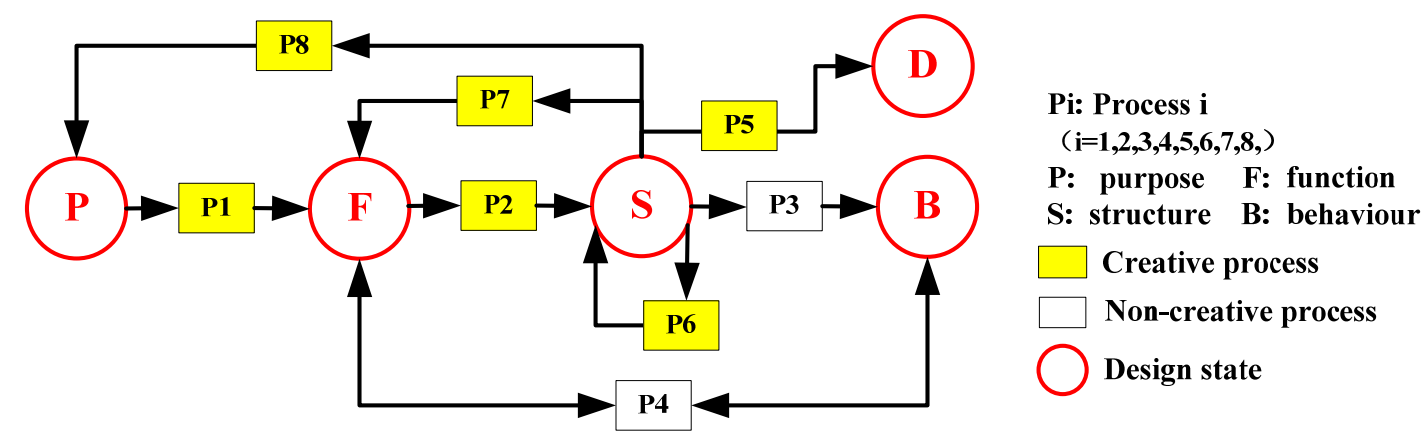

Figure 5.9 Original basic framework of innovative design based on the FBS model

Although the new FBS model provides us with a framework, it lacks relevant elements necessary to completely describe the entire process system. The reflection is an important concept for design and innovation, by which the designer can interact with the internal and external environments and when appropriate propose new or even innovative solutions. The sources of information for innovation include internal factors, external/commercial factors, education/research establishments, generally available information and other external factors. However, in its current state, the new FBS model can simply focus on the internal innovation of design process, but cannot consider other possible innovation opportunities associated with the external. The next two sections introduce the relevant elements (namely innovation, the designer and the environment space) which are not taken into account in the FBS model, but these elements are essential and necessary. After defining these elements, we consider how to incorporate them into the descriptive model we propose. 


\subsubsection{Modifying the basic framework by considering the innovation process}

As we have discussed in Section 5.2.3, an innovative design should break away from existing forms. These characteristics are relevant with innovation process. Therefore, the importance of an understanding of how to combine innovation process with design shapes the ways in which we model innovative design.

The innovation process concerns why and how innovation emerges, proceeds and grows. There is not a widely agreed upon model of a company-level process of innovation that incorporates all the requirement of different disciplines. In practice, innovation is a coupling and matching process, and involves many iterations and much feedback. Numerous recent works recognize these characteristics, and propose more complex, variegated and interactive models. In the section, we will modify the basic framework to adapt to these characteristics.

\subsubsection{Extending the basic framework by introducing the requirement}

One alternative to the linear model, called the "chained-linked model", is proposed by Kline and Rosenberg (1986). They describe how feedback and loops allow the potential innovator to seek existing inter-firm and intra-firm knowledge in the innovation process. Figure 5.10 is a redrawn version of the chained-linked model. The chained-linked model presents a great advance in explaining the necessary interaction for successful innovation. According to the model, a key element in determining the success of innovation is the extent to which a firm manages to maintain effective links between these phases of innovative process.

As for innovative design, these effective links and feedback loops provide the probable sources of innovation. These could include, for example, the feedback from the market, technical advances, and the accumulated knowledge. Recall that the basic framework of innovative design that was shown in Figure 5.9. The original framework, due to the lack of a comprehensive representation of the sources of innovation, is restricted to the internal process of innovative design. According to the descriptions of these elementary processes, these creative processes (Processes 1, 2, 6, 7 and 8) result in the innovative outputs, namely new functions (by Processes 1 and 7), new purposes (by Process 8) and new structures (by Processes 2 and 6). In terms of an innovation process, these creative processes that produce the innovative outputs are not comprehensive. In light of the chained-linked model, the new purposes do not only result from the process $\mathrm{S} \rightarrow \mathrm{P}$ (Process 8), but also from technical push and market pull. Technical push describes the scientific and technological advances that push a new idea into the design process, while market pull places more emphasis on market needs. 


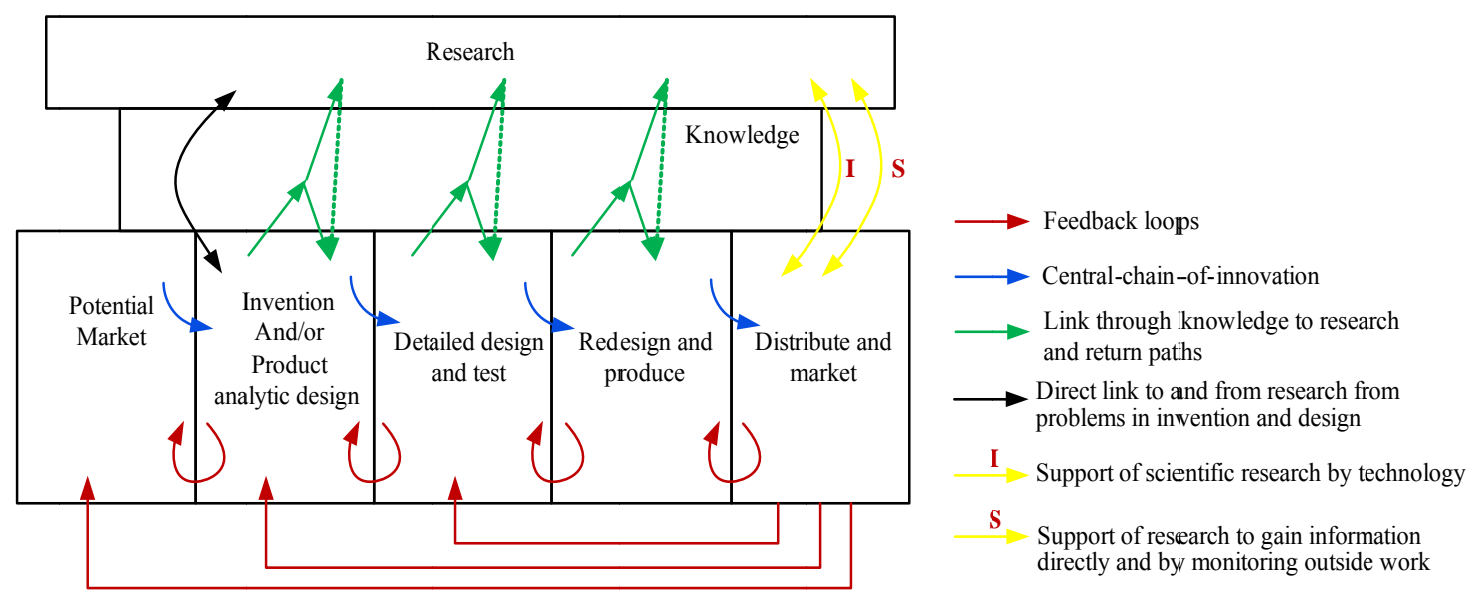

Figure 5.10 Chained-linked model

To better and comprehensively exploit this process, we add requirements $(\mathrm{R})$ into the original framework of innovative design. First, the designer analyzes the stakeholder requirements $(\mathrm{R})$, which come from the technical advance and the market needs, leading to the interpreted purposes $(\mathrm{P})$. Then the purposes $(\mathrm{P})$ are augmented by the designer's own experience or the firm's accumulated knowledge. Therefore, the new basic framework of innovative design is shown in Figure 5.11. An initial design state space is built up by the requirements $(\mathrm{R})$. Because the transformation from $\mathrm{R}$ to $\mathrm{P}$ (Process 0 ) brings on a new purpose, the process 0 is also the generation stage of the creative process.

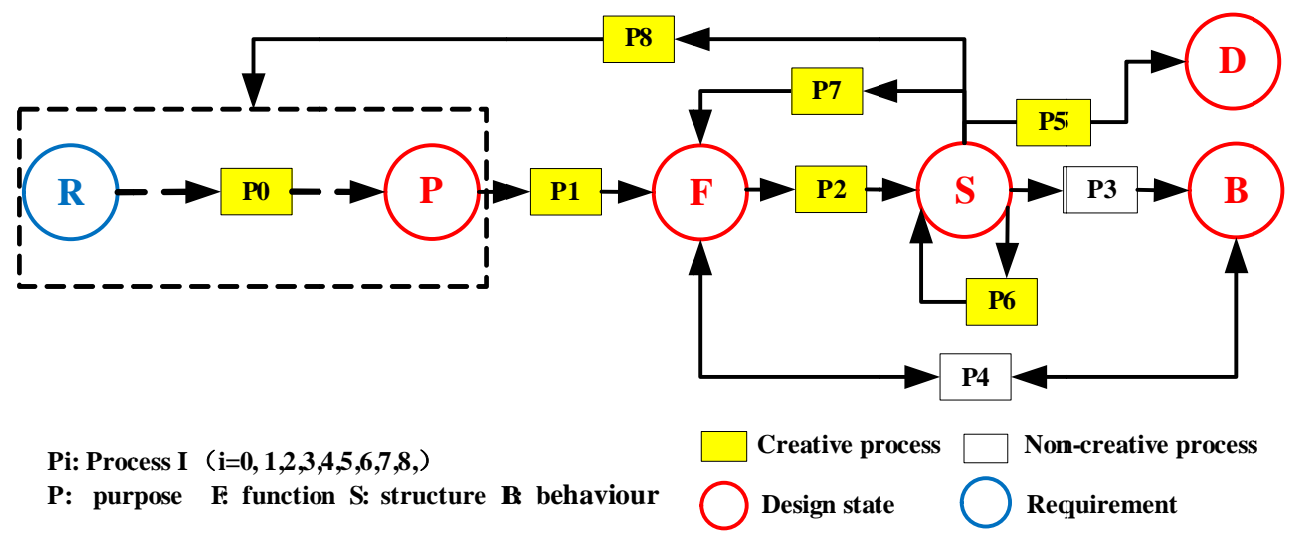

Figure 5.11 New basic framework of innovative design

\subsubsection{Circularity in the basic framework}

In fact, the new version is still a logical development of the innovative design shown in Figure 5.11. A design process proceeds through the Processes 0-8. However, most practitioners do not follow these separate steps in their daily practice, and very few of them can draw straightforward steps in any given process. Some researchers consider the process as an example of CPS (Creative Problem Process), in which the entire process can be 
considered a spiral type. In the CPS domain, it places these processes on a circle and connects these processes with each other. Moreover, it indicates that all these processes are necessary, but the sequence can be varied. Based on these views and the experiences of consultants, Buijs (2003) proposes the circular version of the innovation model, as shown in Figure 5.12. All four stages of innovation (product launch and use, product development, strategy formulation and design brief formulation) are executed in the circular style. Leadership, culture, emotion, motivation, risk-taking and passion are the elements of the term "heart". Thus, we rely on the "heart," the competitive environment and the thinking way the innovation team, as a way to start with out of the four stages.

Inspired by these analyses of Buijs, we conclude that the new version of the framework (Figure 5.11) similarly should be adapted as a circular style. Here, we see two reasons for the circular configuration in which we visualize our basic framework.

Firstly, there is not any iteration in the basic framework. Referring to the theories of innovation and the chained-linked model, we have already recognized innovation process is neither smooth nor linear, nor often well-behaved. Iterations and feedbacks are inevitable elements in the process.

Secondly, due to the complexity and the uncertainty of innovative design, it is impossible to finish the tasks we requested of each individual. So innovative design is by necessity compulsory teamwork, and different team members can perform these elementary processes at the same time. In other words, these processes are carried out in a parallel fashion.

Therefore, our conception of a circular model with three layers provides an initial setting, into which we put these elementary processes of the basic framework. Figure 5.13 shows the circular process model. It consists of three layers:

(1) Mapped onto in the middle layer are the nine elementary processes (described by Table 5.3), with the iterations between these processes shown as dotted lines. The yellow parts denote that these processes are creative processes as in Figure 5.11, while the blue ones are not. The solid black lines represent the transformation and comparison between these design states (described by Table 5.2).

(2) In the central layer, we transform the term 'heart' into 'designer', which drives these elementary processes.

(3) The outer layer focuses on the external environment that contains the influencing factors. Through the change of the form, the iterations and the parallel fashion can be well integrated. In the next section, the details regarding the center and outer layers will be discussed. 


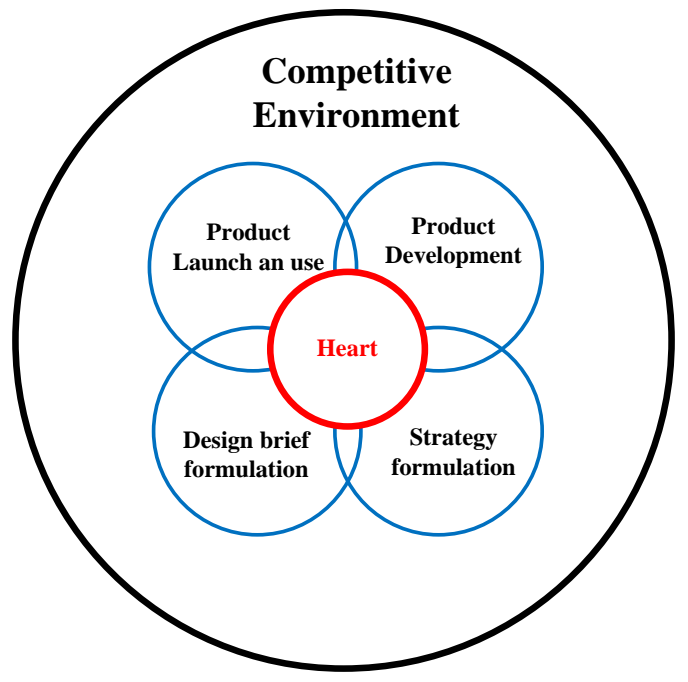

Figure 5.12 Circular model of innovation

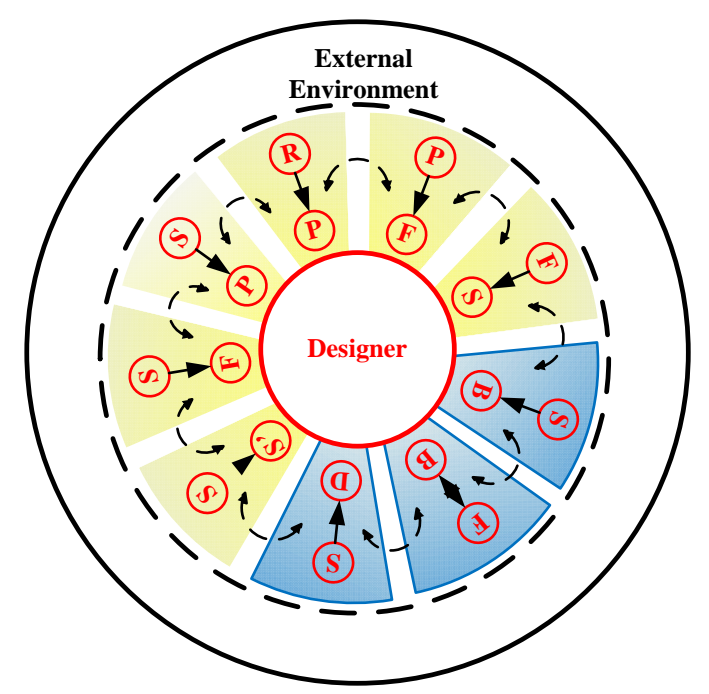

Figure 5.13 Initial circular model of innovative design

\subsubsection{Modifying the basic framework by introducing the designer and the environment space}

We have configured the basic framework with a circular structure having three layers which shows the process of innovative design. However, there still are some questions: How does the designer drive these elementary processes? What is the external environment? How do the three layers interact with each other? In this section we propose answers to these questions.

Design is a "reflective conversation with the materials of a design situation" (Schön, Donald A., 1995). Through the perception of the design situation and the recollection of experiences, the designer decides on further actions (when to do what). That is to say, the designer should actively respond to their actions rather than simply perform the recommended actions. This means that the interaction between the designer and the external environment determines the design process. Furthermore, the considerations taken into account by the designer have already proven to be useful for improving innovation and design process. For example, it is useful to know which design activities are not able to have a positive effect in achieving the desired goal and which can improve the efficiency of design activities. Similarly, the designer plays a vital role in the development of innovation. Designers apply their skills, perspectives and domain knowledge to the innovation process based on their background and experience. Consequently, designers are generally recognized as an engine that drives the process, and a medium of interaction between different layers.

The environment space is of significance in that it both influences and changes innovative design at particular moments. We define the environment space as a set of the 
external factors outside the designer. There are four reasons for introducing the environment space into innovative design.

(1) Innovative design should provide a means to partition the concepts and the knowledge in order to be more innovative (Hatchuel and Weil, 2009). It is impossible to acquire or generate new knowledge or concepts without the support of the environment.

(2) The innovativeness of innovative design depends on the stakeholders involved. The stakeholders evaluate the value and the novelty of an innovative solution by communicating with designers. According to the definition of the "environment space", the stakeholders also should belong to one part of the environment.

(3) The process of innovative design is treated as a system, which evolves by interacting with its environment. These environmental factors, such as organization architecture, organization culture and organization strategy, influence the process of innovative design.

(4) The designer is situated in the environment. The designer perceives and interprets design problems differently as environments change.

Then, a legitimate question that follows from this is how we consider the designer and the environment space together in the circular model. The point can be summarized by the term of reflection-in-action, which views that the entire design process as it proceeds from the designer's perceptions. As we have discussed before, the term reflection-in-action is relevant to the notion of situatedness. Gero and Kannengiesser (2004) describe situatedness as the interaction of the external world, the expected world and the interpreted world (see Figure 5.14). The external world, namely the environment space, is composed is represented as outside of the designer, while the interpreted word and the expected world are built up on the inside of the designer world. The interpreted world refers to sensory experiences, precepts and concepts of the designer. In the expected world, the actions that the designer will perform are imagined. These three worlds are dynamically coupled with each other through three types of processes: interpretation, focusing and action. 


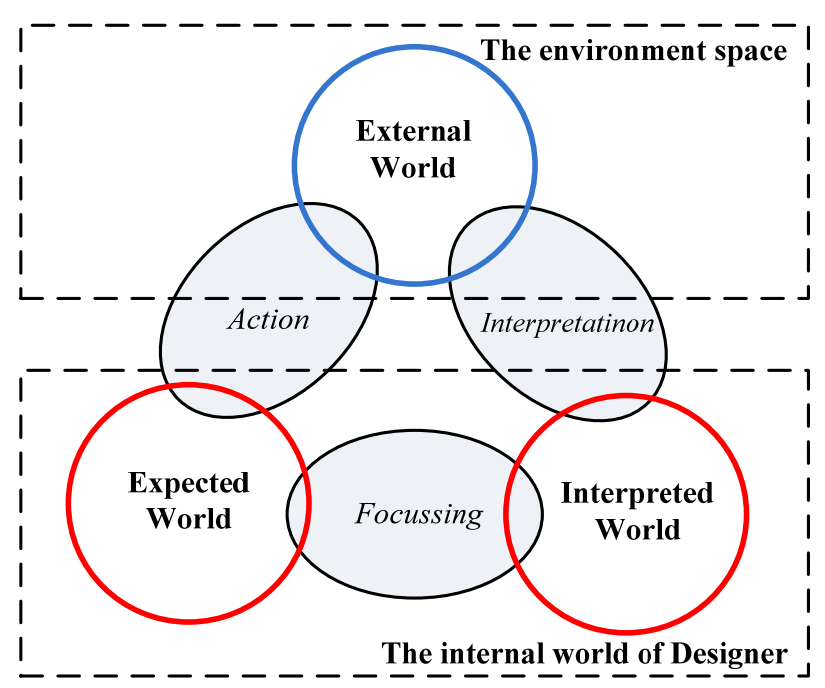

Figure 5.14 Situatedness as the interaction of three worlds

Although Gero and Kannengiesser reconstruct these elementary processes of the FBS model based on the new framework, the external world is not clearly demarcated. That is to say, which elements does the external world include? According to the definition of the external world, the representations of these elements should be able to describe an external influence on the designer's interpretation, and moreover, these are objective and independent of the designer. Furthermore, because the external world is dynamic with time, it should be seen as a time dependent variable. Reymen et al. (2006) develop a concept called design situation to model design which defines the state of the combined concepts at a certain point in time.

Here, we adopt the basic framework of the concept "design situation" to describe the external world, including the state of the design context, the state of the stakeholders, the design state and the state of the design process, as showed in Figure 5.15. The definitions of relevant concepts are listed in Table 5.4.

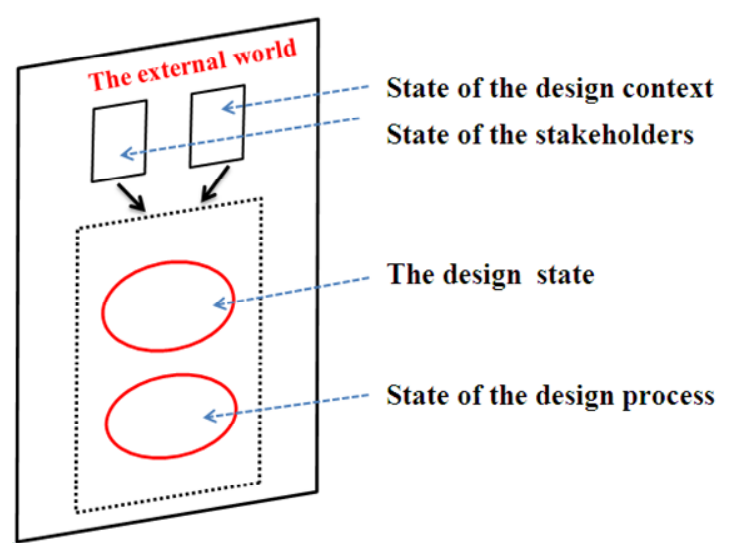

Figure 5.15 External world of the designer 
Table 5.4 Relevant definitions and reasons of the external world

\begin{tabular}{|c|c|c|}
\hline Concept & Definition & Why should it consider these concepts? \\
\hline $\begin{array}{l}\text { Design } \\
\text { context }\end{array}$ & $\begin{array}{l}\text { It is described by the sets of } \\
\text { factors influencing the design state } \\
\text { and the design process at a certain } \\
\text { time. }\end{array}$ & $\begin{array}{l}\text { An innovation process is an adaptive system } \\
\text { which evolves by reacting to its context. } \\
\text { Contextual factors are one of the determinants of } \\
\text { innovation. }\end{array}$ \\
\hline Stakeholder & $\begin{array}{l}\text { A party that has an interest in } \\
\text { innovative design. }\end{array}$ & $\begin{array}{l}\text { The stakeholders play a key role to evaluate } \\
\text { the value and novelty of an innovative solution } \\
\text { by communication with the designer. }\end{array}$ \\
\hline $\begin{array}{l}\text { Design } \\
\text { state }\end{array}$ & $\begin{array}{l}\text { It refers to the key concepts } \\
\text { of the FBS model, including } \\
\text { Purpose Function, Behaviour and } \\
\text { Structure }\end{array}$ & $\begin{array}{l}\text { The four state variables are the temporal } \\
\text { solutions of design. On the basis of the } \\
\text { perceptions of these state variables, the designer } \\
\text { makes expected actions. Therefore, according to } \\
\text { the definition of the external world, design states } \\
\text { are one of parts of the environment. }\end{array}$ \\
\hline $\begin{array}{l}\text { Design } \\
\text { process }\end{array}$ & $\begin{array}{l}\text { It is defined as a series of } \\
\text { design activities that have been } \\
\text { performed by the designer before } \\
\text { the current design state. }\end{array}$ & $\begin{array}{l}\text { The designer learns which activity were not } \\
\text { successful from the accomplished design } \\
\text { activities, and grounds them on previous } \\
\text { knowledge. It can be seen as the external } \\
\text { information of the designer. }\end{array}$ \\
\hline
\end{tabular}

Having described situatedness and the concrete elements of the external world, we are now able to develop a more detailed framework of innovative design. In Figure 5.16, we show the three worlds of described situatedness, similar to Figure 5.15. Comparing with the initial circular model (Figure 5.10), the central layer "designer" is decomposed into the interpreted world and the expected world, and the middle layer and the outer layers consist of the external world. Through the pertinent definitions of Table 5.4, the design state and the state of the design process are located in the inner part of the external world, while the state of the design context and the state of the stakeholders are put into the outer part. In Figure 5.16, we represent more explicitly the process of innovative design as a dynamic environment, and also clearly depict the influencing elements.

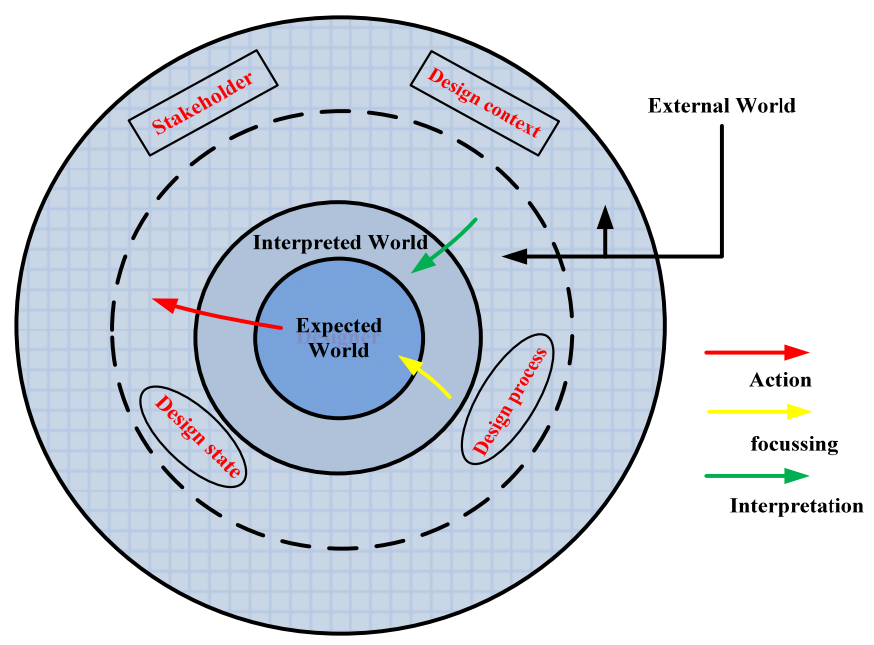

Figure 5.16 Situated model of innovative design 


\subsubsection{Integrated descriptive model of innovative design}

In the section we will attempt to map these elementary processes of the basic framework onto the situated model of innovative design. That is to say, it combines the Figure 5.13 and Figure 5.16 into an integrated descriptive model, as shown in Figure 5.17.

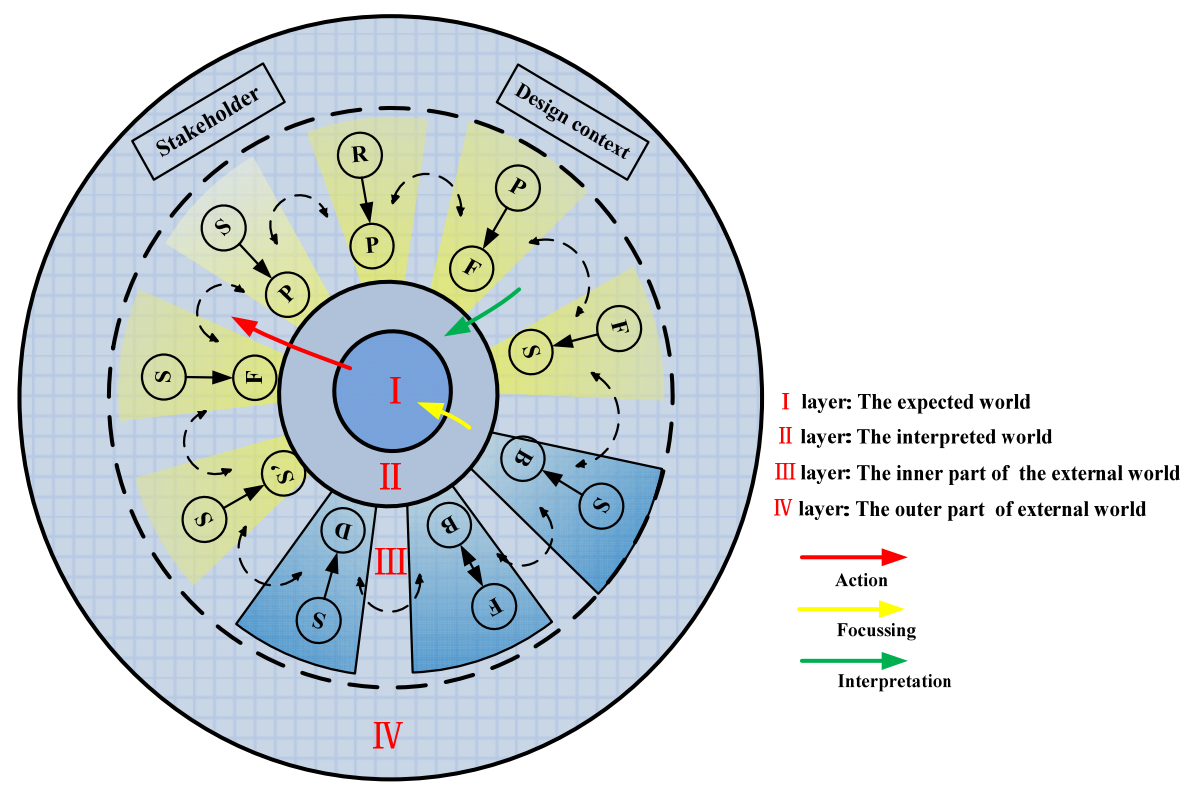

Figure 5.17 Descriptive model of innovative design

As can be seen in Figure 5.17 , the III layer shows the enhanced version of Vermaas and Dorst's model based on the FBS model. The solid lines completely represent the different elementary processes (transformations and comparisons between these design states that are described in Table 5.2) and which can be found listed in Table 5.3. The Vermaas and Dorst' model focuses on the internals of the design process, but does not treat the innovative process, e.g. the process from requirement to purpose.

Another change of the basic framework can be viewed as the adoption of the viewpoint of circularity in the basic framework. Because the complexity and uncertainty of innovative design, these elementary processes are impossible to be performed in sequence rather than in parallel fashion. Moreover, the feed forward loops and feedback loops incorporate the source of innovation. The circularity of these processes has been included in the structure in order to reflect these characteristics of innovation process.

Additionally, the integrated model consists of four layers, in which the I and II layers respectively correspond to the expected world and the interpreted world of the designer, and the III and IV layers represent the external world of the designer. This is a consequence of introducing the designer and the environment space in order to deal with the designer's interaction process with the external world and within oneself. In practice, 
the designer takes command of what he is 'seeing' and 'doing' in the design process, and communicates this information to the stakeholders, then makes actions in the current design context. The basic framework in Figure 5.11 is not able to reflect these interactive activities.

\subsection{Conclusion}

The objective of this chapter is to address the two main research issues: the "definition and analysis" and the "process description" of innovative design. Through the discussion of the two issues, we attempt to build up a comprehensive understanding of innovative design, and provide the basis for management support of innovative design. These objectives are realized by two aspects. To summarized:

The first aspect is to answer the question "what is innovative design?" Before defining innovative design, it necessarily requires a better understanding of innovation and design. In previous chapters, we have respectively discussed the fundamental dimensions of design and innovation. But the isolated discussion does not provide the direct answer to the question above.

Hence, we firstly perform a theoretical comparison between design and innovation in terms of design problem vs. innovative problem, designer vs. innovator and design process and innovation process. We found that both are quite similar endeavors, but there are several distinctions. Based on these findings, we then identify four types of the relationships between design and innovation. Considering the changes in the field of innovation and design and the purpose of this thesis, we argue that the type "design as the means of innovation" can reflect these changes and satisfy our purposes. With this, we contribute a new definition of innovative design. Within the new definition and the understanding of innovative design, this chapter contributes a comprehensive analysis of the nature of innovative design in terms of design problem and design process.

The second aspect focuses on the question "how should we describe the process of innovative design?" Based on the analysis of the nature of innovative design, we propose a descriptive model of innovative design. The model reflects the interaction process between the designer, the design process and the outside environment.

Whilst acknowledging that the process of innovative design observed in practice is more chaotic than the current representation suggests, understanding the relationships of the three parts can improve the process of innovative design. The advantage are summarized as follows: The model helps designers to better find the success factors of innovative design, to integrate different aspect of an innovative design situation, to evaluate communication with the external environment. In addition, insight into the III layer of the model can 
reveal which processes may generate creative output. Firms can focus on these processes in order to enhance creative performance and the quality of the product designed. 


\section{MANAGEMENT SUPPORT FOR INNOVATIVE DESIGN}

\subsection{Overview}

This chapter begins to perform the prescriptive study in Figure 1.4, and addresses the main research issue "management support" outlined in Section 1.2.2. In this thesis, management support is concerned with the balance between control and innovation. In the previous chapter, the discussion of research issues - "process description" and "definition and analysis"- develops a deeper understanding of innovative design. However, it cannot provide enough suggestions about how to achieve the purpose of management support.

As discussed in Chapter 5, innovative design requires the radical expansion or change of the identity of products, and tries to break away from the existing design framework (Le Masson et al., 2010). During this process, creative ideas are applied or implemented to arrive at a product, process or service for a customer and market (Zhang et al., 2011). These characteristics result in high technological and market uncertainty. In turn, the resulting design capabilities and the exact means needed to achieve the expected goal become uncertain. Moreover, during this process, greater challenges arise from the unforeseen uncertainty due to the changing or emerging information about technology or market. In this case, the design team is either unaware of the possible unforeseen uncertainty or deems it unlikely (De Meyer et al., 2002). And if it is unable to deal with this unforeseen uncertainty, it is likely to devise a product that will not meet customer requirements.

To handle these uncertainties, design process models have traditionally been control-oriented, emphasizing hierarchical structures and the division of work and responsibilities (Smith and Morrow, 1999; Nightingale, 2000; Ahmadi et al., 2001; Gil and Tether, 2011; Lenfle and Loch, 2010). Given its frequent reference and use, it seems that this control contributes to adequate on time delivery, cost-effectiveness and technological performance. However, its drawback lies in that it prevents identification and exploration of innovative opportunities in a rapidly changing environment, within which the market and technologies may dramatically shift (Sethi and Iqbal, 2008; Koen et al., 2001; Salomo et al., 2007). Thus, many authors have identified project practices (e.g. delaying the concept freeze point, parallel trials and iterative experiments, early experiments involving customer) that enhance flexibility (Krishnan et al., 1997; Thomke, 1997; Bhattacharya et al., 1998; MacCormack et al., 2001; Buganza et al., 2009). With these practices a design team can 
respond to the dramatic shift in technology and market by keeping the product concept open till the end of the design phase without suffering heavy penalties.

Thus, the question "the balance between control and innovation" can be transformed into "how to balance control and flexibility" in practical operation. As they represent different domains on the mechanistic/organic spectrum, and seemingly conflict with each other (Tatikonda and Rosenthal, 2000), striking an optimal balance between them becomes paramount for innovative design. From a managerial perspective, adopting control and flexibility are contingent upon the rapidly changing environment in which innovative design operates. As discussed before, innovative design not only involves market or technological uncertainty, but also unforeseen uncertainty. As a result, companies should engineer an adequate balance between control practices and flexible practices to manage uncertainty inherent in each specific innovative design.

To address these issues, this chapter aims to:

- To define the sources and types of uncertainty that innovative design entails, and identify project practices needed to cope with uncertainties in terms of control and flexibility

- To investigate how to achieve the right balance between control and flexibility under different uncertainties by means of a case-study of five completed innovative design projects from an automaker..

Discussion proceeds in four sections. We define the sources and the types of uncertainty of innovative design in Section 6.2, and then analyze the existing literature contribution about control and flexibility in Sections 6.3.1 and 6.3.2. Following the theoretical section, the research design is conducted in terms of research questions, research methodology and empirical findings in Section 6.4. Managerial implications are also analyzed and discussed in Section 6.5.

\subsection{Management challenges: Uncertainty}

Uncertainty is inevitable in most projects. Even experienced managers find it difficult to deal with it. Innovative design often encounters two situations: (i) a company has no prior experience in the design of this product or service; (ii) customers have little experience of this product, thus making it difficult for the designer to accurately define requirements in advance. These situations correspond to two sources of uncertainty, namely, technological uncertainty and market uncertainty. The former is defined as the degree of uncertainty in respect of the design solution that will be needed in a project (MacCormack and Verganti, 2003). The latter refers to the level of uncertainty that exists in the external 
environment, with regard to determining the requirements that customers have of the resulting product (MacCormack and Verganti, 2003).

Furthermore, in terms of type of uncertainty, innovative design faces not only foreseen uncertainties identified and understood at the beginning of this process, but also unforeseen ones that cannot be identified during project planning in a rapidly changing environment (Eisenhardt and Tabrizi, 1995; Calantone et al., 2003; Buganza et al., 2009). As to foreseen uncertainty, the design team can anticipate possible risks, such as technological events (e.g test failure), supply chain events (e.g. a supplier not delivering on time), customer events (e.g. change in customer needs). However, in the case of unforeseen uncertainty, the design team is unable to figure out and articulate relevant events that could impact innovative design and their functional relationships (Sommer et al., 2009).

Therefore, innovative design suffers different sources and types of uncertainty. Figure 6.1 depicts a simple view of the issue. On the $\mathrm{X}$-axis is market uncertainty evolving towards unforeseen uncertainty to the right. Here, the existing market breaks down and new ones emerge only slowly. The Y- axis depicts technological uncertainty. Similarly, we move from foreseen technological uncertainty (the design team expects a technological gap and knows how to bridge it) to unforeseen uncertainty (where the design team is unaware of technological gaps and has to conduct experiments in a much more extensive manner).

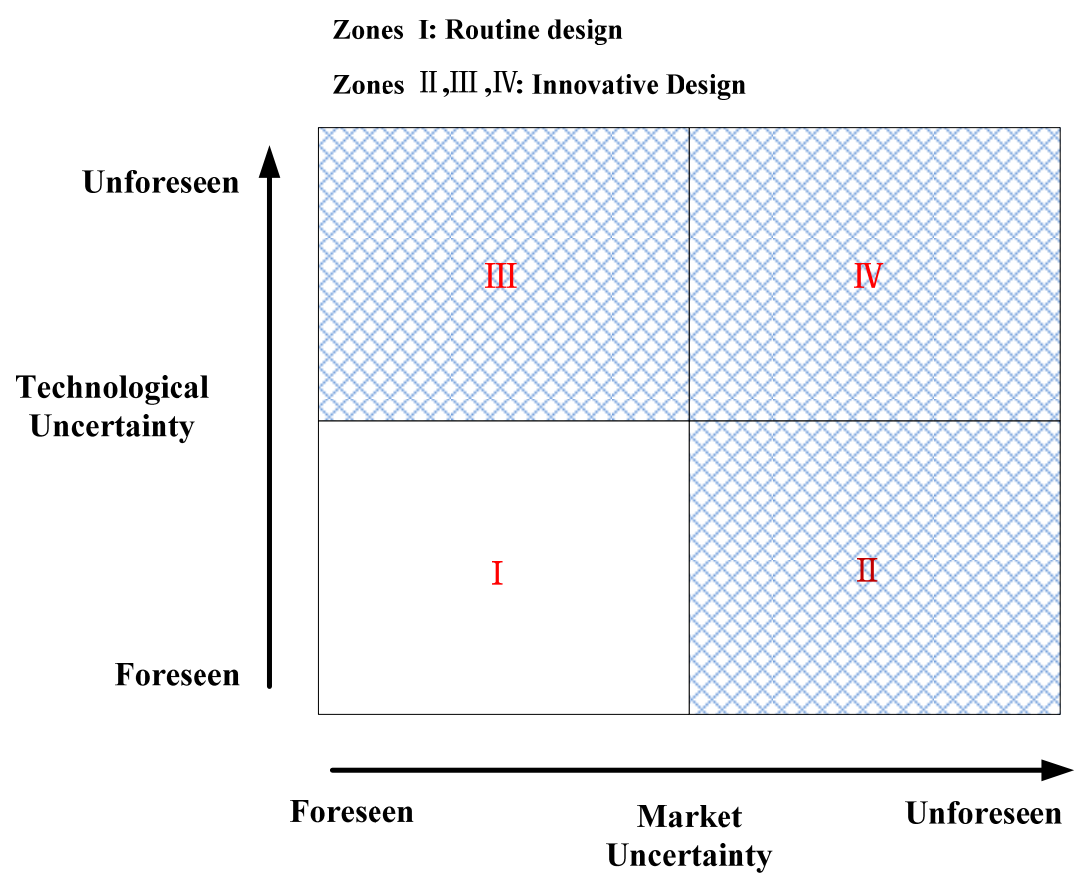

Figure 6.1 Relationship between different uncertainties and designs 
If we map various designs depicted in Figure 6.1, it appears that Zone I corresponds to routine design (e.g. variant design, adaptive design) with a stable product identity. Innovative design tries to break away from the existing design framework, thereby dramatically expanding or changing the product identity. With these characteristics innovative design suffers unforeseen uncertainty. Thus, Zones II, III and IV stand for different environments of innovative design with unforeseen marker uncertainty, technological uncertainty, and both, respectively.

Typically, Zone I features product improvement using existing technologies, design language and targets relative to the existing market. Technology sources and market needs can be anticipated, studied and communicated about in-house. In a nutshell, mature markets lead to incremental product and process improvement. In this case, innovative opportunities can be identified within the organization (Reid and De Brentani, 2004).

Zone II features highly unstable customer requirements, but the company is fully aware of this and knows how to deal with it. For example, world fashion markets can suddenly change and cause customer requirements to become highly unstable (Bessant et al., 2005). But the fashion industry has enough resources to set up the flexible innovation management needed to cope with such instabilities.

Zone III is stable in terms of market but lacks relevant knowledge or technologies during the design phase. In a well-developed market, a company has to conduct research to bridge the gap about the relevant technologies. For example, in the photo industry, the advent of digital images ushered in a camera revolution. However, since the conditions of research on digital images go beyond most companies' normal experience, it is difficult to foresee the significant technology shifts. These cutting edge shifts could bring about unforeseen uncertainty, and a new condition fostering innovation opportunities.

In Zone $\mathrm{IV}$, not only is there a shift in customer requirements but it occurs without the company having either the knowledge or technologies to satisfy customer requirements. The smartphone is a good example of this. On the one hand, when it was first introduced to the retail market, customers had little knowledge about it. On the other hand, in terms of technology, the computational power of this device is similar to the performance of laptops, but with a much smaller footprint and power compared to that of a personal computer, the basic knowledge needed to develop a competitive smartphone is modified.

When addressing these different sources and types of uncertainty, adequate structures are needed to manage design activities. With respect to foreseen uncertainty, several alternative plans can be drawn up to alleviate it. However, unforeseen uncertainty makes 
these plans more difficult to implement because the design team cannot anticipate everything. In the case of unforeseen uncertainty, companies have to rely on much more flexible practices to convert these technological or market uncertainties into innovative opportunities (De Meyer et al., 2002), thereby increasing the flexibility of innovative design.

\subsection{Management support}

To better understand the mains issue of management support, one needs to consider the identification of project practices that could cope with these uncertainties in terms of control and flexibility.

\subsubsection{Control}

The current competitive environment urges companies to develop new products in an effective manner to gain a competitive advantage. Meanwhile, today's product design is extremely sophisticated and risky, and in turn requires the structured process to control risk and uncertainty. Researchers and practitioners put every effort into observing the characteristics of the design process and developing models accounting for these features. Of these, the stage-gate method is probably the one which has attracted most attention (Cooper, 1998). The conventional and linear model depicts the process as a recommended sequence of activities. The latter are listed as a series of stages that can be broken down into tasks that convert the requirements for the new product into manufacturing instructions (Pahl and Beitz, 1996). To do so, a review is conducted at each gate at the end of stage to assess the current project status and determine the following actions, thus ensuring the accuracy of deliverables in downstream activities.

As far as control is concerned, two types can be considered: process control and output control (Ramaswami, 1996; Sethi and Iqbal, 2008).

Process control refers to a series of methods and activities adapted to design tasks; output control focuses on the result obtained relative to outputs goals and criteria. The stage-gate method is the combination of both types. In this paper, six control practices based on these two aspects have been developed. They can be analyzed as follows.

Process control can be represented by process structuration which refers to standardization. It consists of (i) rigorous predefined design activities that should be performed and (ii) a rigorous operation sequence for these activities (Biazzo, 2009). Thus, a rigorous process structuration means that the design process should follow these predefined activities and their operation sequence. 
Output control refers to gate evaluation whose criteria are applied to assess whether the project meets predefined goals or performance standards. Gate evaluation varies in terms of degree of rigor. Sethi and Iqbal (2008) identified the strictness, objectiveness and frequency of control as variables. Thus, we identified three control practices: (i) strict evaluation criteria (ii) objective evaluation criteria and (iii) frequent evaluations. Strictness is meant to ensure that all processes comply with the same criteria regardless of the nature of project. With respect to objectiveness, the evaluation criteria are not interpreted by different project managers and gate evaluators. Frequency emphasizes the number of evaluations within the whole process.

\subsubsection{Flexibility}

Although field-studies concluded that the stage-gate method with control is conducive to a shorter time-to-market and financial success (Clark and Fujimoto, 1991; Griffin, 1997; Tatikonda and Rosenthal, 2000), there is a growing concern that it may not suitable for all types of product because they tend to ignore the features and behaviors of innovative activities (Bhattacharya et al., 1998; Leifer et al., 2000; Lenfle and Loch, 2010; McDermott and O'Connor, 2002). Moreover, some empirical works claim that rigorous process structuration detrimentally impacts project performance resulting in numerous drawbacks, i.e. less flexibility, learning failure, excess red tape and decreased innovativeness (Poskela and Martinsuo, 2009; Sethi and Iqbal, 2008). The rigorous gate evaluation also hampers flexibility as it imposes constraints on the process, making designers more deeply committed to specific targets (Sethi and Iqbal, 2008).

Thus, a legitimate question is as to which project practices support the innovative process in innovative design. Some authors have introduced the "flexibility" concept to match the innovative process fraught with high uncertainty. Flexibility is the ability to cope quickly with the environmental development by adapting to new technology and taking into account market information in order to satisfy the customer's needs with only limited penalty (Thomke, 1997; Biazzo, 2009; Ryan et al., 2013). Previous studies have demonstrated the value of greater flexibility in an innovative process subject to uncertainty, and identified basic flexible practices (Krishnan et al., 1997; Thomke, 1997; Bhattacharya et al.,1998; MacCormack et al., 2001). A flexible method contrasts with the stage-gate method that emphasizes "early and sharp" product definition; in this method, uncertainty is not viewed as a risk but as an opportunity.

However, these flexible practices fail to make a distinction between process flexibility (e.g. earlier feedback from technology and customer) and design flexibility (e.g. investment in architectural design). Sometimes, this leads to a misinterpretation of flexible practices 
(Saleh et al., 2009). Design flexibility focuses on the product or system being designed, while process flexibility emphasizes a process mechanism through which uncertainty is better addressed. Furthermore, innovative design corresponds to a number of items being interconnected via a multitude of relations. Figure 6.2 depicts four dimensions of innovative design (i.e. product, process, organization and knowledge) and their relationships (Zhang et al., 2012b). Therefore, it is necessary to construct flexible practices from a much wider perspective, not only process flexibility and design flexibility. A thorough review of the literature allows us to identify six flexible practices where flexibility can be enhanced affecting process, product (i.e. design), organization and knowledge.

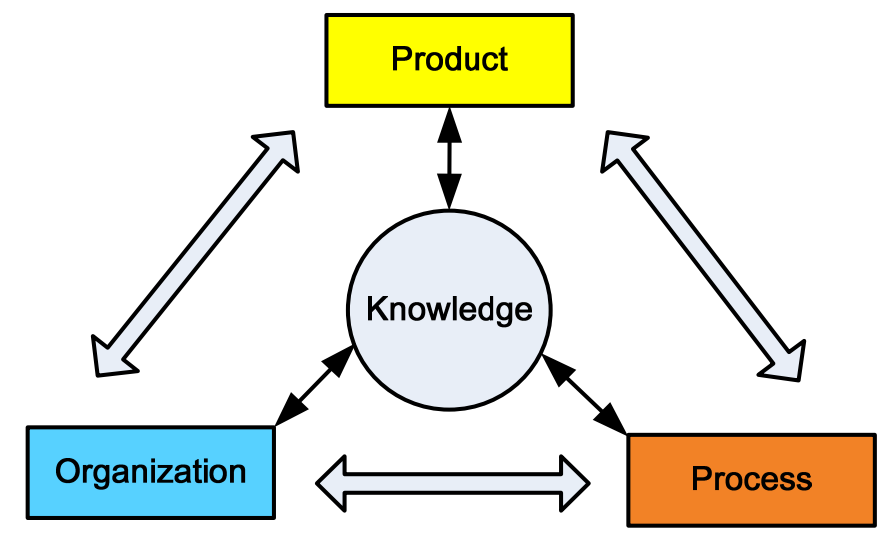

Figure 6.2 Four dimensions of innovative design (Zhang et al., 2012b)

Parallel trials and iterative experiments. Parallel trials refer to several possible solutions tested simultaneously and selecting the best one ex post. This set of options is more likely to lead to the right solutions (Sommer and Loch, 2004). For example, Toyota's "set-based concurrent engineering" envisions sets of design alternatives, rather than one set only, processed iteratively (Ward et al., 1995). Additionally, iterative experimentations can generate information about how well the product functions from a technical perspective (MacCormack et al., 2001). Early feedback from these experiments allows designers to solve the technological problem (e.g. interaction between different product devices or between the product and its operational environment)(McDermott and O'Connor, 2002). Designers thus integrate information into the product design.

Early experiments involving customer. In addition to early experiments designed to solve a technological problem, experiments involving the customer provide the designer with information on those product features requested by customer (MacCormack et al., 2001). Initially, a concept draft is embedded into a prototype (Buganza et al., 2009). It is then tested with the final user to generate information on how well the customer requirements are met.

Delaying concept freeze point. These are highly dynamic markets in which changes 
occur so quickly and unpredictably that information collected in the initial stage can become obsolete by the end of design (Bhattacharya et al., 1998). Similarly, in the high technology industry, the advent of new technologies initially leads to a high level of uncertainty. This compounds the difficulties in articulating product specification in the initial stage of design. Delaying the concept freeze point probably permits the inclusion of new information fraught with technological opportunities and emerging customer requirements, thereby enabling product to come close to customer requirements (Buganza et al., 2009).

Constructing a modular product architecture. This architecture enables set-based design and mass customization. This in turn allows for a wide range of final products to be offered to customers (Gil and Tether, 2011). In addition, design modularity accommodates an early integration of the nascent product design and changes in functionalities later in the design process (MacCormack et al., 2001).

Exploitation of generation knowledge. In a highly dynamic and uncertain environment, basic activities of innovative design consist in learning about new technological solutions and their potential application. Generation knowledge can facilitate these activities, allowing designers to find out an effective experiment strategy to match new pieces of information; it also helps designers integrate new data into the product being designed (MacCormack et al., 2001; Thomke, 1997).

Cross-functional and flat organization structure. As to an innovative product, particularly if it is complex, a designer operating on his own may not have the capabilities to address all issues at hand. So innovative design is by nature a team building activity, and different team members can perform these tasks at the same time. A cross-functional and flat organization structure can provide the resource flexibility. (Tatikonda and Rosenthal, 2000). Moreover, when faced with the changes and requirements of possible creative product architectures, this structure can warrant openness and dynamic communication which in turn will lead to synchronized actions and greater collaboration between the different designers (Zhang et al., 2012b).

\subsection{Empirical design}

\subsubsection{Research questions}

As defined in Chapter 5, innovative design tries to change the product identity whilst breaking away from the existing design framework. In this case, companies often do not correctly anticipate technological or market opportunities or the best way to address them. Hence, innovative design is conducted in a dynamic environment. According to this 
analysis, the uncertainty of innovative design can be defined as follows: (i) the source of uncertainty (market and technological); (ii) the type of uncertainty (foreseen and unforeseen).

In order to deal with these different sources and types of uncertainty, control is required to make the best use of resources and fulfil the design project goals. In this paper, five control practices are defined in respect of process structuration and gate evaluation. These include: (i) rigorous predefined activities (ii) rigorous sequences of activities (iii) strict evaluation criteria (iv) objective evaluation criteria (v) frequent evaluation. Meanwhile, innovative design also requires a high level of autonomy and an open environment to deal with these uncertainties. In the literature cited in the previous section six different practices are described to increase flexibility: (i) parallel trials and iterative experiments (ii) early experiments involving customer (iii) delaying the concept freeze point (iv) constructing a modular product architecture (v) exploitation of generation knowledge (vi) cross-functional and flat organization structure. So engineering the right balance between control and flexibility is a great challenge for the management of innovative design.

Moreover, different types of uncertainty originating from different sources may require different project practices (MacCormack and Verganti, 2003; Buganza et al., 2009; Poskela and Martinsuo, 2009). This paper aims to discuss how control and flexibility can be balanced using different sources and types of uncertainty; in particular, the goal is to identify the relationships between different sources and types of uncertainty and specific project practices that support control or flexibility (see Figure 6.3).

Starting from these statements, the main research questions can be formalized as follows:

(1) Do control and flexibility contradict each other in the process of innovative design in the event of uncertainty?

(2) What are the control practices or flexible practices used by innovative design teams in the event of different sources and types of uncertainty?

(3) If the answer to (1) is yes, then how does innovative design combine control practices and flexible practices to address each type and source of uncertainty? 


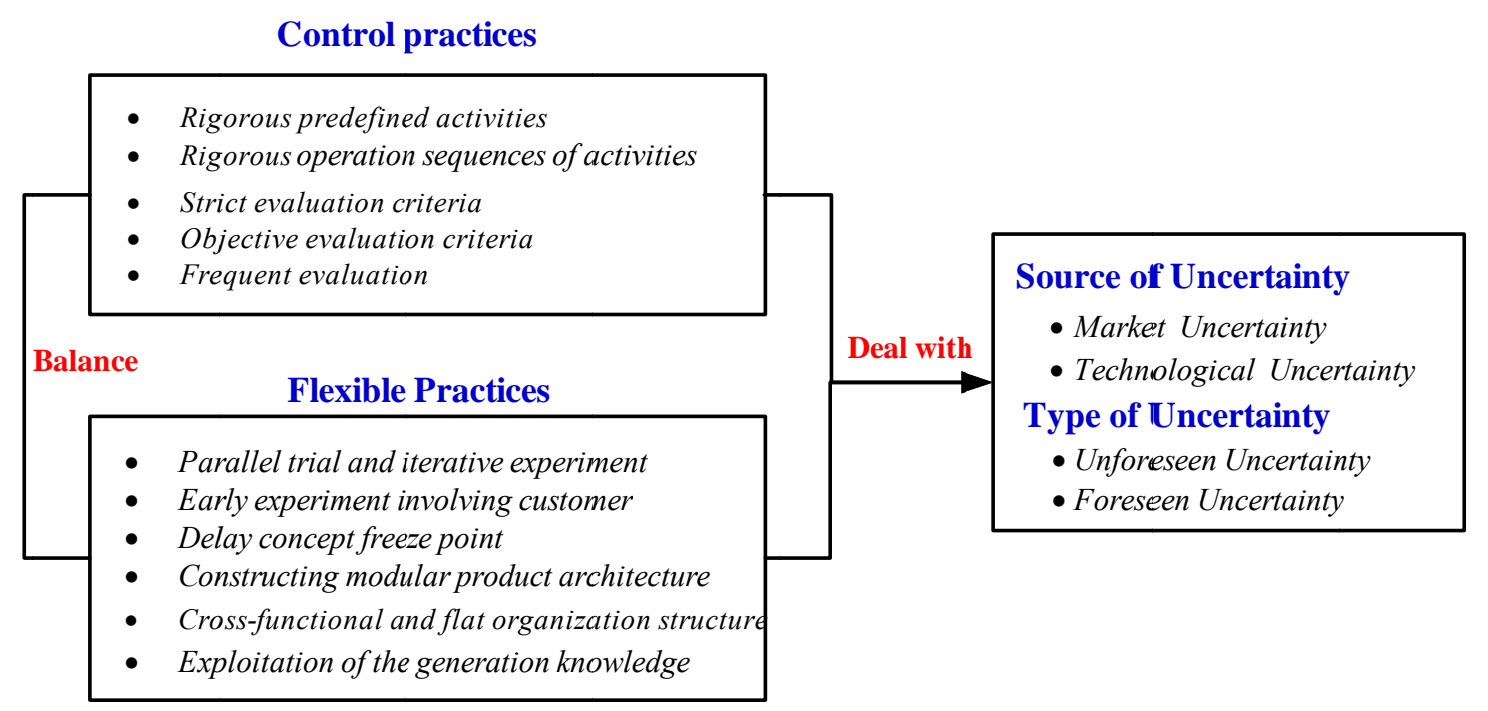

Figure 6.3 Theoretical research framework

\subsubsection{Research methodology}

To deal with the research questions mentioned in the previous section, a case-study approach is selected. Investigating case studies is particularly fruitful for understanding nascent phenomena whose scope is not fully defined yet (Yin, 2002). Although innovative design has been increasingly emphasized, its scope remains unclear. Therefore, a detailed and comprehensive view is needed and can be obtained by investigating ongoing projects. In particular, emphasis is placed on how to balance control and flexibility during this process and how various project practices address the uncertainties of innovative design.

\subsubsection{Sampling}

To be able to compare different project practices coping with different sources and types of uncertainty in a similar context, we focus on projects managed by the same company. Moreover, in order to observe the innovative design process, it is important to follow the project from beginning to end. This is achieved by conducting a longitudinal study. Based on these criteria, we selected five innovative design projects carried out by a Chinese automaker from 2000 to 2010. During this period the company registered tremendous growth:

- China became a member of the World Trade Organization in 2001. The Chinese automotive industry sustained high competitive pressure from foreign companies. This company needed to design and develop a series of innovative products to keep abreast of competition and even gain some market share.

- Because this company was a new entrant in 2001 , there were no adequate mature 
technologies and platforms, and therefore, it had to introduce the new generation of design technology and devices.

- At that time the Chinese market was booming, and customer requirements were also changing quickly. The new innovative products should adapt to the new emerging requirements.

Five in-depth case studies of innovative design projects were conducted. As listed in Table 6.1, these projects have an exploratory purpose from a technological or market viewpoint, and dealt with different sources and types of uncertainties. For example, Projects 2-4 had to overcome technological difficulties and looked for novel solutions within a high and even unforeseen technological uncertainty environment, while Project 1 was developed with unforeseen market uncertainty. In particular, Project 5 suffered unforeseen uncertainty from market and technological perspective. Thus, these studies endeavored to identify control and flexible practices and investigate different types and sources of uncertainty.

Table 6.1 Brief description of five automobile design projects

\begin{tabular}{|c|c|}
\hline Item & Description \\
\hline (1) & $\begin{array}{l}\text { - This project aimed to design the first mini-car with an attractive look and fashionable configuration to } \\
\text { cater for fashion-conscious people. Before, there had not been any successful mini-car project in China, } \\
\text { and customers had little consumer experience. } \\
\text { - After developing a series of automobiles, the design teams expertly handled the existing technologies. } \\
\text { - This automobile was launched in June } 2003 \text { after a period of about } 28 \text { months. }\end{array}$ \\
\hline (2) & $\begin{array}{l}\text { - It focuses on the mid-and-high level commercial sedan segment. This market is relatively mature, and } \\
\text { customers are familiar with their requirements. } \\
\text { - During the design process an } 8 \text { percent more fuel efficient new lightweight technology was introduced by } \\
\text { the company and the design team was asked to implement it. } \\
\text { - This car was launched in July } 2005 \text { after approximately } 24 \text { months of development. }\end{array}$ \\
\hline (3) & $\begin{array}{l}\text { - SUVs have always been very popular ever since they were introduced in China. The company decided to } \\
\text { design this model to gain market share. } \\
\text { - Because SUVs use a new platform, irrespective of design (style, engine or structure), new devices and } \\
\text { knowledge are needed. } \\
\text { - This model was launched in March } 2005 \text { and lasted about } 28 \text { months }\end{array}$ \\
\hline (4) & $\begin{array}{l}\text { - It is defined as a family sedan a targeting the young and trendy. This market is also relatively mature, and } \\
\text { customer requirements are very clear. } \\
\text { - To be more attractive, the design team cooperated with other famous style design teams for the car's } \\
\text { exterior and interior. Also, the five-star safety rating was adopted to warrant quality. } \\
\text { - This model was launched in September } 2009 \text { after approximately } 22 \text { months of development. }\end{array}$ \\
\hline (5) & $\begin{array}{l}\text { - With rising gas prices, future vehicles will be fuel efficient, energy-savers. This project aimed to design an } \\
\text { electric car which would be more energy efficient with lower regulated emissions. } \\
\text { - As the electric car differs from traditional vehicles in terms of energy savings, energy transformation and } \\
\text { control system, the project suffers high technology uncertainty. Moreover, customers also had limited } \\
\text { consumer experience. } \\
\text { - This model was launched in May } 2010 \text { after a period of approximately } 20 \text { months. }\end{array}$ \\
\hline
\end{tabular}




\subsubsection{Data collection}

The method used for collecting data relies on interviews and document studies. As in Project 4 , given the cooperation enjoyed with this automaker, one of the authors, attended in house management workshops as an observer and coordinated meetings. Before conducting the interviews and making observations, some preliminary data was collected by consulting the project database (organization and project objectives) and related work reports (e.g market analysis report, feasibility analysis report). The information gathered facilitated understanding of the project environment (e.g. uncertainty), its milestones and schedules.

Semi-structured and in-depth interviews were conducted with the main actors (director of the institute of Automotive Engineering, Project Manager, designers, project leaders in other posts, like Marketing, Manufacturing and Information Technology). In total, 18 interviews were made. In order to provide consistency, a checklist was drawn up and followed with each interviewee: (i) overall project description (e.g. goals, design team, constraints and duration); (ii) factors and events impacting the design process (e.g. the emerging new technology, feedback from Marketing); (iii) control practices or flexible practices retained. The most detailed discussion focused on the last item. The interviewees were asked to describe the way they coped with the uncertainties and the tools they used. They were also requested to explain why they used these tools and methods.

For more reliability, along with interview data, documentary materials were used to get an accurate picture of how control practices and flexible practices were adopted to alleviate the uncertainties in the projects.

\subsubsection{Data analysis}

Data analysis was in two steps. Firstly initial uncertainties in each project were assessed from the point of view of sources and types of uncertainty. To get an accurate evaluation, three interviewees were enrolled. Later on they shared their understanding to arrive at a common evaluation. The end result is given in Figure 6.4: (i) Projects 2, 3 and 4 suffered unforeseen technological uncertainty as early as the introduction of new design platform or new technology (lightweight technology). In terms of market, as the targeted markets are relatively mature, the three projects supported foreseen market uncertainty. (ii) Since Project 1 tried to tap a new customer market based on the existing design platform and technological base and new customer requirements were only emerging, it was difficult to define product specifications accurately. Thus, this project mainly dealt with unforeseen market uncertainty. (iii) Project 5 was the so-called "novel strategic project" with new markets, unknown customer reactions and unknown technology. It had to deal with 
unforeseen technological uncertainty and market uncertainty.

Secondly, the adoption of control practices and flexible practices in each project was investigated. These practices were evaluated on the basis of interviews with the main actors in each project. For more reliability, the preliminary results were checked by researchers in direct collaboration with interviewers. Table 6.2 summarizes data collection per interviews and document studies. The rows stand for project practices that support management control and flexibility respectively, while the right columns list the five cases. The empty circle $(O)$ means that this case adopts this specific project practice.

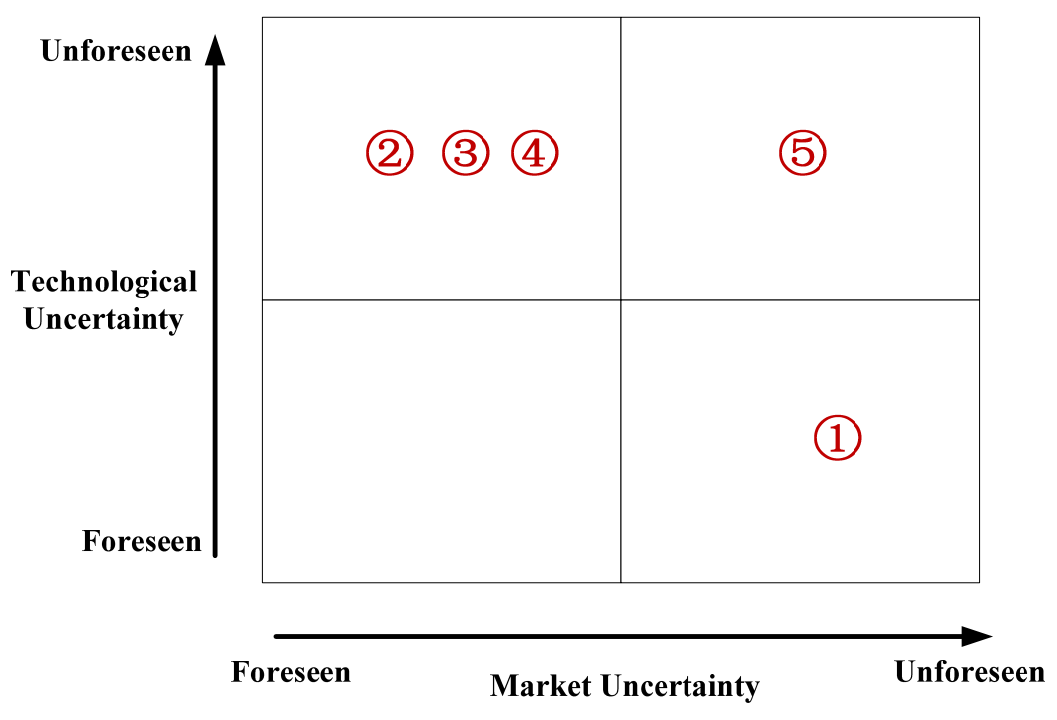

Figure 6.4 Uncertainty assessments for each project

Table 6.2 Project practices of case studies in terms of control and flexibility

\begin{tabular}{|c|c|c|c|c|c|c|}
\hline \multicolumn{2}{|r|}{ Project Practices } & (1) & (2) & (3) & (4) & (5) \\
\hline $\begin{array}{c}\text { Control } \\
\text { practices }\end{array}$ & $\begin{array}{l}\text { - Rigorous predefined activities } \\
\text { - } \text { Rigorous operation sequences of activities } \\
\text { - Strict evaluation criteria } \\
\text { - } \text { Objective evaluation criteria } \\
\text { - } \quad \text { Frequent evaluation }\end{array}$ & $\begin{array}{l}0 \\
0\end{array}$ & 0 & 0 & 0 & 0 \\
\hline $\begin{array}{l}\text { Flexible } \\
\text { practices }\end{array}$ & $\begin{array}{l}\text { - Parallel trial and iterative experiment } \\
\text { - Early experiment involving customer } \\
\text { - Delay concept freeze point } \\
\text { - Constructing modular product architecture } \\
\text { - Cross-functional and flat organization structure } \\
\text { - Exploitation of the generation knowledge }\end{array}$ & $\begin{array}{l}0 \\
0 \\
0 \\
0\end{array}$ & $\begin{array}{l}0 \\
0 \\
0\end{array}$ & $\bigcirc$ & $\begin{array}{l}0 \\
0 \\
0\end{array}$ & $\begin{array}{l}0 \\
0 \\
0 \\
0 \\
0 \\
0\end{array}$ \\
\hline
\end{tabular}




\subsubsection{Empirical findings}

\subsubsection{Adopting of control practices}

The first empirical finding relates to the adoption of control practices for different kinds of uncertainties. Once initial uncertainties are assessed, project managers respond by adopting adequate control practices. Looking at Table 6.2 in the "control practices" row it clearly appears that despite different types and sources of uncertainty in each project, similar control practices are retained.

In terms of process structuration, all projects maintained predefined design activities, but did not strictly follow the sequences of these activities except for Project 1 . The director of the Institute of Automotive Engineering in the company, in charge of developing the overall design strategy and management, stated:

"Although the Institute of Automotive Engineering has developed different types of vehicles, the basic design activities in these projects are not all that different. First of all, an automobile is a relatively mature and complex product. To provide quality and security, the overall design process must follow the standards of the automotive industry. Secondly, the definition of these activities is the result of several years of in house experience which led to the drawing up of a set of design documents. Moreover, the so-called "light process strategy" has been retained in which structured and formal design stages are scheduled, but the detailed sequence of design activities varies in accordance with the design project, as decided by project managers."

At the time of Project 1, as a new entrant, this automaker eagerly hoped to enhance brand recognition and competitiveness by developing the first mini-car in China. Project 1 not only faced unforeseen market uncertainty but also time-to-market pressure. To implement this strategy successfully, Project 1 adopted standard practices, such as a strict sequential order of design activities and a set of document management formats.

With respect to gate evaluation, irrespective of the kind of uncertainty, all projects avoided the strict and objective evaluation criteria and frequent evaluation. For example, from a technological point of view, uncertainty in Project 2 is extremely high. Given the lack of experience on the new "lightweight technology" in terms of fuel consumption, the entire design team could not anticipate how the features of the new technology would affect the identification of the technical specification. In order to avoid premature choices, the project manager refrained from adopting strict and frequent gate evaluations, favoring instead slightly more lax project objectives. As a member of the design team of Project 2, a designer clearly explained this:

"In the case of Project 2 a relatively important technological challenge had to be taken up. We tried to bridge the technology gap created by the new lightweight technology by performing a series of 
experiments. If this project was controlled by a number of technological criteria as before, design team members may strive to define detailed technological specification early in the design phase, thereby resulting in a premature choice."

\subsubsection{Adoption of flexible practices}

The second empirical finding is that these projects adopt adequate flexible practices commensurate with the uncertainties encountered. As can be seen in Table 6.2, even if all the flexible practices identified in the literature have been followed in these projects, they are seldom applied at the same time. On the contrary, some specific flexible practices are often used to cope with a specific kind of uncertainty. This empirical result is listed in Table 6.3 and discussed below.

Table 6.3 Flexible practices in case studies with respect flexibility

\begin{tabular}{l|l|l}
\hline & \multicolumn{1}{|c|}{ Technological uncertainty } & \multicolumn{1}{c}{ Market uncertainty } \\
\hline $\begin{array}{l}\text { Different } \\
\text { Practices }\end{array}$ & $\begin{array}{l}\text { Parallel trial and iterative experiment } \\
\text { Exploitation of generation knowledge }\end{array}$ & $\begin{array}{l}\text { Early experiment involving customer } \\
\text { Cross-functional and flat organization } \\
\text { structure }\end{array}$ \\
\hline Common & $\bullet$ Delaying the concept freeze point & \\
Practices & - Constructing a modular product architecture \\
\hline
\end{tabular}

(1) Common flexible practices

According to Table 6.3, under any form of uncertainty (market or technological based), companies respond by delaying the concept freeze point and by constructing the modular product architecture. All projects prolonged the duration of the concept design stage to include information from different departments. In other words, by delaying the concept freeze point relevant changes can be introduced. In Project 3, the product concept for the SUV was frozen before the second trial production of the prototype, which exceeds the phase of traditional concept design. As the SUV required a completely new design platform in this company, the project management decided to delay the concept frozen point to take advantage of any contributions from the different departments (e.g. R\&D centers and industrial test facilities).

However, constructing a modular product architecture may be the requisite for project practice with automakers. Given the high degree of sophistication of a new vehicle, even in h low uncertainty projects, companies always perform design activities in accordance with the modular architecture. A project manager with seven years of experience in the auto industry stated: 
"More and more companies opt for a modular product architecture to reduce costs, enhance the response to customer requirements e.g., MQB (Modular Quer Baukasten) of Volkswagen, EMP2 (Efficient Modular Platform 2) of PSA Peugeot Citroën. In our company, all types of vehicle follow the basic modular product architecture."

\section{(2) Technological uncertainty}

All projects characterized by unforeseen technological uncertainty adopted (i) parallel trials and iterative experiments and (ii) the exploitation of generation knowledge.

Parallel trial and iterative experiment. Indeed, when exploring unknown technological terrain, multiple trials and iterative experiments do provide the best hope of getting a satisfactory solution (Sommer and Loch, 2004), whilst allowing designers to "probe and learn" rather than invest in accurate preliminary analyses. For example, in the development of the electric car, technology standards and solutions were not defined and, therefore, fraught with unforeseen uncertainty. Project 5 simultaneously performed several technological routine for the electric power, because it was still unclear which technology would win. Meanwhile, Project 5 devised an information shared mechanism involving different technological teams, and allowed each technological routine to evolve as new information was obtained from other teams. Finally, all technological routines were merged into the best satisfactory solution (i.e. the belt driven starter generator technology). The project manager in charge of Project 5, stated:

"In this project, targets are not given but originate from a broad desired strategy, and technological details are only hypotheses first and evolve later. At that time, there were several technological routines for electric power. This project is an experimental learning process exploring several technological routines simultaneously. We try to perform targeted experiments to generate knowledge about external technological challenges, emerging device interactions."

Exploitation of the generation knowledge. We captured the amount of generation knowledge in each design team of Projects 2-5 by asking project managers to assess the proportion of designers with several generations of experience. In our analysis, we adopted four categories (i.e. no previous experience, one generation of experience, two generations of experience, greater than two generations of experience), as our indicator for generation knowledge. The result is summarized in Table 6.4. It shows that the proportion of designers with greater than two generations of experience exceeds the other categories. Particularly, the design team of Projects 5 is composed of designers with greater than two generations of experience. Additionally, there were many examples of designers having acquired experience in previous projects helping in the rapid identification of information and proposing a new solution. 
Table 6.4 Proportion of designers with generation experience in Projects 2-5

\begin{tabular}{l|cccc}
\hline \multirow{2}{*}{$\begin{array}{l}\text { - no previous experience } \\
\text { - one generation of experience }\end{array}$} & Project 2 & Project 3 & Project 4 & Project 5 \\
\cline { 2 - 4 } - two generations of experience & $27 \%$ & $6 \%$ & $10 \%$ & 0 \\
\cline { 2 - 5 } - greater than two generations of experience & $26 \%$ & $18 \%$ & $27 \%$ & 0 \\
\cline { 2 - 5 } & $35 \%$ & $67 \%$ & $52 \%$ & $100 \%$ \\
\hline
\end{tabular}

\section{(3) Market uncertainty}

In Table 6.3 only two projects face unforeseen market uncertainty. In that case, companies retained (i) early experiments with customer and (ii) cross-functional and flat organization structures.

Early experiment involving customer. When product specifications cannot be defined under unforeseen market uncertainty, innovative design should allow the evolution of customer needs to be tested continually as it rapidly evolves during the design process (Buganza et al., 2009). Thus, Projects 1 and 5 characterized by unforeseen market uncertainty introduced early experiments involving the customer. For example, Project 1 planned continuous experiments and a series of market surveys during the design of the mini-car. The project managers of Project 1 argued that:

"At the time Chinese customers had little consumer experience with the mini-car, so often they could not identify their own needs. As a result, we envisioned different digital prototypes during the concept design phase and trial-produced the corresponding physical prototypes. We then got customer feedback. Moreover, we developed a so-called "fans discussion forum" on the internet in order to accurately and timely get customer feedback."

Cross-functional and flat organization structure. Under unforeseen market uncertainty, the new information constantly provided by markets makes it impossible to define product concepts once and for all from the beginning. While a change of product concept from marketing is being introduced, it has to receive approval from the technical department (i.e. institute of design engineering, manufacture department) which rapidly assesses the feasibility and the time needed to implement it. Conversely, this technical department might submit some current technological trends to the marketing department in way of innovative concepts. The cross-functional and flat organization structure provides the direct link between marketing departments and technological departments, thus facilitating cooperation and communication. For example, this organization structure was retained in Projects 1 and 5. 
"In the case of Projects 1 and 5 which differ from standard projects where there is an obvious partition of assignments and roles, the marketing, design and manufacturing departments can work together right from the start and interact directly with each other. Not only does it alleviate coordination issues between different departments, but also facilitate information sharing."

However, under unforeseen technological uncertainty, few projects retained this organization structure. For example, design teams in Projects 2-4 were composed exclusively of experienced designers from the technical departments and did not enroll staff from other functional departments. The manager of Project 2 explained:

"This design team composition is preferred, because front-end projects targeting the leading edge technology are developed independently within the technological department. No intensive collaboration with other functions is needed. To alleviate the coordination issue, we adopted the relative unitary team."

\subsection{Managerial implications}

Companies implementing an innovative design project have a practical concern with "balancing control and flexibility. The analysis of empirical findings mentioned in the previous section highlights managerial implications that can alleviate this balance problem.

First of all, according to these findings, all projects studied involving varying degrees of uncertainty followed the structured process (i.e. rigorous predefined activities), but avoided strict gate evaluation (i.e. strict, objective and frequently applied gate review criteria). Based on this, it is argued that by applying stricter, more objective, and frequent gate review criteria, the innovative design project will become less flexible. Thus, companies should refrain from frequently performing strict and objective gate review during this process. In other words, they could put in place slightly more lax project objectives when operating under unforeseen technological and/or market uncertainty. In addition, the result also shows that regardless of the kind of uncertainty suffered, each project still maintains similar control practices. This means that companies can manage many innovative design projects in a broadly similar fashion. Control could be straightforward, using similar control practices in all projects.

Secondly, our empirical findings show that each project opted for not only similar control practices but also at least four flexible practices. Delaying the concept freeze point and constructing a modular product architecture may well be the solution preferred to deal with technological and market uncertainty. But the use of other flexible practices depends on the source of uncertainty. In the event of unforeseen technological uncertainty, companies tend to rely heavily on parallel trials and iterative experiments and the exploitation of generation knowledge. In the case of unforeseen market uncertainty, the 
early experiment involving customers and a cross-functional and flat organization structure are much more effective.

Based on these results, it is the authors' opinion that process structuration and flexibility are compatible, and can therefore coexist within the process of innovative design. But the strict gate evaluation reinforces the inflexibility of innovative design. This has clear implications in practice. Companies should first diagnose the uncertainty profile of the innovative design project, and then simultaneously adopt adequate control practices and the corresponding flexible practices to cope with uncertainties inherent in innovative design.

However, this managerial implication contrasts with some previous studies (Sethi and Iqbal, 2008; Koen et al., 2001; Salomo et al., 2007). Indeed these authors argue that control practices hamper the identification and exploration of innovative opportunities in the turbulent environment. In our option, the conflicting conclusion may stem from the lack of distinction between innovative design and new product development (NPD). The latter concept encompasses the overall product life cycle, while innovative design involves the definition of product identity and the formulation of design problems corresponding only to one part of the product life cycle. Innovative design emphasizes the expansion and change of product identity needed to identify innovative opportunities, thereby generating product concepts; NPD tries to explore and formulate the design problem based on the well-defined identity of products. To complete these two contents, the flexible process should tackle different uncertainties. But the flexible process should not be considered as the abandonment of process structuration, but rather as the co-presence of problem definition and problem implementation. In these processes, the clear process structuration is maintained. Process structuration still plays a critical part in the success of innovative design. It can ensure that activities deemed critical $\mathrm{n}$ are thoroughly accomplished (Poskela and Martinsuo, 2009), and prevent looseness and ambiguity from getting out of control.

In summary, the analysis responds to the three main research questions defined in Section 6.4.1. Process structuration and flexibility can coexist. But the strict gate evaluation conflicts with flexibility. Therefore, the question of "how can control and flexibility be balanced" involves determining the degree to which a formal process can be applied to the project, while allowing for flexibility in the activities to be carried out. Companies should create control at the project-level by devising a formal design process, and allow flexibility at the operation- level by performing a series of flexible practices. The adoption of the corresponding flexible practices depends on the uncertainties encountered during innovative design.

Thus the first managerial insight for process modeling of innovative design is described as follows. 
Managerial insights 1: Innovative design should create control in a project-level in terms of a formal process, and encourage innovation in an operation- level in terms of flexibility.

On the other hand, our empirical finding shows that innovative design should adopt appropriate flexible practices according to uncertainties that it faces, which is synthesized by the second managerial insights as follows.

Managerial insights 2: In order to develop a general process model, innovative design needs to integrate all flexible practices that deal with the corresponding uncertainties.

\subsection{Conclusion}

This chapter was to find the best way to achieve an optimal balance between control and flexibility under different uncertainties during innovative design. In other words, the aim was to identify the relationships between different sources and types of uncertainty and particular project practices that support control or flexibility in innovative design. The first finding is that control and flexibility can coexist in this process. Control is achieved through process structuration at the project level, which provides an overall review and control in the entire process and at each level. Flexibility is achieved by a series of flexible practices at the operation-level. These practices promote some degree of autonomy which in turn facilitates innovative work and makes it possible to respond to emerging innovative opportunities. The second finding is about how to adjust practices to achieve an optimal balance between control and flexibility under different uncertainties. Firstly, in terms of control, uncertainty always requires predefined design activities, whilst denying the strict operation sequence of these activities. Secondly, the corresponding flexible practices depend on the source of uncertainty (see Table 6.3). Irrespective of the kind of uncertainty encountered by the innovative design team, the delay of the concept freeze point has to be retained. Along with the common flexible practice, in the event of unforeseen technological uncertainty, innovative design should emphasize the parallel trial and iterative experiment and the exploitation of generation knowledge, while innovative design adopts the early experiment involving customer and the cross-functional and flat organization structure in case of unforeseen market uncertainty .

From an academic point of view, there are some limitations to this study. First, we focused on how to balance of control and flexibility by adopting the various project 
practices according to the uncertainties, not addressing other context factors. However, the selection of project practices (management control or flexible practices) depends not only on the source and type of uncertainty, bus also on other factors, such as the project scope, complexity, corporate culture and the attitude and skills of designers and project managers. Therefore, the conditions that impact the choice of project practices need to be further developed. Second, some authors have recently emphasized the importance of industrial design for innovation. This deals with a new type of innovation, so-called 'design-driven', which begins with comprehending subtle and unspoken dynamics in the sociocultural model and radically changes the emotional and symbolic content of a product. It results in a dramatically new design meaning and language. In this case, uncertainty only originates from technology and market. Thus, the issue of balance for 'design-driven' innovation will have to be addressed. 


\section{PROCESS MODELING OF INNOVATIVE DESIGN FOR MANAGEMENT SUPPORT}

\subsection{Overview}

The previous chapter identifies the relationships between different sources and types of uncertainty and particular project practices that support control or flexibility in the process of innovative design. These findings provide the theoretical and practical suggestions for management support of innovative design. In this chapter, we will further discuss the research issue "management support". That is:

- Question 3: How do we model the innovative design process in a systematic method to stand by management support?

In Chapter 2, design process models are divided into the procedural model and the activity-based model in terms of the degree of abstraction. In the procedural-level, these models attempt to build up the unifying framework and the macro guide for the design process. It decomposes the design process into a series of design stages to structuralize the whole process. Activity-based models are much finer division than the procedural model, which decompose a process into a network of interacted activities to support detailed design planning and schedule. Hence, in accordance with this classification, the process modeling of innovative design also is respectively developed in the procedural level and the activity-based level.

As analyzed in Chapter 6, we conclude that control and flexibility can coexist within innovative design. Control is achieved through the process structuration in the project level, which provides an overall review and process control in the entire process. Flexibility is increased by performing a series of flexible practices in the operation-level, which allows somewhat autonomy to get innovative work done and respond to emerging innovative opportunities, and thereby achieving the purpose of encouraging innovation. Therefore, in the procedural level, we construct the conceptual framework based on managerial insights above, and answer the following two sub-questions: (1) what design stages should be performed in the procedural level? (2) What process structure do we employ in the procedural level to balance control and innovation?

In the activity-based level, in order to make the schedule and realistic commitment, given a series of goals or objectives, design managers must determine appropriate process 
architecture to balance innovation and control. The activity-based model attempts to capture process behaviors of innovative design, and propose a method of process design to aid managers and designer make decisions.

In order to respond to the questions above, this chapter will proceed in three sections. Section 7.2 develops a procedural process model to balance innovation and control through the structuration of process stage and the integration of flexible practices. Section 7.3 proposes the activity-based model, within which process architecture is progressively constructed by adaptively selecting design activities.

\subsection{Procedural process model of innovative design}

As we analyzed in Chapter 3, the procedural model emphasizes a specific aspect of the design, such as the design-focused model and the manage-focused model. In the case of design-focused model, many academics and practitioners propose different models to describe behaviors and characteristics of design, or prescribe process models or methods to guide design activities. The manage-focused mode prescribes standard, high-level stages that aim to ensure good practices such as proper evaluation and review activities.

Through the review of the recent literature on the two aspects, we find that the trend of combing the design-focused model with manage-focused model is emerging. Some researchers proposed some models that incorporate the design-focused model and the manage-focused model to deal with the general problems that the design process may encounter (e.g. the uncertainty, the complexity). The trend inspires us that we should combine the related management method or models with the design-focused model to develop a comprehensive procedural process model of innovative design.

As stated before, this process model should be developed to respectively reflect control practices and flexible practices in the project-level and the operational-level. The next questions that follow this conclusion are: how to respectively achieve the purpose in the two levels; what support do design-focused models and manage-focused models provide in the two levels?

In order to address these issues above, in this section we firstly discuss the theoretical basis of the procedural model based on the design paradigms in Section 7.2.1, and then develop this model step by step in Section 7.2.2.

\subsubsection{Theoretical basis: Combing the rational problem-solving paradigm and the reflective practice paradigm}

Design paradigm determines the methodologist's perception of the scope, 
characteristics and ways of working on design methodology itself (Dorst, 1997, p. 11). As discussed in Section 3.2, we have identified two main design paradigms (i.e. the rational problem-solving paradigm and the reflective practice paradigm) and explored their properties and ability to describe design. The two paradigms differ fundamentally in the way they treat the three fundamental dimensions (designer, design problem and design process) of design.

Thus, the question of which design paradigm to use arises at the beginning of the developing the procedural model. Dorst argues that the choice of design paradigm depends on three factors: the research goals, the objects of study, and, most importantly, the kind of design activity (Dorst, 1997, pp. 166-167), and analyze the appropriateness of these paradigms to the three factors above. Based on this analysis result, we identify three factors of the procedural process model, as shown in Table 7.1.

Table 7.1 Appropriateness of using paradigms for research goals, objects and subjects in this dissertation

\begin{tabular}{|c|c|c|}
\hline Brief of the procedural process model & $\begin{array}{c}\text { The rational problem } \\
\text { solving paradigm }\end{array}$ & $\begin{array}{c}\text { The reflective } \\
\text { practice paradigm }\end{array}$ \\
\hline \multicolumn{3}{|l|}{ Goal } \\
\hline $\begin{array}{ll} & \text { Formal model }\end{array}$ & $\mathrm{O}$ & \\
\hline - General prescriptive method & 0 & \\
\hline \multicolumn{3}{|l|}{ Objects } \\
\hline - Design process & $\mathrm{O}$ & \\
\hline - Designer & & 0 \\
\hline - $\quad$ Design problems & 0 & 0 \\
\hline \multicolumn{3}{|l|}{ Subjects } \\
\hline - $\quad$ Subjective of design activities & & $\mathrm{O}$ \\
\hline - $\quad$ Objective of design activities & 0 & \\
\hline
\end{tabular}

The O indicates that the paradigm is well-suited for this

Looking at the first column from the upper to the down in Table 8.1, there is brief of the procedural process model. The goal of the procedural process model is to prescribe the general process framework of innovative design to balance innovation and control. In this sense, the goal includes the formal model and the general prescriptive method. In Chapter 2, we identified design process, designer and design problem as the fundamental dimensions of design. Hence, to develop a comprehensive model of innovative design, the objects also include the three dimensions. With regard to the subjects, innovative design involves with design activities that are partly subjective and partly objective. For example, conceptual design activities are mainly determined by a series of objective constraints of design 
environment and subjective interpretation of designers.

In Table 7.1, we can see that these elements of innovative design have different appropriateness of using the paradigm. More details are discussed as following.

(1) Research goal

As stated before, the procedural model prescribes the general innovative design process and guides to ensure good practices. In this case, the formal model and the general prescriptive method need the objective interpretation provided by the rational problem solving paradigm.

(2) Research objects

- Design process

Innovative design, in despite of involving something of an art, still has many consistent patterns. In other words, while innovative design seeks to design something innovative, the designer or the design team tends to follow a design pattern.

This conclusion is consistent with some scientific evidences. (Griffin, 1997) studies effectiveness of structured product development process, and finds that companies that adopt the structured development process completes complex projects more quickly than those that did not. Try and colleagues studies the effectiveness of the structured problem-solving process in addressing manufacturing problems, and also found that the use of the structured process is associated with both better solutions and faster completion. So the innovative design process requires some repeatable structures based on the rational problem-solving paradigm.

- Designer

As analyzed in Chapter 6, designers actively reflect their actions, not simply performing the recommended actions. Designers perceive and interpret design problem, depending on individual and group prerequisites and characteristics of the current situation (Dorst and Cross, 2001).

Recall that the reflective practice paradigm that is analyzed in Section 3.2.2. The paradigm views designers as an engine that drives the whole process. The perspective of designers on design problem and design situation is key elements in the whole process. Designer's knowledge, stakeholder and design context exert an important influence on the construction of the perception (Gero and Kulinski, 2000). Therefore, the reflective practice could take into account subjective interpretations of designers. 
- Design problem

Innovative design is a problem-solving process for the outside world (increasing turnover and profit, the design of innovative product). In this case, the innovative design project needs to be controlled and the decisions should be justified for the outside world (Dorst, 1997).Therefore, there is an emphasis to objectify and explicitly list the goal space and constraints, to eliminate the implicitness and elements of 'subjective interpretation'. Meanwhile, any interpretation and understanding of design problem should explicitly be made, and then become a subject of discussion between the designer and stakeholders.

On the other hand, innovative design is a creative process with the expansive and the non-definitive design problem. In such a case, the subjective interpretation is only way to understand and make sense of this design problem. So design problem can be explained and described by the rational problem-solving paradigm and the reflective paradigm.

(3) Research subjects, the kind of design activities that is to studied

Since different design stages have distinct targets, the kind of design activities varies in design stage. For example, the first four stages (i.e exploration stage, task clarification, concept design and embodiment design) generate new function, new behavior or new structure (Howard et al., 2008). Thus, design activities of these stages are essentially subjective activities, which can be well described by the reflective practice paradigm. But subjective activities could extend over whole design process. In this aspect, the question of which design paradigm to use is changed into the question of which stage and activities of innovative design are suitable for the rational problem-solving paradigm or the reflective practice paradigm.

Based on the analysis above, it is impossible to use a single design paradigm as the theoretical basis for the procedural process model of innovative design. As stated in Section 3.2 , although the rational problem-solving paradigm or the reflective practice paradigm describes and explains the fundamental dimensions of design in very a different and quite incompatible way, they are complementary. The properties and limitations of each of the two paradigms are such that they could be used in combination. It means that we should combine the two design paradigms to develop the procedural process model. The next question is how to combine the two paradigms?

Return for a moment to the purpose of management support: to balance innovation and control. As stated before, the balance problem involves determining the degree to which to apply a formal process to innovative design in the project-level, while allowing flexibility to conduct work in the operation level. According to the managerial insights in Chapter 7, control happens via utilization of structured processes, while innovation requires 
management flexibility for an organization or an individual.

As discussed in Section 3.3, the rational problem-solving paradigm can provide us with a structured framework to achieve the purpose of control. It involves a review at each level in the execution of the project to assess process status and determines the necessary revisions. The reflective practice paradigm can adequately capture the extent to which an organization or an individual is responsible for these work activities. Therefore, in the project-level, the rational problem-solving paradigm is the theoretical basis of the structuration of process stage; in the operation level, the reflective practice paradigm contributes to the integration of flexible practices.

\subsubsection{Modeling innovative design}

Based on these propositions above, we construct the procedural process model of innovative design in two levels: In the project-level, we construct the basic process framework of innovative design based on the Vee model in Section 7.2.2.1, which builds up a formal process for innovative design; in the operation-level, we develop a circular model that tries to map flexible practices introduced into process elements of innovative design in 7.2.2.2. After the two steps, we integrate the process framework and the circular model together in Section 7.2.2.3.

\subsubsection{Structuring the process of innovative design}

The Vee model provides an illustration of systems engineering activities during the life cycle process (Forsberg and Mooz, 1991). In Vee model, time and system maturity proceed from left to right. It starts with stakeholder needs on the upper left and ends with the validation of these needs on the upper right. On the left side of the Vee model, system decomposition and definition descend in a waterfall model; the process from integration to verification and validation flows up at the right side.

There are some reasons to explain why this attention to the Vee model is warranted for innovative design. (1) The process of the Vee model accords with the development logic of the rational problem-solving process. As we have discussed before, innovative design is something of an art but with many consistent patterns. (2) The Vee model emphasizes the definition of the validation plan during requirement development, the in-process verification with the stakeholders and the importance of continuous risk assessment (INCOSE, 2006). As discussed in Section 7.2, in the case of innovative design, because of technological uncertainty and market uncertainty, associated with the cost risk and schedule risk arising therefrom, it requires in-process and continuous reviews to reduce these uncertainties. 
Therefore, we construct the basic process framework of innovative design based on the Vee model in the project-level, as shown in Figure 7.1. The left side of the framework depicts the process from the problem definition to the solution generation with a waterfall pattern. Referring to the systematic model of design process (Pahl and Beitz, 1996), this process includes task clarification, concept design, system-level design and detail design. When design solutions are constructed, integrated and verified, the right side of this framework is executed. Additionally, the scope of innovative design is extended from the idea generation of product to the description of the product that is to be made (as discussed in Section 5.2.3). We consequently integrate the stage "exploration stage" into the process of innovative design. In summary, we divide the process of innovative design into the eight stages as follows, which features many feedback loops.

At each step, a verification process is invoked, in order to justify the expression of needs, technical requirements, design choices, and to ensure traceability right through the development process. Finally, a validation process is performed to compare technical requirements to performances obtained during in situ tests

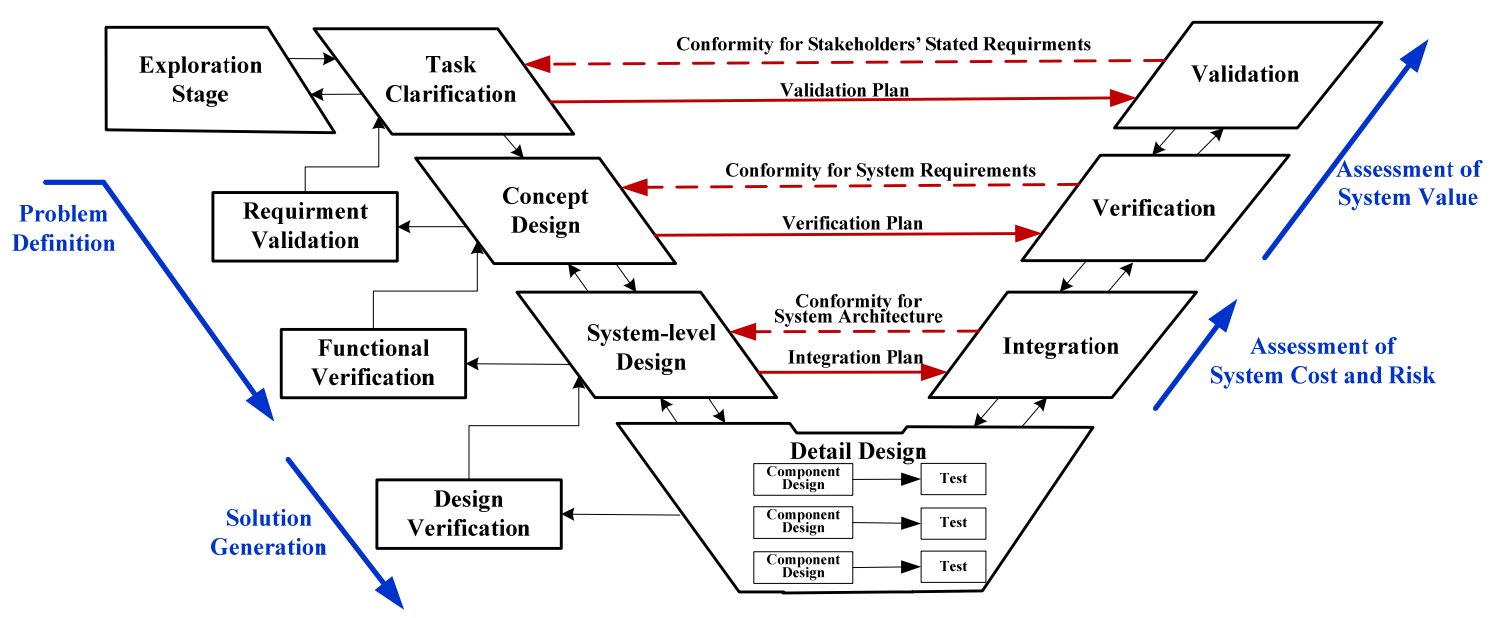

Figure 7.1 The basic process framework of innovative design in the project-level

Exploration stage. The design problem of innovative design is the result of the expansion of product identity by adding unusual and innovative properties (Hatchuel, 2001). Hence, how to expand product identity becomes the start point of innovative design. In accordance with the new concept development model from Koen et al. (2001), the exploration stage consists of opportunity identification, opportunity analysis, idea genesis and idea generation. First, it is required to identify the opportunity of expanding or changing product identity in terms of new design meaning and language (Verganti, 2011), market need and technology source (Burkart and Sayles, 2004; Rothwell, 1994). After 
opportunity identification, the process should pass the phase of opportunity analysis, which translates opportunity identification into special business and technology opportunities and make related assessment, then idea genesis, which develop the opportunity into a concrete idea, finally arrive at the phase of idea selection.

Task clarification. The purpose of task clarification is to collect information about the requirements that should be fulfilled by the product and constraints (Pahl and Beitz, 1996). The activities, needs identification and requirement definition, develop new product identities and customer needs into technology requirements. If new product identities are driven by the technology or the design-driven innovation, it may require design team to identify customer needs and establish target specifications in the form of requirement list to match the given technologies. As for new product identities from market needs, the design team should select appropriate technologies to meet customer needs.

Concept design. This stage mainly includes concept exploration, concept selection and concept testing (Ulrich and Eppinger, 1995). A flexible process should encompass a mechanism for generating and responding to new information. The need to generate new information requires the exploration of concept space that may address customer needs within the concept exploration. Concept selection is required to explore simultaneously the implications of several product concept decisions by rapid and early experimentation in order to get the earlier feedback on a product's system-level performance. So concept testing should establish intensive links with the target market to verify whether customer needs have been met or not, and assess the market potential of the product.

System-level design and detail design. Our previous empirical study in Chapter 7 shows that the modular product architecture can support an early integration of the emerging product design, and endure new emerging information in the later stage of the design process without a large modification for product architecture. We thus replace the term "embodiment design" identified in Section 6.3 by the "system-level design" to emphasize the importance of the modular product architecture. The goal of system-level design is to identify the modular product architecture and decompose the product into subsystems and these further into components. During detail design, various component designs are performed with a parallel fashion by many design teams that work at once or separately. The main missions of detail design include the complete specification of geometry, materials and tolerance (Ulrich and Eppinger, 1995), and the test in the component-level.

Integration, Verification and Validation: The three stages mainly focus on the integration and the evaluation of the whole product design. When completing detail design, it needs to integrate all subsystem designs or component designs into the whole product 
design according to the integration plan. The stage of verification is planned to make sure that all system requirements have been met. At the end of the design process, the stage of validation checks whether the whole design can satisfy stakeholders' requirements or not.

\subsubsection{Constructing the flexibility of innovative design}

In the previous section we construct the basic process framework of innovative design in the project-level shown in Figure 7.1. In fact, the process framework is still a logical development of innovative design. A design process proceeds through the Vee model. However, most designers do not follow these separate steps in the operation-level, and very few of them can draw straightforward steps in any given process. Moreover, designers play a vital role in the development of innovation. Designers apply their skills, perspectives and domain knowledge to innovation process based on their creativity, thinking style and personality (Van de Ven et al., 2000).Therefore, in order to encourage innovation, it should construct flexibility in the operation-level.

In Section 5.4, we propose the circular version of descriptive model of innovative design (see Figure 5.17) with three layers, within which these nine elementary processes of the basic framework are executed in the circular style. Designers are considered as the core element of the term "heart" to drive the implement of these elementary processes. In the outer layer, the environment contains the influence factors. Through the circular form, a series of flexible practices, such as the iteration and the parallel execution, are integrated into this model. Although this model in Section 5.4 aims to describe the process of innovative design, the circular form provides a way to integrate the flexible practices introduced in Section 6.3.2.

Therefore, inspired by this descriptive model of innovative design, we conclude that the flexible operation-level process model likewise should be adapted as a circular style. This circular model with three layers provides an initial setting, in which we construct flexibility of innovative design. Figure 7.2 shows the circular process model.

Mapped onto in the middle layer are the basic design activities of the first four stages of innovative design (exploration stage, task clarification, concept design and system-level design, as described in Section 7.2.2.1). These stages correspond with the problem definition of Figure 7.1, and accords with the generation stage of the creative process that results in the generation of new function, new behavior or new structure (Howard et al., 2008). However, the design activities of other design stages, such as detail design, are performed in accordance with design specifications that specified by the first four stages of innovative design. Thus the flexible process model is developed in the first four stages. As can be seen in Figure 7.2, each stage is decomposed into a series of activities. For example, 
the exploration stage is defined by opportunity identification, opportunity analysis, idea genesis and idea generation. Iterations between these design activities are represented with dotted arrows. This iterative sequence accords with the flexible requirements. Referring to flexible process practices (i.e. parallel trial and iterative experiment, early experiment involving customer and delay concept freeze point), we have already recognized the operation process of innovative design is neither smooth nor linear, nor often well-behaved. Iterations and feedbacks are inevitable elements in the process.

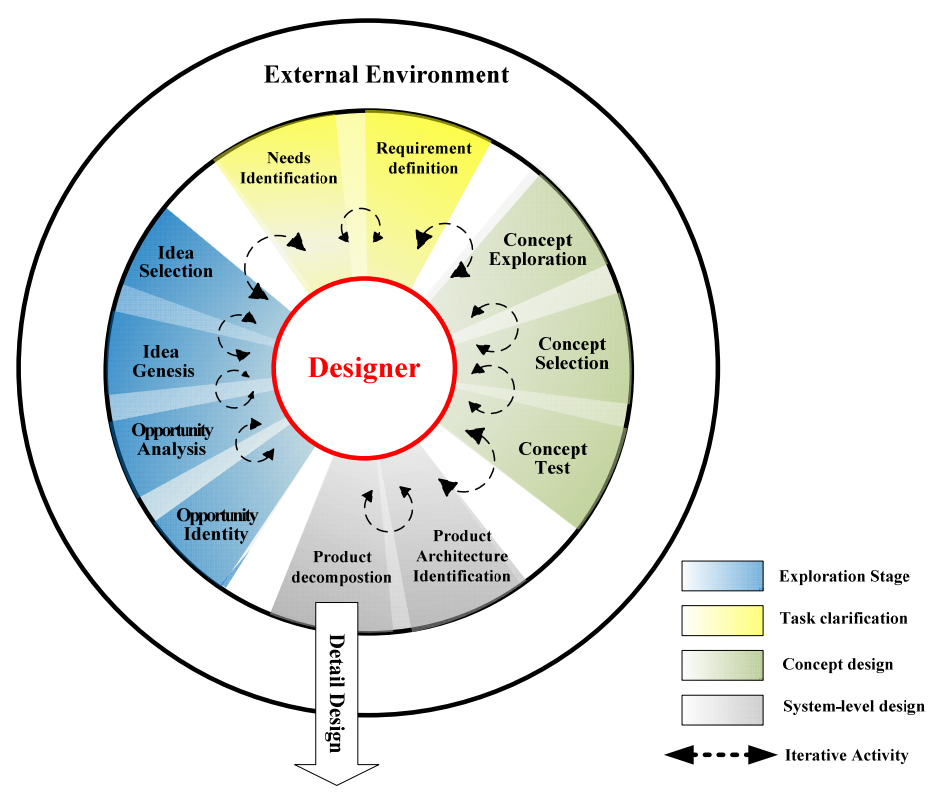

Figure 7.2 The circular model of innovation

In the central layer, designers are generally recognized as an engine that drives these design activities, and a medium of interaction between different layers. Design is a "reflective conversation with the materials of a design situation" (Schön, Donald A., 1995). Through the perception of the design situation and the recollection of experiences, designers decide on further actions (when to do what). That is to say, designers should actively respond to their actions rather than simply perform the recommended actions. Furthermore, the considerations taken into account by knowledge flexibility ("generational" knowledge" of designers) have already proven to be useful for developing the flexibility of innovative design. Designers apply their skills, perspectives and domain knowledge to the innovation process based on their background and experience.

The outer layer focuses on the external environment that contains the influencing factors. Here, we define the external environment as a set of external factors within the organization inside. Innovative design is surrounded and influenced by environment factors that consist of the company's business strategy, risking taking policy, its organization capability, structure and climate, and technology maturity (Galanakis, 2006; Koen et al., 
2001). No matter who tries to propose a new idea about product identities, it needs to be aligned with the business strategy to ensure uninterrupted, flowing the pipeline of new products and processes. Meanwhile, how to select new ideas from lots of innovative opportunities depends on the company's risking taking policy. Sustainable exploration of product identities can occur when these explorative activities are accomplished with the organizational capability. The organization flexibility (cross-functional and flat organization structure) influences the ability of expanding product identities.

\subsubsection{Procedural process model of innovative design}

As suggested in Section 7.2.1, we should combine the rational problem-solving paradigm and the reflective practices paradigm to achieve the balance between innovation and control. In this section we will attempt to map the flexible process model onto the structured framework of innovative design. That is to say, it combines the Figure 7.1 and Figure 7.2 into an integrated model, as shown in Figure 7.3.

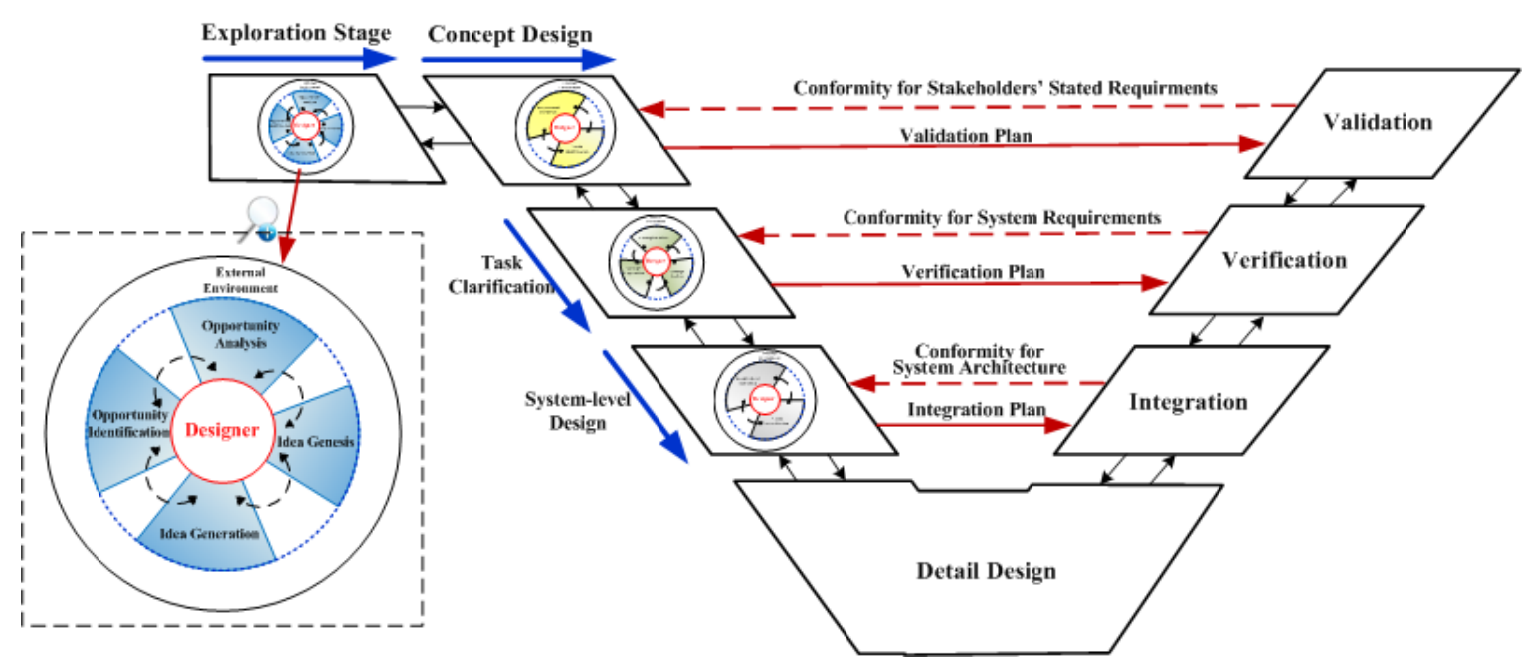

Figure 7.3 The procedural process model of innovative design

As can be seen, the process framework of innovative design and the flexible process model are respectively developed in the project-level and the operation-level. In the project-level, control happens via utilization of structured processes. This Vee-model provides us with a structured framework to achieve the purpose. In the case of the operation-level, as we discussed in Section 7.2.2.2, it focuses on the first four stages of innovative design (exploration stage, task clarification, concept design and system-level design) by developing flexibility for an organization or an individual. According to the process framework of the four stages, we divide the general flexible process model of innovative design (ref. Figure 7.2) into the four sub-models. For example, as shown in Figure 7.3, with regard to the exploration stage the flexible sub-model adopts the similar model structure of Figure 7.2. And the middle layer only focuses on the basic design 
activities of the exploration stage, not all four stages. Similarly, the other three sub-models also are developed with the same structure.

Generally, this model provides a useful illustration of structured process of design activities. This Vee-model emphasizes validation and verification to achieve the purpose of control. In addition, the circular configuration is meant to suggest that ideas about design problems are expected to flow circulation and iteration between these design activities. So it provides a certain degree of autonomy and liberty for designers. Designers can construct design problems based on the perception of the situation, and search an innovative solution with a wider scope.

\subsection{Activity-based adaptive process model of innovative design}

In the previous sections, we introduce a procedural process model of innovative design to balance innovation and control. Although this procedural model is still macro-level model, it builds up the common understanding of this process of innovative design, and prescribes main process stages and design activities. Based on this process framework or guide, considering a process as "a set of interrelated or interacting activities which transform inputs into outputs" (IEEE Std 15288 2004), we construct the process architecture of innovative design using an activity-based representation.

Because different process architectures can create varied "recipes" for designing a product or service, alternative process architectures result in different degrees of effectiveness and efficiency. Therefore, modeling and comparing alternative process architectures are one of the main aspects of process improvement. As we have analyzed in Section 3.4, most existing activity-based techniques and models to construct the process architecture have two assumptions: first, design activities (including interactions and variables) are known a priori (Browning and Ramasesh, 2007); second, the expected goal can be achieved by these known design activities.

However, this is rarely the reality in innovative design. These management challenges, such as high technological and market uncertainties, the emergent information during the design process, even the participant of designers, can explain that the two assumptions are not appropriate for innovative design. Therefore, it is impossible to develop a complete contingency model, and the activity-based model should evolve as the project proceeds. That is, the process architecture of innovative design is constructed dynamically according to the current state of design.

To address these above issues, we introduce an activity-based adaptive process model that views innovative design as a complex adaptive system (CAS). In order to facilitate 
'real-time orientations' of this process, at each decision point of the process a set of possible activities is considered depending on the current design situation. We offer the designer the possibility to choose among them by assigning a value to each activity. This value is calculated from expert assessments based on the information created by the design activity that increases the probability of successfully satisfying design targets. So this model progressively constructs the process architecture by adaptively selecting design activities. The activity value, as the selecting criterion to balance innovation and control, is determined by expert evaluations based on the current design situation. More precisely, we use the function of the information that reduces complexity and the corresponding design targets in the light of the current design situation. This process model thus becomes adaptive and promotes innovative design.

Discussion proceeds as follows. Section 7.2.1 discusses basic elements and phenomena of the complex adaptive system, and frames innovative design as a complex adaptive system based on characteristics of innovative design. Section 7.3.2 constructs the framework for this adaptive model and defined its model elements. Section 7.3.3 indicates how the model is progressively built using expert evaluations.

\subsubsection{Theoretical basis: Framing innovative design as complex adaptive systems}

The concepts and study of the CAS originate from biology science. Researchers have applied the CAS theory to engineering science (Holland, 1992; Krothapalli and Deshmukh, 1999), organization theory (Anderson, 1999; Dooley and Van de Ven, 1999; Dooley, 1997), supply networks (Choi et al. 2001; Pathak et al. 2007), product design (Chiva-Gomez, 2004) and product development (Lévárdy and Browning, 2009; McCarthy et al., 2006). In order to apply the CAS theory to innovative design, this section will discuss basic elements and phenomena of the CAS, and how these basic phenomena appear in the process of innovative design.

A CAS is a complicated system composed of independent but connected elements, named agents, with the adaptive ability to self-organize, and cause the emergence of new system configurations and corresponding levels of order or disorder (Holland 1992). The CAS lies in the structure and the connectivity of agents (McCarthy et al., 2006). An individual agent is adaptive in response to changes in the environment. In accordance with the view of the bounded rationality, agents cannot anticipate the overall system-level consequences of their individual actions. Actions of agents are depicted with "schemata" that determine which action the agent takes, according to its understanding of the environment (Anderson, 1999). The schemata can refer to norms, values, beliefs (Choi et al. 2001). Each agent observes and acts based on local information only, derived 
from other agents to whom he is connected.

All these characteristics result in the basic phenomena of a CAS, non-linearity, selforganization and emergence and system evolution, which are the basis of adaptability in the CAS. Adaptability, as the ability of a CAS to be changed to fit varied circumstances, is a value variable of system performance (Engel et al., 2012). Through the analysis of characteristics of innovative design, these phenomena also can be found in the process of innovative design, as illustrated bellows.

Nonlinearity. CAS lies in the structure and connectivity between agents. Agents are partly connected to and interact with other agents (McCarthy et al., 2006). CAS behaves in a nonlinear fashion due to this structure and connectivity. For example, greater input changes could lead to small changes in outcome, and vice versa. In other words, CAS is highly sensitive to changes in the environment (Choi et al. 2001).

Self-organization and emergence. Agent actions are depicted using "schemata" that determine which action the agent takes, according to local information only derived from other agents to whom the agent is connected (Anderson, 1999). Through the adoption of simple actions individual agents also interacting with other connected agents, produce a system agency and collective behavior that result in self-organization and the emergence of new system configurations (Choi et al. 2001).

System evolution. A CAS is a nested and hierarchic system that contains other CASs. The latter change and make others around them change too. Therefore, every aspect of the CAS, such as agent schemata, strength and type of connections between agents, and their fitness functions, change over time (Anderson, 1999)..

Based on these CAS concepts, we now explore how the process architecture of innovative design is constructed. Findings are summarized in the form of basic model ideas (see Figure 7.4). The process of innovative design is a CAS devised to fit varying circumstances. Within this framework, design activities correspond to CAS agents; design situations correspond to deliverables that connect design activities; the activity value of each activity refers to the "schemata" of the agent. To illustrate this, the upper part of Figure 7.4 shows two levels of abstraction. In the aggregate view, there are four design activities that partly connect to and interact with other activities. The second level with the disaggregate view shows the activity $\mathrm{A}_{4}$ in greater details with a basic illustration of its schemata (activity value) and potential subsequent activities in design space. According to the current design situation, decisions are needed to select a design activity from the design space based on the activity value. Since iteration is the main characteristic of the innovative design process, the design activity that has been performed before can also be one of the 
potential design activities in the design space. The activity value is determined by the state of the design situation and the design activity itself. The design activity with the highest activity value, such as potential activity $\mathrm{P}_{2}$ in Figure 7.4 is selected as next activity $\mathrm{A}_{5}$. Thus the activity value lies at the core of self-organization and the emergence of a process architecture. After selecting the design activity, the design situation is changed.

A pattern emerges (i.e., a process architecture of innovative design, as shown in the bottom part of Figure 7.4) from a series of selected activities. These activities respond to feedbacks from the emerging process architecture and continually adapt accordingly. A positive feedback (e.g. the emerging process architecture might generate more innovative results, such as new functions, product behavior and structure), these activities expand on their own, and lead to complex global process choices in an aggregate manner. A. negative feedback (e.g. said architecture prevents the discovery of innovative opportunities), these activities will not be subsequently selected. Eventually, the collective choice of these design activities leads to a stable process architecture of innovative design through a number of adaptive iterations.

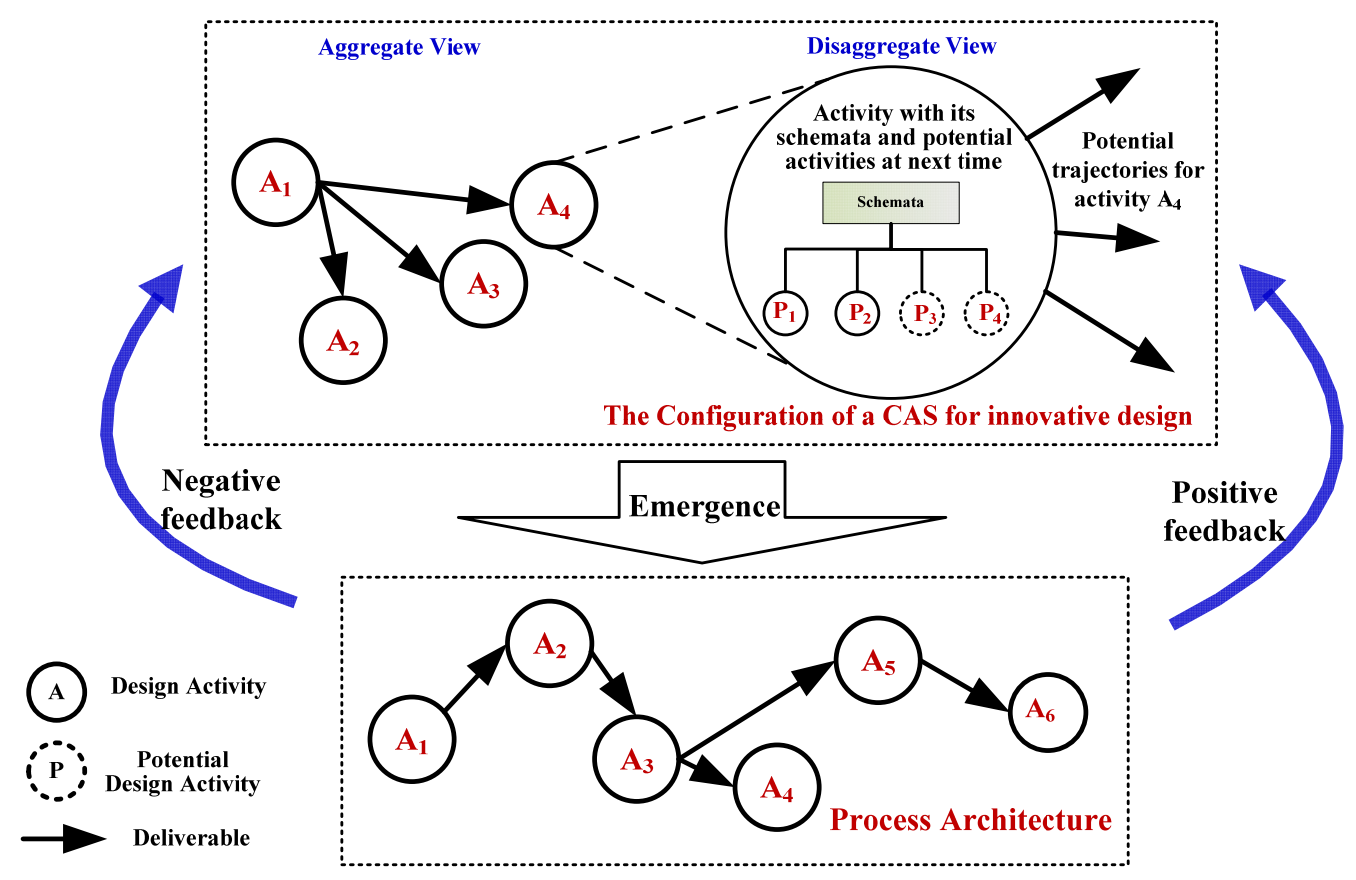

Figure 7.4 Framing innovative design as a CAS

\subsubsection{Adaptive model framework and model elements}

Our proposed adaptive model framework stems from the basic ideas of Figure 7.4. In this section, we will propose the adaptive model framework and its model elements. 


\subsubsection{Model framework}

We perform the evolution of innovative design through a series of state-transitions, as shown in Figure 7.5. In this model, design activities correspond to agents of the CAS; design situations correspond to deliverables that connect design activities. According to the current design situation, decisions need to be made for selecting a design activity from a design space based on the activity value at time $(i)$. The activity value is determined by the state of the design situation and the design activity itself. The design activity with the highest value of activity value, such as the design activity 2 in Figure 7.5, is chosen. The activity value thus is the basis of self-organization and the emergence of process architecture. After performing the design activity chosen, the design situation is changed at time $(i+1)$. Design situations and design activities also evolve over the course of the innovative design. Eventually, the process architecture emerges from the series of activity selections. Therefore, in order to construct the adaptive process model, it is the necessary to the modeling of the design situation, design activity and activity value. We will develop these model elements in the following sections.

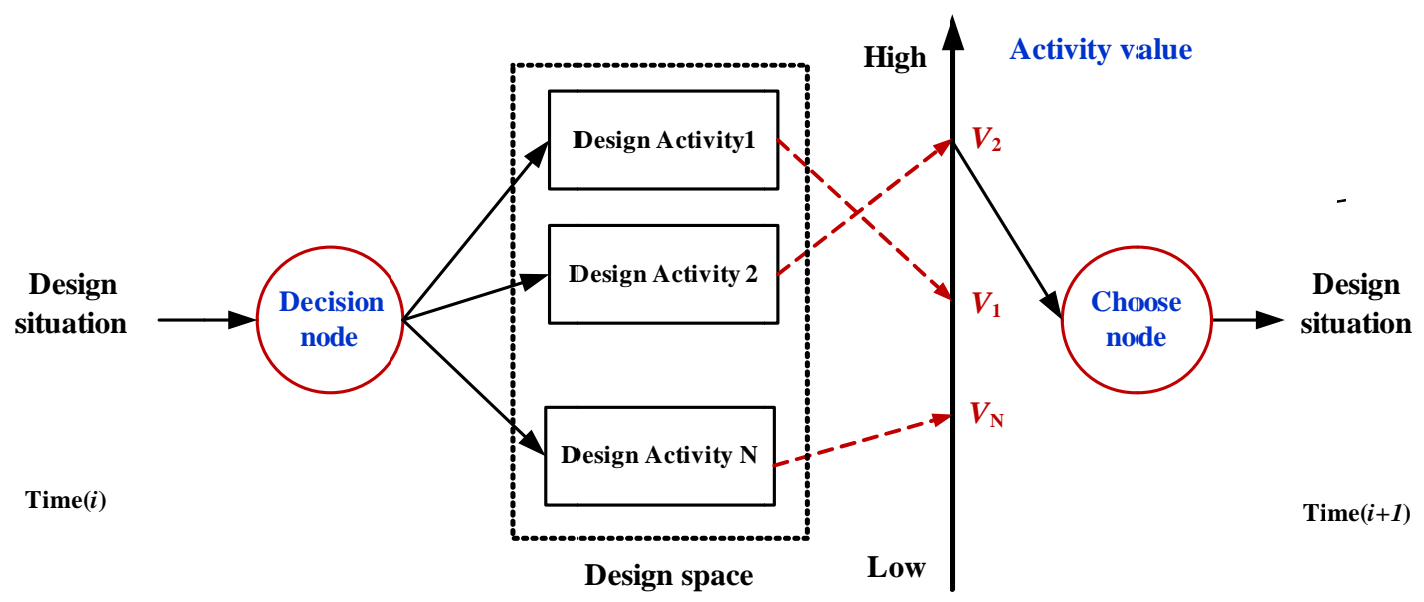

Figure 7.5 The model framework of activity-network adaptive process model

\subsubsection{Design Situation}

Some researchers have modeled the design process through state-transition model. For example, the "Signposting" model considers the confidence level (i.e. the extent of satisfying design specifications) of product parameters as the variety of states (Clarkson and Hamilton, 2000), while the APDP model encompasses cost, schedule, quality (Lévárdy and Browning, 2009). However, these definitions of state are either more detailed or not complete for innovative design. In order to construct a comprehensive representation of the "design situation", we adopt the definition of the design situation introduced in Section 5.4.3 (see Figure 5.15). which is defined as the combination of the state of the varied 
concepts at a certain moment, namely the product being designed, the design context, the stakeholders and the state of design process at that moment (Zhang et al., 2012a), as shown in Figure 7.6. These elements are discussed as follows.

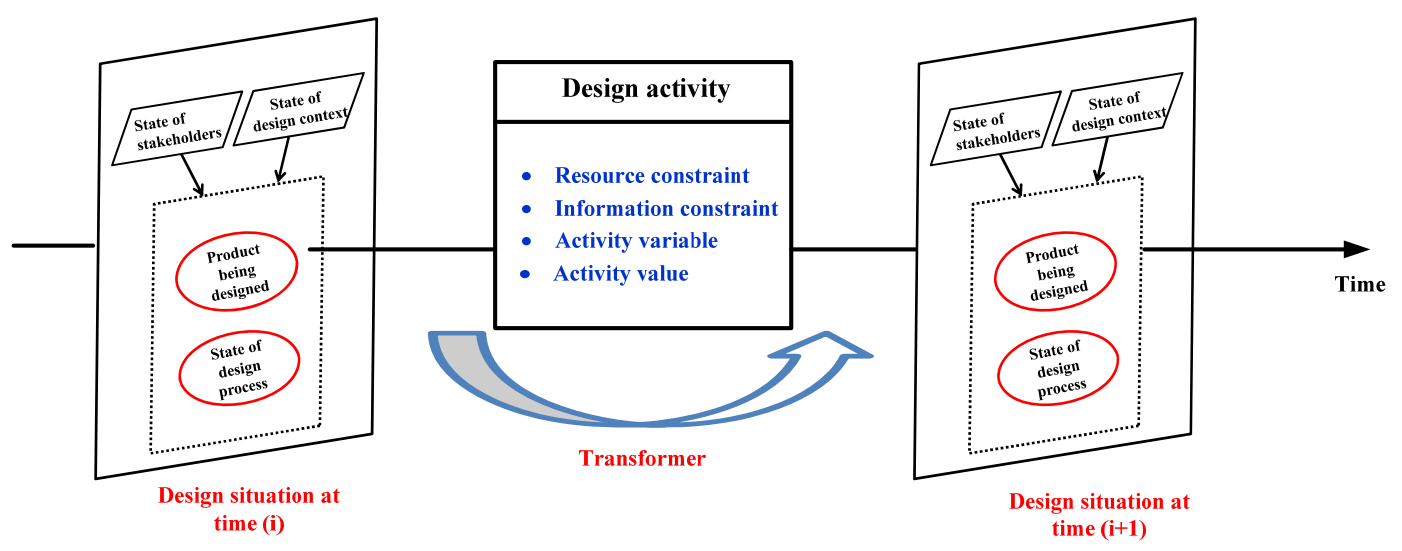

Figure 7.6 The model of design activity and design situation

Product being designed refers to the representation of a product under design because the final product itself does not exist yet during this phase. A design process can be regarded as the mapping of the product's initial state space into the expected state through a series of transformations (design activity). Given a description of the expected product's functions and behaviors, designers propose a structural representation of a product that could produce these functions and meet these behaviors. By constantly modifying the representation of a product in the process of being designed, designers finally arrive at the right solution. Therefore, the state transition of innovative design means the change to representation of said product.

Design context is described as the sets of factors impacting the design state and design process at a certain time. Introducing the design context into the design situation can be performed for three reasons. Firstly, innovative design should provide a means of partitioning concepts and knowledge in order to be more innovative (Hatchuel and Weil, 2009). It is impossible to acquire or generate new knowledge or concepts without a supportive environment. Secondly, the process of innovative design evolves by interacting with its environment. Design context factors, such as organization architecture and organization strategy, influence the process of innovative design. Lastly, designers operate within the design context. Designers perceive and interpret design problems differently as and when the design context changes.

Stakeholder indicates one party with an interest in innovative design. This party consists of internal stakeholders (e.g. project manager, designer and senior manager) and external ones (e.g. customer and supplier). The innovativeness of innovative design 
depends on the stakeholders involved. The latter evaluate the value and novelty of an innovative solution by communicating with the designer. Some new requirements from stakeholders will bring about a change in the product being designed, even a redefinition.

The state of design process is defined as a series of design activities performed by the designer before reaching the current design state. It is useful to know those design activities which will not have the effect on the desired goal and those likely to improve the efficacy of design activities. Designer gains experience from these completed design activities, and adds them to the already accumulated knowledge.

\subsubsection{Design Activity}

A design activity is a transformation aimed at reaching the design goal at that moment, carried out by designers, causing the change of elements to the design situation. Many activity-based models such as the Signposting model (Clarkson and Hamilton, 2000) and the APDP (Lévárdy and Browning, 2009) model, associate aspects of product-related uncertainty to the design activity. These models qualify the information that the activity requires and the product by describing different aspects of its maturity. Recently, Wynn et.al (2011) specified the design activity as a function of uncertainty levels associated with input descriptions to study the impact of evolving uncertainty levels on the design process. In this paper we summarize the aforementioned representations to depict the design activity. Properties of design activity are (i) resource constraint; (ii) information constraint; (iii) activity variable; (iv) activity value. The first three are detailed below, and the last one will be discussed in Section 7.3.2.4.

Resource constraint and information constraint dictate the resource and information requirement of each design activity. Each constraint indicates the number and variety of resource units and information which the activity requires to operate. Since design activities tend to be interdependent, each one requires information from other design activities. A design activity cannot be carried out until there is sufficient information available. Likewise, if the amount of resources in the current situation is not sufficient, the design activity cannot be performed.

Activity variable represents the attributes needed to carry out the dlesign activity. What matters here is the cost and duration of a design activity. The triangular probability distribution is employed to depict the cost and duration of design activity since it is difficult to get these values in real time. For each design activity, three estimates are given (optimistic, most likely and pessimistic) for the expected value of durations and costs of one-time execution. . 


\subsubsection{Activity value}

Activity value is a dynamic measurable variable that serves as basis for choosing the design activity in the adaptive model. Within different design situations, the same design activity may have different design performances, that is to say, different activity values.. Browning et al. (2002) define the value as the useful information that reduces uncertainty and/or ambiguity; Chase (2000) proposes a metric consisting of eight types of attributes (performance, risk, schedule, cost, form, fit, function and timelines ) to define the value; Gries and Gericke (2009) define the value in terms of knowledge generation and influence degree for subsequent activities.

As discussed before, the innovative design process is described in terms of mapping between design situations through a series of design activities. Design targets for a product are represented in terms of product description. The design activity is intended to achieve the set of specified targets by mapping the initial design situation to the expected one. Thus, the selection of a design activity determines the probability of achieving these targets.

According to the analysis above, as for a successful innovative product, the probability of achieving design targets increases over time during the design process (see Figure 7.7). At the start of an innovative design process $\left(t_{0}\right)$, due to the unavailability of information and project uncertainty, designers' probability of reaching the targets is at its lowest. As more information produced by a series of design activities becomes available, this probability reaches a peak at the end of the design $\left(t_{f}\right)$. In other words by producing and making information available, the design activity can increase the probability of achieving design targets. As shown in Figure 7.7, during a design activity (interval $\Delta t$ ), the information produced by the design activity causes a probability increase $(\Delta p)$. Thus, the activity value is defined as the information produced by the design activity which increases the probability of successfully achieving design targets.

Figure 7.7 depicts the ideal innovative design process where probability increases monotonically over time. However, in practice over the course of design, the change in probability between time $\left(t_{i}\right)$ and time $\left(t_{i+1}\right)$ depends on the current design situation. Figure 7.8 depicts some alternative probability profiles. In designs $\mathrm{B}$ and $\mathrm{C}$, the overall composite probability increases more steadily, but the change in probability may decrease at some intervals. At these points, some activities may create information that will reveal a high activity value, but are revising (downward) the probability added by previous activities (q.v., the downward-sloped portion of Design B in Figure 7.8), or vice versa (q.v., the upward-sloped portion of Design B in Figure 7.8).In the former case, not all information created by these activities is useful for meeting design targets. For example, the necessary activities that are used to explore several new product concepts may involve a risk of failure. 
If this happens, the information (knowledge) generated by these activities cannot directly contribute to the achievement of the current design targets. In the latter case, these activities increase the probability of satisfying design targets in several areas and from several perspectives, in addition to the information content, such as, test activity.

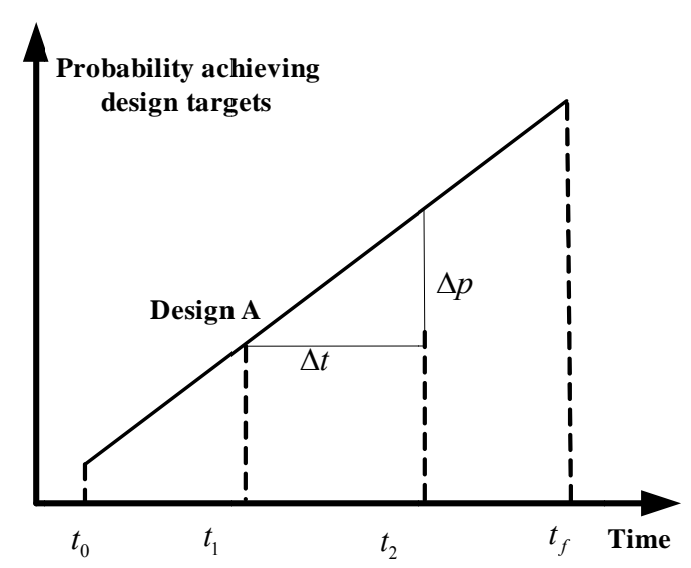

Figure 7.7 The profile of the probability of achieving design targets

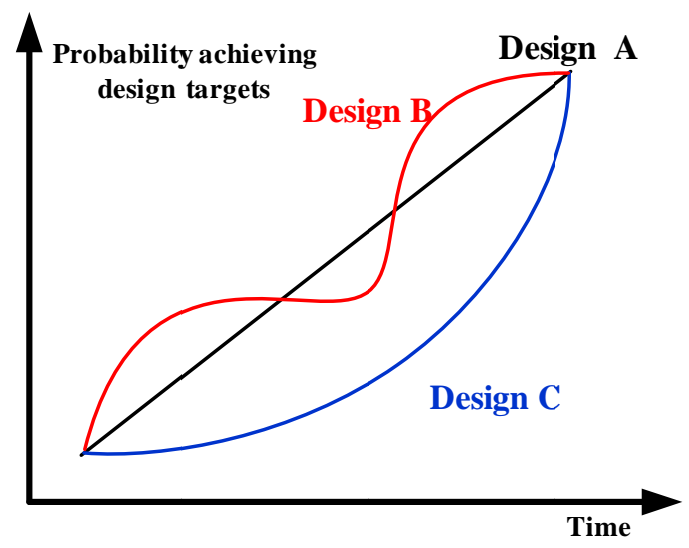

Figure 7.8 Alternative profiles of the probability of achieving design targets

\subsubsection{Expert evaluation to adapt the model}

This section presents an expert evaluation to elaborate the adaptive design process presented in Figure 7.5, and makes it evolve along the project progress with the objective to balance innovation and control. Section 7.3.3.1 introduces the basic steps of the evaluation. Section 7.3.3.2 constructs design targets of innovative design as the basic element of the evaluation, and Section 7.3.3.3 specifies the evaluate methods.

\subsubsection{Evaluation Steps}

At given steps in the design (decision nodes), the objective is to determine in the current design situation, the activity which should then be performed among a set of 
potential activities. Expert evaluation is proposed to guide in the decision process. In what follows we describe the basic evaluation steps of expert evaluation.

\section{Step 1: Establishing the design space at time (i)}

The design space includes a series of potential design activities that designers or project planners can anticipate based on the current design situation. Lévárdy and Browning (2009) proposed a method for developing the superset of activities including all possible activity modes based on the work breakdown structure. As innovative design involves a large amount of foreseen and unforeseen uncertainties (De Meyer et al., 2002), it seems impossible to list all design activities. The design space should therefore be kept open to enable designers to add activities when they find new ones.

\section{Step 2: Constructing the set of targets for each potential design activity}

As a basis for evaluation, it should first define targets and specify target value ranges. Since design targets vary with the stage of the innovative design process, these targets should be selected according to the current design situation. On the one hand, we thus define a set of design targets in terms of innovation and control. Generally, these targets allow designers to evaluate the balance between innovation and control at a given step in the design process. On the other, the whole process of innovative design can be broken down into nine elementary processes. It will be helpful to assess the distance separating these targets from the process achievement. More details will be given in Section 7.3.3.2.

\section{Step 3: Evaluating the activity value of each potential design activity}

When design targets and their value ranges for each potential design activity are defined in Step 2, we specify the activity value as a logarithmic function of these design targets and the goal for each one. We combine these to arrive at a numerical value related to the information created by the activity at time $(i)$. The practical evaluation method will be discussed in Section 7.3.3.3.

\section{Step 4: Selecting the most appropriate design activity}

The evaluation result of Step 3 allows us to select the most adequate design activity with the highest value in terms of numerical value.

\subsubsection{Constructing design targets}

\section{(1) Defining design targets}

We define design targets for innovative design in terms of control and innovation (for more details see Table 7.2.). In terms of control, emphasis is placed on ensuring accuracy of 
deliverables to downstream activities, and delivering adequate output on time, cost and technology performance. So the main control-related targets are technical performance, product unit-cost and time-to-market (Tatikonda and Rosenthal, 2000). However, the successful execution process does not mean that a new product can be accepted by customers. Whether or not the new product accurately meets changing customer requirements is also the main target of product design (Unger 2003). Thus, the chosen "design to" functions that the customers would specify are also the control-related target.

Differing from routine design in which prototypes with variables and structures do not change, innovative design tries to break away from existing design prototypes to generate new ones (Le Masson et al., 2010). Gero (1990) proposed three classes of variables (function, behavior, structure) to describe different aspects of a design object. Based on this, we define the innovation targets with respect to the function, behavior and structure of the product (Howard et al., 2008).

Table 7.2 Design targets of innovative design

\begin{tabular}{|c|c|c|}
\hline Dimension & Description & Design targets \\
\hline \multirow{4}{*}{ Control } & $\begin{array}{l}\text { Design targets regarding a product's technical attributes } \\
\text { and compliance with its technological requirements, } \\
\text { assessing whether product design is technologically } \\
\text { feasible and performs as expected. }\end{array}$ & - Technical performance \\
\hline & $\begin{array}{l}\text { Design targets regarding a product unit-cost and project } \\
\text { cost, assessing whether a product is designed in } \\
\text { accordance with the financial resource available. }\end{array}$ & - Unit-cost \\
\hline & $\begin{array}{l}\text { Design targets regarding project duration, assessing } \\
\text { whether a product is designed within the allotted time. }\end{array}$ & - Duration \\
\hline & $\begin{array}{l}\text { Design targets regarding product functionality, assessing } \\
\text { whether product design meets customer requirements. }\end{array}$ & - Function \\
\hline Innovation & $\begin{array}{l}\text { Design targets regarding product's innovativeness for } \\
\text { customers in terms of function, behavior and structure, } \\
\text { assessing whether product design meets innovation } \\
\text { requirements. }\end{array}$ & $\begin{array}{l}\text { - Innovation } \\
\text { (function, behavior, } \\
\text { structure) }\end{array}$ \\
\hline
\end{tabular}

\section{(2) Correspondences between design stages and design targets}

Since different design stages exhibit specific targets, the activity value varies according to the design stage. For example, targets at the concept design stage might address the assessment of customer requirements while the verification stage might deal with the cost of prototyping. Before clarifying the design targets of different design stages, it is necessary to describe fully the design stages of innovative design. Using the Function-Behaviour-Structure (FBS) model, we divide the whole process of innovative design into nine elementary processes (see Table 7.3). 
Gero (1990) proposed the FBS model of design as theoretical basis for understanding design. According to this model, design consists of eight elementary processes e defined in terms of key concepts of function, behaviour and structure. Five of them transform the desired functions of the artefact into the design descriptions in sequence. The first process is called formulation process (process 1) and transforms functions $(\mathrm{F})$ into behaviour $(\mathrm{Be})$ expected to enable the functions. Secondly, the expected behaviour $(\mathrm{Be})$ is transformed by the synthesis process (process 2) into solution structure (S) intended to exhibit this desired behaviour (Be). Then the analysis process (process 3 ) derives the actual behaviour (Bs) of the artefact from the synthesized structure (S). Fourthly, this actual behaviour (Bs) is evaluated by comparing it with the expected behaviour $(\mathrm{Be})$ in Process 4 . If the evaluation result is satisfactory, the design description (D) is documented for manufacturing the artefact with structure (S) (process 5). If not, the design process will return to three elementary loop-back processes (processes 6-8), within which it generates new structure $\left(\mathrm{S}^{\prime}\right)$, new expected behaviour (Be') and new function ( $\left.\mathrm{F}^{\prime}\right)$, turning designing into an iterative procedure.

Due to a lack of comprehensive representation of the sources of innovation in the FBS model, Processes 1-8 are restricted to the internal process of innovative design. To better and comprehensively exploit the innovative design process, we add requirements $(\mathrm{R})$ to the FBS model (Zhang et al., 2012a), to add the exploration process (Process 0). In this process, the designer analyzes the requirements(R), which derive from the technical advance and the market needs, leading to the interpreted functions (F). Then the functions (F) are augmented by the designer's own experience or the firm's accumulated knowledge.

Hence, the whole process of innovative design is extended to the nine elementary processes (processes 0-8). Table 7.3 also shows the relationship between design stages and design targets. The empty circle $(\mathrm{O})$ denotes dependence of the design stage on the design targets. These processes correspond to different design targets as indicated in the first row of Table 7.3.

The "Innovation" column depicts the design target in accordance with the degree of creativity. The creative process forms an integral part of innovative design. Three creative process elements (analysis, generation and evaluation) can be mapped onto a view of the design process. Processes $0,1,2,6,7$ and 8 correspond to the generation stage of the creative process, resulting in the generation of a new function, a new behavior or a new structure. Hence, these processes should consider the degree of creativity as one of the design targets. The "Function" column represents the design target for the product function. Processes 0 and 8 involve the creation of functions through a transformation of requirements or structures. Whether these functions can meet the requirements or match the 
structures is the main issue within these processes. Since processes 0 and 1 occur at the initial stage of innovative design, it may not be possible to know whether certain requirements will be met. In that case, the likelihood of fulfilling technical performance may not be assessed. Additionally, processes 3, 4 and 5 focus on analysis activity only, and not on an increase in technical performance. As a result, only processes 2, 6, 7 and 8 should address technical performance in the "technical performance" column. The "unit-cost" column indicates that a product's economic characteristics should be viewed as constraints. A product should be sold at the right price. Hence, the economic aspects should be taken into account whilst design solutions are being produced (i.e. processes 1,2,6,7 and 8). The "duration" column represents the time spent. The expected duration is the key process metrics and objective functions used by most of models. Therefore, to make sure the deadline has not been exceeded, duration should be monitored in every process (processes $0-8)$.

Table 7.3 The corresponding relationship between design stages and design targets

\begin{tabular}{|c|c|c|c|c|c|}
\hline \multirow[b]{2}{*}{ The nine elementary process of innovative design } & \multicolumn{5}{|c|}{ Design targets } \\
\hline & Innovation & Function & $\begin{array}{c}\text { Technical } \\
\text { performance }\end{array}$ & $\begin{array}{l}\text { Unit } \\
\text { cost }\end{array}$ & Duration \\
\hline $\begin{array}{lll}\text { Process0 } \quad \mathrm{R} \rightarrow \mathrm{F} & \begin{array}{l}\text { Transformation of customer requirements } \\
\text { into functions expected to contribute to } \\
\text { these requirements }\end{array}\end{array}$ & $\begin{array}{c}\bigcirc \\
\text { new } \\
\text { function }\end{array}$ & O & & & O \\
\hline $\begin{array}{cc}\text { Process } 1 \quad \mathrm{~F} \rightarrow \mathrm{B}_{\mathrm{e}} & \begin{array}{l}\text { Transformation of these functions into } \\
\text { behaviors that are expected to enable the } \\
\text { functions }\end{array}\end{array}$ & $\begin{array}{c}\bigcirc \\
\text { new } \\
\text { behavior }\end{array}$ & & & O & O \\
\hline $\begin{array}{ccc}\text { Process2 } & \mathrm{B}_{\mathrm{e}} \rightarrow \mathrm{S} & \begin{array}{l}\text { Transformation of the expected behaviors } \\
\text { into a solution structure that is intended } \\
\text { to exhibit the desired behaviors. }\end{array} \\
\end{array}$ & $\begin{array}{c}\text { O } \\
\text { new } \\
\text { structure }\end{array}$ & & O & O & O \\
\hline $\begin{array}{ll}\text { Process3 } & \mathrm{S} \rightarrow \mathrm{B}_{\mathrm{s}} \begin{array}{l}\text { Derivation of the 'actual' behaviors from } \\
\text { the synthesized structures }\end{array}\end{array}$ & & & & & O \\
\hline Process $4 \quad B_{s} \leftrightarrow B_{e} \begin{array}{l}\text { Comparison the behavior derived from } \\
\text { structure with the expected behavior }\end{array}$ & & & & & O \\
\hline Process $5 \mathrm{~S} \rightarrow \mathrm{D}$ Production of the design description & & & & & O \\
\hline Process6 $\mathrm{S} \rightarrow \mathrm{S}^{\prime}$ Choice of a new structure & $\begin{array}{c}\mathrm{O} \\
\text { new } \\
\text { structure }\end{array}$ & & O & O & O \\
\hline Process $7 \mathrm{~S} \rightarrow \mathrm{B}_{\mathrm{e}}$ Choice of new expected behavior & $\begin{array}{c}\mathrm{O} \\
\text { new } \\
\text { behavior }\end{array}$ & & $\mathrm{O}$ & $\mathrm{O}$ & O \\
\hline Process8 $\quad \mathrm{S} \rightarrow \mathrm{F}^{\prime}$ Choice of new functions & $\begin{array}{c}\mathrm{O} \\
\text { new } \\
\text { function }\end{array}$ & O & O & $\mathrm{O}$ & O \\
\hline
\end{tabular}

$\mathrm{R}$ : requirement; F: function; $\mathrm{S}$ : structure; $\mathrm{B}$ : behavior; $\mathrm{B}_{\mathrm{e}}$ : expected behaviors; $\mathrm{B}_{\mathrm{s}}$ : behavior derived from structure 


\subsubsection{Evaluating the activity value}

As defined in Section 7.3.2.4, the activity value is defined as the information produced by the design activity that increases the probability of successfully fulfilling design targets. Here, the overall activity value is calculated using the following equation:

$$
V=\sum_{i} w_{i} I_{i}
$$

where, $i$ stands for target $T_{i}$ for the design activity, the $i$ sum denotes the number of target $T_{i} ; w_{i}$ is the weight, and all $w_{i}$ sum to one. Since the activity value depends on the design situation, $w_{i}$ is the dynamic factor determined by the current needs in the particular targets identified. $I_{i}$ stands for information produced by the activity that increases the probability of fulfilling target $T_{i}$.

In information theory, entropy refers to the expected value of information in a message. Within the context of a probabilistic model Shannon defined entropy and proposed an entropy rationale (Shannon, 1948). In this paper, each individual $I_{i}$, following the equation of information entropy, is evaluated as:

$$
I_{i}=\log _{b}\left(P_{i}\right)^{-1}
$$

where, $P_{i}$ stands for the probability of achieving target $T_{i}$. Thus, in order to evaluate each $I_{i}$, it is essential to specify the actual possible range and the target value range for a specified target $T_{i}$.

However, given the difficulty of getting information for each target $T_{i}$ in Table 2, different methods are used to evaluate $I_{i}$. Therefore, we will discuss the evaluation method in the case of design target "innovation" and other control-related targets.

(1) Evaluation of innovation performance

Innovation performance reflects the degree of creativity of the product's design variables (i.e. function, behavior, structure) in a design activity. Mensch (1979) studied the frequency of innovation with different degrees of creativity. He noted that radical innovation happens 29 times, and major improvement innovation 145 times, while the frequency of minor product or process differentiation with new technology occurs 760 times during the period 1953-1973. In other words, the greater the degree of creativity, the smaller its frequency. As for innovative design, there is a lower probability (or higher uncertainty) for a design activity whose degree of creativity is important. More information is needed to get the generation of radical design variable(s). 
According to information theory, a random variable with a greater probability (uncertainty) contains more information. Hence, one considers the valuation of information embedded in the design as the representation structure for the evaluation of innovation performance. Here, the information content $\left(I_{\text {innovation }}\right)$ of innovation performance for a design activity is assessed by calculating the uncertainty of change in the state space of the product being designed.

Let $X_{1}, X_{2}, \cdots, X_{L}$ be independent, where each $X_{l}$ denotes a new design variable (function, behavior and structure) generated by a design activity, and $L$ is the number of changed design variables. Furthermore, $P\left(X_{l}\right)$ is the probability for $X_{l}$ occurrence, which reflects the degree of creativity of $X_{l}$. If $X_{l}$ is a new function with the higher degree of novelty, meaning that $P\left(X_{l}\right)$ is smaller. According to the information theory, information for $X_{l}$, as innovation performance of $X_{l}$, can be defined as

$$
I_{\text {innovation }}\left(X_{l}\right)=\log _{b}\left(P\left(X_{l}\right)\right)^{-1}
$$

Since $X_{l}$ is independent, the information content of innovation performance for a design activity $I_{\text {innovation }}\left(X_{1}, X_{2}, \ldots, X_{L}\right)$ can be defined as

$$
\begin{aligned}
& I_{\text {innovation }}\left(X_{1}, X_{2}, \ldots ., X_{L}\right)=I\left(X_{1}\right) I\left(X_{2}\right) \ldots \ldots . . I\left(X_{L}\right) \\
& =\log _{b}\left(P\left(X_{1}\right) P\left(X_{2}\right) \ldots \ldots . . P\left(X_{L}\right)\right)^{-1}
\end{aligned}
$$

Hence, in the case of innovation performance, information content $I_{i}$ of Equation (2) is computed using Equation (4).

The next question is to determine how to generate the value of $P\left(X_{l}\right)$. Since the degree of creativity is related to $X_{l}$ 's distance from the current design paradigm, $P\left(X_{l}\right)$ depends somehow on the particular design problems. Moreover, different ways of generating of $X_{l}$ result in different degrees of creativity. In the absence of further information, the estimate is employed to generate $P\left(X_{l}\right)$ by expert assessment. Designers may rely on various methods such as the Delphi method or the AHP method to estimate the value of $P\left(X_{l}\right)$.

(2) Evaluation of control performances

Unlike innovation performance, values of control-related targets listed in Table 7.2 can be estimated early in the design process, as soon as the baseline is built. In addition, the functional requirements and technical performance become more accurate as design progresses. After specifying each target value, the next step is to generate the possible outcomes of this design activity. As designers do not have much information about all possible outcomes for these targets, these potential outcomes can be depicted using the optimistic value, the mostly like value and the pessimistic value forming a triangular 
probability distribution function (PDF) (Figure 7.9.). The PDF of the design activity illustrates possible outcomes and the relative probability. The actual range determined by the PDF may differ from target value, as shown in Figure 7.9. The overlapping portion shows the probability of successfully satisfying the design targets (shaded area in Figure 7.9.)

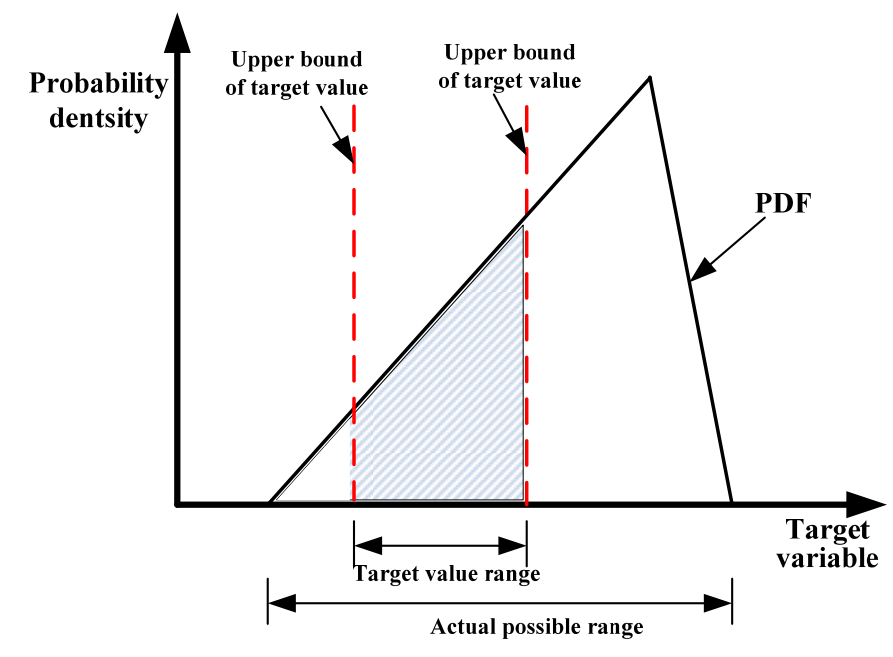

Figure 7.9 Probability of successfully satisfying design targets

According to the Figure 7.9, if the actual possible range for a specified target $\left(T_{i}\right)$ is represented $p_{x}\left(T_{i}\right)$ (e,g, the probability density function of the target), probability $P_{i}$ of achieving $T_{i}$ is computed using the following equation:

$$
P_{i}=\int_{G_{x}{ }^{l}}^{G_{x}{ }^{u}} p_{x}\left(T_{i}\right) d\left(T_{i}\right)
$$

Where, $G_{x}^{l}$ and $G_{x}{ }^{u}$ stand for lower and upper values of the target value range. In addition, since the target values of the "product unit-cost" and "duration" items are single numerical values, there is no lower value. Hence, for these two design targets, the probability $P_{i}$ of achieving $T_{i}$ follows Equation (6):

$$
P_{i}=\int_{-\infty}^{G_{x}} p_{x}\left(T_{i}\right) d\left(T_{i}\right)
$$

Then, the information content $I_{i}$, of Equation (2) can be transformed into the following equations according to the design target:

$$
I_{i}=\log _{b}\left(\int_{G_{x}{ }^{u}}^{G_{x}{ }^{l}} p_{x}\left(T_{i}\right) d\left(T_{i}\right)\right)^{-1}
$$


Or

$$
I_{i}=\log _{b}\left(\int_{-\infty}^{G_{x}^{l}} p_{x}\left(T_{i}\right) d\left(T_{i}\right)\right)^{-1}
$$

\subsubsection{Stylized example}

The complete evaluation steps for a simple design activity during embodiment design are now demonstrated. According to the steps detailed in Section 7.3.3.1, the design space at that particular time is defined. Here, design space includes three potential activities, two of which can be considered as general innovative design activities (Activity 1, Activity 2 ), while the remaining one of accounts for rework modes designed to overcome specific failures (Activity 3). Then, design targets are drawn up for these activities and their target value range is predefined. Because these activities are part of the embodiment design (i.e. process 2 in Table 7.3), according to Table 7.3, design targets consist of three items: innovation in structure, technical performance (the target value range $<0.2,0.4>$ ), unit cost (target value: 10) and duration (target value: 2 ).

The third step computes the value of the three potential activities. For example consider Activity 2. According to Equation (1), $i$ equals 4, the activity value of Activity 2 $V_{2}=w_{1} I_{\text {innovation }}+w_{2} I_{t}+w_{3} I_{c}+w_{4} I_{d}$, where $I_{\text {innovation }}, I_{t}, I_{c}, I_{d}$ respectively refer to information produced by Activity 2 to increase the probability of achieving design targets in terms of innovation performance, technical performance, unit cost and duration. With respect to their respective weightings in Equation (1), they are assumed to be as follows: $w_{1}=0.6, w_{2}=0.3$, and $w_{3}=0.1$. Since the creative outcomes of embodiment design (process 2 ) focuses on product structure, in this example designers estimate that three new structure variables may emerge, $\left(X_{S 1}, X_{S 2}, X_{S 3}\right)$, generated by Activity 2, with a probability of occurrence of $0.7,0.6$ and 0.3 respectively. Thus, based on Equation (4), $I_{\text {innovation }}=\log _{2}\left(\mathrm{P}\left(X_{S 1}\right) \mathrm{P}\left(X_{S 2}\right) \mathrm{P}\left(X_{S 3}\right)\right)^{-1}=$ $\log _{2}\left(0.7 * 0.6^{*} 0.3\right)^{-1}=2.98$. Meanwhile, designers respectively ascribe the optimistic value, mostly like value and pessimistic value of technical performance $(0.1,0.6,0.9)$, unit-cost (3, $9,12)$ and duration $(1,3,9)$ for Activity 2 to create the triangular PDFs. Given the target value ranges for the three targets, based on their PDFs and Equations (7) and (8), one gets $I_{t}$ $=2.32, I_{c}=0.23, I_{d}=4$. In other words, the activity value of Activity 2 $V_{2}=w_{1} I_{\text {innovation }}+w_{2} I_{t}+w_{3} I_{c}+w_{4} I_{d}=2.32 * 0.6+0.23 * 0.3+4 * 0.1=1.861$. Similarly, the activity value of Activity $\left(V_{l}\right)$ and Activity $3\left(V_{3}\right)$ are 1.342 and 1.57 resp. Therefore, we select Activity 2 with the highest activity value as the next design activity based on this evaluation result.

\subsection{Conclusion and discussion}

This chapter mainly addresses the research issue "management support". That is, it 
shows that how to use the process modeling to support the balance between control and innovation. We developed the procedural process model and the activity-based adaptive model to achieve this purpose. To summarized:

The procedural process model is constructed by the two levels. In the project level, we construct the formal structured process based on the Vee-model. We identify the main stages of innovative design and each stage's main activities, and place these into the Vee-model, thereby forming the whole process framework. In the operation-level, the multi-layer circular process model is built up to develop flexibility. In this circular process model, it emphasizes the interaction between design activities underlying of each stage, and much more importantly, the interaction process between the designer, the design process and the outside environment.

The procedural process model could be a starting point for developing more effective management methods and tools to be used by companies in practices. These methods and tools have the advantages that creativity activities are performed regularly based on a systematic approach. This should help to reduce the uncertainty of innovative design, to generate more innovative ideas, and to design innovative products more quickly.

However, the current model is still a high-level description for innovative design. Having a portfolio of detailed models and detailing available will help companies and designers to better deal with the process. Therefore, the next step should answer the question "How and at what level should we decompose the high-level model to provide the daily decisions for designers and managers?"

In the second step, we develop an activity-based process model that viewed innovative design as a complex adaptive system. In contrast to conventional process models that predefine the process architecture, we adaptively select design activity by the activity value in the light of the current design situation. Moreover, this model contributes a method to evaluate the activity value of innovative design as a function of the information that reduces complexity. The method is based on the comprehensive understanding of design stages of innovative design and their design targets, and it integrates the evaluation of innovative performance and other design targets to balance innovation and control. 


\section{VERIFICATION AND REFLECTION}

\subsection{Verification of procedural process model}

\subsubsection{Verification framework}

As discussed in Section 7.2, the procedural process model is respectively developed in the project-level and the operation-level. In the project-level, the Vee-model provides the structured process framework for innovative design. In the operation-level, the circular model with three layers maps the flexible practices into process elements of innovative design. Hence, in order to verify this model, it should consider the effectiveness of this procedural process model in terms of the process structuration and the process flexibility. Starting from these statements, the verification should answer questions as follows:

(1) Is the process structuration of the procedural process model effective and appropriate for innovative design?

(2) Is the circular framework with three layers in the first four stages of the procedural process model effective and appropriate for innovative design?

Since the procedural process model is the conceptual framework of innovative design, it is difficult to apply it into the practice. Here, we compare a series of innovative design project that has been performed with the procedural process model to achieve the verification purpose (see Figure 8.1). The verification process is performed in two parts. The upper part of Figure 8.1 focuses on the verification of the process structuration of this model, while the down part mainly verifies the circular model.

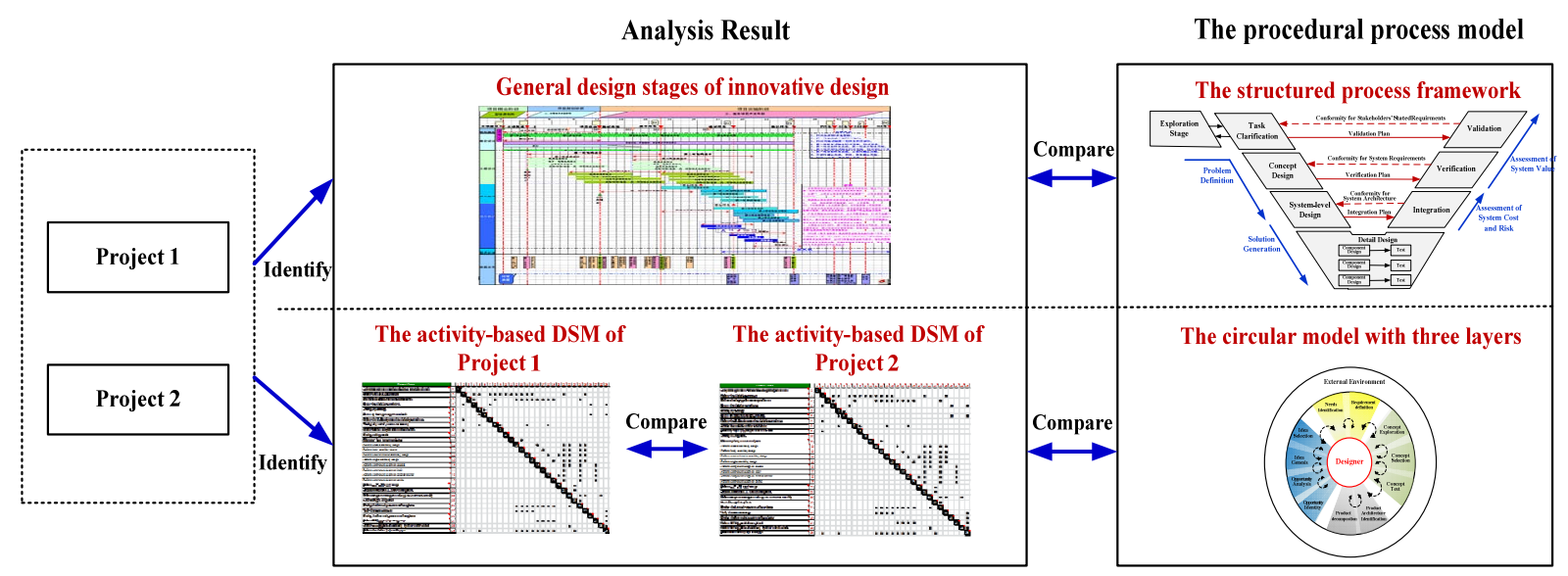

Figure 8.1 The verification framework of the procedural process model 
As for the first part, we firstly identify and analyze the main design stages of the selected projects, and construct the general design stages and their relationships. Then we compare the identified general design process with the structured process framework of the procedural process model (i.e. the Vee-model, see Figure 7.1), to verify whether the structured process framework could be appropriate for these innovative design projects, and observe whether the identified relationships between design stages could be described by the process framework.

With regard to the second part, it needs to perform a much deeper analysis of design activities for these innovative design projects, including the identification of design activities, the flow interaction and the data interaction between these design activities. Thereby we develop the design structure metric (DSM) of each project. Through the comparison between the interactions happened within each project, we attempt to distinguish the differences of these projects, and thereby combine with the performance of each project, to verify the efficiency and the appropriateness of the circular framework

As the premise of the verification, the selection of innovative design projects should follow some criteria: (1) the selected innovative design project should have different performance (e.g. the profit, the market share). (2) there are a great variety of variables that influence the performance of the innovative design project. In order to reduce the dependent variables, the verification should concentrate on the innovative design projects managed by the same company; (3) it needs to follow a longitude study of the selected project from the beginning of execution to the completion.

\subsubsection{Case description and data synthesis}

\subsubsection{Case description}

According to these criteria above, two innovative design projects that have been conducted in the same automobile company (Chery Automobile Co. Ltd) are represented here as the case studies. In fact, the two projects have been studied in Section 6.4. But this purpose of the previous empirical study is to discuss managerial practices, not design activities and the process of the whole project. Therefore, the current case study needs a deeper analysis of design activities performed by these projects.

To recap, the brief descriptions of the two cases are shown in Table 8.1. Through interviews with the project managers and designer, there is the common conclusion that the Project 1 is much more successful than Project 2.

Table 8.2 provides evidences to support this conclusion. The mini-car that the Project 1 designed all the time occupies the first rank of the market of mini-car in China since the 
launch, and the profit margin is higher than the average of profit margin of the Chinese market $(27.58 \%)$. However, as for the Project 2, whether the market share or the profit margin has a lower performance than the first one. Therefore, different performances are the comparison base of the two design projects.

Table 8.1 The Brief description of two automobile innovative design projects

\begin{tabular}{|c|c|}
\hline Item & Description \\
\hline (1) & $\begin{array}{l}\text { - This project aimed to design first mini-car with appealing look and fashionable } \\
\text { configurations to cater for fashion-conscious people. Before the project, there is no } \\
\text { existing successful mini-car in the Chinese automobile market, the customers have litter } \\
\text { consumption experience about it. } \\
\text { - After developing a series of automobiles, the design teams can expertly manipulate these } \\
\text { existing technologies. } \\
\text { - This automobile is launched in June } 2003 \text { after a development period of about } 28 \\
\text { months. }\end{array}$ \\
\hline (2) & $\begin{array}{l}\text { - The SUV enjoys great popularity since the first SUV is introduced into the China. The } \\
\text { company thus decided to design the related automobiles to gain the market share. } \\
\text { - Because the SUV is a completely new platform, whatever the style design, engine design } \\
\text { or structure design need new devices and knowledge. } \\
\text { - This automobile s launched in March } 2005 \text { and it lasted about } 28 \text { months }\end{array}$ \\
\hline
\end{tabular}

Table 8.2 The marketplace and economic indicators of the two projects

\begin{tabular}{r|ccc}
\hline Item & Rank of market share & Profit margin & Number of sales \\
\hline (1) & 1 & $36.26 \%$ & $\begin{array}{c}1000,000 \\
\text { (the period from 2003 to 2010) }\end{array}$ \\
\hline (2) & 17 & $27.34 \%$ & $\begin{array}{c}50,000 \\
\text { (the period from 2005 to 2010) }\end{array}$ \\
\hline
\end{tabular}

\subsubsection{Data synthesis}

The data analysis is done in two steps. The first step is to compare the process stages between the procedural process model and the whole automobile development process. By analyzing the documentation and interview with process engineers, the whole automobile development process consists of the product planning stage, the concept stage and the development stage (see Figure 8.2). According to the check points, this process can be decomposed into a series of sub-processes (P0, P1.., and P9) in further. The main design activities are performed in the processes $\mathrm{P} 0 \sim \mathrm{P} 6$, such as concept design and digital engineering design. The comparison result is shown in Table 8.3. The first row is the process stages listed in the procedural process stages in Section 7.2. The second row is the design process of the two projects that correspond to the stages of the first row.

The second step is to compare design activities between the two projects. Based on the 
above basic process model and the procedural process model, the analysis details are summarized in Table 8.4. This comparison focuses on design activities of the first four stages of the procedural process model. The rows represent the sub-processes or process of the four stages, while the columns indicate the number of activities identified and the number of their flow and data interactions from left to right.

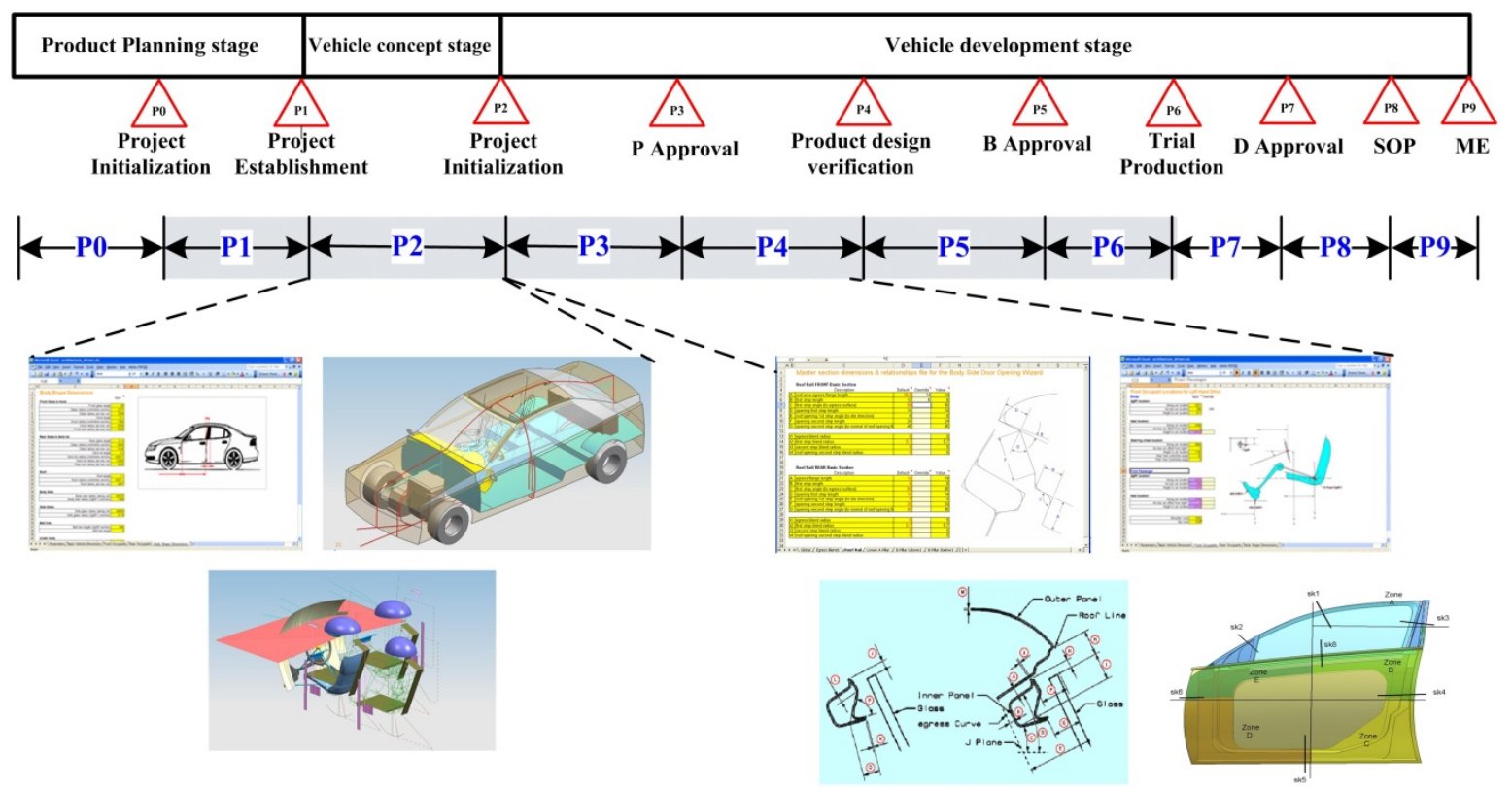

Figure 8.2 The whole automobile development and design process

Table 8.3 The comparison of process stages

\begin{tabular}{c|c|c|c|c|c|c|c|c}
\hline Stage & $\begin{array}{c}\text { Exploration } \\
\text { stage }\end{array}$ & $\begin{array}{c}\text { Task } \\
\text { clarification }\end{array}$ & $\begin{array}{c}\text { Conceptual } \\
\text { design }\end{array}$ & $\begin{array}{c}\text { System-level } \\
\text { design }\end{array}$ & $\begin{array}{c}\text { Detail } \\
\text { design }\end{array}$ & Integration & Verification & Validation \\
\hline Case & P0 & P1 & P2, P3 & P4 & P5 & P4,P6 & P2 & P1 \\
\hline
\end{tabular}

Table 8.4 The comparison of design activity

\begin{tabular}{l|l|c|c|c|c|c|c}
\hline \multirow{2}{*}{\multicolumn{2}{c|}{ Item }} & \multicolumn{2}{c|}{$\begin{array}{c}\text { Activity } \\
\text { definitions }\end{array}$} & \multicolumn{2}{c|}{ Flow interaction } & \multicolumn{2}{c}{ Data interaction } \\
\cline { 3 - 9 } \multicolumn{2}{c|}{} & 11 & 2 & 1 & 2 & 1 & 2 \\
\hline \multirow{4}{*}{$\begin{array}{l}\text { Exploration } \\
\text { stage }\end{array}$} & $\begin{array}{l}\text { Opportunity } \\
\text { identification }\end{array}$ & 5 & 9 & 29 & 22 & 1 & 1 \\
\cline { 2 - 9 } & Opportunity analysis & 12 & 12 & 19 & 23 & 5 & 2 \\
\cline { 2 - 9 } & Idea genesis & 16 & 15 & 16 & 12 & 4 & 4 \\
\cline { 2 - 9 } & Idea generation & 14 & 14 & 23 & 16 & 2 & 2 \\
\hline \multirow{2}{*}{$\begin{array}{l}\text { Task } \\
\text { clarification }\end{array}$} & Needs identification & 6 & 6 & 32 & 32 & 2 & 2 \\
\cline { 2 - 9 } & $\begin{array}{l}\text { Requirement } \\
\text { definition }\end{array}$ & 5 & 5 & 7 & 5 & 1 & 1 \\
\hline Conceptual & Concept exploration & 23 & 23 & 32 & 30 & 9 & 6 \\
\hline
\end{tabular}




\begin{tabular}{l|l|c|c|c|c|c|c}
\hline design & Concept selection & 8 & 8 & 26 & 25 & 1 & 1 \\
\cline { 2 - 8 } & Concept testing & 19 & 19 & 12 & 12 & 3 & 4 \\
\hline \multirow{2}{*}{$\begin{array}{l}\text { System-level } \\
\text { design }\end{array}$} & $\begin{array}{l}\text { Identification of } \\
\text { product architecture }\end{array}$ & 56 & 56 & 21 & 23 & 9 & 6 \\
\cline { 2 - 8 } & $\begin{array}{l}\text { Product } \\
\text { decomposition }\end{array}$ & 21 & 21 & 14 & 13 & 4 & 2 \\
\hline
\end{tabular}

\subsubsection{Results analysis}

Through the analysis of the two innovative design projects, it verifies that the procedural process model is effective and appropriate for innovative design from the two aspects. With regard to the first aspect, we focus on the analysis and the comparison of the process stages.

(1) By analyzing the design process of the two projects, although these projects involve with the implementation of innovative design, it still follows a predefined structured process stages (i.e. P0, P1..., and P9 of Figure 8.2 ).

(2) According to Table 8.3, we can see that the main process stages of the procedural process model can cover the design process of the two projects. It means that the process stages defined is appropriate for the process of innovative design.

(3) Table 8.3 also indicates that the integration, verification and validation stages (i.e. the right side of the procedural process model, see Figure 7.3 ) the relationship with the task clarification, conceptual design and system-level design (i.e. the left side of $\mathrm{t}$, see Figure 7.3 ) by performing the same design process. It can verify that it is necessary to build the connection between the left side and the right side of the procedural process model in Figure 7.3.

As for the second aspect, we concentrate on the verification of the application of flexible practices into the procedural process model. In order to achieve this purpose, we mainly analyze design activities of the first four stages and their flow and data interactions.

(1) According to Table 8.4, we can see that, although Project 1 and Project 2 are conducted by different design team, there is no great difference in activity definition. That is to say, the two projects performed the same design activities.

(2) However, the great differences lie in the interaction of these activities. In the columns, "Flow interaction" and "Data interaction", the number of interactions of Project 2 is less than Project 1 within most activities. Particularly, during the exploration stage and the conceptual design, Project 2 has a larger amount of flow and data interaction. This comparison highlights that iterations and 
communications are frequent in Project 1. Combing with the argument that Project 1 has better performance than Project 2 in Section 8.1.2, we can conclude that the moderate flow and data interactions are uesful to get the better performance. This conclusion is accordance with what is emphasized by the circular model of the first four stages (exploration stage, task clarification, concept design and system-level design).

\subsection{Simulation of activity-based adaptive process model}

\subsubsection{Simulation Framework}

Discrete-event simulation is used to construct the process architecture of innovative design based on the adaptive process model. Simulation selects a design activity according to its activity value and the current information available. Each simulation run begins at design situation $t(0)$, with a series of design goals (budgets, duration, product unit-cost) and requirement information.

The simulation framework follows the evaluation steps given in Section 7.3.3.1, as shown in Figure 8.3. At each design situation $t(i)$, simulation first identifies the next design activities available that satisfy both precedence and resource constraints. Because iteration is the basic characteristic of the design process, simulation also supports iterations between design activities. Thus, potential design activities could consist of these previously performed activities. Then the activity value $\left(V_{a}\right)$ of each potential design activity is computed according to the evaluation method discussed in Section 7.3.3.3. The design activity with the highest value is then selected as the next one in the set of design activities. Simulation generates the real values of process and activity variables using a randomly sampled Monte Carlo technique. Duration of the design situation is defined as the shortest activity in the set of design activities. Once the shortest design activity ends, the activity duration and cost, as well as the effects of the work done on the set of design activities, are added to the next design situation. If all remaining design activities are completed or the cumulative time reaches the design duration (termination condition), one simulation run is complete. 


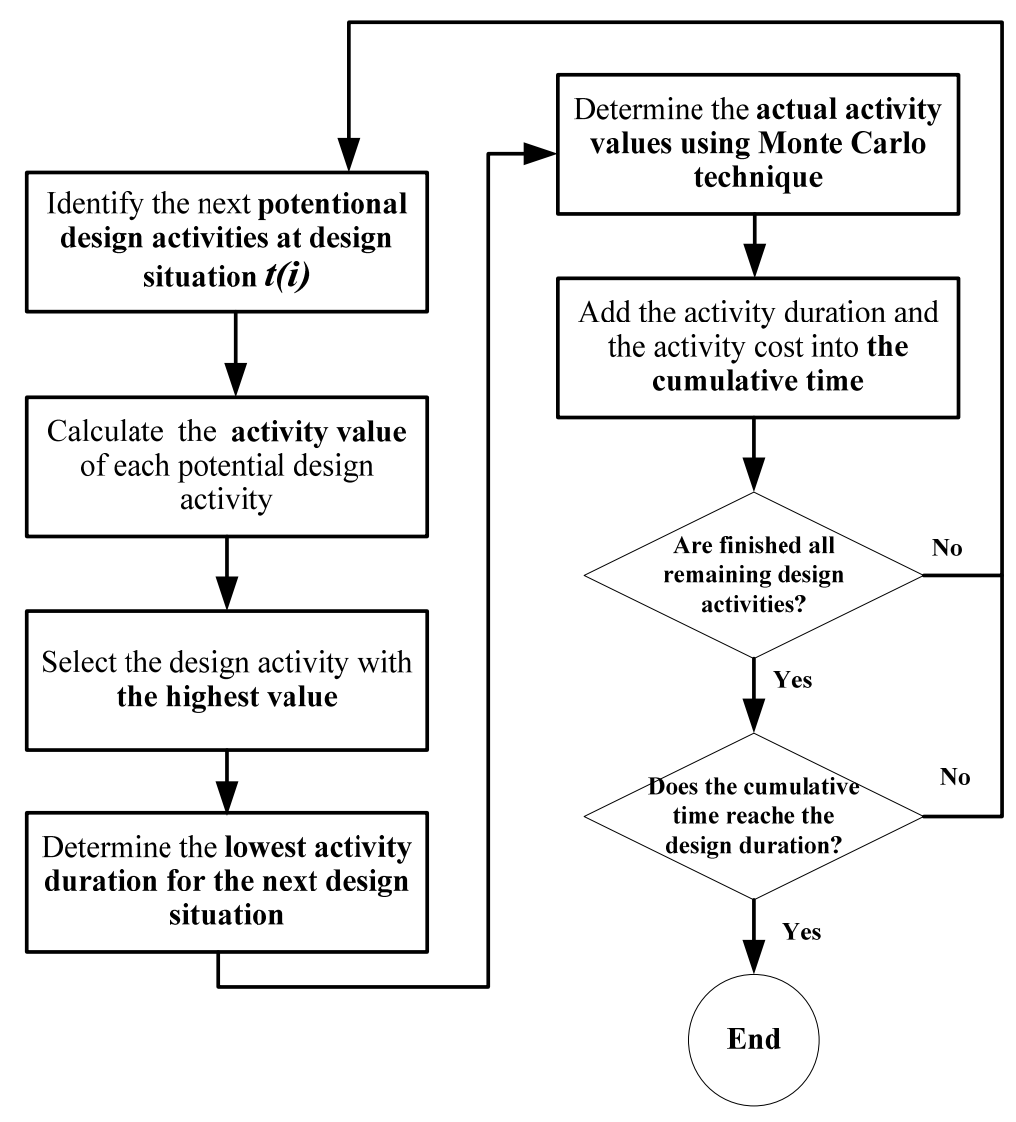

Figure 8.3 The simulation framework of the activity-based adaptive model

\subsubsection{Case description and model inputs}

We applied the adaptive process model to simulate the first innovative design project of Section 8.1. The adaptive process model is applied to simulate an innovative design project that primarily intends to design a series of mini-cars for an automaker. Among the set of requirements are an attractive look, trendy configurations, and high quality at a low usage cost. Therefore, innovation should address style design, structure design and engine design to meet the aforementioned requirements while paying attention to product cost. The innovative design project was retained because : (i) this automaker is a new entrant to the Chinese car industry ( the company set up in 1997), there is a lack of existing mature technologies and platforms, and therefore, the new design technology and devices are needed; (ii) this project aimed to design the first mini-car in China. Customers have only limited experience about this product. Therefore, this project suffered the technological and market uncertainties all innovative design projects face.

The Design Structure Matrix (DSM) shown in Figure 8.4 depicts the information network for the main design activities. This matrix was built by consulting the designers and the design documents available in order to figure out the information flow between 
design activities. Based on the DSM, the design space of each activity was constructed and featured potential design and rework activities. According to the designers interviewed, design targets can be defined as follows: "innovation" target focusing on "behavior" and "structure" parts while "technical performance" target addresses engine and appearance which are the key parameters of the end product; for the "unit-cost" target, the project sets the future sale price range as a design constraint; for the "duration" target, the design budget and deadline were defined in the early phase. The PDF for each potential design activity was refined by conducting interviews with designers and project managers. With respect to weightings in Equation (1), these are defined by project managers according to the current design situation, and are allowed to vary dynamically. For example, at the start of the project (i.e. Process 0 in Table 2), as generation has been emphasized, weights ascribed are $w_{\text {innovation }}=0.35, w_{\text {function }}=0.5$, and $w_{\text {function }}=0.15$ resp.

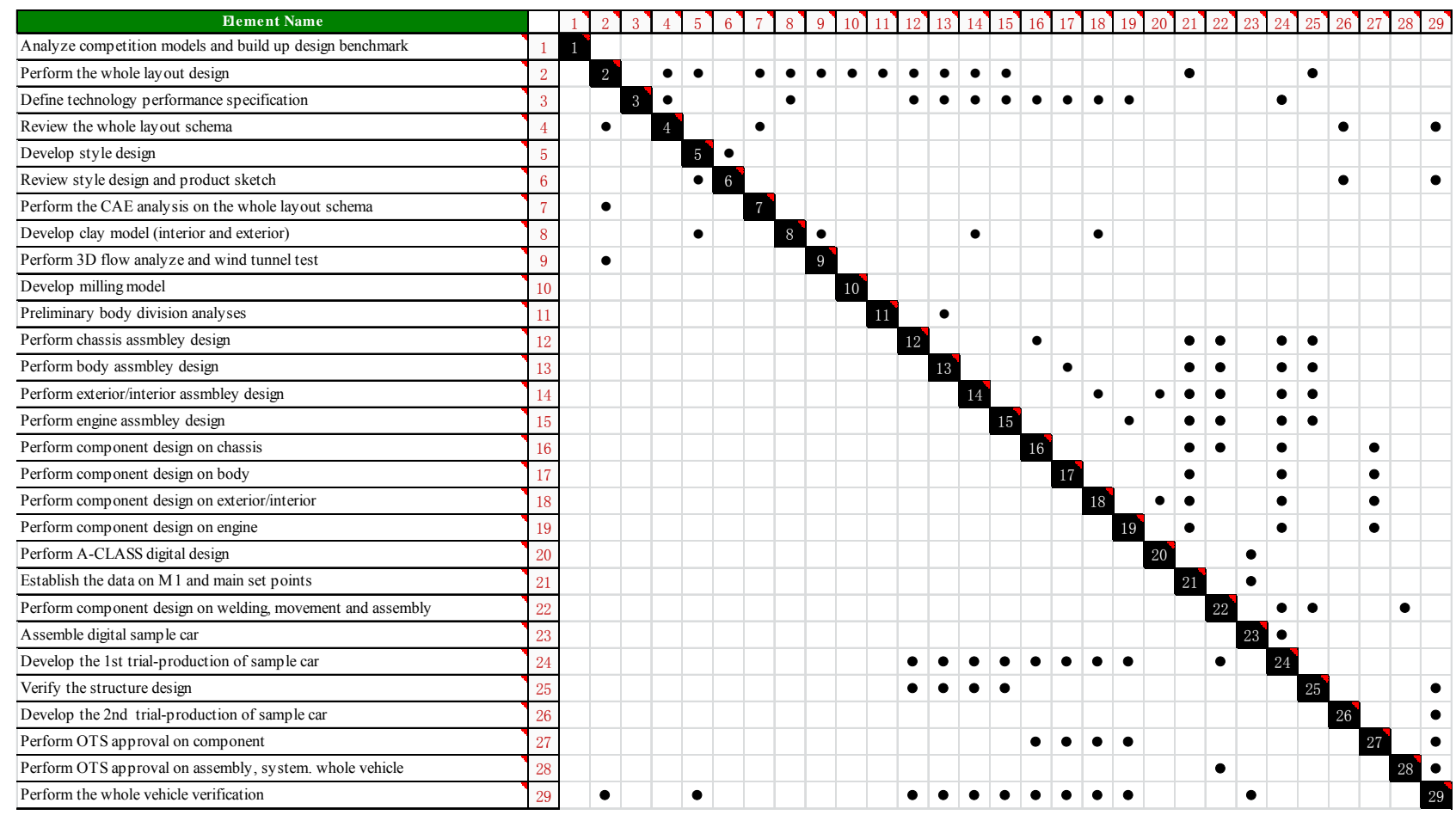

Figure 8.4 Activity-based DSM for the overall vehicle design

\subsubsection{Simulation results and managerial insights}

The goal of the adaptive process model is to generate the process architecture of innovative design. Therefore, the outcome of each simulation run is a network of design activities, within which every activity is selected based on its contribution to satisfy design targets. Since the outcome of each simulation run may be different, we opted for the analysis of a batch of 2,500 simulation runs to better evaluate the simulation results. Thus two results and their managerial insights are presented. 
Simulation result 1: After 2,500 simulation runs, we recorded the most frequent process architecture (109 occurrences), as shown in Figure 8.6. The black line indicates the duration of the design activity, while the red one stands for the iteration of this design activity. Compared with the current design process architecture in the project (see Figure $8.5)$, the most frequent process architecture shortened the iteration of conceptual design activities by sequencing them. The result was in good agreement with the goal of this project and adaptive model. As one of the goals was to design a new fashionable mini-car, the innovative activities were carried out during the conceptual design phase. This resulted in iterations to explore innovative ideas. Moreover, the activity value is key when it comes to balancing innovation and control, and shortening the iterations. At the engineering design stage (i.e. embodiment), the difference highlighted the shorter duration. Because engineering design is highly mature in the automotive industry and follows a standard and rigid operation process, not many modifications can be introduced in the design space and sequences. For the last two, emphasis was placed on the verification of the overall car and components. Hence, there was little difference between the two process architectures.

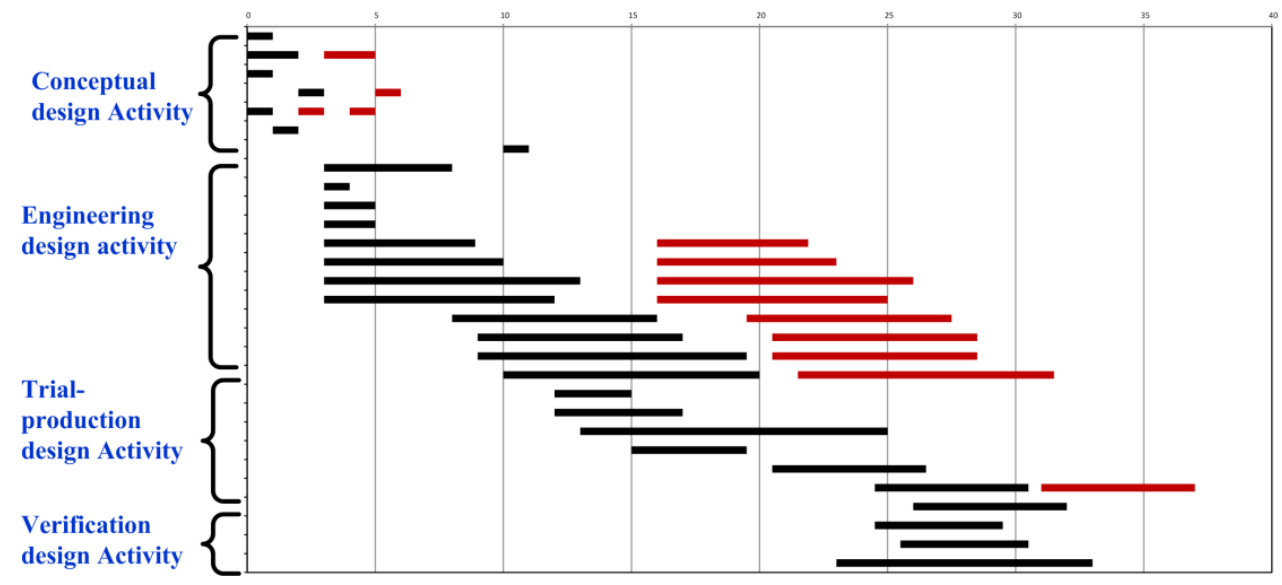

Figure 8.5 Current design process architecture

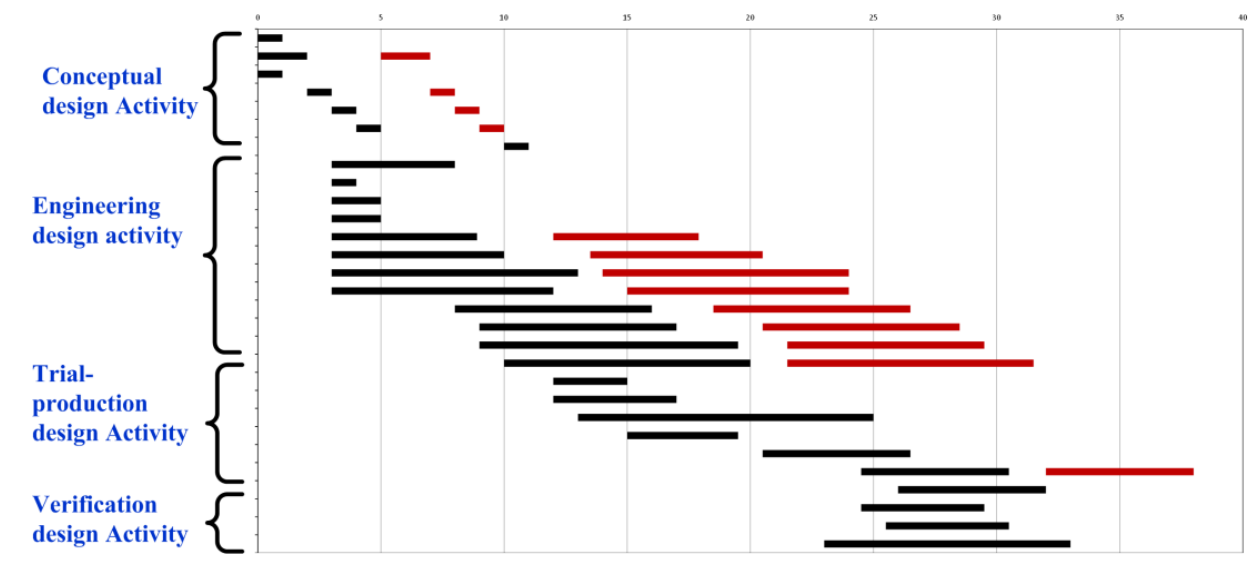

Figure 8.6 The most frequent design process architecture 
Managerial insights 1: Simulation results suggest that, even in the case of the design activity following simple rules (i.e. assessment of activity value), the process architecture (Figure 8.6) of innovative design can be generated more effectively than with the current architecture (Figure 8.5). In this process, the entire simulation can lead to the faster emergence of an optimal process architecture of innovative design, without having to micromanage each state transition decision, because each design activity is endowed with known information and simple rules to self-organize the work. Additionally, the process architecture in Figure 8.6.is composed of iterations, resulting in nonlinear behavior of innovative design. This value enables us to understand how simple rules of design activities can generate different aggregated outcomes that affect process adaptability and innovative output using CAS. And it shows that CAS concepts can be used by managers to explore the construct of process architecture of innovative design.

Managerial insights 2: Relative to other simulation results, the result of Figure 8.6.suggests that the most frequent process architecture necessitates more potential activities in the design space at each decision point. This enables managers and designers to respond the uncertainties suffered by innovative design by creating more alternatives. This aligns well with the CAS characteristics. With CAS, the greater number and variety of agents can increase system adaptability (McCarthy et al., 2006). Meanwhile, it can also get similar managerial findings using a set-based design from the Toyota product development (Ward et al., 1995), showing that this broad set of options makes it more likely to lead to better solutions (Sommer and Loch, 2004).

Managerial insights 3: Figure 8.6 suggests that the most frequent process architecture exhibits the characteristics of front-loaded innovative design, with many explorative iterations occurring early in the process. Early feedback from these explorative iterations allows designers to address the technological problem (e.g. interaction between different product components or product and its operational environment)(McDermott and O'Connor, 2002). Designers thus factor the information into product design. Hence, it is necessary to plan explorative iterations and allocate adequate resources to support.

Simulation result 2: Figure 8.7 shows the information value profile that increases the probability of successfully satisfying each design target for the most frequent design process architecture. It depicts the change in innovation performance and other control performances. During conceptual design (time $<1 \sim 6>$ ), assembly design (time $<12-14>$ ) and component design (time $<15 \sim 18>$ ), it appears that innovation performance is much higher than during other stages. This change is in good agreement with the innovation goals of this project that emphasizes the "behavior" and "structure" of the product, thereby resulting in many innovative activities during these stages. Other control peformances vary according 
to the characteristics of each design stage. For example, the information value of technical performance reaches a peak during middle stages. this points to the fact that design activities at this stage contribute to an increase in technical performance. These results demonstrate that the evaluation method of innovation performance and other control performances proposed in Section 7.3.3 can be applied to innovative design.

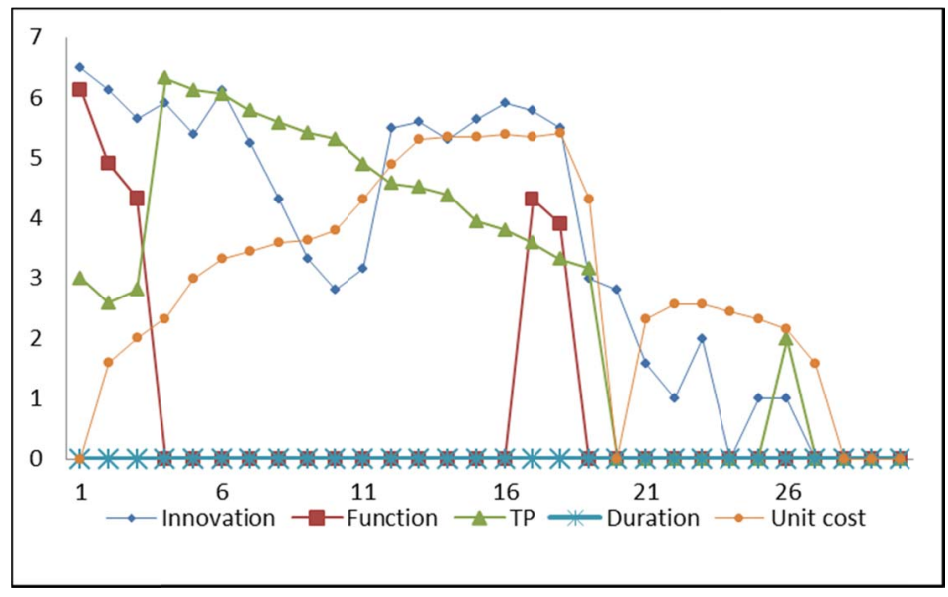

Figure 8.7 Information value profile increasing the probability of satisfying each design target in this simulation

Managerial insights 4: According to the simulation result 2, innovation performance and other control performances can lead to an optimal balance at different stages in this project. This empirical result contrasts with some previous studies (Sethi and Iqbal, 2008; Salomo et al., 2007) in which it seems that control practices hampered the identification and exploration of innovative opportunities. In our option, the conflicting conclusion may stem from the lack of distinction between different stages of innovative design. For example, innovative design involves the definition of product identity and the formulation of design problem. The first one emphasizes the expansion and change in product identity to identify innovative opportunities, thereby generating the product concept; the latter one tries to explore and formulate the design problem based on the previously well-defined product identities. Since different design stages have distinct targets, companies should set design targets based on the current design situation to achieve the balance needed between control and innovation.

Additionally, the information given in Figure 8.7 can help managers decide where to invest in encouraging innovation (the area with higher information value corresponding to the innovation performance) and emphasizing control (the area with higher information value corresponding to the control performance), thereby achieving the balance between innovation and control in this process. 


\subsection{Conclusion}

This chapter discusses the verification of the procedural process model and the activity-based adaptive process model to support a number of process analysis and simulation. To summarize:

Verification of the procedural process model is achieved by the comparison between the models with two innovative design projects in an automobile company. This comparison is performed in two steps. The first step focuses on the verification of the process structuration of the procedural process model. We firstly analyze and identify the main process stages of the two innovative design projects to construct the general design stages, and thereby distinguish its differences from the procedural process model. The second step is to verify the appropriateness of the circular model for innovative design. Within this step, we perform a deeper analysis of design activities of the two projects and their interactions. The comparison between the DSMs of the two projects proves the effectiveness of the circular model.

The activity-based adaptive process model is verified by the discrete-event simulation to construct the process architecture of innovative design. The simulation proceeds with selecting a design activity according to its activity value within the current available information. The simulation results verify the method of process design involved in the activity-based adaptive process model. Moreover, we can find a series of managerial insights that testify the characteristics of innovative design. 


\section{CONCLUSION}

\subsection{Research contributions}

Innovative design has received a rising interest from the CEOs of corporations to improve or sustain the distinctive competence. However, a good innovative design does not by accident, but rather the result of a managed process. Both individuals and organizations pay more attention on how to design and manage the design process that heavily influences design efficiency and performance.

However, uncertainty caused by innovation causes a great challenge to innovative design. Accordingly, the main question above becomes "Can companies carry out control and provide structures for activities of innovative design while at the same time encouraging more innovation?" In order to respond to this question, we conducted the research in term of definition \& analysis, process description and management support, following the design research methodology (DRM) from the description to the prescription. The contributions of this dissertation are reflected in the three aspects. In summary:

(1) Definition and analysis

A formal definition of innovative design can contribute to define the scope and content, and explain the nature and essential qualities of innovative design. Moreover, the definition should reflect the progress and the development of the object to be defined. As we analyzed in Chapters 2, 3 and 4, two core elements of innovative design, innovation and design, have largely changed in the last two decades. Different from the traditional view that design is passively sub-process within product development, these new change emphasize the role of leader in the whole product development process. With regard to innovation, the rapid renewal and the tendency to one-off innovation make innovation suffer the dynamic product identifies in the beginning of the design process. Thus, in the basis of the analysis of a broad set of articles addressing innovative design, as well as the theoretical comparison between innovation and control, we proposed a new definition of innovative design to reflect these changes.

Within this definition, the nature of innovative design is analyzed in theoretical. Generally, the design problem is considered as the ill-defined problem. Beyond the ill-defined problem, innovative design emphasizes the radical expansion and the change of the product identities. Thus, the innovative design problem is expansive, rather than stable. 
Moreover, since the expansive nature and the evolutionary process between design problem and design solution, it appears to the non-definitive design problem at the start point of the design process.

\section{(2) Process description}

According to the analysis above, innovative design involves many variables whose characteristics and interactions are not well understood. Meanwhile, the complexity of requirements, design activities, and organization is increasing the difficulty of controlling the process. Although there is a large amount of process models to support and describe design, they often focus on the special dimensions of design (e.g., the management inquiry, the design inquiry), thereby not providing an accurate model to describe innovative design.

In this aspect, we introduced a descriptive model of innovative design. The model reflects the actual process and pattern of innovative design by extending and circularizing the basic framework of innovative design based on the FBS model. Meanwhile, through the identification of creative elementary processes, it locates innovation opportunities in the design process. Finally, we introduced the conception "situatedness" of designers into this model to support a systematic perspective whose focus is on the external and internal factors affecting the success of innovative design.

Although the process of innovative design observed in practice is more chaotic than the current representation suggests, the descriptive model can contribute to better find the successful factors, to integrate different aspect of an innovative design situation, to evaluate communication with the external environment. Moreover, it facilitates focusing on these processes in order to enhance creative performance and the quality of the product designed.

\section{(3) Management support}

Although innovative design can provide companies with competitive advantage, the relationship between innovative design and company performance is conditional. It is very likely that the impact of innovative design on company performance will vary depending on the management of this process. In this dissertation, another important contribution is to analyze the management challenges and then proposed the systematic process models to deal with the balance between innovation and control.

Since the nature of innovative design (e.g. expansive problem, non-definitive problem etc.) and its interaction with other dimensions, these characteristics result in the great management challenges. We analyzed the market uncertainty and the technology uncertainty that innovative design faces. Each combination of different uncertainties requires the corresponding management strategy. 
To deal with these challenges, we identified five practices to support control and six practices to support flexibility by reviewing the literature. However, it seems that control and flexibility conflict, as they represent different directions of management. The achievement of an optimal balance between them is thus one of the greatest challenges for management support.

Although this balance problem is assumed to have an impact on design effectiveness, no empirical research had previously studied. In this dissertation, an extra step has been taken toward perform an empirical study to investigate how to balance control and flexibility in practices. The empirical results have important managerial insights to balance innovation and control. The first insight is that innovative design should create control in a project-level in terms of a formal process, and encourage innovation at an operation-level in terms of flexibility. Secondly, in order to develop a general process model, innovative design needs to integrate all flexible practices that deal with the corresponding uncertainties. The two management insights constitute the theoretical basis of the systematic prescriptive models of innovative design for management support.

Then, the development of the systematic prescriptive models is implemented in the procedural-level and the activity-level. Firstly, the procedural process model prescribes a series of processes and their structure, which contribute to systematically manage and organize the innovative design process to lead to innovation. More detail, the procedural model provides the conceptual framework to balance innovation and control by the structuration of process stages and the integration of flexible practices in the project-level and the operational level.

The activity-based adaptive model attempts to propose a method of process design to aid managers and designer make decisions based on a flexible framework, to guide innovation in design. This model considers innovative design as a complex adaptive system, and thereby progressively constructs the process architecture by adaptively selecting design activities. We proposed the concept "activity value" as the selecting criterion to balance innovation and control, which determined by expert evaluations based on the current design situation. More precisely, we use the function of the information that reduces complexity and the corresponding design metrics in light of the current design situation.

Finally, the procedural process model and the activity-based adaptive model are verified through the comparison and simulation with the automobile industry cases. The verification results reflect that the two models are effective and efficient. 


\subsection{Limitations}

There are some special limitations for the descriptive model and the prescriptive model that are respectively developed in the research issues "process description" and "management support". There are:

(1) The descriptive model of innovative design. Although this model describes the interaction between the designer, the elementary processes and the environment, it does not indicate how to happen and interact between three layers, particularly between the elementary processes and the environment. Some researchers have pointed to environmental factors that may affect design activities and design choices. However, what are the environmental factors really? In this model, we don't clearly indicate these factors. In further, it also indicates that these factor how to influence innovative design.

(2) The procedural process model of innovative design. In this dissertation, we proposed the procedural process model to prescribe the innovative design process. To some extent, these models explain that what made some companies, such as BMW, Apple and IDEO, have 'better' design performance than others? However, as stated before, the theoretical basis of the model mainly originates from the managerial insights of the same company in the automobile industry. Hence, to explore the generality of the findings through additional case studies is an opportunity for further research.

(3) The activity-based adaptive model of innovative design. Although this adaptive model provides a new framework and method to dynamically construct the process architecture of innovative design, some improvements will still be needed for the activity-based process model in future. First, the current construction of design space is mainly based on the designer expertise. But we think the choice of different activities in the design space can also be guided by product or process architecture. Secondly, the evaluation of innovation performance is calculated by designers based on the comparison with the existing product. Therefore, the construction of knowledge resource on innovation seems worth a further study.

\subsection{Opportunities for further research}

Based on the current findings and limitations, as well as the emergent research trends, we identify and discuss avenues for further investigation in innovative design studies. In order to move from a piecemeal representation of the structural of the field to a more holistic understanding of our object of analysis, we discuss the further opportunities around five main areas of research, to draw attention to their convergence in comprehensively explaining fundamental elements involved in innovative design, as shown in Figure 9.1. 
The five area are design problems (what kinds of problem that company and designers should solve), innovative design process (how design problems are or should be solved), designers (how designers solve design problems), organizational environment (how the organizational factors influence the performance of innovative design) and design result (how the result of innovative design influence firm performance).

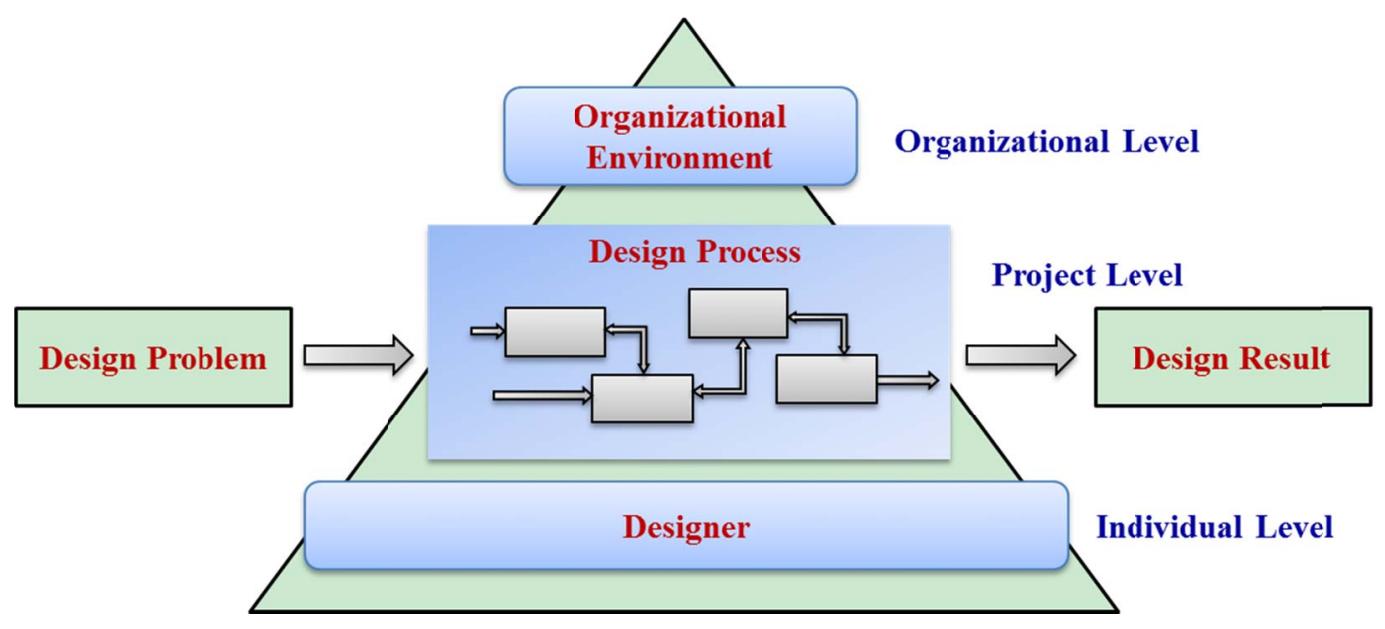

Figure 9.1 The emerging areas of research in innovative design

(1) Innovative design problem

In this dissertation, we still follow the historical position emphasizing engineering design (focused primarily on product "function"). More recently, however, research across fields has paid increasing attention to properties of product form. These studies point out that the product form is more than simply consequential expression of a function (Ravasi and Stigliani, 2012), and provide interesting questions for innovative design problem.

Several authors have focused on the importance of industrial design for innovation management, and proposed the application of established theories of innovation to the study of change in the formal and symbolic qualities of products. The centre of this perspective is to emphasize product semantics and the notion of design as a language. This helped identify a new type of innovation, “design-driven' innovation (Verganti, 2008). In the case of design-driven innovation, what resources do designers draw on? Whether can the existing technological innovation theories explain this new type? Whether do the procedural process model and activity-based adaptive model proposed in this thesis work?

Additionally, in the past two decades, the outcome of design has been extending their remit to intangible objects, such as services, systems and environment (Ravasi and Stigliani, 2012). Companies not only produce manufacture goods, but have tries to offer the combination of products and services as the innovation offering in order to attract customers (Shankar et al., 2009). The shift from tangible objects to intangible objects 
triggers a series of interesting questions: Are the existing design theories and methods still appropriate for the design of intangible objects? How do we deal with the relationships between intangible parts and tangible parts within the same product?

(2) Innovative design process

As stated in Section 10.2, the procedural process model of innovative design needs to perform additional case studies in other industries to explore the generality of the findings. These observations should be built on the longitudinal, in-depth investigation of social practices and structure in these case studies. These observations try to answer the question of what are design capabilities and where do they come from?

Additionally, as we defined in Section 6.2.3, innovative design is a kind of process from the exploration of innovative opportunities to the description of a product that is to be made. The definition extends the design boundaries to the exploration of innovative opportunities. Although this dissertation builds its relationship with other elements and process stages of innovative design, the process mechanism of this stage is still not clear.

(3) Organizational environment

Any design process is highly complex socio-technical process (Wynn and Clarkson, 2005). The success of product design is not only simply a matter of hiring better designers, giving them a plenty of resources, and involving them early in the development process, but also the way of organizing and managing design resources. The latter ones belong to the organizational environment. In our models, we point to organizational environment that may affect design activities and the outcome of design choices. This study is too general to constitute the detailed analysis of organizational environment.

Hence, there are some interesting organizational elements to be further discussed in this aspect. For example, the design philosophy (company-specific beliefs and principles about appropriate ways of designing products), and the design strategy (the breadth of a portfolio, the degree of innovation).

(4) Designer

In this dissertation, we investigate the role of designers in innovative design. Designers observe and interpret what they are 'seeing', and then decide on new actions, instead of simply performing the recommended actions. Hence, designers have freedom to perceive and interpret design problems based on their abilities and experience. As stated above, design philosophy and design strategy influence design choices. Hence, further study should investigate designers how to coordinate their design solutions with the design philosophy and the design strategy of companies. 
(5) Design result

Design results refer to how the product to be designed to influence company performance and customer. As we known, the 'good design' does not mean the 'good product'. Only if the good design has been successfully commercialized, the product could strengthen company's competitiveness, thereby improve company performance. Hence, how to integrate product design and commercialization is also the future avenue in this aspect. The integration includes facilitating product appropriateness and adoption.

Consumer research has traditionally focused on the aesthetic aspects of product design, considering product form as the first opportunity for the formation of a customer's impression of a product (Ravasi and Stigliani, 2012). However, as stated before, the product is the combination of form and functions. Thus the future study should investigate the consumer response to the product form and the product functions. 


\section{REFERENCE}

Abernathy, W.J. and Clark, K.B. (1985), "Innovation: Mapping the winds of creative destruction", Research Policy, Vol. 14 No. 1, pp. 3-22.

AFIS. (2010,September), “AFIS”, available at: www.afis.fr.

Ahmadi, R., Roemer, T.A. and Wang, R.H. (2001), "Structuring product development processes", European Journal of Operational Research, Vol. 130 No. 3, pp. 539-558.

Ajamian, G. and Koen, P. (2002), "Technology stage-gate : A structured process for managing high-risk new technology projects", in Belliveau, P., Griffen, A. and Sorermeyer, S. (Eds.),PDMA Toolbook for New Product Development, John Wiley and Sons, New York, pp. 267-298.

Albert, A. and Braun, Andreas. (2012), "Towards handing complexity-testing the IPEM process modeling approach", Proceedings of TMCE 2012, Presented at the Tools and Methods of Competitive Engineering Symposia, Karlsruhe, Germany, pp. 293-303.

Ali, A., Krapfel, R. and LaBahn, D. (1995), "Product innovativeness and entry strategy: Impact on cycle time and break-even time", Journal of Product Innovation Management, Vol. 12 No. 1, pp. 54-69.

Amabile, T.M., Conti, R., Coon, H., Lazenby, J. and Herron, M. (1996), "Assessing the work environment for creativity”, The Academy of Management Journal, Vol. 39 No. 5, pp. 1154-1184.

Anderson, P. (1999), "Complexity theory and organization science", Organization Science, Vol. 10 No. 3, pp. 216-232.

Archer, L.B. (1968), Systematic Method for Designers, The Design Council, London, UK.

Bahill, A.T. and Gissing, B. (2002), "Re-evaluating systems engineering concepts using systems thinking", IEEE Transactions on Systems, Man, and Cybernetics, Part C: Applications and Reviews, Vol. 28 No. 4, pp. 516-527.

Baregheh, A., Rowley, J. and Sambrook, S. (2009), "Towards a multidisciplinary definition of innovation", Management Decision, Vol. 47 No. 8, pp. 1323-1339.

Baxter, M. (1995), Product Design: a Practical Guide to Systematic Methods of New Product Development, Chapman \& Hall, New York.

Becheikh, N., Landry, R. and Amara, N. (2005), "Lessons from innovation empirical studies in the manufacturing sector: A systematic review of the literature from 1993-2003", Technovation, Vol. 26 No. 5-6, pp. 644-664.

Belkadi, F. (2006), Contribution au pilotage des compétences dans les activités de conception: De la modélisation des situations à la caractérisation des compétences, Université de Franche-Comté.

Ben, M.-J.S., Charue-Duboc, F. and Fourcade, F. (2006), "Managing creativity process in innovation driven competition", Presented at the the 13th international product development management conference, Milano, Italy, pp. 111-126.

Bernstein, B. and Singh, P.J. (2006), "An integrated innovation process model based on practices of Australian biotechnology firms", Technovation, Vol. 26 No. 5-6, pp. 561-572. 
Bessant, J., Lamming, R., Noke, H. and Phillips, W. (2005), "Managing innovation beyond the steady state", Technovation, Vol. 25 No. 12, pp. 1366-1376.

Best, K. (2006), Design management: Managing design strategy, process and implementation, AVA Publishing, Lausanne, Switzerland.

Best, P. (2008), "Branding and design innovation leadership: What's Next?", Design Management Review, Vol. 19 No. 3, pp. 44-50.

Beswick, C. and Gallagher, D. (2010), The Road to Innovation, Let's Think Beyond, London.

Bhattacharya, S., Krishnan, V. and Mahajan, V. (1998), "Managing new product definition in highly dynamic environments", Management Science, Vol. 44 No. 11, pp. 50-64.

Biazzo, S. (2009), "Flexibility, structuration, and simultaneity in new product development", Journal of Product Innovation Management, Vol. 26 No. 3, pp. 336-353.

Blessing, L. (1996), "Comparison of design models proposed in prescriptive literature", in Perrin, J. and Vinck, D. (Eds.),Proceedings of the COST A3/COST A4 International Research Workshop, Social Science Series, Lyon, Vol. 5.

Blessing, Lucienne T.M. and Chakrabarti, Amaresh. (2009), DRM, a Design Research Methodology, Springer, London, available at: (accessed 21 June 2012).

Boehm, B.W. (1988), “A spiral model of software development and enhancement”, Computer, Vol. 21 No. 5, pp. 61-72.

Bonjour, E. and Micaelli, J.-P. (2010), "Design Core Competence Diagnosis: A Case From the Automotive Industry", IEEE Transactions on Engineering Management,, Vol. 57 No. 2, pp. $323-$ 337.

Booz, E., Allen, J. and Hamilton, C. (1967), Management of new products, Booz, Allen \& Hamilton Inc., New York, USA.

Browning, T.R. (2001), "Applying the design structure matrix to system decomposition and integration problems: a review and new directions", IEEE Transactions on Engineering Management, Vol. 48 No. 3, pp. $292-306$.

Browning, T.R. (2009), "The many views of a process: Toward a process architecture framework for product development processes”, Systems Engineering, Vol. 12 No. 1, pp. 69-90.

Browning, T.R., Deyst, J.J., Eppinger, S.D. and Whitney, D.E. (2002), “Adding value in product development by creating information and reducing risk", IEEE Transactions on Engineering Management, Vol. 49 No. 4, pp. 443 - 458.

Browning, T.R. and Eppinger, S.D. (2002), "Modeling impacts of process architecture on cost and schedule risk in product development", IEEE Transactions on Engineering Management, Vol. 49 No. 4 , pp. $428-442$.

Browning, T.R. and Ramasesh, R.V. (2007), "A survey of activity network-based process models for managing product development projects", Production and Operations Management, Vol. 16 No. 2, pp. $217-240$.

Bruce, M. and Bessant, J. (2002), "Managing design as a process", in Bruce, M. and Bessant, J. (Eds.),Design in businees: strategic innovaiton through design, Prentice Hall, Essex., pp. 36-58. 
Brunner, R., Emery, S. and Hall, R. (2008), Do you matter? How great design will make people love your company, FT Press, New York, USA, 1 sted.

Buckler, S.A. (1997), “The spiritual nature of innovation”, Research Technology Management, Vol. 40 No. 2, p. 43.

Buganza, T., Dell'Era, C. and Verganti, R. (2009), "Exploring the relationships between product development and environmental turbulence: the case of mobile TLC services", Journal of Product Innovation Management, Vol. 26 No. 3, pp. 308-321.

Buijs, J. (2003), "Modelling product innovation processes, from linear logic to circular chaos", Creativity and Innovation Management, Vol. 12 No. 2, pp. 76-93.

Burkart, R.A. and Sayles, L.R. (2004), "Transforming invention into innovation: the conceptualization stage", Strategic management of technology and innovation, McGraw-Hill, Boston.

Calantone, R., Garcia, R. and Dröge, C. (2003), "The effects of environmental turbulence on new product development strategy planning”, Journal of Product Innovation Management, Vol. 20 No. 2, pp. 90-103.

Chapman, C. (1990), "A risk engineering approach to project risk management", International Journal of Project Management, Vol. 8 No. 1, pp. 5-16.

Chapman, R.L. and Magnusson, M.G. (2006), "Continuous innovation, performance and knowledge management: an introduction”, Knowledge and Process Management, Vol. 13 No. 3, pp. 129-131.

Chase, J. (2000), Measuring value in product development, Cambridge, MA: Massachusetts Institute of Technology.

Cheng, Y.-T. and Ven, A.H.V. de. (1996), "Learning the innovation journey: order out of chaos?", Organization Science, Vol. 7 No. 6, pp. 593-614.

Chiva-Gomez, R. (2004), "Repercussions of complex adaptive systems on product design management", Technovation, Vol. 24 No. 9, pp. 707-711.

Choi, T.Y., Dooley, K.J. and Rungtusanatham, M. (2001), "Supply networks and complex adaptive systems: control versus emergence", Journal of Operations Management, Vol. 19 No. 3, pp. 351366.

Chung, M.J., Kwon, P. and Pentland, B.T. (2002), "Making process visible: A grammatical approach to managing design processes", Journal of Mechanical Design, Vol. 124 No. 3, pp. 364-374.

Clark, K.B. and Fujimoto, T. (1991), Product development performance: Strategy, organization, and management in the world auto industry, Harvard Business Press, Boston.

Clarkson, J. and Eckert, C. (2005), Design process improvement: a review of current practice, Springer, New York.

Clarkson, P.J. and Hamilton, J.R. (2000), “'Signposting', A Parameter-driven task-based model of the design process", Research in Engineering Design, Vol. 12 No. 1, pp. 18-38.

Cooper, R. and Press, M. (1995), The design agenda: a guide to successful design management, Wiley, Chichester.

Cooper, R.G. (1980), "Project newProd: Factors in new product success", European Journal of Marketing, Vol. 14 No. 5/6, pp. 277-292. 
Cooper, R.G. (1990), "Stage-gate systems: a new tool for managing new products", Business Horizons, Vol. 33 No. 3, pp. 44-54.

Cooper, R.G. (1998), Product leadership: Creating and launching superior new products, Perseus Books, New York.

Cooper, R.G. and Kleinschmidt, E.J. (1993), "Screening new products for potential winners", Long Range Planning, Vol. 26 No. 6, pp. 74-81.

Cross, N. (2001), Engineering design methods: strategies for product design, John Wiley, London.

Cross, N. (2004), “Expertise in design: an overview”, Design Studies, Vol. 25 No. 5, pp. 427-441.

Cross, N. (2008), Engineering Design Methods: Strategies for Product Design, John Wiley \& Sons, London.

Cross, N., Dorst, K. and Roozenburg, N. (1992), Research in design thinking, Delft University Press, Delft.

Damanpour, F. and Daniel Wischnevsky, J. (2006), "Research on innovation in organizations: Distinguishing innovation-generating from innovation-adopting organizations", Journal of Engineering and Technology Management, Vol. 23 No. 4, pp. 269-291.

Danilovic, M. and Browning, T.R. (2004), "A formal approach for domain mapping matrices (DMM) to complement design structure matrices (DSM)", Proceeding of the sixth design structure matrices (DSM) international workshop, Trinity Hall College, University of Cambridge, Cambridge, UK.

Danilovic, M. and Browning, T.R. (2007), "Managing complex product development projects with design structure matrices and domain mapping matrices", International Journal of Project Management, Vol. 25 No. 3, pp. 300-314.

Danilovic, M. and Sandkull, B. (2005), "The use of dependence structure matrix and domain mapping matrix in managing uncertainty in multiple project situations", International Journal of Project Management, Vol. 23 No. 3, pp. 193-203.

Darian Unger and Steven Eppinger. (2011), "Improving product development process design: a method for managing information flows, risks, and iterations”, Journal of Engineering Design, Vol. 20 No. 10, pp. 689-699.

Darke, J. (1984), "The primary generator and the design process", in Cross, N. (Ed.),Development in design methodology, John Wiley \& Sons Ltd., Chichester.

Dell'Era, C. and Verganti, R. (2009), "Design-driven laboratories: organization and strategy of laboratories specialized in the development of radical design-driven innovations", $R \& D$ Management, Vol. 39 No. 1, pp. 1-20.

Deniaud, I., Lerch, C. and Caillaud, E. (2011), "Eco-design of complex products using systems engineering.", Proceedings of the 4th International Conference on Industrial Engineering and Systems Management: Innovation Approches and Technologies for Network Manufacturing Entreprise Management, Presented at the 4th International Conference on Industrial Engineering and Systems Management, ENIM, Metz, France.

Design Council. (2007), Eleven lessons: managing design in eleven global companies-desk research report, London: Design Council.

Dooley, K.J. (1997), “A complex adaptive systems model of organization change”, Nonlinear Dynamics, Psychology, and Life Sciences, Vol. 1 No. 1, pp. 69-97. 
Dooley, K.J. and Van de Ven, A.H. (1999), "Explaining complex organizational dynamics", Organization Science, Vol. 10 No. 3, pp. 358-372.

Dorst, K. (1997), Describing design: a comparison of paradigms, Delft : Technische Universiteit Delft.

Dorst, K. (2006), “Design problems and design paradoxes”, Design Issues, Vol. 22 No. 3, pp. 4-17.

Dorst, K. and Cross, N. (2001), "Creativity in the design process: co-evolution of problem-solution", Design Studies, Vol. 22 No. 5, pp. 425-437.

Dorst, K. and Dijkhuis, J. (1995), “Comparing paradigms for describing design activity”, Design Studies, Vol. 16 No. 2, pp. 261-274.

Dorst, K. and Vermaas, P.E. (2005), “John Gero's Function-Behaviour-Structure model of designing: a critical analysis", Research in Engineering Design, Vol. 16 No. 1-2, pp. 17-26.

Dym, C.L. and Little, P. (1999), Engineering Design: A Project Based Introduction, Wiley, New York.

Eisenbart, B., Gericke, K. and Blessing, L. (2011), "A framework for comparing design modelling approaches across disciplines", Proceedings of 18th International Conference on Engineering Design, Presented at the 18th International Conference on Engineering Design, Copenhagen, Vol. 2, pp. $344-355$.

Eisenhardt, K.M. and Tabrizi, B.N. (1995), "Accelerating adaptive processes: product innovation in the global computer industry”, Administrative Science Quarterly, Vol. 40 No. 1, pp. 84-110.

Eisner, H. (2008), Essentials of project and systems engineering management, John Wiley \& Sons, Hoboken, N.J.

Engel, A., Reich, Y., Browning, T.R. and Schmidt, D.M. (2012), "Optimizing system architecture for adaptability”, Proceedings of the 12th International Design Conference DESIGN 2012, pp. 16771688 .

Eppinger, S.D., Nukala, M.V. and Whitney, D.E. (1997), "Generalised models of design interation using signal flow graphs", Research in Engineering Design, Vol. 9 No. 2, pp. 112-123.

Eppinger, S.D., Whitney, D.E., Smith, R.P. and Gebala, D.A. (1994), "A model-based method for organizing tasks in product development", Research in Engineering Design, Vol. 6 No. 1, pp. 1-13.

Evbuomwan, N.F.O., Sivaloganathan, S. and Jebb, A. (1996), "A survey of design philosophies, models, methods and systems", Proceedings of the Institution of Mechanical Engineers, Vol. 210 No. 42, pp. 301-320.

Fagerberg, J. (2006), "Innovation: A Guide to the Literature", in Fagerberg, J., Mowery, D.C. and Nelson, R.R. (Eds.), The Oxford Handbook of Innovation, Oxford University Press, available at: (accessed 10 August 2013).

Finger, S. and Dixon, J.R. (1989a), "A review of research in mechanical engineering design. Part II: Representations, analysis, and design for the life cycle", Research in Engineering Design, Vol. 1 No. 2, pp. 121-137.

Finger, S. and Dixon, J.R. (1989b), "A review of research in mechanical engineering design. Part I: Descriptive, prescriptive, and computer-based models of design processes", Research in Engineering Design, Vol. 1 No. 1, pp. 51-67.

Forsberg, K. and Mooz, H. (1991), "The relationship of system engineering to the project cycle", Center for Systems Management, Presented at the National Council On Systems Engineering and American 
Society for Engineering Management, Center for Systems Management, Chattanooga, TN, Vol. 9, pp. 57-65.

Forsberg, K., Mooz, H. and Cotterman, H. (2005), Visualizing Project Management: Models and Frameworks for Mastering Complex Systems, John Wiley \& Sons, New York.

Freeman, C. and Soete, L. (1997), The economics of industrial innovation, Routledge, Printer, 3th edition.

French, M. (1998), Conceptual Design for Engineers, Springer, London.

Galanakis, K. (2006), “Innovation process. Make sense using systems thinking”, Technovation, Vol. 26 No. 11, pp. 1222-1232.

Galle, P. (2009), “The ontology of Gero's FBS model of designing”, Design Studies, Vol. 30 No. 4, pp. 321-339.

Garcia, R. and Calantone, R. (2003), "A critical look at technological innovation typology and innovativeness terminology: a literature review", Journal of Product Innovation Management, Vol. 19 No. 2, pp. 110-132.

Gericke, K. and Blessing, L. (2012), “An Analysis of Design Process Models Across Disciplines", Proceedings of the International Design Conference - DESIGN 2012, Presented at the 12th International Design Conference DESIGN 2012, Vol. 1, pp. 171-183.

Gero, J.S. (1990), "Design prototypes: a knowledge representation schema for design", AI magazine, Vol. 11 No. 4, pp. 26-36.

Gero, J.S. and Kannengiesser, U. (2004), "The situated function-behaviour-structure framework", Design Studies, Vol. 25 No. 4, pp. 373-391.

Gero, J.S. and Kulinski, J. (2000), "A situated approach to analogy in designing", CAADRIA2000, CASA, Singapore, pp. 225-234.

Gil, N. and Tether, B.S. (2011), "Project risk management and design flexibility: Analysing a case and conditions of complementarity”, Research Policy, Vol. 40 No. 3, pp. 415-428.

Gries, B. and Gericke, K. (2009), "A method for identifying improvement potentials within product development processes", Proceedings of the International Conference on Engineering Design ICED09, Presented at the International Conference on Engineering Design 2009, Stanford, Vol. 1, pp. 291-298.

Griffin, A. (1997), "PDMA research on new product development practices: updating trends and benchmarking best practices", Journal of product innovation management, Vol. 14 No. 6, pp. 429 458.

Hatchuel, A. (2001), "Towards design theory and expandable rationality: The unfinished program of Herbert Simon”, Journal of management and governance, Vol. 5 No. 3, pp. 260-273.

Hatchuel, A. and Weil, B. (2003), "A new approach of innovative design: an introduction to CK theory", Proceedings of the international conference on engineering design, Presented at the International conference on engineering design, Stockholm, pp. 109-124.

Hatchuel, A. and Weil, B. (2009), "C-K design theory: an advanced formulation", Research in Engineering Design, Vol. 19 No. 4, pp. 181-192. 
Hazelrigg, G.A. (1996), Systems engineering: An approach to information-based design, Prentice Hall, Upper Saddle River, N.J.

Heany, D.F. (1983), "Degrees of product innovation”, Journal of Business Strategy, Vol. 3 No. 4, pp. 314.

Herbert, B. (Ed.). (2011), The Future of Design Methodology, Springer, London, available at: (accessed 22 May 2012).

Hobday, M. (1998), "Product complexity, innovation and industrial organisation", Research Policy, Vol. 26 No. 6, pp. 689-710.

Holland, J.H. (1992), Adaptation In Natural And Artificial Systems, MIT Press, Cambridge, MA.

Howard, T.J., Culley, S.J. and Dekoninck, E. (2008), "Describing the creative design process by the integration of engineering design and cognitive psychology literature", Design studies, Vol. 29 No. 2, pp. 160-180.

Hubka, V. (1980), Principles of Engineering Design, Butterworth Scientific, Belfast.

IEEE Computer Society. (2005a), "ISO 15288: Adoption of ISO/IEC 15288:2002 Systems Engineering-System Life Cycle Processes".

IEEE Computer Society. (2005b), "IEEE 1220:IEEE Standard for application and Management of the Systems Engineering Process".

INCOSE. (2006,June), “Systems Engineering Handbook”.

INCOSE, IEEE-CS and SERC. (2013), "Guide to the Systems Engineering Body of Knowledge”.

K. G. Cooper. (1993), "The rework cycle: Why projects are mismanaged”, Engineering Management Review, Vol. 21 No. 3, pp. 4-12.

Kazakç1, A.O. and Tsoukias, A. (2005), "Extending the C-K design theory: A theoretical background for personal design assistants", Journal of Engineering Design, Vol. 16 No. 4, p. 399.

Kelley,Jr, J.E. and Walker, M.R. (1959), "Critical-path planning and scheduling”, Proceeding Easter Joint Computation Conference, ACM, New York, pp. 160-173.

Kim, K.-J. and Meiren, T. (2010), "New service development process", in Salvendy, G. and Karwowski, W. (Eds.),Introduction to Service Engineering, John Wiley \& Sons, Inc., pp. 253-267.

Kline, S.J. and Rosenberg, N. (1986), “An overview of innovation”, in Landau, R. and Rosenberg, N. (Eds.),The Positive sum strategy: harnessing technology for economic growth, National Academies Press, Washington, D.C., pp. 275-307.

Koen, P., Ajamian, G., Burkart, R., Clamen, A., Davidson, J., D’Amore, R., Elkins, C., et al. (2001), "Providing clarity and a common language to the "Fuzzy Front End", Research-Technology Management, Vol. 44 No. 2, pp. 46-55.

Koput, K.W. (1997), "A chaotic model of innovative search: Some answers, many questions", Organization Science, Vol. 8 No. 5, pp. 528-542.

Kossiakoff, A., Sweet, W.N., Seymour, S. and Biemer, S.M. (2011), Systems engineering principles and practice, John Wiley \& Sons, New York.

Krishnan, V., Eppinger, S.D. and Whitney, D.E. (1997), "A model-based framework to overlap product development activities”, Management science, Vol. 43 No. 4, pp. 437-451. 
Krishnan, V. and Ulrich, K.T. (2001), "Product development decisions: A review of the literature", Management Science, Vol. 47 No. 1, pp. 1-21.

Krothapalli, N.K.C. and Deshmukh, A.V. (1999), "Design of negotiation protocols for multi-agent manufacturing systems", International Journal of Production Research, Vol. 37 No. 7, pp. 16011624.

Lawson, B. (1994), Design in mind, Butterworth-Heinemann, Oxford.

Leifer, R., McDermott, C.M., O'Connor, G.C. and Peters, L.S. (2000), Radical innovation: How mature companies can outsmart upstarts, Harvard Business Press, Cambridge, available at: (accessed 8 February 2013).

Lenfle, S. and Loch, C. (2010), "Lost Roots: How project management came to emphasize control over flexibility and novelty", California Management Review, Vol. 53 No. 1, pp. 32-55.

Lévárdy, V. and Browning, T.R. (2009), "An adaptive process model to support product development project management", IEEE Transactions on Engineering Management, Vol. 56 No. 4, pp. $600-$ 620 .

Luchs, M. and Swan, K.S. (2011), "Perspective: The emergence of product design as a field of marketing inquiry”, Journal of Product Innovation Management, Vol. 28 No. 3, pp. 327-345.

Luecke, R. and Katz, R. (2003), Managing creativity and innovation, Harvard Business Press, Boston, MA.

MacCormack, A. and Verganti, R. (2003), "Managing the sources of uncertainty: matching process and context in software development", Journal of Product Innovation Management, Vol. 20 No. 3, pp. $217-232$.

MacCormack, A., Verganti, R. and Iansiti, M. (2001), 'Developing products on 'internet time': The anatomy of a flexible development process", Management Science, Vol. 47 No. 1, pp. 133-150.

Maidique, M.A. (1980), "Entrepreneurs, Champions, and Technological Innovation”, Sloan Management Review, Vol. 21 No. 2, pp. 59-76.

Maier, J.R.. and Fadel, G.M. (2009), “Affordance based design: a relational theory for design”, Research in Engineering Design, Vol. 20 No. 1, pp. 13-27.

Malcolm, D.G., Roseboom, J.H., Clark, C.E. and Fazar, W. (1959), "Application of a Technique for Research and Development Program Evaluation”, Operations Research, Vol. 7 No. 5, pp. 646-669.

Marinova, D. and Philimore, J. (2003), "Models of innovation", in Shavinina, L. (Ed.),The International Handbook on Innovation, Pergamon, Elsevier Science Ltd., Oxford, pp. 44-53.

Marxt, C. and Hacklin, F. (2005), "Design, product development, innovation: all the same in the end? A short discussion on terminology", Journal of Engineering Design, Vol. 16 No. 4, pp. 413-421.

Le Masson, P., Weil, B. and Hatchuel, A. (2010), Strategic management of innovation and design, Cambridge University Press, New York.

McCarthy, I.P., Tsinopoulos, C., Allen, P. and Rose-Anderssen, C. (2006), "New Product Development as a Complex Adaptive System of Decisions", Journal of Product Innovation Management, Vol. 23 No. 5, pp. 437-456.

McDermott, C.M. and O'Connor, G.C. (2002), "Managing radical innovation: an overview of emergent strategy issues”, Journal of Product Innovation Management, Vol. 19 No. 6, pp. 424-438. 
Meinadier, J.P. (1998), Ingénierie et intégration des systèmes, Hermes, Paris.

Mensch, G. (1979), Stalemate in technology: innovations overcome the depression, McGraw-Hill, Cambridge, Ma.

De Meyer, A., Loch, C.H. and Pich, M.T. (2002), "Managing project uncertainty: From variation to chaos”, MIT Sloan Management Review, Vol. 43, pp. 60-67.

Navarro, B., Camisón-Zornoza, C., Alcamí, R.L., Segarra-Ciprés, M. and Montserrat, X. (2004), “A meta-analysis of innovation and organizational size", Organization Studies, Vol. 25 No. 3, pp. 331361.

Neumann, K. and Steinhardt, U. (1979), GERT Networks and the Time-Oriented Evaluation of Projects, Springer-Verlag, New York.

Newell, A. and Simon, H.A. (1972), Human problem solving, Prentice-Hall Englewood Cliffs, NJ.

Nightingale, P. (2000), "The product-process-organisation relationship in complex development projects”, Research Policy, Vol. 29 No. 7-8, pp. 913-930.

O’Brien, C. (2002), “Global manufacturing and the sustainable economy”, International Journal of Production Research, Vol. 40 No. 15, pp. 3867-3877.

O'Donovan, B., Eckert, C. and Clarkson, P.J. (2004), "Simulating design processes to assist design process planning", 2004 Proceedings of Design Engineering Technical Conference \& Computers \& Information Engineering Conference, Presented at the 16th International Conference on Design Theory and Methodology, Salt Lake City, Utah, USA, Vol. 3, pp. 503-512.

OECD. (1991), The nature of innovation and the evolution of the productive system, Paris: OECD.

OECD. (1997), Proposed guidelines for collecting and interpreting technological innovation data: Oslo Manual, Paris: OECD.

Ogot, M.M. and Okudan-Kremer, G. (2004), Engineering Design: A Practical Guide, Trafford Publishing, Victoria, Canada.

Padmore, T., Schuetze, H. and Gibson, H. (1998), "Modeling systems of innovation: An enterprise-centered view", Research Policy, Vol. 26 No. 6, pp. 605-624.

Pahl, G. and Beitz, W. (1996), Engineering design: a systematic approach, Springer Verlag, London.

Pathak, S.D., Day, J.M., Nair, A., Sawaya, W.J. and Kristal, M.M. (2007), "Complexity and adaptivity in supply networks: Building supply network theory using a complex adaptive systems perspective", Decision Sciences, Vol. 38 No. 4, pp. 547-580.

Pavitt, K. (2006), "Innovation Processes", in Fagerberg, J., Mowery, D.C. and Nelson, R.R. (Eds.),The Oxford Handbook of Innovation, Oxford University Press, available at: (accessed 10 August 2013).

Perks, H., Cooper, R. and Jones, C. (2005), "Characterizing the role of design in new product development: An empirically derived taxonomy", Journal of Product Innovation Management, Vol. 22 No. 2, pp. 111-127.

Pich, M.T., Loch, C.H. and De Meyer, A. (2002), "On uncertainty, ambiguity, and complexity in project management", Management Science, Vol. 8 No. 48, pp. 1008-1023.

Plessis, M. du. (2007), "The role of knowledge management in innovation", Journal of Knowledge Management, Vol. 11 No. 4, pp. 20-29. 
Poskela, J. and Martinsuo, M. (2009), "Management control and strategic renewal in the front End of innovation", Journal of Product Innovation Management, Vol. 26 No. 6, pp. 671-684.

Pugh, S. (1990), Total design: Integrated methods for successful product development, Addison-Wesley, England, 1st edition.

Ramaswami, S.N. (1996), "Marketing controls and dysfunctional employee behaviors: A test of traditional and contingency theory postulates", Journal of Marketing, Vol. 60 No. 2, pp. 105-120.

Ravasi, D. and Stigliani, I. (2012), "Product design: a review and research agenda for management studies", International Journal of Management Reviews, Vol. 14 No. 4, pp. 464-488.

Reid, S.E. and De Brentani, U. (2004), "The Fuzzy Front End of new product development for discontinuous innovations: A theoretical model", Journal of Product Innovation Management, Vol. 21 No. 3, pp. 170-184.

Reymen, I.M.M.., Hammer, D.K., Kroes, P.A., Van Aken, J.E., Dorst, C.H., Bax, M.F.. and Basten, T. (2006), "A domain-independent descriptive design model and its application to structured reflection on design processes", Research in Engineering Design, Vol. 16 No. 4, pp. 147-173.

Rhea, D. (2003), "Bringing clarity to the fuzzy front end", in Laurel, B. (Ed.),, MIT Press, Cambridge.

Roozenburg, N.F.M. and Cross, N.G. (1991), "Models of the design process: integrating across the disciplines”, Design Studies, Vol. 12 No. 4, pp. 215-220.

Roozenburg, N.F.M. and Eekels, J. (1995), Product design: Fundamentals and methods, John Wiley \& Sons.

Rothwell, R. (1994), "Towards the fifth-generation innovation process", International Marketing Review, Vol. 11 No. 1, pp. 7-31.

Ryan, E.T., Jacques, D.R. and Colombi, J.M. (2013), "An ontological framework for clarifying flexibility-related terminology via literature survey”, Systems Engineering, Vol. 16 No. 1, pp. 99 110 .

Safoutin, M.J. (2003), A methodology for empirical measurement of iteration in engineering design processes (PhD thesis), University of Washington, available at: (accessed 13 September 2012).

Sage, A.P. and Armstrong, J.E. (2000), Introduction to systems engineering, Wiley.

Sage, A.P. and Rouse, W.B. (2011), Handbook of Systems Engineering and Management, John Wiley \& Sons.

Saleh, J.H., Mark, G. and Jordan, N.C. (2009), "Flexibility: a multi-disciplinary literature review and a research agenda for designing flexible engineering systems", Journal of Engineering Design, Vol. 20 No. 3, pp. 307-323.

Salomo, S., Weise, J. and Gemünden, H.G. (2007), "NDP planning activities and innovation performance: The mediating role of process management and the moderating effect of product innovativeness", Journal of Product Innovation Management, Vol. 24 No. 4, pp. 285-302.

Schön, D.A. (1992), "Designing as reflective conversation with the materials of a design situation", Knowledge-Based Systems, Vol. 5 No. 1, pp. 3-14.

Schön, Donald A. (1995), The reflective practitioner: How professionals think In action, Ashgate Publishing Limited, New York, 1 sted. 
Schumpeter, J.A. (1934), The theory of economic development, Harvard University Press, Cambridge, MA.

Sethi, R. and Iqbal, Z. (2008), "Stage-gate controls, learning failure, and adverse effect on novel new products", Journal of Marketing, Vol. 72 No. 1, pp. 118-134.

Shankar, V., Berry, L. and Dotzel, T. (2009), "A practical guide to combining products and services”, Harvard Business Review, No. 87, pp. 94-99.

Shannon, C.E. (1948), “A mathematical theory of communication”, Bell System Technical Journal, Vol. 27 No. 3, pp. 379-423.

Simon, H.A. (1969), The science of the artificial, MIT Press, Cambridge.

Simon, H.A. (1973), “The structure of ill structured problems", Artificial Intelligence, Vol. 4 No. 3-4, pp. 181-201.

Simon, H.A. (1995), "Problem forming, problem finding, and problem solving in design", in Collen, A. and Gasparski, W. (Eds.),Design \& systems: general applications of methodology, Transaction Publishers, New Brunswick, Vol. 3, pp. 245-257.

Simon, H.A. (1999), The sciences of the artificial, MIT Press, Cambridge, The third Edition.

Simon, H.A., Newell, A. and Shaw, J.C. (1979), "The processes of creative thinking", Models of thought, Yale University Press, New Haven and London, pp. 144-174.

Smith, R.P. and Morrow, J.A. (1999), "Product development process modeling”, Design Studies, Vol. 20 No. 3, pp. 237-261.

Sommer, S.C. and Loch, C.H. (2004), "Selectionism and learning in projects with complexity and unforeseeable uncertainty", Management Science, Vol. 50 No. 10, pp. 1334-1347.

Sommer, S.C., Loch, C.H. and Dong, J. (2009), "Managing Complexity and Unforeseeable Uncertainty in Startup Companies: An Empirical Study”, Organization Science, Vol. 20 No. 1, pp. 118-133.

Von Stamm, B. (2004), “Innovation-What's design got to do with it?", Design Management Review, Vol. 15 No. 1, pp. 10-19.

Von Stamm, B. (2008), Managing innovation, design and creativity, Wiley, Chichester.

Stempfle, J. and Badke-Schaub, P. (2002), "Thinking in design teams-an analysis of team communication”, Design Studies, Vol. 23 No. 5, pp. 473-496.

Steward, D. (1981), "The design structure system: A method for managing the design of complex systems", IEEE Transactions on Engineering Management, Vol. 28 No. 3, pp. 71-74.

Tatikonda, M.V. and Rosenthal, S.R. (2000), "Successful execution of product development projects: Balancing firmness and flexibility in the innovation process", Journal of Operations Management, Vol. 18 No. 4, pp. 401-425.

Terwiesch, C. and Loch, C.H. (1999), "Measuring the effectiveness of overlapping development activities", Management Science, Vol. 45 No. 4, pp. 455-465.

Thomke, S.H. (1997), "The role of flexibility in the development of new products: An empirical study", Research Policy, Vol. 26 No. 1, pp. 105-119.

Thompson, G. and Lordan, M. (1999), "A review of creativity principles applied to engineering design", Proceedings of the Institution of Mechanical Engineers, Part E: Journal of Process Mechanical Engineering, Vol. 213, pp. 17-31. 
Tidd, J. (1997), "Complexity, networks \& learning: Integrative themes for research on innovation management", International Journal of Innovation Management, Vol. 1 No. 1, pp. 1-21.

Tidd, J. and Bessant, J. (2011), Managing innovation: Integrating technological, market and organizational change, John Wiley \& Sons.

Tim, B. (2008), “Design Thinking”, Harvard Business Review, available at: (accessed 18 May 2012).

Tischner, U., Schmincke, E., Frieder, R. and Prosler, M. (2000), How to do EcoDesign?: a guide for environmentally and economically sound design, Art Books International Limited, Frankfurt.

Tomala, F. and Sénéchal, O. (2004), "Innovation management: a synthesis of academic and industrial points of view", International journal of project management, Vol. 22 No. 4, pp. 281-287.

Trott, P. (2008), Innovation management and new product development, Pearson Education, Edinburgh, England, The fourth edition.

Ullman, D.G. (1992), “A taxonomy for mechanical design”, Research in Engineering Design, Vol. 3 No. 3, pp. 179-189.

Ullman, D.G. (2003), The mechanical design process, McGraw-Hill, New York, 3rd edition.

Ulrich, K.T. (2011), Design: Creation of Artifacts in Society, University of Pennsylvania.

Ulrich, K.T. and Eppinger, S.D. (1995), Product design and development, McGraw-Hill, New York.

Unger Darian W. (2003), Product development process: improving company response to market pressure, regulation, and changing customer needs ( $\mathrm{PhD}$ thesis), Massachusetts Institute of Technology, Cambridge.

Utterback, J.M. (2006), Design-inspired innovation, World Scientiific, New York.

Utterback, J.M., Allen, T.J., Hollomon, J.H. and Sirbu, M.A. (1975), The process of innovation in five industries in Europe and Japan, MIT Press, Cambridge, MA.

Valkenburg, R.C. and Dorst, K. (1998), "The reflective practice of design teams", Design Studies, Vol. 19 No. 3, pp. 249-271.

Van de Ven, A.H., Angle, H.L. and Poole, M.S. (2000), Research on the management of innovation: The Minnesota studies, Oxford University Press, New York.

Verganti, R. (2008), "Design, meanings, and radical innovation: A metamodel and a research agenda", Journal of Product Innovation Management, Vol. 25 No. 5, pp. 436-456.

Verganti, R. (2011), "Radical design and technology epiphanies: a new focus for research on design management", Journal of Product Innovation Management, Vol. 28 No. 3, pp. 384-388.

Vermaas, P.E. and Dorst, K. (2007), “On the conceptual framework of John Gero's FBS-model and the prescriptive aims of design methodology”, Design Studies, Vol. 28 No. 2, pp. 133-157.

Verworn, B., Herstatt, C. and Nagahira, A. (2008), "The fuzzy front end of Japanese new product development projects: impact on success and differences between incremental and radical projects", $R \& D$ Management, Vol. 38 No. 1, pp. 1-19.

Visser, W. (2002), A Tribute to Simon, and Some -Too Late- Questions, by a Cognitive Ergonomist.

Ward, Liker, J.K., Cristiano, J.J. and Sobek, D.K. (1995), “The second Toyota paradox: How delaying decisions can make better cars faster”, Sloan Management Review, Vol. 36 No. 3, pp. 43-61. 
Whitney, D.E. (1990), "Designing the design process", Research in Engineering Design, Vol. 2 No. 1, pp. 3-13.

Wong, A., Tjosvold, D. and Liu, C. (2009), "Innovation by Teams in Shanghai, China: Cooperative Goals for Group Confidence and Persistence”, British Journal of Management, Vol. 20 No. 2, pp. $238-251$

Wynn, D. and Clarkson, J. (2005), "Models of designing", in Clarkson, J. and Eckert, C. (Eds.),design process improvement a review of current practice, Springer, Cambridge, pp. 35-59.

Wynn, D., Grebici, K. and Clarkson, P. (2011), "Modelling the evolution of uncertainty levels during design", International Journal on Interactive Design and Manufacturing, Vol. 5 No. 3, pp. 187202.

Wynn, D.C. (2007), Model-based approaches to support process improvement in complex product development ( $\mathrm{PhD}$ thesis), University of Cambridge.

Wynn, D.C., Eckert, C.M. and Clarkson, P.J. (2006), "Applied signposting: a modeling framework to support design process improvement", Proceedings of IDETC/CIE 2006 ASME, Presented at the International Design Engineering Technical Conferences \& Computers and Information in Engineering Conference, Philadelphia, PA, pp. 10-13.

Wynn, D.C., Eckert, C.M. and Clarkson, P.J. (2007), "Modelling iteration in engineering design", Presented at the International Conference on Engineering Design, Paris, available at: (accessed 25 August 2012).

$\mathrm{Xu}, \mathrm{J}$. (2010), Dynamic knowledge management modeling for the innovation in engineering design ( $\mathrm{PhD}$ thesis), Université de Strasbourg, Strasbourg.

Xu, J., Houssin, R., Caillaud, E. and Gardoni, M. (2010), "Macro process of knowledge management for continuous innovation”, Journal of Knowledge Management, Vol. 14 No. 4, pp. 573-591.

Yan, J. and Stephen, L. (1998), "Toward a better understanding of engineering design models", in Grabowski, H., Rude, S. and Grein, G. (Eds.),Proceeding of the workshop universal design theory, Shaker Verlag, Karlsruhe, Germany, pp. 73-84.

Yin, R.K. (2002), Case Study Research: Design and Methods, SAGE Publications, 3rded.

Zhang, Q., Deniaud, I., Caillaud, E. and Baron, C. (2011), "Process modeling in innovative design using systems engineering", Insight, Vol. 14, pp. 31-32.

Zhang, Q., Deniaud, I., Caillaud, E. and Baron, C. (2012a), "Descriptive model for interpreting innovative design", Proceedings of DESIGN 2012, Presented at the International Design Conference, Marjanovic Dorian, Storga Mario, Pavkovic Neven, Bojcetic Nenad, Dubrovnik Croatia, pp. 343-353.

Zhang, Q., Deniaud, I., Caillaud, E. and Baron, C. (2012b), "Modelling in innovative design using systems engineering", Presented at the 9th International Conference of Modeling, Optimization and Simulation, Bordeaux, France. 


\section{ANNEXES}

\section{Annex 1. Definition and key elements of Systems Engineering}

\section{Definition}

There are many ways in which to define systems engineering. Some of these definitions are expressed in below

- Systems engineering is a discipline that concentrates on the design and application of the whole (system) as distinct from the parts. It involves looking at a problem in its entirety, taking into account all the facets and all the variables and relating the social to the technical aspect.

- Systems engineering is an iterative process of top-down synthesis, development, and operation of a real-world system that satisfies, in a near optimal manner, the full range of requirements for the system (Eisner, 2008).

- Systems engineering is an interdisciplinary approach to enable the realization of successful systems. It integrates all the disciplines and specialty groups into a team effort, forming a structured development process that proceeds from concept to operation (INCOSE, 2006).

- The function of systems engineering is to guide the engineering of a complex system (Kossiakoff et al., 2011).

- Systems engineering is an appropriate combination of theories and tools, carried out through the use of a suitable methodology and set of procedures appropriate for the resolution of real-world problems of large scale and scope (Sage and Armstrong, 2000). The purpose of systems engineering is to organize information and knowledge to provide management and direction to development, production and operation of total systems (Sage and Rouse, 2011).

According to these definitions, systems engineering is considered as a profession, a process, a perspective and a combination of methods and theories. For the purpose of this dissertation, we will consider systems engineering as a combination of methods and theories to guide the engineering of innovative design. Some terms in this definition adopted are described further below. 


\section{Key elements of systems engineering}

According to the definition above, systems engineering is a multidiscipline methods to enable the realization of successful system. The successful system should meet the requirements of its customers, users and other stakeholders, its successful operation in the field and a long, useful operating life (Kossiakoff et al., 2011). Some key elements of systems engineering are highlighted in Figure 1 and include:

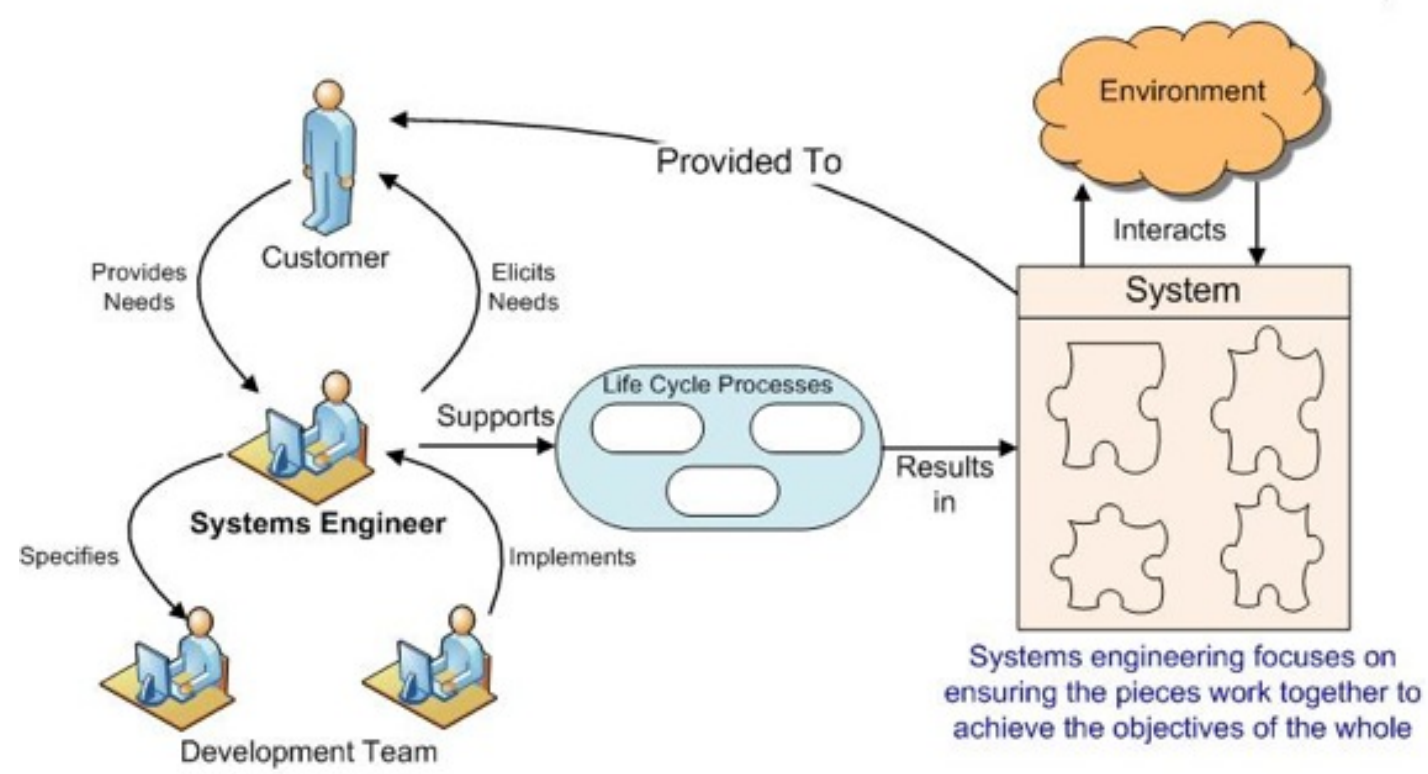

Figure 1 The key elements of systems engineering (INCOSE et al., 2013)

\section{- System}

The term "system", as in the case of the most common English words, has a very broad meaning. A system is "a set or arrangement of elements [people, product (hardware and software) and process (facilities, equipment, material, and procedures)] that are related"(IEEE Computer Society, 2005b). Another definition of the term "system" is "a combination of interacting elements organized to achieve one or more stated purposes" (IEEE Computer Society, 2005a). The two definitions imply a multiplicity of interacting parts that collectively perform a significant function.

\section{- System engineer}

A systems engineer is a person or role who supports this interdisciplinary approach. In particular, the systems engineer often serves to elicit and translate customer needs into specifications that can be realized by the system development team. Moreover, system engineers help to assure the system fit together to accomplish the objectives of the whole. 


\section{- System life cycle}

In order to enable the realization of successful system, systems engineers should support the system life cycle. The system life cycle is referred to the stepwise evaluation of a new system from concept through development and to production, operation, and ultimate disposal.

\section{- System engineering process}

As was described above, every system has a life cycle from the time when a need for it is recognized and a feasible technical approach is identified, through its development and introduction into operational use. During the system life cycle, a series of systems engineering activities and related approaches and methods are applied at each step of this cycle. Because the type of work is different from the conceptual design to engineering development and testing, to production and operational use, the role of systems engineering changes. 


\section{Annex 2. System engineering method}

In the preceding section, the development of a successful system is divided into a series of phases or stages. Although many given problems of each stage are particular to the state of system definition, the system engineering activities employed are basically similar from one phase to the next. These system engineering activities are referred as the "systems engineering process" or "systems engineering method". The systems engineering method can be thought of as the systematic application of scientific methods to the development of a system.

Three commercial standards (i.e. IEEE-1220, ISO-15288 and EIA-632) propose their particular systems engineering process.

(1) Figure 3 presents the IEEE-1220 process. This process includes the requirement analysis, the function analysis and the synthesis, as well as a verification or validation step in between. The main control activity concerns on the technical problem and information management.

(2) Figure 4 Presents the ISO-15288 process. This standard presents process for both the system life cycle and systems engineering activities. In this process, it consists of four processes (agreement process, enterprise process, project process and technical process), in which are further decomposed into 25 sub-processes.

(3) The EIA-632 standard presents a collection of 13 processes that are linked together in Figure 5. The 13 processes are classified into five sets: technical management, acquisition and supply, system design, product realization and technical evaluation. Processes within the technical management are continuously performed during the system life cycle, and the technical evaluation commences before a physical product is available. The middle three processes are carried out sequentially with feedback and iterations. 


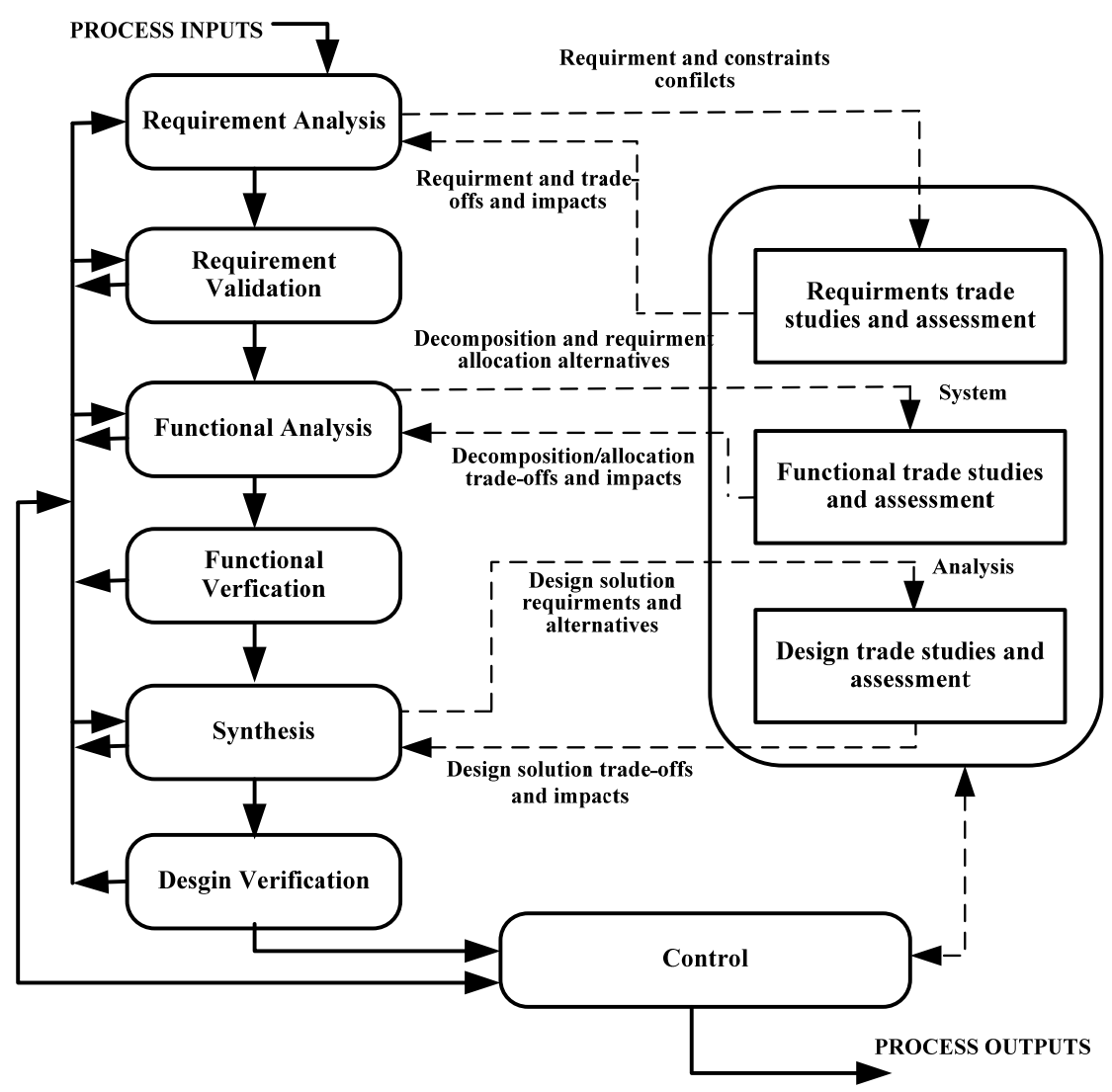

Figure 3. The system engineering process of IEEE-1220
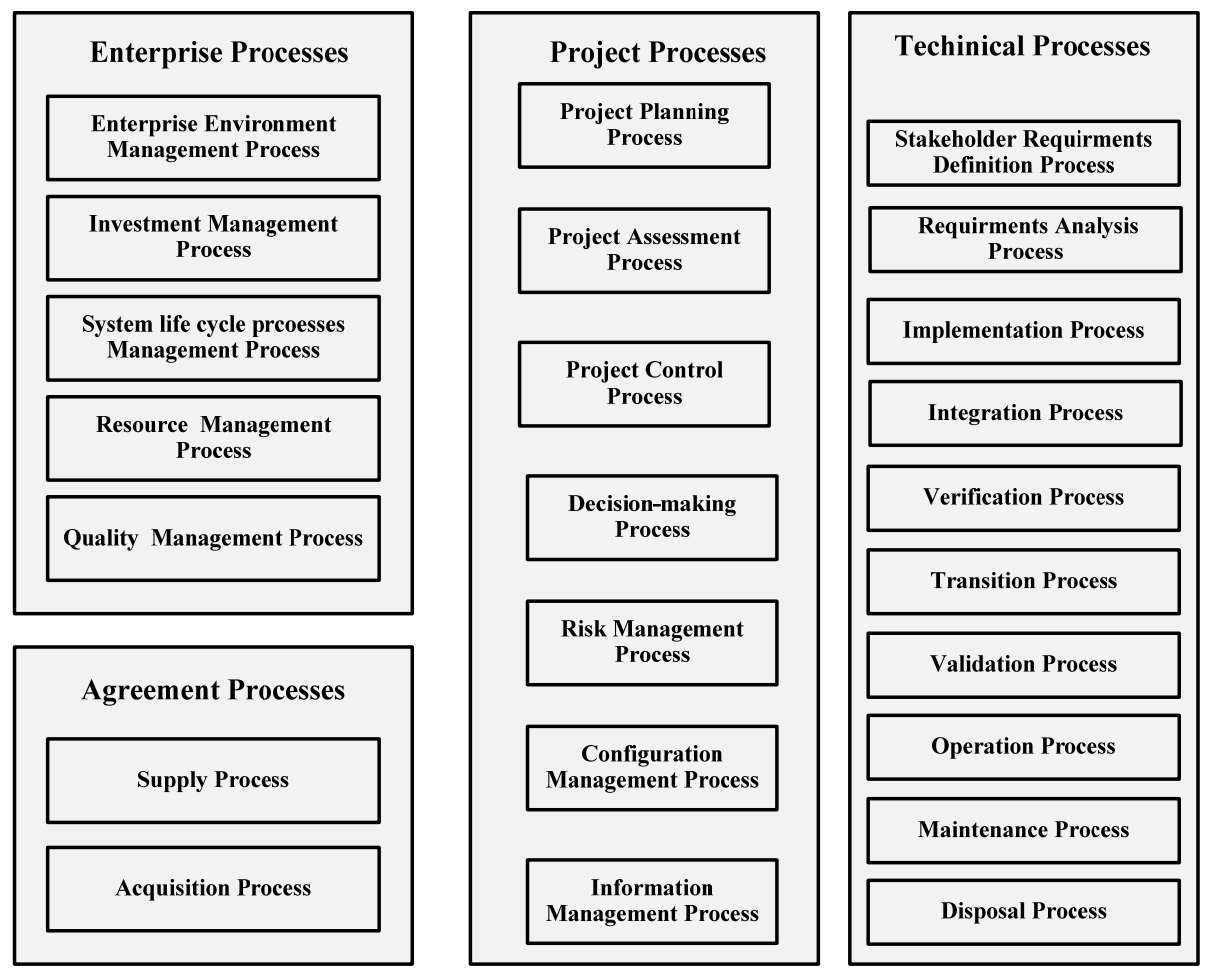

Figure 4. The system engineering process of ISO-15288 


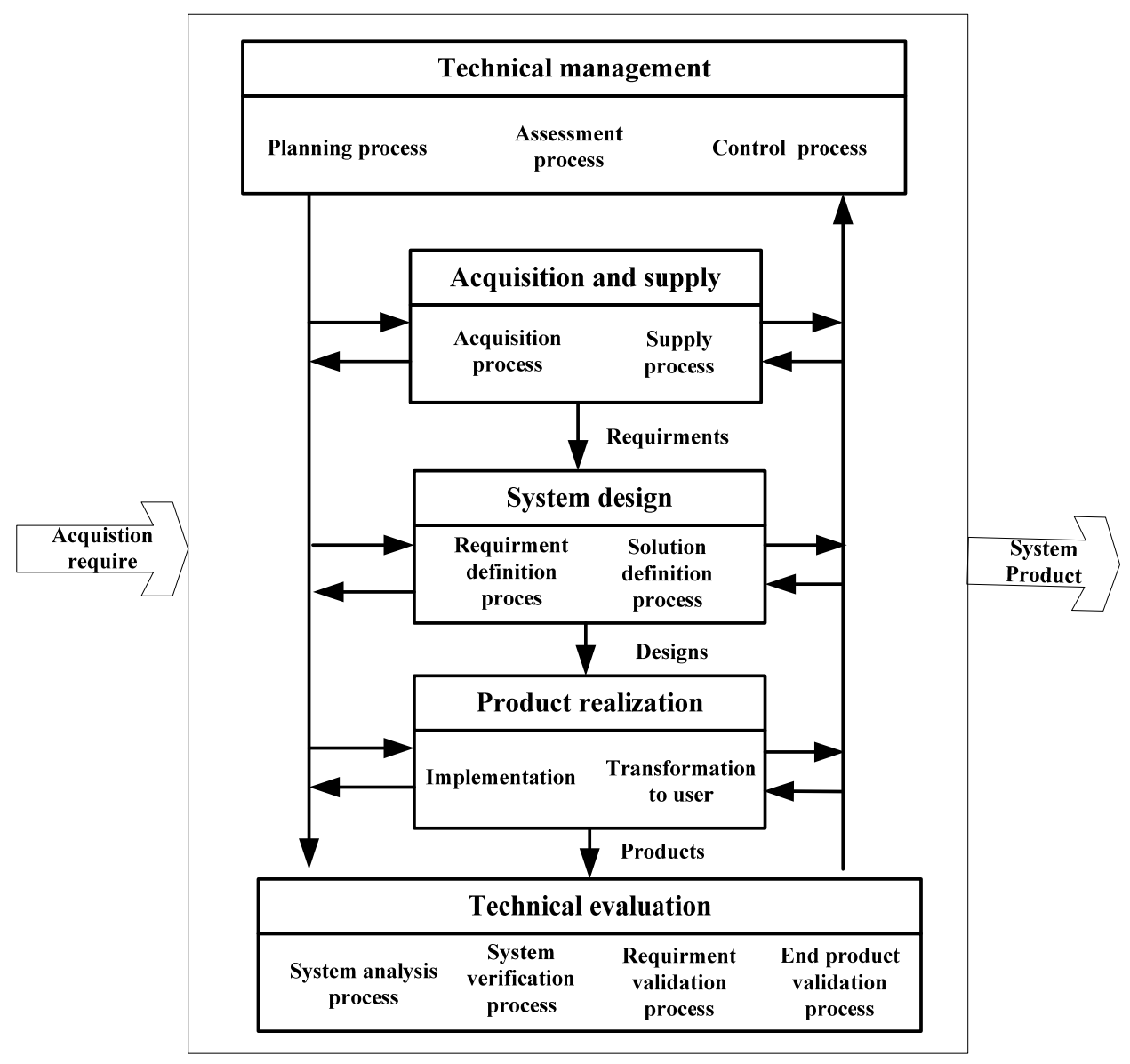

Figure 5. The system engineering process of EIA-15288 


\section{Annex 3. Systems engineering standards}

\section{The role of systems engineering standards}

The goal of systems engineering is to control the whole system development process, in order to guarantee the quality of a product or a service, and thus the satisfaction of the customer. Within this framework, systems engineering standards define general reference processes to manage the system from its initial concept to its delivery through its design and its realization. There is no point in defining the specific role of the service in the company or the responsibilities of a person, but the goal is to coordinate all of the engineering activities in order to achieve a common goal.

These standards rely on the idea that certain concepts are common to all projects, whatever the field of activity or the system to be developed (Bahill and Gissing, 2002). By identifying good practices and by ensuring the consistency of engineering activities, the standards help: matching the needs with quality products; anticipating problems and master risks in relation to the project as well as the system and its environment, throughout the whole life cycle; controlling the complexity of large systems and complex products; controlling lead times and deadlines; controlling the costs, by determining at an early stage the all-inclusive cost of the life cycle; ensuring effective coordination of teamwork involving different disciplines and, multiple actors; satisfying all stakeholders; optimizing the global trade-off.

Within these standards, by identifying good practices, these systems engineering standards define the interdisciplinary tasks and processes that are required from transforming stakeholder needs, requirements, and constraints to a system solution. The recommended processes described in the standards can be applied to the whole system life cycle including design, development, production, use, support and withdrawal. Meanwhile, they can be also applied in a concurrent, iterative or recursive way to a system and its components.

The systems of interest may be small or large in size, simple or complex, prototypes or industrial series, software, hardware, services or a combination of the latter, depending on the considered sphere of application.

\section{Main standards of system engineering}

Since the 1990's, the number of systems engineering standards has grown to guide developers to master the development of complex systems, such as IEEE 1200, ISO 15288, EIA 632. Table 1 illustrates the brief introduction for the three standards. All three ones: 
- are international references that are recognized by re-searchers and manufacturers,

- cite good practices established over many years,

- cover a large part of the system life cycle,

- are generic and cover many fields of activities from the medical to the military one through services

Table 1. Brief of three standards of systems engineering

\begin{tabular}{c|l|l}
\hline Standard & \multicolumn{1}{|c}{ Name } & \multicolumn{1}{|c}{ Organization } \\
\hline IEEE 1200 & $\begin{array}{l}\text { Standard for Application and Management } \\
\text { of the Systems Engineering Process }\end{array}$ & $\begin{array}{l}\text { Institute of Electrical and Electronics } \\
\text { Engineers }\end{array}$ \\
\hline ISO 15288 & $\begin{array}{l}\text { Systems Engineering-System Life cycle } \\
\text { process }\end{array}$ & $\begin{array}{l}\text { Institute of Electrical and Electronics } \\
\text { Engineers }\end{array}$ \\
\hline EIA 632 & $\begin{array}{l}\text { Processes for Engineering } \\
\text { a System }\end{array}$ & $\begin{array}{l}\text { Government Electronics and } \\
\text { Information Technology Association }\end{array}$ \\
\hline
\end{tabular}

Although these standards imply many similarities, the three standards cover the different scope and types, as illustrated in Figure 6. As discussed before, IEEE 1220 defines a single process, SEP (systems engineering process), which is divided into eight sub processes. Therefore, IEEE 1220 emphasizes the management and control system development, that is to say the technical process. EIA 632 has a much boarder scope from the conceptual phase to the development phrase, thereby including the technical process and the contract process. ISO 15288 focus on the whole enterprise environment, including the agreement processes, the enterprise processes, and the technical processes. In sum, in terms of the coverage of process types, IEEE 1220 and EIA 632 define one of many possible frameworks for systems definition and management that could be defined with the scope of ISO 15288.

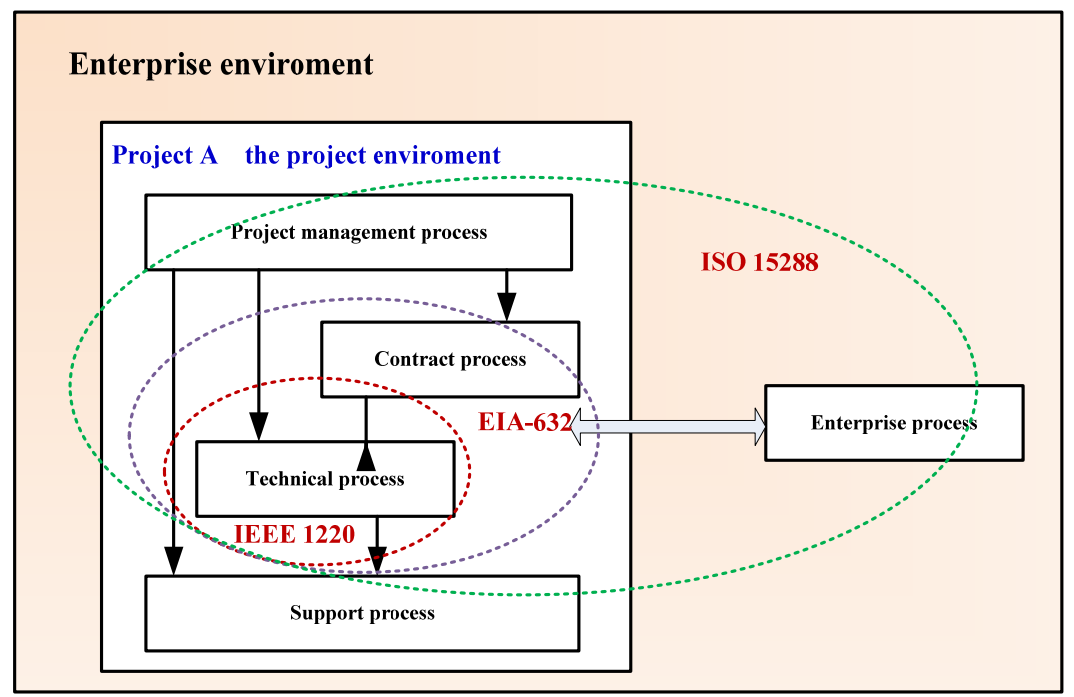

Figure 6. The coverage of process types of systems engineering standards 
Additionally, Figure 7 illustrates the difference on a detail level between different standards. IEEE 1220 implements a narrower set of detail activities than EIA 632 and ISO 15288. Each stage of the system life cycle could be defined in terms of broad purpose and outcomes, and then specific activities of the systems engineering process can be applied for partial fulfillment of each stage.

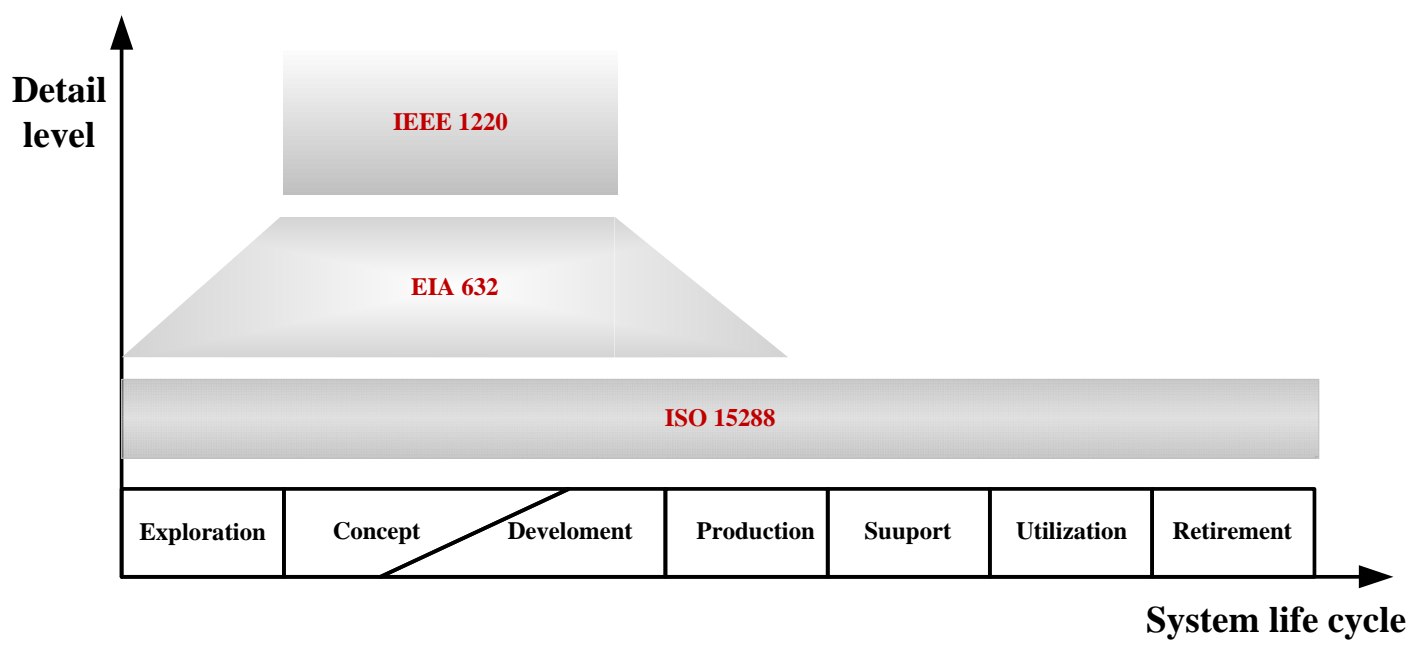

Figure 7. The coverage of the system life cycle of systems engineering standards 


\section{Publication List}

\section{Journal paper}

- ZHANG Q., DENIAUD I., CAILLAUD E. and BARON C. (2011). "Process Modeling in Innovative Design using Systems Engineering", INCOSE INSIGHT, 14(4), p. 31-33

- ZHANG Q., DENIAUD I. BARON C. and CAILLAUD E. (2013). "Managing Uncertainty of Innovative Design: Balancing Control and Flexibility". Journal of Engineering and Technology Management.(Under second revision)

- ZHANG Q., DENIAUD I. BARON C. and CAILLAUD E. (2013). "An activity-based adaptive process model for innovative design". International journal of Production Research. (Under second revision)

\section{Conference paper}

- ZHANG Q., DENIAUD I., CAILLAUD E. and BARON C. (2012). "Descriptive model for Interpreting innovative design", International Design Conference - DESIGN 2012, May 21 - 24, Dubrovnik, Croatia.

- ZHANG Q., DENIAUD I., CAILLAUD E. and BARON C. (2012). "Analysis and model of systematic innovation for design", TMCE'12: Tools and Methods of Competitive Engineering, 7-11 May, Karlsruhe, Germany.

- ZHANG Q., DENIAUD I., CAILLAUD E. and BARON C. (2012). "Modeling Innovative design using systems engineering", $9^{\text {ème }}$ Conférence Internationale de Modélisation et SIMulation - MOSIM'12 , 6-8 June, Bordeaux, French

- ZHANG Q., DENIAUD I. BARON C. and CAILLAUD E. (2013). "Proposal of an activity -based adaptive process model for innovative design", ASME 2013 International Design Engineering Technical Conferences \& Computers and Information in Engineering Conference IDETC/CIE 2013, August 4-7, 2013, Portland, Oregon, USA 


\section{Qiang ZHANG}

\section{Modélisation de processus de \\ conception innovante en utilisant \\ l'Ingénierie Système}

\section{Résumé}

Nous développons une série de modèles de processus pour décrire exhaustivement et gérer efficacement la conception innovante, en suivant la méthodologie de «design research methodology » (DRM : description-prescription). D'abord, nous présentons un modèle descriptif de la conception innovante. Ce modèle reflète les processus fondamentaux qui sont utiles pour comprendre les diffferentes dimensions et étapes impliqués dans la conception innovante. Il permete aussi de localise les possibilités d'innovation dans ce processus, et soutien un point de vue systématique focalisé sur facteurs internes et externes qui influencent le succès de la conception innovante. Deuxièmement, nous effectuons une étude empirique pour étudier la façon dont le contrôle et la flexibilité peuvent être équilibrés pour gérer l'incertitude dans la conception innovante. Après avoir identifié les pratiques de projets qui traitent de ces incertitudes en termes de contrôle et de flexibilité, un exemple d'études de cas sur la base de cinq projets de conception innovants auprès d'une société automobile est analysé. Cet exemple montre que le contrôle et la flexibilité peuvent coexister. En se basant sûr les résultats managériaux issu de cette étude empirique, nous développons, pour la conception innovante, un modèle procédurale de processus et un modèle adaptatif à base d'activité. Le premier propose le cadre conceptuel pour équilibrer l'innovation et le contrôle par la structuration des processus au niveau du projet et par l'intégration des pratiques flexibles au niveau opérational. Le second modèle considère la conception innovante comme un système adaptatif complexe. Il propose ainsi une méthode de conception qui construit progressivement l'architecture du processus de la conception innovante. Enfin, les deux modèles sont vérifiées en analysant un certain nombre de processus et en faisant des simulations au sein de trois projets de conception innovante.

Mots clés: conception innovante, modélisation de processus, innovation, conception, ingénierie système 


\title{
Qiang ZHANG
}

\section{Process Modeling of Innovative Design using Systems Engineering}

\begin{abstract}
We develop a series of process models to comprehensively describe and effectively manage innovative design in order to achieve adequate balance between innovation and control, following the design research methodology (DRM) from the description to the prescription. Firstly, we introduce a descriptive model of innovative design. This model reflects the fundamental processes of innovative design to be useful in understanding the patterns involved in the process, locates innovation opportunities in the process and supports a systematic perspective whose focus is the external and internal factors affecting the success of innovative design. Secondly, we perform an empirical study to investigate how control and flexibility can be balanced to manage uncertainty in innovative design. After identifying project practices that cope with these uncertainties in terms of control and flexibility, a case-study sample based on five innovative design projects from an automotive company is analyzed and shows that control and flexibility can coexist. Based on the managerial insights of the empirical study, we develop the procedural process model and the activity-based adaptive model of innovative design. The former one provides the conceptual framework to balance innovation and control by the process structuration at the project-level and the integration of flexible practices at the operation-level. The latter model considers innovative design as a complex adaptive system, and thereby proposes the method of process design that dynamically constructs the process architecture of innovative design. Finally, the two models are verified by supporting a number of process analysis and simulation within three innovative design projects.
\end{abstract}

Key words: innovative design, process model, innovation, design, systems engineering 